\title{
Modular track panels for improved safety in the mining transportation industry
}

\author{
Donald Sterling Tusing \\ West Virginia University
}

Follow this and additional works at: https://researchrepository.wvu.edu/etd

\section{Recommended Citation}

Tusing, Donald Sterling, "Modular track panels for improved safety in the mining transportation industry" (2003). Graduate Theses, Dissertations, and Problem Reports. 1300.

https://researchrepository.wvu.edu/etd/1300

This Thesis is protected by copyright and/or related rights. It has been brought to you by the The Research Repository @ WVU with permission from the rights-holder(s). You are free to use this Thesis in any way that is permitted by the copyright and related rights legislation that applies to your use. For other uses you must obtain permission from the rights-holder(s) directly, unless additional rights are indicated by a Creative Commons license in the record and/ or on the work itself. This Thesis has been accepted for inclusion in WVU Graduate Theses, Dissertations, and Problem Reports collection by an authorized administrator of The Research Repository @ WVU. For more information, please contact researchrepository@mail.wvu.edu. 


\title{
Modular Track Panels for Improved Safety in The Mining Transportation Industry
}

\author{
Donald S. Tusing \\ Thesis submitted to the \\ College of Engineering and Mineral Resources \\ at West Virginia University \\ in partial fulfillment of the requirements \\ for the degree of \\ Master of Science \\ in \\ Civil Engineering \\ Hota V.S. GangaRao, Ph.D., P.E., Chair \\ Udaya B. Halabe, Ph.D., P.E. \\ Samer H. Petro, P.E. \\ Department of Civil and Environmental Engineering \\ Morgantown, West Virginia \\ 2003
}

Keywords: Mining Developments, Ladder Track System, Ladder Sleeper, Railpads, Fiber Reinforced Polymer (FRP) Composite Panel 


\begin{abstract}
Modular Track Panels for Improved Safety in The Mining Transportation Industry

Donald S. Tusing

Locomotives and "mine cars" often derail (often two or three times daily) in coalmines causing fatal injuries, fires initiated from sparks during derailment, and costly downtimes. Modular track panels (resembling the ladder track systems used in Japan) were designed and tested for bending behavior and load sharing characteristics, between track modules and also between rails, to improve safety of miners during transportation. Prefabricated track modules made of prestressed concrete and fiber reinforced polymer (FRP)

composites were evaluated. Two modular prestressed concrete modules, each $15 \mathrm{ft}$ long, were tested, as well as one set of prestressed concrete half-panels to test the proposed open joint. One FRP panel was also tested. Tests on the panels included static and dynamic loading at discrete locations to determine the response of the beams in a simulated mine foundation. Static tests of the modular panels included both vertical and horizontal loading. Fatigue tests were used to determine the change in stiffness of the modules. Rubber railpads were used to distribute load on the prestressed concrete panel. Two rubber pads were individually tested under dynamic loading to determine their change in stiffness and secant modulus. Results show good load distribution of the panels based on deflection and strain measurements. The results are compared to theoretical measurements obtained by using the program, Enercalc, and by also conducting a finite element analysis. The load distribution of the prestressed concrete and FRP modules are also compared.
\end{abstract}




\section{Acknowledgements}

The author wishes to express his appreciation to Dr. Hota V.S. GangaRao, Chairman of his advisory committee, for his inspiration and guidance in preparing this thesis. The author also wishes to thank Mr. Samer Petro for his assistance and technical contributions during the duration of the project and Dr. Udaya Halabe for his assistance in reviewing this paper. The author wishes to thank his parents for their love, support, and guidance over the years.

The author wishes to thank Mr. Woraphot Prachasaree for his assistance in finite element modeling and Mr. Srinivas Aluri for his assistance in using the Enercalc program for beams modeled on an elastic foundation. The author also wishes to thank Mr. Dana Humberson for his help in setting up tests in the laboratory.

The author wishes to thank the West Virginia Governor's Office for their financial support. 


\section{Table of Contents}

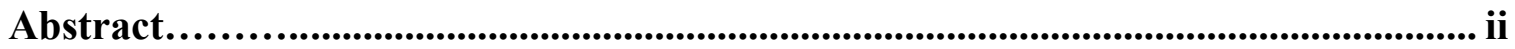

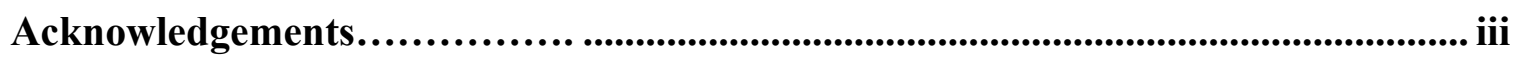

List of Tables.......................................................................... vii

List of Figures...................................................................viii

List of Symbols.................................................................... xiv

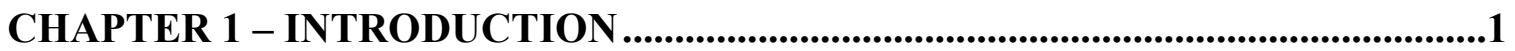

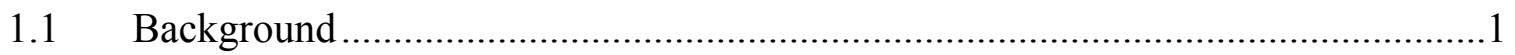

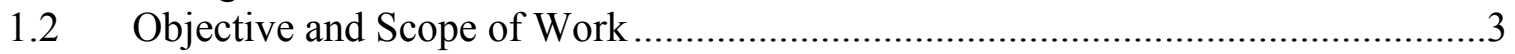

CHAPTER 2 - TRACK COMPONENTS AND LOADING ..................................4

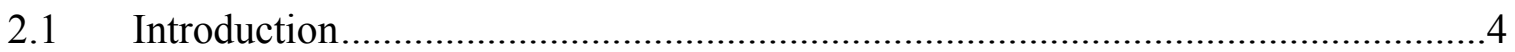

2.2 Construction............................................................. 4

2.3 Ballast vs. Non-ballast Track........................................... 4

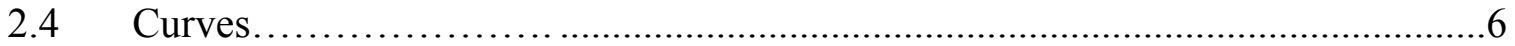

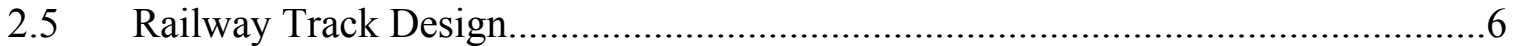

2.6 Recent Developments..................................................... .

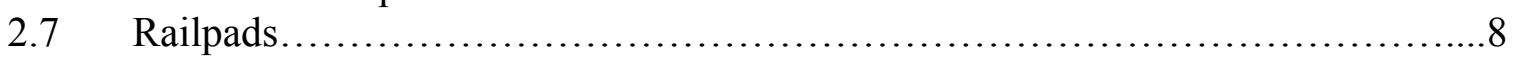

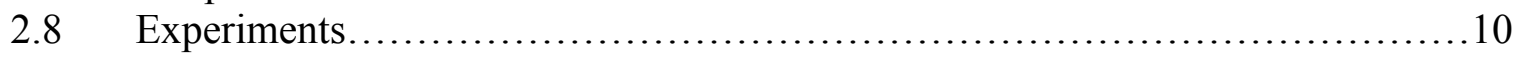

$2.9 \quad$ Testing Set-Up........................................................ 11

2.9.1 Testing Approach - Prestressed Concrete Panels......................... 12

2.9.2 Testing Approach - Rubber Railpads................................16

2.9.3 Testing Approach - Fiber Reinforced Polymer (FRP) Composite Panel...16

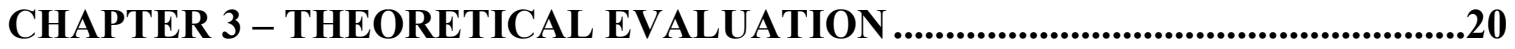

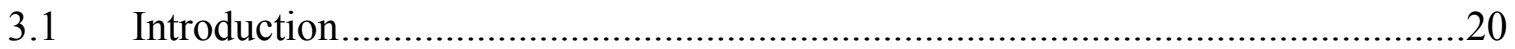

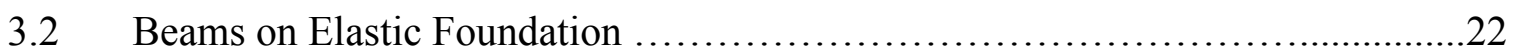

3.3 Beams on Elastic Foundation Software ........................................................24

3.4 Finite Element Analysis For Beam on Elastic Foundation..................... 26

CHAPTER 4 - LABORATORY TESTING AND ANALYSIS...................................28

4.1 Prestressed Concrete Panels - Introduction.....................................28

4.2 Full-Size Prestressed Concrete Panel 1.......................................28

4.2.1 Modular Track Panel Fabrication and Set-Up ...................................28

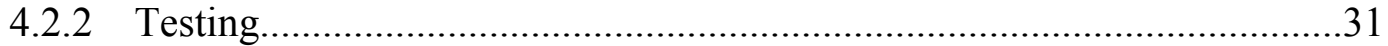

4.2.2.1 Load at Midspan .............................................................32

4.2.2.2 Single Point Load at Interior Crosstie.....................................34

4.2.2.3 Load in Middle of Outer Crossties..........................................36

4.2.2.4 Two Point Loads at Midspan ...................................................39 
4.2.2.5 Two Point Loads at Interior Crosstie (Left).................................41

4.2.2.6 Two Point Loads at Interior Crosstie (Right) ..............................43

4.2.2.7 Conclusion and Summary of Prestressed Concrete Panel 1 .......44

4.3 Full-Size Prestressed Concrete Panel 2.................................................................46

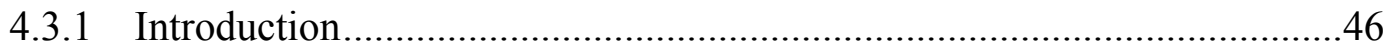

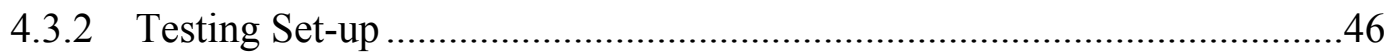

4.3.3 Static Load Testing ...............................................................................47

4.3.3.1 Single Point Load at Midspan....................................................47

4.3.3.2 Single Point Load at Interior Crosstie............................................50

4.3.3.3 Single Point Load in Middle of Outer Crossties (Left)................54

4.3.3.4 Two Point Loads at Midspan .........................................................57

4.3.3.5 Two Point Loads Over Left Interior Crosstie ……………….......59

4.3.3.6 Two Point Loads Over Right Interior Crosstie .............................63

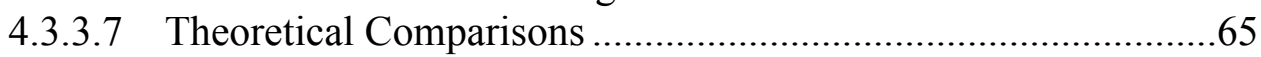

4.3.3.7.1 Single Point Load at Midspan....................................65

4.3.3.7.2 Single Point Load at Left Crosstie ..............................66

4.3.3.7.3 Single Point Load in Middle of Outer Crossties.......67

4.3.3.7.4 Two Point Loads at Midspan .......................................68

4.3.3.7.5 Two Point Loads at Left Interior Crosstie ................69

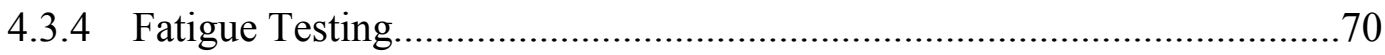

4.3.5 Summary and Conclusions of Full-Size Prestressed Concrete Panel 2 .....73

4.4 Jointed Prestressed Concrete Panels ....................................................................74

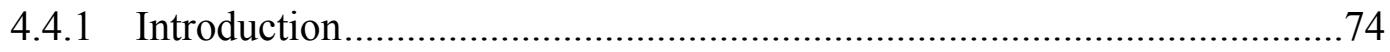

4.4.2 Single Point Load Applied Over Joint ......................................................76

4.4.3 Two Point Loads Applied Centrally Over Joint .........................................8

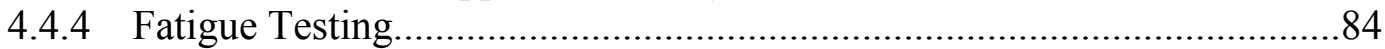

4.4.5 Conclusions on Set of Half Prestressed Concrete Panels ...........................85

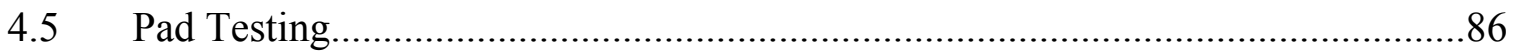

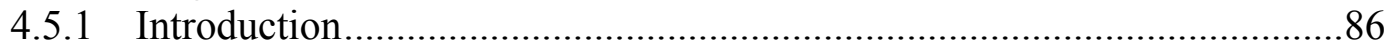

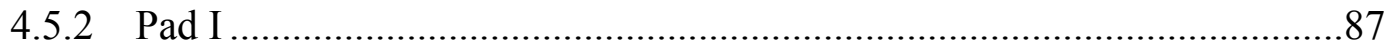

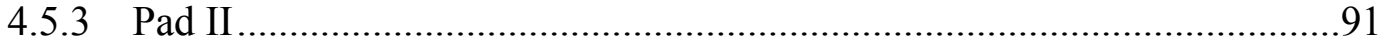

4.5.4 Conclusions of Rubber Pad Testing......................................................94

4.6 Fiber Reinforced Polymer (FRP) Composite Panel............................................95

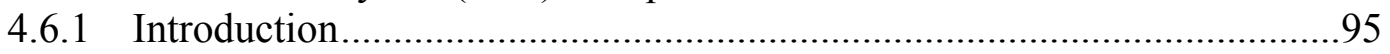

4.6.2 Single Point Load at Midspan..............................................................98

4.6.3 Single Point Load at Center of Midspan and Left Crosstie ......................102

4.6.4 Single Point Load at Center of Midspan and Right Crosstie ....................105

4.6.5 Two Point Load Centrally Applied at Midspan.........................................109

4.6.6 Two Point Loads Applied Centrally Between Left and Midspan Crossties ......................................................................112

4.6.7 Two Point Loads Applied Centrally Between Right and Midspan Crossties ......................................................................115

4.6.8 Fatigue Testing..................................................................................119

4.6.9 Conclusions on Full-Size FRP Panel ....................................................120

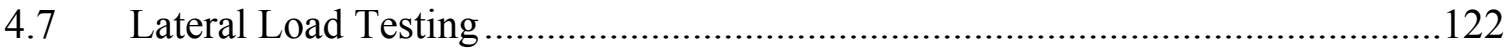

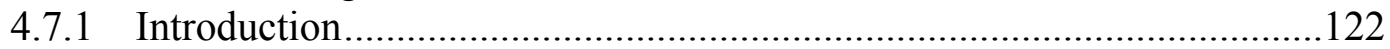




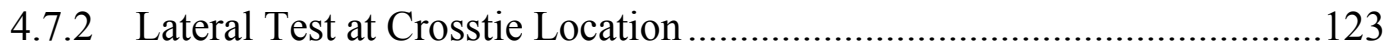

4.7.3 Lateral Test at the Midspan of Two Crossties .....................................125

4.7.4 Lateral Testing of FRP Panel ............................................................. 128

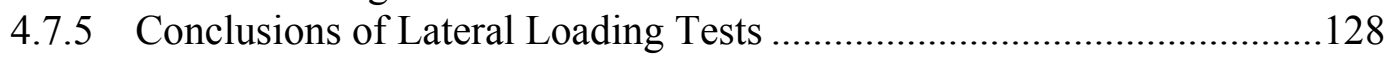

CHAPTER 5 - COMPARISONS OF FRP TRACK PANEL ..................................129

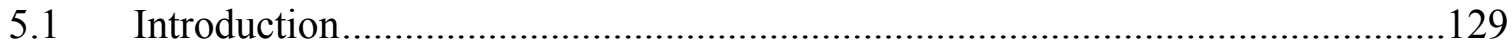

5.1.1 Single Point Load Applied At Midspan................................................129

5.1.2 Double Point Loads Applied Centrally At Midspan................................130

5.1.3 Single Point Load Applied at Midspan of Left and Midspan Crossties ..131

5.1.4 Double Point Loads Applied at Midspan of Left and Midspan

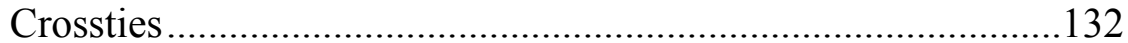

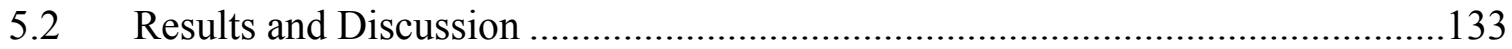

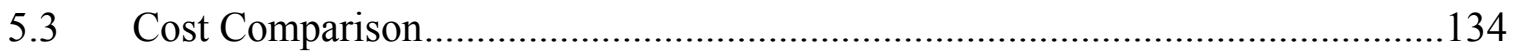

5.3.1 Cost of Prestressed Concrete Panel......................................................... 134

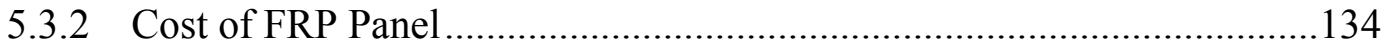

5.3.3 Cost of Existing Track Structure........................................................134

CHAPTER 6 - CONCLUSIONS AND RECOMMENDATIONS .............................136

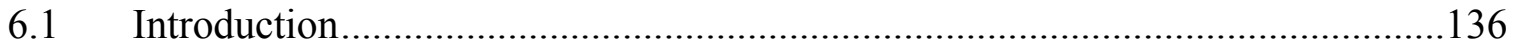

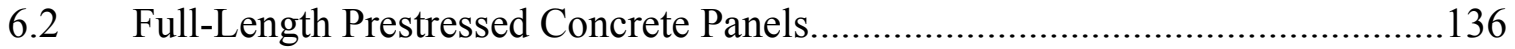

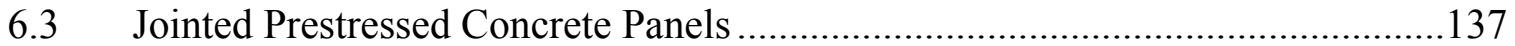

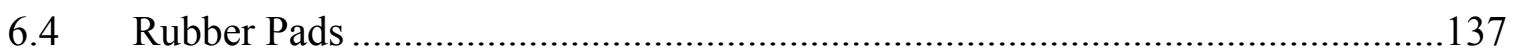

6.5 Fiber Reinforced Polymer (FRP) Composite Panel.........................................138

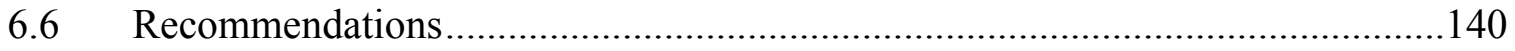

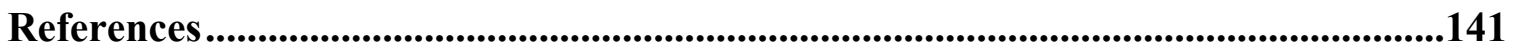

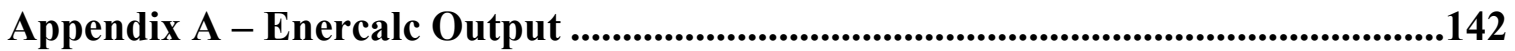

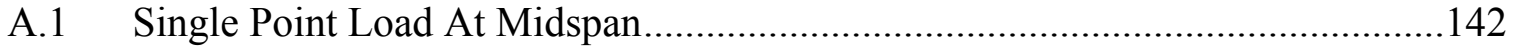

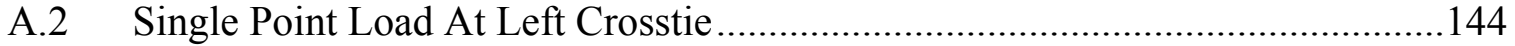

A.3 Double Point Loads At Midspan....................................................................... 146

A.4 Double Point Loads At Left Crosstie................................................................ 148

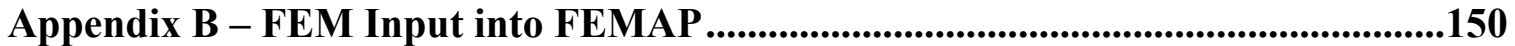

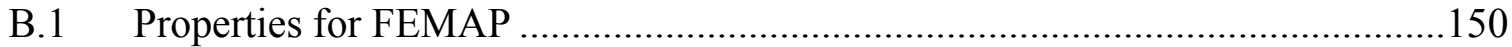

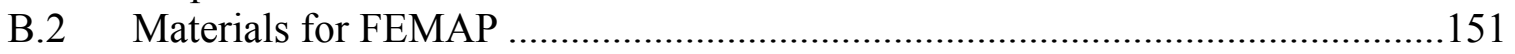

Appendix C - FEM Analysis Provided By Interrail, Inc.. .........................................152

Appendix D - Prestress Calculations ................................................................155

Appendix E - Cost Calculations .................................................................................157

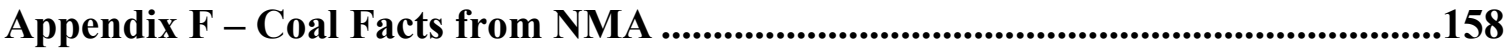




\section{List of Tables}

Table 3.1. Deflections for Single Point Load at Midspan Using

Respective Analysis...........................................26

Table 3.2. Deflections for Double Point Load at Midspan Using

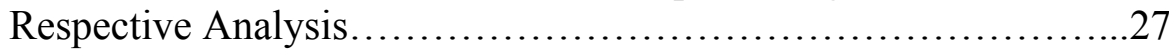

Table 4.3.1. Deflections at Pad Location for Respective Analysis.................66

Table 4.3.2. Deflection for Single Point Load at Left Interior Crosstie..............67

Table 4.3.3. Deflections for Single Point Load in Middle Of Outer Crossties......68

Table 4.3.4. Deflections for Two Point Loads at Midspan..........................69

Table 4.3.5. Deflections for Two Point Loads at Left Interior Crosstie.............70

Table 4.3.6. Deflection of Concrete Beam at Indicated Pad Location..............72

Table 4.5.1. Stiffness and Secant Modulus for Each Pad at Indicated Number of Cycles...................................................93

Table 4.5.2. Maximum Deflections for Each Pad at Indicated Number of Cycles. 94

Table 5.1. Cost Comparison Between Panels and Existing Track Structure.......135

Table 6.1. Maximum Deflections and Strains for Indicated Loading Cases........139

Table 6.2. Stiffness and Changes of Stiffness of Panels After Indicated Applied Cycles..................................................139 


\section{List of Figures}

Figure 2.1. Ballast Track Used At Garden Railroad, Pennsylvania..................................5

Figure 2.2. Ballast Track Used for Surface Mining .........................................................5

Figure 2.3. Concrete Twin-Block Sleeper System.......................................................6

Figure 2.4. Cross-Section of Gravel Bin and Prestressed Concrete Beams.....................11

Figure 2.5. Full-Size Prestressed Concrete Panel Set-Up...........................................13

Figure 2.6. Full-Scale Prestressed Concrete Panel Dimensions .....................................13

Figure 2.7. Set of Half Panels with Rubber Pads.........................................................14

Figure 2.8. Half-Panel Dimensions............................................................................. 15

Figure 2.9. Cross-Section of Steel Crossties used in Full and Half Prestressed

Concrete Panels................................................................................15

Figure 2.10. Post-Tensioned Prestressed Concrete Panel Cross-Section ........................16

Figure 2.11. Cross-Section of FRP Panel ................................................................. 17

Figure 2.12. FRP Composite Panel Dimensions.......................................................... 18

Figure 2.13. Steel Rail Attached to Two-Cell FRP Box Beam .....................................19

Figure 2.14. Deflection of Foundation for Indicated Load ..........................................19

Figure 3.1. Foundation Response of Rigid Block Comparing the Winkler Idealization to

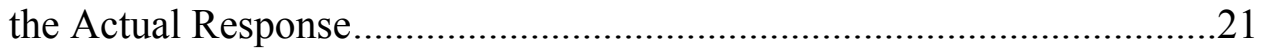

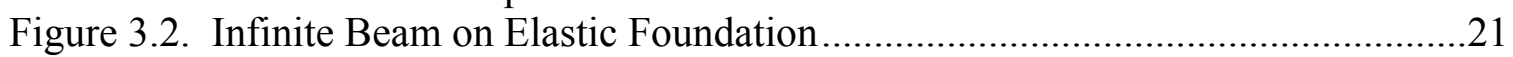

Figure 3.3. Free-Body Diagram of Beam on Elastic Foundation ..................................22

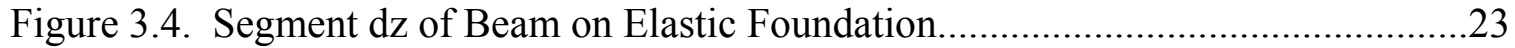

Figure 4.2.1. Crack located at 4'3'" from Midspan ......................................................29

Figure 4.2.2. Pandrol Mineclip 7100 Series used to Attach Rail.....................................30

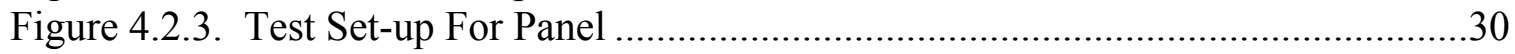

Figure 4.2.4. Dial Gages and Strain Gages on Test Specimen ........................................

Figure 4.2.5 Test Set-Up for Single Point Load at Midspan ........................................32

Figure 4.2.6. Deflected Shape of Beams at Maximum Load of 20 kips.........................33

Figure 4.2.7. Strain vs. Position for Beam 1 at Indicated Loads .....................................33

Figure 4.2.8. Strain Distribution Along Beam 1 for Indicated Loads for Point

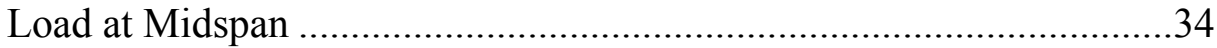

Figure 4.2.9. Test Set-Up for Single Point Load Applied Over Left Crosstie..................34

Figure 4.2.10. Deflected Shapes of Beams at Maximum Load of 20 kips for Interior Crosstie Loading ...........................................................35

Figure 4.2.11. Strain Distribution Along Beam 1 for Indicated Loads at Interior

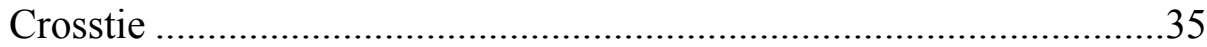

Figure 4.2.12. Strain vs. Position for Beam 1 at Indicated Loads ................................36

Figure 4.2.13. Test Set-Up for Single Point Load Applied At Midspan of Outer Left

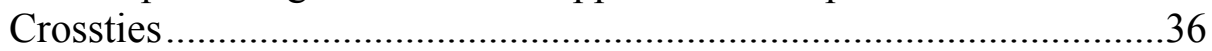

Figure 4.2.14 Deflected Shapes of Beams at Maximum Load of 20 kips for Load in Middle of Outer Crossties..................................................................37

Figure 4.2.15. Strain Distribution for Beam 1 at Indicated Loads for Load Applied In Middle of Outer Crossties ............................................37

Figure 4.2.16. Strain vs. Position for Beam 1 at Indicated Loads .................................38 
Figure 4.2.17. Test Set-Up for Double Point Loads Applied Centrally At Midspan .......39

Figure 4.2.18. Deflection of Beam 1 at Maximum Load of 20 kips for Two Point Loads at Midspan (10 kips Each Point)

Figure 4.2.19. Strain Distribution for Beam 1 at Indicated Loads for Two-Point Loads at Midspan (Load is Total Load Applied to Each Beam) .................40

Figure 4.2.20. Strain vs. Position for Beam1 at Indicated Loads ..................................40

Figure 4.2.21. Test Set-Up for Double Point Loads Applied Over Left Crosstie.............41

Figure 4.2.22. Deflected Shape of Beam 1 at Maximum Load of 20 kips for Two Point Loads at Inner Cross-Tie (10 kips at Each Point).

Figure 4.2.23. Strain Distribution for Beam 1 at Indicated Loads for Two-Point Loads at Interior Crosstie....................................................................42

Figure 4.2.24. Strain vs. Position for Beam 1 at Indicated Loads ................................42

Figure 4.2.25. Test Set-Up for Double Point Loads Applied Over Right Crosstie .........43

Figure 4.2.26. Deflected Shape of Beam 1 at Maximum Load of 20 kips for Load at Inner Cross-tie (10 kips at Each Point) .......................................43

Figure 4.2.27. Strain Distribution for Beam 1 at Indicated Loads for Load at Inner Crosstie ...........................................................................44

Figure 4.2.28. Strain vs. Position for Beam 1 At Indicated Loads ..................................44

Figure 4.3.1. Strain Gage and Dial Gage Location on Prestressed Concrete Panel ........47

Figure 4.3.2. Post-Tension Concrete Beam Cross-Section...........................................47

Figure 4.3.3. Schematic for Single Point Load at Midspan ..........................................48

Figure 4.3.4. Deflected Shape of Beam at 5 and 10 kips Loading ................................48

Figure 4.3.5. Deflection Distribution vs. Position for Load of 10 kips ..........................49

Figure 4.3.6. Strain vs. Position at Maximum Load of 10 kips ....................................49

Figure 4.3.7. Strain Distribution vs. Position at Load of 10 kips ...................................50

Figure 4.3.8. Load vs. Pressure for Single Point Load at Midspan ................................50

Figure 4.3.9. Schematic for Interior Cross-Tie Loading..............................................51

Figure 4.3.10. Deflected Shape of Beams at Indicated Loads for Interior

Crosstie Loading ......................................................................5

Figure 4.3.11. Deflection Distribution vs. Position at Maximum Load of 10 kips

For Loading at Interior Crosstie......................................................52

Figure 4.3.12. Strain vs. Position for Maximum Load of 10 kips ................................52

Figure 4.3.13. Strain Distribution vs. Position for Maximum Load of 10 kips ................53

Figure 4.2.14. Total Load vs. Pressure for Single Point Load

At Interior Crosstie .......................................................................53

Figure 4.3.15. Schematic for Application of Load in Middle of Outer Crossties.............54

Figure 4.3.16. Deflection vs. Position for Load in Middle of Outer Crossties .................54

Figure 4.3.17. Deflection Distribution for Single Point Load in Middle of

Outer Crossties................................................55

Figure 4.3.18. Strain vs. Position for Single Point Load in Middle of

Outer Crossties..................................................55

Figure 4.3.19. Strain Distribution for Load Applied in Middle of Outer Crossties..........56

Figure 4.3.20. Load vs. Pressure for Load in Middle of Outer Crossties ........................56

Figure 4.3.21. Schematic for Application of Two Central Point Loads ..........................57

Figure 4.3.22. Deflection vs. Position at Indicated Loads for Two Point Loads

At Midspan.... 
Figure 4.3.23. Deflection Distribution vs. Position for Two Point Loads at Midspan .....58

Figure 4.3.24. Strain vs. Position for Two Point Loads at Midspan...............................58

Figure 4.2.25. Strain Distribution for the Application of Two Point Loads at Midspan ..59

Figure 4.3.26. Load vs. Pressure for Two Point Loads Applied at Midspan....................59

Figure 4.3.27. Schematic of Interior Crosstie Two Point Load Application ....................60

Figure 4.3.28. Deflection vs. Position for Two Point Loads Applied Over Left

Left Interior Crosstie.

Figure 4.3.29. Deflection Distribution vs. Position for Two Point Loads Applied

Over Left Interior Crosstie.....

Figure 4.3.30. Strain vs. Position for Two Point Loads Applied At Left Interior Crosstie

Figure 4.3.31. Strain Distribution vs. Position for Two Point Loads Applied At Left Interior Crosstie

Figure 4.3.32. Load vs. Pressure Experienced by Foundation at Maximum Load for Application of Two Point Loads at Interior Crosstie........................62

Figure 4.3.33. Schematic of Interior Crosstie Two Point Load Application ....................63

Figure 4.3.34. Deflection vs. Position for Two Point Loads Applied At Right Interior Crosstie.

Figure 4.3.35. Load Distribution Based on Deflection for Application of Two

Point Loads at Right Interior Crosstie

Figure 4.3.36. Strain vs. Position for Two Point Loads Applied At Right

Interior Crosstie.

Figure 4.3.37. Strain Distribution vs. Position for Two Point Loads Applied

At Right Interior Crosstie.

Figure 4.3.38. Deflection Results for Single Point Load at Midspan...................66

Figure 4.3.39. Deflection for Indicated Analysis for Single Point Load at Left Interior Crosstie.

Figure 4.3.40. Deflection for Indicated Analysis for Single Point Load in Middle

Of Outer Crossties..............................................68

Figure 4.3.41. Deflections for Indicated Analysis for Two Point Loads at Midspan......69

Figure 4.3.42. Deflection Analysis for Two Point Loads at Left Interior Crosstie ..........70

Figure 4.3.43. Deflection of the Concrete Beam after Indicated Fatigue Cycles .............71

Figure 4.3.44. Stiffness of Concrete Beam after Indicated Fatigue Loading Cycles........72

Figure 4.4.1. Dial and Strain Gage Locations for Joint Testing ....................................74

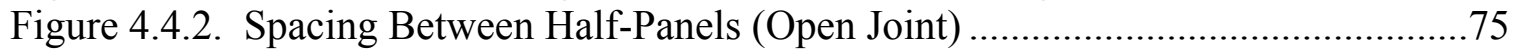

Figure 4.4.3. Experimental Setup for Single Point Load at Joint ..................................76

Figure 4.4.4. Deflected Shape of Beams for Single Point Load Applied Directly Over

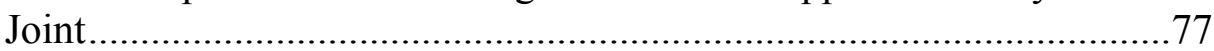

Figure 4.4.5. Load Distribution Based on Deflection for Single Point Load Applied

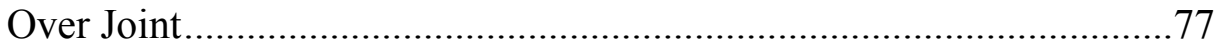

Figure 4.4.6. Strain vs. Position for Maximum Load of 10 kips ..................................78

Figure 4.4.7. Load Distribution Based on Strain for Single Point Load Applied

Over Joint................................................................................ 79

Figure 4.4.8. Pressure in the Foundation Under the Joint for a Single Point Load

Applied over the Joint...........................................79

Figure 4.4.9. Experimental Setup for Two Point Loads Applied Centrally Over Joint....80 
Figure 4.4.10. Deflected Shape of Beams At Total Load of 20 kips/beam

Figure 4.4.11. Load Distribution Based on Deflection for Double Point Load Applied Over Joint

Figure 4.4.12. Strain vs. Position for Double Point Load Applied Centrally Over Joint .82 Figure 4.4.13. Load Distribution based on Strain for Double Point Loads Applied Centrally Over Joint............................................83

Figure 4.4.14. Pressure in the Foundation for Double Point Loads Applied Centrally Over the Joints

Figure 4.4.15. Deflection of Beam for Static Test Conducted After Indicated Applied Cycles.

Figure 4.5.1. 0.24" Resilient Rubber Pad Used for Prestressed Concrete Panels............86

Figure 4.5.2. Test Set-up in Instron Machine for Pad Testing........................................87

Figure 4.5.3. Pad Stiffness Before Fatigue Testing Began ............................................87

Figure 4.5.4. Pad Stiffness After 100,000 Cycles.........................................................8

Figure 4.5.5 Pad Stiffness After 250,000 Cycles........................................................89

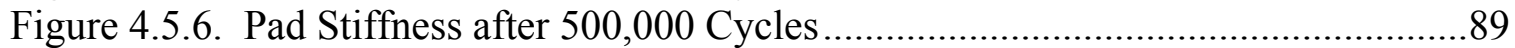

Figure 4.5.7. Pad Stiffness After 1,000,000 Cycles .....................................................90

Figure 4.5.8. Load vs. Deflection Curves for Individual Tests......................................90

Figure 4.4.9. Stiffness of Pad 2 Before Fatigue Testing ............................................... 91

Figure 4.5.10. Stiffness of Pad 2 after 100,000 Cycles of Applied Load ........................91

Figure 4.5.11. Stiffness of Pad 2 After 250,000 Cycles of Applied Load ........................92

Figure 4.5.12. Stiffness of Pad 2 After 500,000 Cycles of Applied Load ........................92

Figure 4.5.13. Stiffness of Pad 2 after 1,000,000 Cycles of Applied Load .....................93

Figure 4.6.1. Cross-Section of FRP Beam with Rail Attached....................................96

Figure 4.6.2. FRP Beams Bonded Together with Epoxy ..............................................96

Figure 4.6.3. High-Strength Dywidag Rod Used as Crosstie .......................................97

Figure 4.6.4. FRP Panel Set-Up in Gravel Bin ...........................................................99

Figure 4.6.5. Schematic for Single Point Load at Midspan Test ...................................98

Figure 4.6.6. Deflection of Beam Under Single Point of 10 kips Load Applied At

Midspan.

Figure 4.6.7. Load Distribution from Deflection for Single Load Applied At Midspan..99

Figure 4.6.8. Strain of FRP Beam Under Single Point Load of 10 kips Applied at Midspan.

Figure 4.6.9. Strain Distribution for Single Point Load of 10 kips Applied at Midspan 100

Figure 4.6.10. Pressure of Foundation for Single Point Load of 10 kips at Midspan ....101

Figure 4.6.11. Schematic for Single Point Load at Center of Midspan and Left Crossties 102

Figure 4.6.12. Deflection of FRP Beam Under Single Point Load of 10 kips Applied at Center of Midspan and Left Crossties ...............................................103

Figure 4.6.13. Load Distribution Based on Deflection for Single Point Load of 10 kips Applied at the Center of the Midspan and Interior Crossties.

Figure 4.6.14. Strains in the FRP Beam Under a Single Point Load of 10 kips Applied at The Center of Midspan and Left Crossties .......................................104

Figure 4.6.15. Load Distribution Based on Strain for Single Point Load of 10 kips Applied At The Center of Midspan and Left Crossties .104

Figure 4.6.16. Pressure for Single Point Load of 10 kips Applied the Center of 
Midspan and Left Crossties 105

Figure 4.6.17. Schematic for Single Point Load at Center of Midspan and Right Crosstie 106

Figure 4.6.18. Deflection Values of FRP Beam Under Single Point Load of 10 kips

Applied At Center of Midspan and Right Crosstie....................106

Figure 4.6.19. Load Distribution Based on Deflection for Single Point Load of 10 kips Applied at Center of Midspan and Right Crosstie

Figure 4.6.20. Strain Values FRP Beam Under Single Point Load of 10 kips Applied

At Center of Midspan and Right Crosstie 107

Figure 4.6.21. Load Distribution Based on Strain for Single Point Load of 10 kips Applied at Center of Midspan and Right Crosstie. 108

Figure 4.6.22. Pressure for Single Point Load of 10 kips Applied the Center of Midspan and Right Crossties ...... 108

Figure 4.6.23 Schematic for Two Point Loads Centrally Loaded at Midspan 109

Figure 4.6.24. Deflection Values for Two Point Loads Applied Centrally At Midspan 110

Figure 4.6.25. Load Distribution from Deflection for Two Point Loads Applied Centrally At Midspan...........................................110

Figure 4.6.26. Strain Values for Two Point Loads Centrally Loaded At Midspan.......111 Figure 4.6.27. Load Distribution Based on Strain for Two Point Loads Applied Centrally At Midspan

Figure 4.6.28. Pressure for Two Point Loads Applied Centrally At Midspan.................112

Figure 4.6.29. Schematic of Test Setup for Two Point Loads Applied Centrally Between Left and Midspan Crossties...............................112

Figure 4.6.30. Deflection Values for Two Point Loads Applied Centrally Between Left and Midspan Crossties........................................113

Figure 4.6.31. Load Distribution Based on Deflection for Two Point Loads Applied Centrally Between Left and Midspan Crossties. 113

Figure 4.6.32. Strain Values for Two Point Loads Applied Centrally Between Left and Midspan Crossties...............................................114

Figure 4.6.33. Load Distribution Based on Strain for Two Point Loads Applied Centrally Between Left and Midspan Crossties................................114

Figure 4.6.34. Pressure for Two Point Loads Applied Centrally Between Left And Midspan Crossties. . .115

Figure 4.6.35. Schematic for Two Point Loads Applied Centrally Between Right and Midspan Crossties...............................................116

Figure 4.6.36. Deflection of Beam for Two Point Loads Applied Centrally Between Right And Midspan Crossties.......................................116

Figure 4.6.37. Load Distribution Based on Deflection for Two Point Loads Applied Centrally Between Right and Midspan Crossties....................117

Figure 4.6.38. Strain Values for Two Point Loads Applied Centrally Between Right And Midspan Crossties...........................................117

Figure 4.6.39. Load Distribution Based on Strain for Two Point Loads Applied Centrally

Between Right And Midspan Crossties..............................118

Figure 4.6.40. Pressure for Two Point Loads Applied Centrally Between Right And Midspan Crossties.............................................118

Figure 4.6.41. Deflection of FRP Beam After First Dynamic Load Testing..................119 
Figure 4.6.42. Deflection of FRP Beams After Second Dynamic Loading Test..... 120

Figure 4.7.1. Prestressed Concrete Cross-Section and Loading Location for Lateral Tests

Figure 4.7.2. Lateral Testing Set-Up on Prestressed Concrete Specimen ......................123

Figure 4.7.3. Dial Gage Location for Lateral Load Test at Crosstie Location ...............124

Figure 4.7.4. Strain in Crosstie for Lateral Test at Cross-Tie Location..........................124

Figure 4.7.5. Deflection of Steel Rail for Lateral Test Conducted At Cross-Tie Location

Figure 4.7.6. Dial Gage Locations for Lateral Test at Midspan of Two Crossties.........126

Figure 4.7.7. Strain in Steel Rail for Lateral Test Conducted at Midspan of Two Crossties

Figure 4.7.8. Deflection of Steel Rail for Lateral Load Applied at Midspan of Two Crossties

Figure 5.1. Comparison of Load Distribution Based on Deflection for Single Point Load Applied At Midspan

Figure 5.2. Load Distribution Based on Deflection for Double Point Loads Centrally Applied At Midspan.

Figure 5.3. Load Distribution Based on Strain for Double Point Loads Applied Centrally At Midspan. 131

Figure 5.4. Load Distribution Based on Deflection for a Single Point Load Applied At the Midspan of the Left and Midspan Crossties

Figure 5.5. Load Distribution Based on Strain for a Single Point Load Applied At the Midspan of the Left and Midspan Crossties 132

Figure 5.6. Load Distribution Based on Deflection for Double Point Loads Applied at

Midspan of Left and Midspan Crossties 132

Figure 5.7. Load Distribution Based on Strain for Double Point Loads Applied at Midspan of Left and Midspan Crossties 


\title{
List of Symbols
}

\author{
$\mathrm{k}_{\mathrm{o}}=$ foundation parameter \\ $\mathrm{b}=$ width of concrete beam, in \\ $\mathrm{y}=$ deflection, in \\ $\mathrm{p}_{\mathrm{f}}=$ pressure on foundation, $\mathrm{psi}$ \\ $\mathrm{E}=$ elastic modulus, psi \\ $\mathrm{I}=$ moment of inertia, in ${ }^{4}$ \\ $\mathrm{f}^{\prime} \mathrm{c}=$ concrete compressive strength, psi \\ $\mathrm{h}=$ concrete beam height (depth), in \\ $\beta=$ defined parameter for beams on elastic foundation \\ $\mathrm{k}=$ spring coefficient
}




\section{CHAPTER 1 - INTRODUCTION}

\subsection{Background}

Coal, the most abundant fossil fuel resource in the United States, is produced through underground and surface mining methods to generate electric power. More recently, the American Coal Council (ACC) estimated that for every \$1 billion worth of coal production, \$19 billion worth of electricity is generated. In addition, the U.S. coal production has reached its highest levels in decades producing almost a billion tons annually by roughly 1,500 active mines in 26 states. For example, in FY 2000, West Virginia mines produced over 169 million tons of coal, which accounted for $15 \%$ of the total U.S. coal production (National Mining Association, 2002).

Over the past several years, there has been an increase in the number and severity of safety related concerns in the coal transportation and energy infrastructure industry. These concerns, including inadequate and less than safe transportation systems, threaten markets for West Virginia products, weaken prices, and undermine the ability to create jobs and contribute to economic growth.

Furthermore, the more recent spectacular and heavily publicized flooding and subsequent rescuing of nine miners in the Quecreek underground mine in Somerset County, Pennsylvania, has refocused attention on mine safety. Other accidents and even fatalities due to coal car or locomotive derailment have raised the issue of underground coal transportation using old and beat-up mine tracks. Derailments are more frequent than originally thought of or even admitted to by coalmine owners. Derailments usually end up costing a lot of time and money in lost production, down time, and excessive maintenance.

These accidents and even fatalities may have been prevented if proper tracks are installed and maintained on proper track bed foundations. Currently, ballasted tracks or tracks installed without a ballast with transverse wood crossties are typically installed in the cheapest and quickest way possible resulting in uneven track settlement and derailment.

Also, tracks in underground mines are generally in poor condition and this is exacerbated by a general lack of maintenance of the track facilities. The operating conditions also generally dictate that the installation of track is completed in the shortest time possible and that the track be available for use immediately after a short section has been completed. In many instances the 
track is only required to operate for a short period of time and then the preferred option is to be able to lift the track and reuse the components of the basic track structure elsewhere. In other cases, the track is installed in a main haulage line and will be expected to perform over a number of years. Obviously, the cost of required maintenance and labor should be minimized.

This research, funded by the office of the governor of West Virginia, explores new and innovative methods to develop robust modular track panels for the mining transportation industry that will improve coal mining productivity and safety in West Virginia and eliminate track structural problems.

Specifically, this research study is concerned with testing and evaluating a ballastless tangent (straight-section) modular track panel. The proposed panels consist of two (2) parallel post-tensioned concrete beams interconnected at discrete intervals by steel crossties to be used initially in the mining railways. The use of such a low maintenance modular track system will provide continuous support, thereby reducing track bed foundation settlement and improving overall efficiency and safety. The modular track panels will then be evaluated for highway-rail crossings and transition track going from softer rail track systems to stiffer highway-rail crossing systems. The specific requirements for the proposed track system are to:

- Have very low level of maintenance requirement at low cost

- Have rapid installation with semi-skilled labor

- Be able to be installed either on a permanent basis or temporary basis

- Have a low track profile for coalmines

- Have good riding quality for miners

- Be able to be used for repair of existing track or the installation of new track

- Be capable of sustaining axle loads of 10 tons for the mine cars and 50 tons for the locomotives for a minimum of 500,000 cycles

- Be capable of being placed in service immediately after installation

The Constructed Facilities Center (CFC) of West Virginia and Interrail, Inc., a West Virginia based company in Grafton, developed the preliminary design of the proposed modular track post-tensioned concrete panel. Interrail, Inc. first developed the concept of the modular track panel. The laboratory testing and analysis conducted during this research by the CFC involved constructing two (2) full-scale prestressed (post-tensioned) concrete modular track panels and two adjacent half panels subjected to static and fatigue loads. The testing will simulate the panels' response under tangent track conditions. In addition, a lightweight fiber reinforced polymer (FRP) panel is tested and compared to the post-tensioned concrete panel. 


\subsection{Objective and Scope of Work}

The primary objective of this research study is to test and evaluate a ballastless tangent modular post-tensioned concrete track panel to be used in the mines to provide a stable track structure. The specific objectives are to:

1. Construct two (2) post-tensioned concrete panels, and a set of half-panels to evaluate the their joining mechanism.

2. Test panels under static and fatigue loads by evaluating strains, deflections, and foundation pressure in a simulated mine foundation.

3. Compare and validate experimental results with theoretical models and with finite element analyses.

4. Test and evaluate resilient railpads.

5. Develop and test an all FRP track panel.

A detailed description of track components for mine application and the testing approach for this research are provided in Chapter 2. It provides information on types of track, railway track design, and recent developments in mining applications. Chapter 2 also provides the testing approach for the program outlined. A rigorous analysis of beams on elastic foundation using the Winkler model and finite element modeling are presented in Chapter 3. Chapter 4 provides the experimental program including testing of two full-scale prestressed concrete panels, one set of prestressed concrete half-panels, testing of the resilient railpads, and testing of an FRP panel. Results from a prestressed concrete panel and the FRP panel are compared in Chapter 5. Comparisons primarily involve load sharing characteristics between the two panels, stiffness, deflections, and degradation rates under fatigue. Finally, conclusions are provided in Chapter 6 . 


\section{CHAPTER 2 - TRACK COMPONENTS AND LOADING}

\subsection{Introduction}

Locomotives and mine cars in underground mines often derail causing casualties and production and money losses. Mine cars carry miners and equipment throughout the mine. Coal is mostly carried to its destination on conveyor belts. The following sections discuss the components of track construction in general.

\subsection{Construction}

There is a sub-structure supporting the track for both surface and underground mines. It consists of three main components: the formation, the sub-ballast, and the ballast. The formation is the ground that the track is laid upon. It can be natural grade or an embankment. The track is supported on a ballast, usually made of crushed stones. The ballast also transfers load and provides drainage for the track. The ballast is generally made of stones rough in texture to lock together and resist movement. The track rails are secured on sleepers, called crossties in the United States, to keep the rails the correct distance apart or the gauge. Another type of concrete sleeper is known as the twin-block sleeper or longitudinal sleeper in which two rectangular concrete beams are placed parallel to each other and joined by a steel bar (Figure 2.3). The twin-block sleeper tracks are 30\% lighter than conventional concrete sleepers (Railway Technical Pages).

\subsection{Ballast vs. Non-Ballast Track}

There are a wide variety of track forms and systems that use a concrete base or other support that does not require ballast. Most of these require a shallower foundation compared to ballasted track. There is, however, a greater need for accuracy in placement, which is not needed for ballasted track. One of the weaknesses of ballast track is its ability to allow track realignment. Passing trains on a curved section of track cause lateral movements resulting in maintenance costs. Weather can also cause damage and add to maintenance costs. Damage to the ballast leads to tracks "pumping" as a train passes. After a period of time, rail or sleeper damage will occur. A ballast system requires regular packing or tamping to ensure correct alignment and will also have to be cleaned or replaced every few years. Typical ballasted track 
systems are shown in Figures 2.1 (http://hometown.aol.com/twcoegr/GardenRR/ballasted.htm) and Figure 2.2 (Railway Technical Pages, 2001). Figure 2.3 shows a picture of a twin-block sleeper concrete track (http://www.rrtie.com).

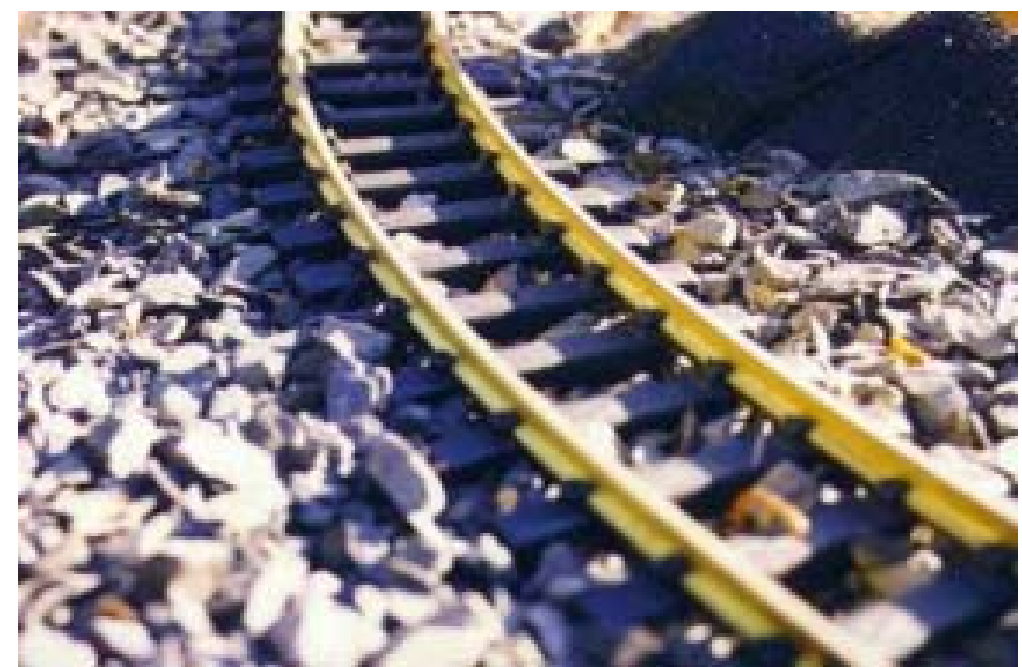

Figure 2.1 Ballast Curved Track Used At Garden Railroad, Pennsylvania

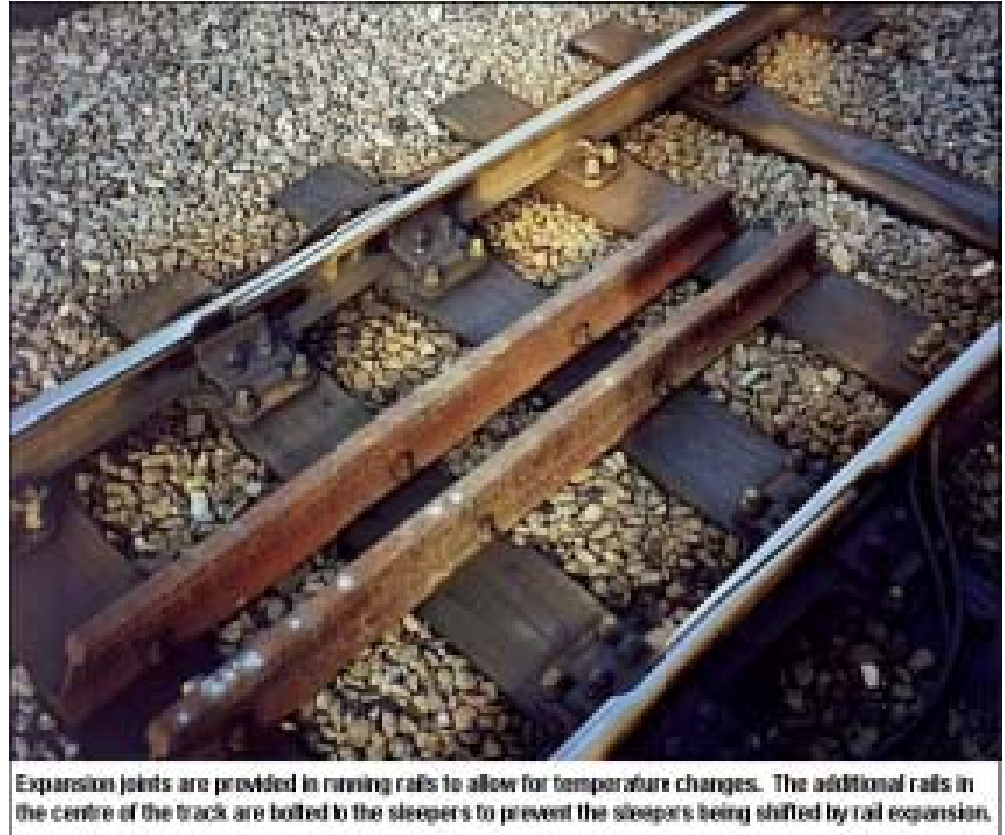

Figure 2.2 Ballast Track Used for Surface Mining 


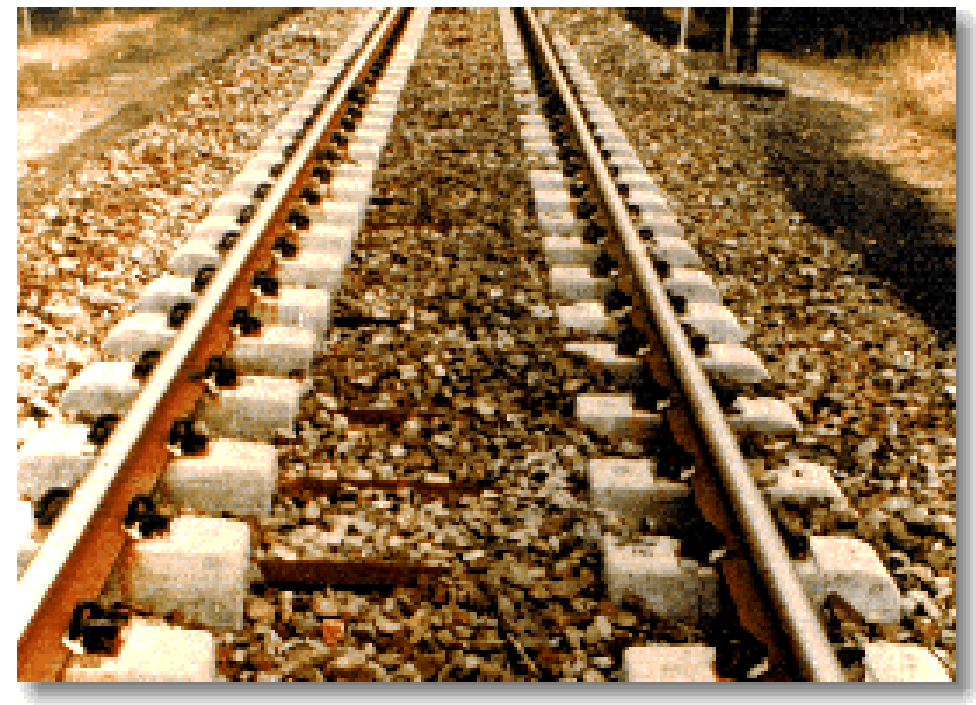

Figure 2.3. Concrete Twin-Block Sleeper System

\subsection{Curves}

Sections of curved track require careful design to allow for trains or mine cars in underground mines to reach sufficient speeds without causing enough lateral stress on the track to induce derailment. Vertical and horizontal curves both exist in the transportation system. The location that the track changes from tangent to a curve or from one radius to another is known as transition (Railway Technical Pages, 2001).

\subsection{Railway Track Design}

In the early part of the $20^{\text {th }}$ century, the design of railway tracks relied on engineering experience. New techniques and technologies have changed this view and allow for an optimum design approach to include geometry and speed. Track structures vary tremendously between every field situation including:

- Different axle loads (Locomotives - 20-50 tons, Mine Cars - 10-20 tons)

- Different operating speeds

- Curved and tangent tracks

- Urban and rural areas (surface mines)

- Tracks in transition zones

- Tracks in level crossings 
- Tracks on bridges, in tunnels, or other major structures

- Tracks on different types of soils

Surface and underground mine tracks presently used are limited for reasons of

- Constructability

- Maintainability

- Reliability

Tracks are generally designed and constructed conservatively to avoid possible failures during operation or to meet new operational requirements in future use. Most track structures, however, are still based on past engineering experience and empirical relations as opposed to a basis of track behavior involving numerical simulation and optimization techniques (Markine, de Man, and Esveld, 1998).

\subsection{Recent Developments}

A more recent concept of a railway structure developed by Japanese engineers involves using longitudinal prestressed concrete beams placed on a stone bed to provide continuous support. Prestressed concrete is useful because of its crack resistance. Experiments were conducted in France, Japan, and the Soviet Union between the 1940s and the 1960s on longitudinal precast prestressed concrete sleepers placed in parallel pairs under the rails. The experiments were unsuccessful and attention was turned to transverse concrete sleepers, as well as twin block concrete sleepers joined by steel bars.

The Structural Engineering Group of Japan's Railway Technical Research Institute (RTRI), in 1993, conducted research on the longitudinal sleepers to determine the reason for their earlier failure. It was determined that the designers of the longitudinal sleepers did not sufficiently maintain the track gauge. The longitudinal sleepers also required a greater amount of concrete than transverse sleepers. The fundamental principal of placing parallel pairs of sleepers under the rail, however, was sound and provides the much needed stability and minimizes the uneven track settlement found in ballasted systems. The sleeper and rail act as a composite beam. An advantage of using this type of system is that weak spots in the track path can be bridged leading to lower maintenance costs.

Furthermore, ladder sleepers have been designed and tested in service. They are manufactured as two longitudinal concrete beams joined by steel pipes or square tubes that act as 
gauge ties. The finished system resembles a ladder laid on the ground. This configuration results in a light-weight sleeper that is approximately the same weight per track length as the concrete cross-tie systems. One such experimental ladder sleeper made of partially prestressed concrete using three or five strands and a pipe diameter of $80 \mathrm{~mm}$ (3.15 in) was installed in February of 1996 and by June 1997, it had carried 20 million gross tons. The section tested was $100 \mathrm{~m}$ (328 ft) in length and had dimensions of $400 \mathrm{~mm}$ x $155 \mathrm{~mm}$ (15.75" x 6.1"). Results showed that the ladder sleepers performed well in tests with considerations of pressure and load distribution.

An advantage of using stone ballast is the ease with which the line and level can be adjusted by tamping to compensate for soil settlement. A bed made of concrete has also been attempted. However, concrete trackbeds require little maintenance. The main difference between the two types is that stone ballasts are made to be tamped by machines to provide the required rail level and can be easily adjusted.

Tests results of a repetitive loading of $80 \mathrm{kN}$ (Wakui et al., 2001) showed that settlement rates at the midspan of ladder sleepers were eight times less than those with conventional track. In regards to ballast pressure, a more even distribution is achieved using ladder sleepers and the pressure gradient is much smoother. The maximum pressure is approximately halved, compared with conventional concrete crossties. The ends of the sleepers, however, had greater settlement, leading to the need for more research. The development of a joint is necessary to decrease the ladder end settlements. The results also showed that the ladder sleeper had been designed to withstand wheel flat impacts. The ladder tracks resulted in ensuring train safety, maintenance reduction, and environmental improvements. Steel pipes are used between the beams to maintain the gauge. The ground pressure is more evenly distributed, hence lower than the pressure from conventional concrete crossties (Wakui et al., 2001).

\subsection{Railpads}

A modern railway track constructed of steel rails and concrete sleepers on ballast relies on the importance of railpads. The railpads not only provide electrical insulation between the rails, but also protect the sleepers from wear and tear from impact loads on the rails. Their most important function may be their influence on the stiffness and damping of the entire track. 
Until about ten years ago, railpads could be placed into two categories - those with some resilience and those with long life spans. It had been difficult to find materials in the market satisfying both requirements. The pads with some resilience were made from grooved, generally synthetic, rubber, $5 \mathrm{~mm}$ in thickness. Those that provided extended life were made from much harder polymers (Pandrol, 1995). Pandrol (1995) conducted research to find materials to use that provided both resilience and durability.

It was thought that it was best to absorb the energy of any vibration in the track within the railpad. This leads to the concept that the pad must have a high hysteresis. There are two issues associated with this. One is that a large damping coefficient causes the pad to be stiff at high rates of loading based on the following mathematical equation

$$
\mathrm{P}=\mathrm{k} \delta+\eta(\mathrm{d} \delta / \mathrm{dt})
$$

where $\mathrm{k}$ is the stiffness, $\eta$ is the damping coefficient, $\mathrm{P}$ is the load, $\delta$ is the deflection, and $\mathrm{d} \delta / \mathrm{dt}$ is the change in deflection with time. The high value of hysteresis implies that the pad absorbs all of the energy. This leads to a lesser value of life for the pad. The amount of energy absorbed by the pad is proportional to the temperature of the pad. As the temperature of the pad increases, the mechanical properties of the pad change and could lead to failure of the pad.

An additional requirement of the pad material is to be able to sustain the static loading of the rail fastener toe load, even when there are no applied live loads. Elastomeric materials "creep" under sustained loading even while the stresses in the material are much less than its ultimate strength. Rubbers and other thermosetting polymers are less likely to creep and are generally the material of choice for resilience. If certain thermoplastic materials are treated after molding to improve the molecular cross-linking, they can act more like a thermoset material.

Pandrol concluded, after much evaluation, that the best materials for the manufacture of resilient railpads were natural rubber compounds with filler materials designed to provide low hysteresis. Pandrol shaped the surface of the pad in the form of cylindrical studs. As the pad is initially loaded, the studs act as a set of springs, and at higher loads, the studs expand until they are touching one another. The pad stiffness dramatically increases when the latter occurs.

There are four (4) principal ASTM standards used to evaluate railpads: drop-weight tests, load-deflection tests, high frequency stiffness measurements, and assembly durability. The impact attenuation of railpads is measured by dropping a weight on the rail head and measuring 
the transient strains induced in the sleeper. The pad attenuation is measured by comparing the peak sleeper bending strain after the impact to the peak strain measured on a "standard" nonresilient railpad. The impact attenuation is defined as

$$
\% \text { attenuation }=100\left(1-\varepsilon_{\text {test }} / \varepsilon_{\text {standard }}\right)
$$

where $\varepsilon_{\text {test }}$ and $\varepsilon_{\text {standard }}$ are the peak strain levels measured in the test pad and standard pad, respectively. Load-deflection tests are used to determine the secant modulus of the pad. The secant modulus is found from two points, the clip toe load and the live load under a train. The secant modulus is a better measure of resilience than is the attenuation factor. The high frequency stiffness measurements can provide the absolute measurements of a pad's dynamic characteristics. The pad may be compressed between two plattens, usually steel plates, with one of the plattens being excited at a known frequency by an electromagnetic shaker. Force and displacement are measured, allowing the stiffness to be calculated. An alternative method is to excite the entire assembly and measure the resonant response.

The selection of railpad for any particular application is influenced by the track and traffic conditions, as well as th e quality of sleeper used. If the pad is to be used with an existing sleeper, a number of restraints are considered on the pad's geometry and performance (Pandrol, 1995).

\subsection{Laboratory Testing and Evaluation of Railpads}

Dean and Harrison (1982) conducted studies on the effect of railpad stiffness on bending moments in sleepers caused by impact loads. Drop tests were performed on a portion of a rail mounted on a single sleeper with varying railpad types. The researchers found that the impact attenuation increased as the stiffness of the railpad decreased. They concluded however that the stiffness was not a reliable parameter of the level of attenuation. Grassie (1989) studied impact attenuations in existing tracks and also in a test set-up similar to that of Dean and Harrison (1982). He found that the measurements in the test set-up yielded the same rating of the railpads as the existing track measurements. Grassie (1989) also obtained results from experiments in a triangular resonance frame. The stiffness and damping of the pad were then obtained at the resonance frequency of the frame for three railpads. 
Several other researchers have commented on the influence of the pad stiffness on the track response. Fermer and Nielson (1995) conducted experiments using soft and stiff railpads. They measured the influence on wheel-rail contact force, sleeper end acceleration, and rail head acceleration. The results showed that using soft railpads resulted in lower sleeper end acceleration and a higher rail head acceleration. The effect of the railpads on the wheel-rail contact force was dependent on the train speed. Vincent et al. (1996) optimized the stiffness and damping of the railpads to limit the noise radiated from the track. They concluded that stiff railpads reduced the total vibrational noise more efficiently than did soft railpads. The noise from the sleepers, however, increased (Fenander, 1997).

\subsection{Laboratory Testing Approach}

Laboratory testing was conducted at the major units lab at West Virginia University. However, before testing could begin, a foundation with a comparable subgrade modulus to one found in a typical coalmine was needed. The typical value for the subgrade modulus of coalmines in West Virginia is in the range of 280-500 pci (CONSOL, 2002). A $20 \mathrm{ft} \times 6 \mathrm{ft}$ bin was constructed from $\mathrm{C} 15 \times 33.9$ steel channels. Approximately 5 tons of gravel rising 13 " in the bin was used to simulate the foundation. A jackhammer with a tampering plate attached was used to compact the gravel. A plate test was conducted to determine the subgrade modulus and it was found to be 310 pci. A plate test involves loading a steel plate of known area on the foundation and measuring the defection of the plate. The load is divided by the area of the plate and the deflection measured to obtain the subgrade modulus. A cross-section of the bin with the beam placed in parallel is shown in Figure 2.4.

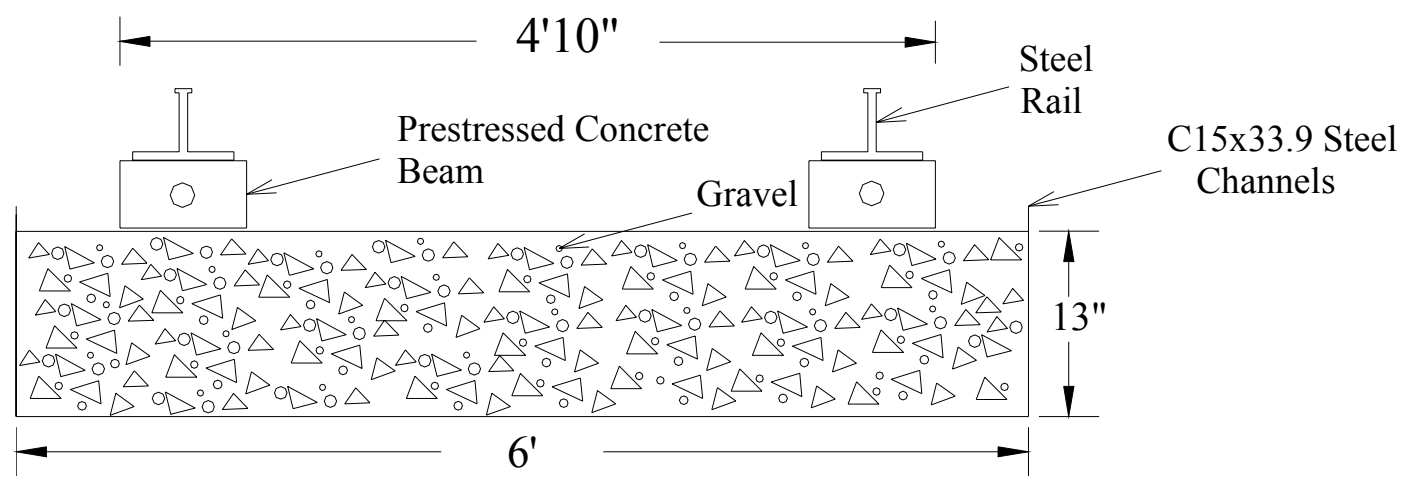

Figure 2.4. Cross-Section of Gravel Bin and Prestressed Concrete Beams 


\subsubsection{Testing Approach - Prestressed Concrete Panels}

Two (2) full-size panels were tested under static and dynamic loadings. The full panels were 14'9" in length and 4'10" in width. Four (4) steel I-beams were used at discrete intervals and served as crossties. The two concrete beams had a cross-section of 10-5/8" x 5". The beams were each prestressed using a 5/8" high-strength (150 ksi) dywidag rod with $10 \mathrm{kips}$ to minimize cracking due to bending (Appendix D). The cross-section and number of dywidag rods depend on the anticipated wheel loads.

The beams also were reinforced with supplemental reinforcement of four (4) (two top and two bottom) No. 3 bars. Shear reinforcement consisting of No. 3 bars at four inch center-tocenter spacing was also provided as shown in Figure 2.10.

Static tests consisted of both single and twin axle configurations. Static tests were conducted at various locations to determine the response of the beam. The static tests were used to determine:

- Strains and stresses in crossties

- Strains and stresses in the prestressed concrete beam

- Deflection of the steel rail

- Deflection of the prestressed concrete beam

- Load distribution

- Change in pressure experienced by the foundation

Fatigue testing was conducted on the second full-size prestressed concrete panel, as well as the set of half panels. Static tests after 250,000 and 500,000 of applied load were used to determine the change of stiffness in the beam. A loading rate of $0.5 \mathrm{~Hz}$ was used. Figure 2.5 shows the testing set-up and layout of the full-size prestressed concrete panels. 


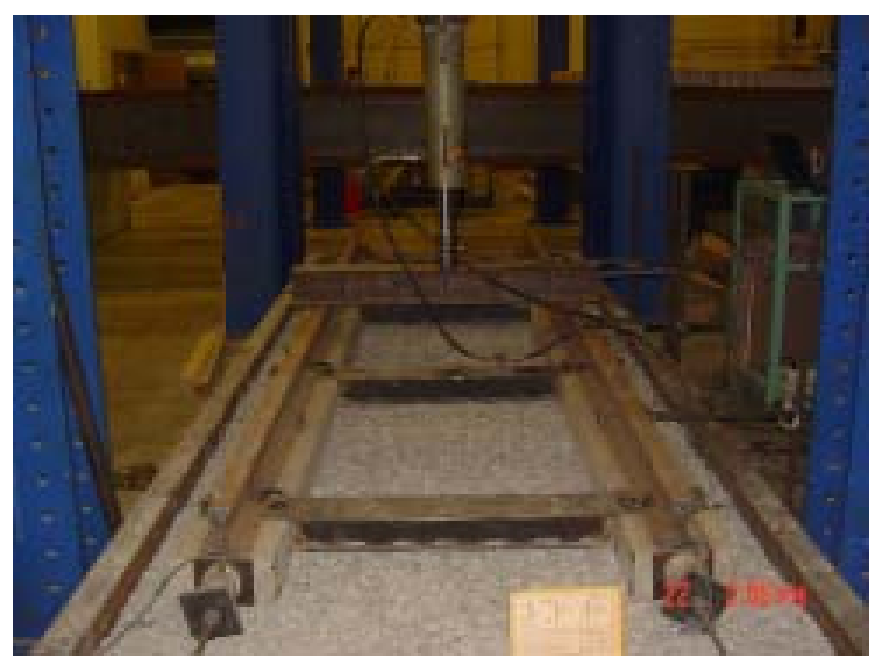

Figure 2.5. Full-Size Prestressed Concrete Panel Set-Up

The dimensions of the full panels are shown in Figure 2.6. The pads are also shown and with their corresponding numbers in elevation view. The numbering scheme remained constant for both full-size panels throughout the testing.

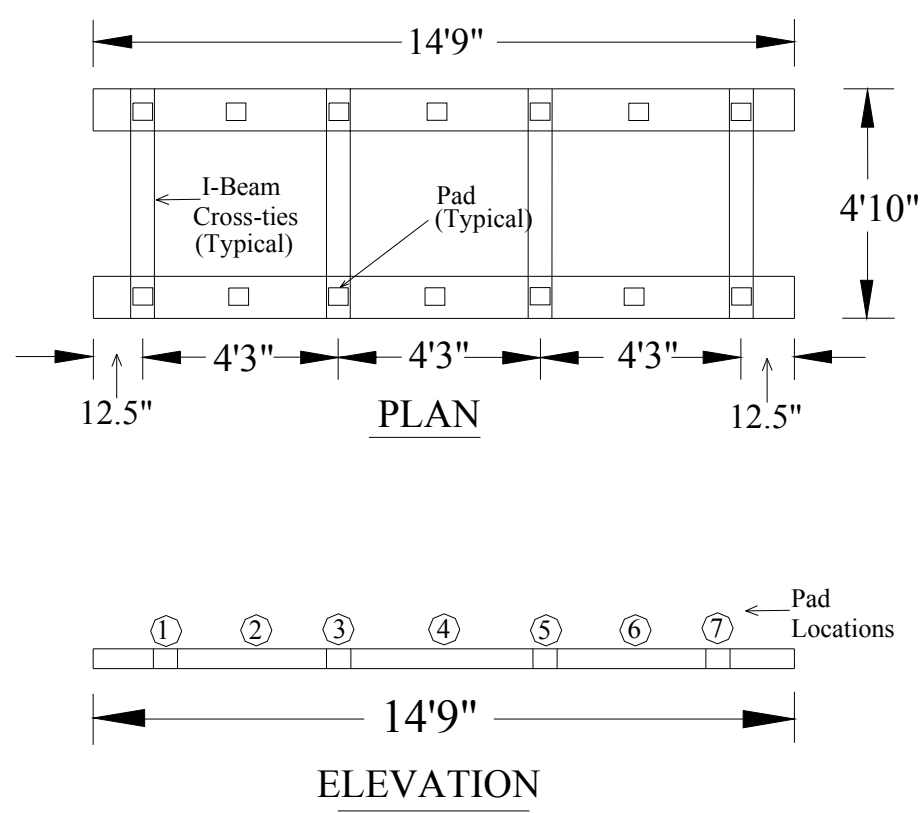

Figure 2.6. Full-Scale Prestressed Concrete Panel Dimensions 
One (1) set of half panels was also tested to test the response of the beams at the joint locations. Figure 2.7 gives a picture of the set of half panels. The half panels consisted of the same reinforcement and was also prestressed with 10 kips. The dimensions of the half panels are shown below in Figure 2.8. The pads are also shown in Figure 2.8 and their corresponding numbers in elevation view.

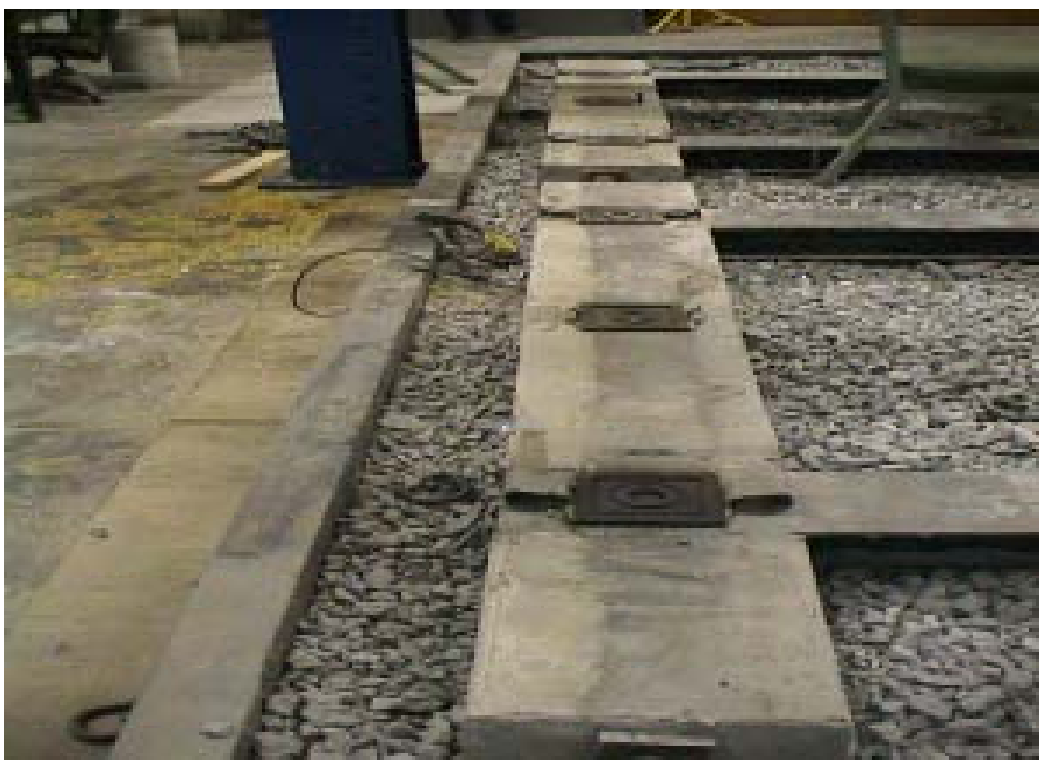

Figure 2.7. Set of Half Panels with Rubber Pads 

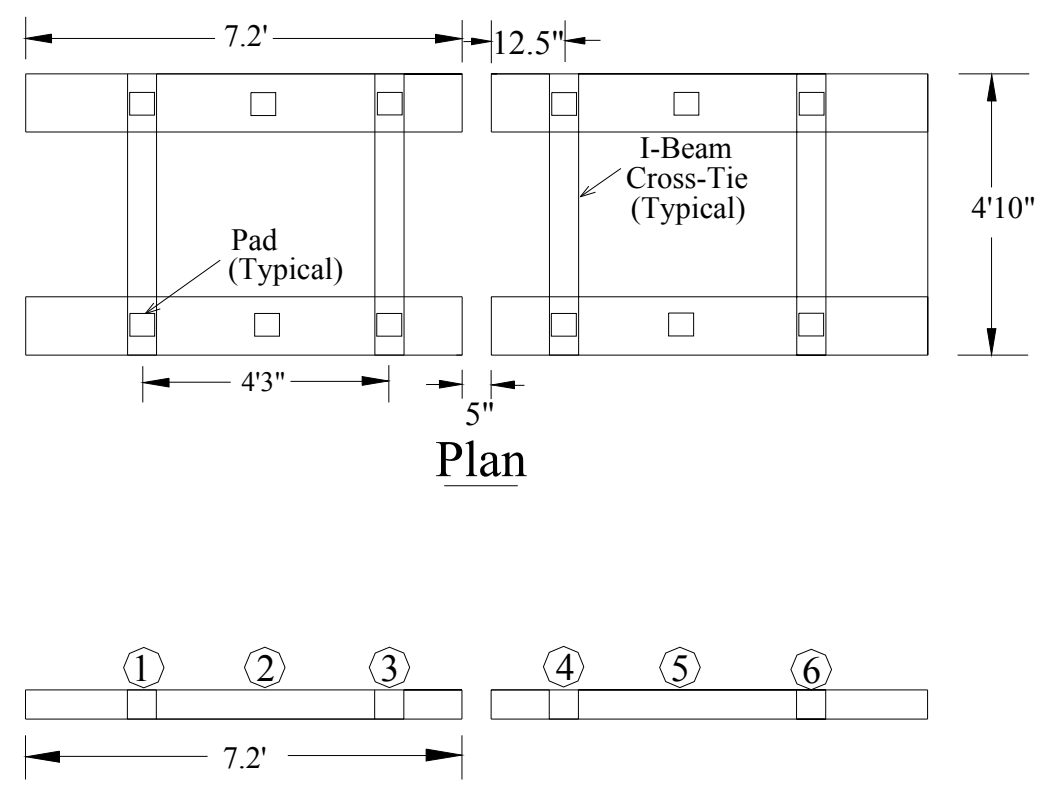

\section{Elevation}

Figure 2.8. Half-Panel Dimensions

Figure 2.9 shows the cross-section of the crossties. The cross-section of the prestressed concrete panels is shown in Figure 2.10. This cross-section was used for both full-scale panels, as well as the set of half panels. In Figure 2.9, $\mathrm{t}_{\mathrm{f}}$ if the thickness of the flanges and web.

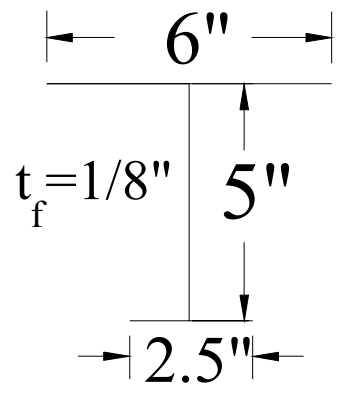

Figure 2.9. Cross-Section of Steel Crossties used in Full and Half Prestressed Concrete Panels 


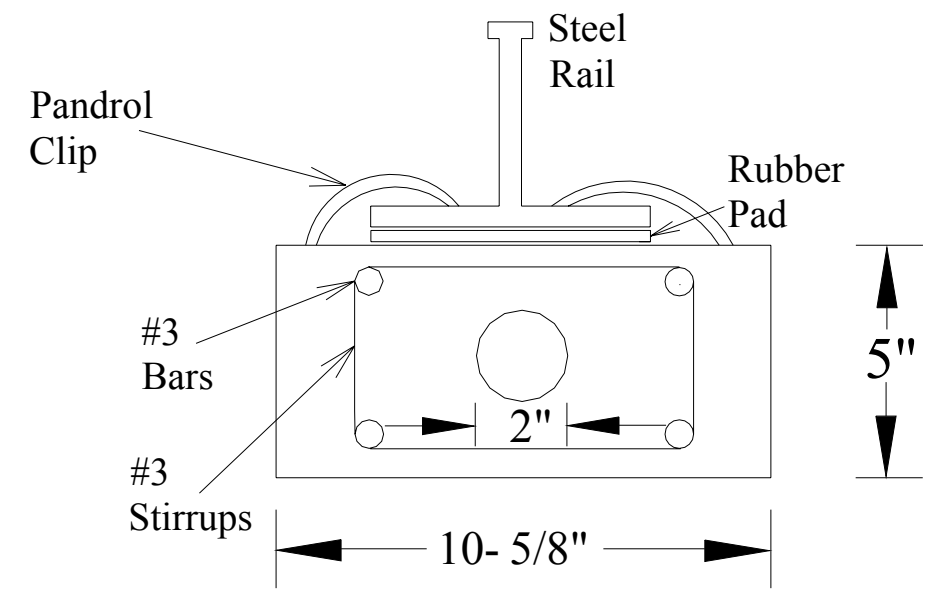

Figure 2.10. Post-Tensioned Prestressed Concrete Panel Cross-Section

\subsubsection{Testing Approach - Rubber Railpads}

The steel tee rails were placed on seven (7) resilient rubber pads and attached the prestrssed concrete beams using Pandrol clips. The rubber pads were spaced at 2'-1.5" c-c designed to provide efficient load distribution to the entire beam length. The rubber pad locations are shown in Figure 2.6 Two (2) rubber pads were individually tested under fatigue loading to determine the life of the pad, and the change in the stiffness of the pad after each cycle of applied loading. Cycles of 100,000, 250,000,500,000, and 1,000,000 were used. The rubber pads were tested in an Instron loading machine and placed between two $1 / 2$ " steel plates to ensure the entire pad was equally loaded. A pad was tested beforehand without the use of steel plates and it was observed that the corners of the pad were not experiencing any load indicating inaccurate deflection results.

\subsubsection{Testing Approach - Fiber Reinforced Polymer (FRP) Composite Panel}

An all fiber reinforced polymer (FRP) panel was also tested in the same steel bin constructed for testing the prestressed concrete panels. A two-cell FRP cross-section was tested to evaluate its response to axle loads and to determine its load sharing characteristics. A distinct advantage of FRP over steel and concrete is its strength-to-weight ratios and its crack resistance. The cross- 
section of the FRP beams tested was two FRP boxes (6"x 4") connected together with an adhesive. The total cross-sectional dimensions, therefore, were 12" x 4" (shown in Figure 2.11). The beams tested were 15' long in order to compare the results to those analyzed from the prestressed concrete beams. The steel rail was attached to the FRP beams using an adhesive known as Pliogrip manufactured by the Ashland Specialty Chemical Company. Three 5/8" dywidag rods were used as cross-ties to hold the FRP beams in position. Each was stressed with 500 pounds to keep the nuts from rotating, thereby allowing the rods to lose tension, which in turn, would allow the beams to move out of position. The locations of the rods are shown in Figure 2.12. Similar static and fatigue tests were conducted on the FRP panel compared to the prestressed concrete panels.

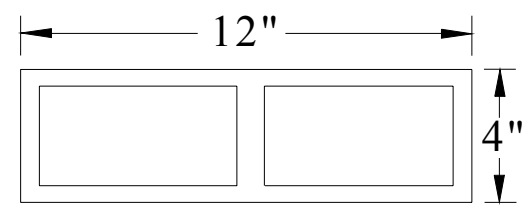

Figure 2.11. Cross-Section of FRP Panel 

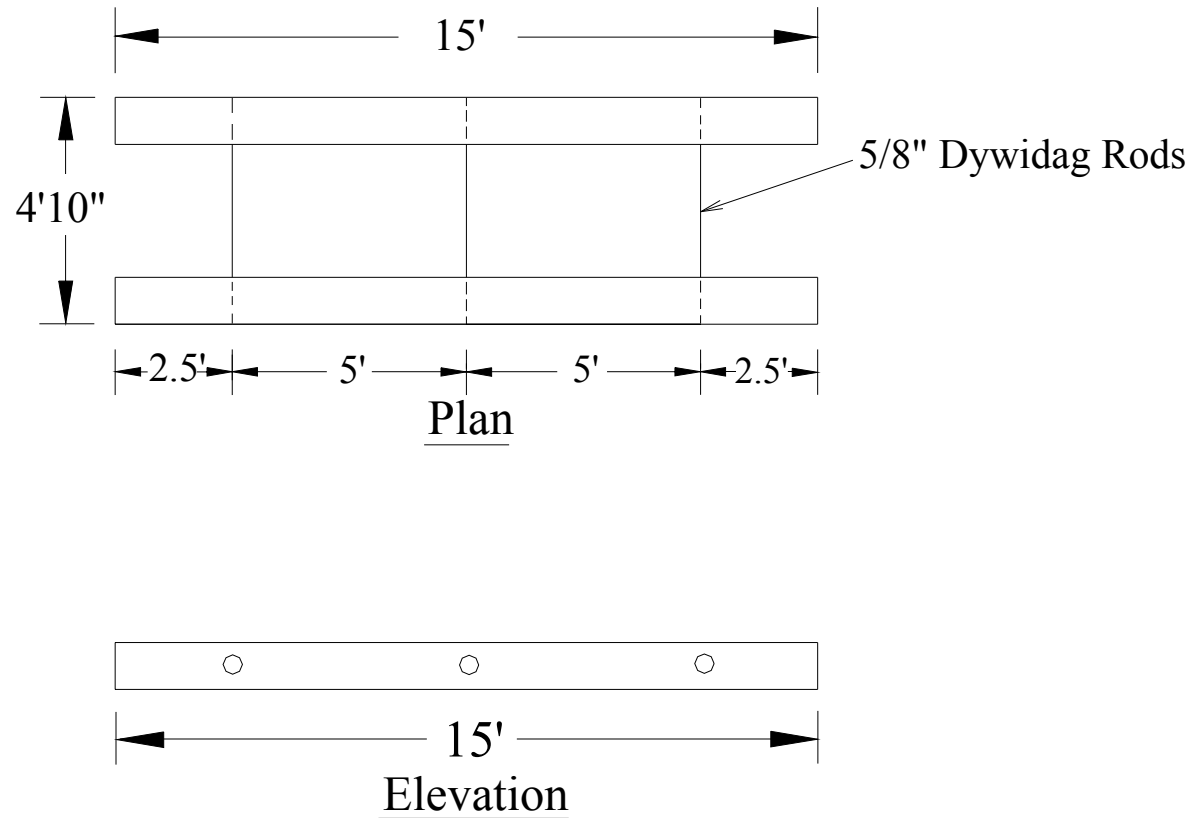

Figure 2.12. FRP Composite Panel Dimensions

Figure 2.13 shows a picture of the two-cell box cross-section, as well as the steel rail attached to the FRP beam. 


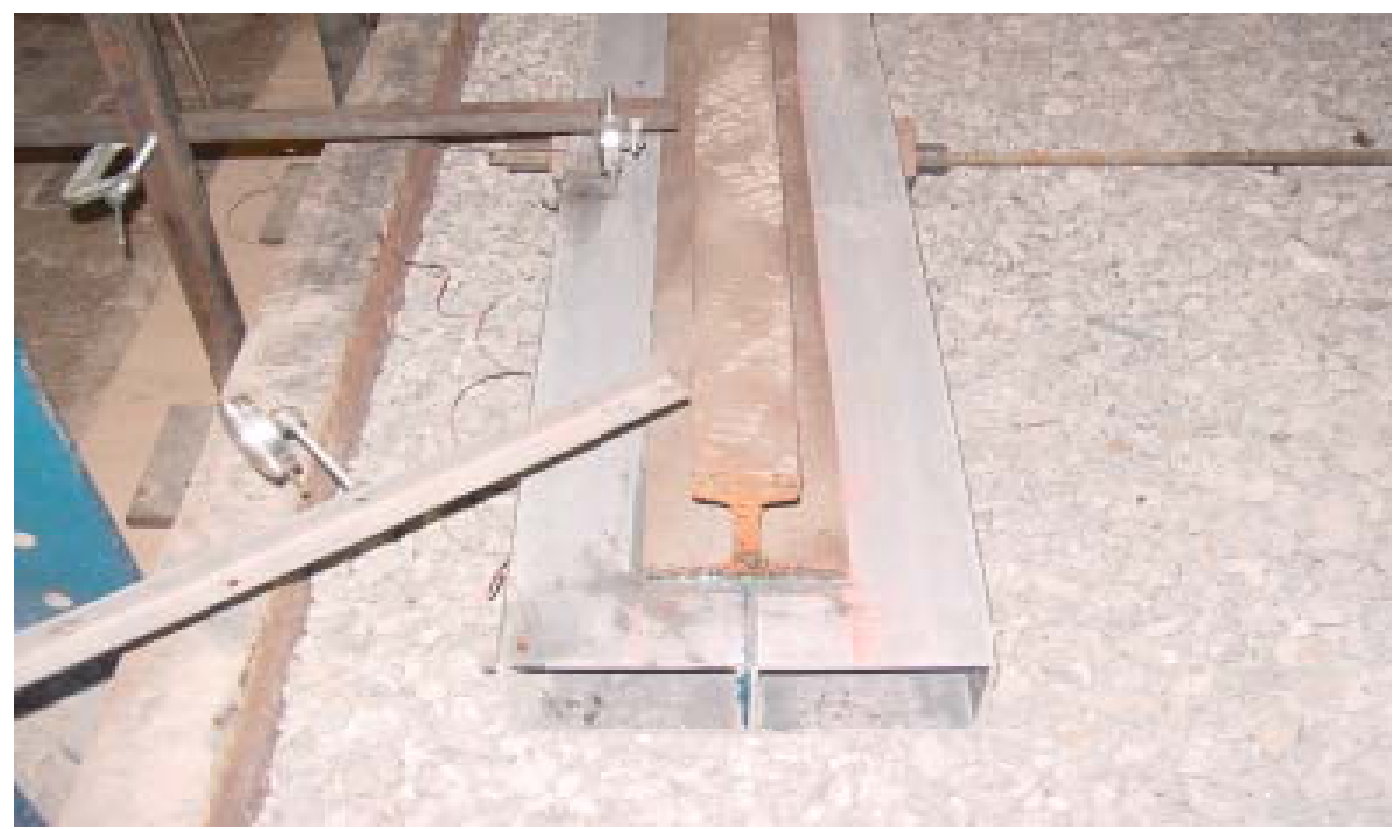

Figure 2.13. Steel Rail Attached to Two-Cell FRP Box Beam

Figure 2.14 shows a typical plot of a plate test conducted on the foundation, which was found to have a subgrade modulus of 310 pci. It can be determined from Figure 2.14 that the foundation behaves as a nonlinear spring and the stiffness of the foundation increases with load.

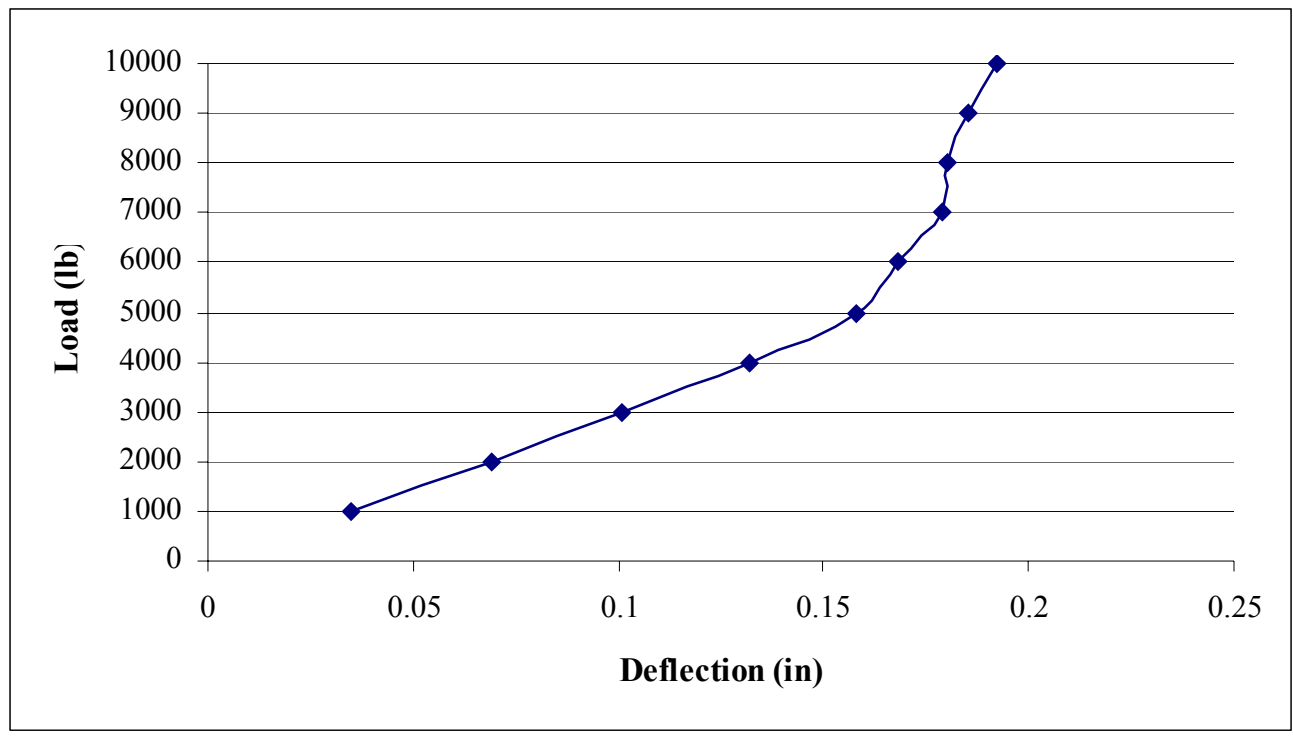

Figure 2.14. Load vs. Deflection for the Simulated Foundation 


\section{CHAPTER 3 - THEORETICAL EVALUATION}

\subsection{Introduction}

The theoretical model adopted for this research follows the Winkler model. The rail is attached to the concrete beam, which is resting on the foundation and the concrete beam is modeled as a beam on an elastic foundation. Finite element analysis was also used to model the response. The following section describes the theoretical model and the FEM analysis.

\subsection{Beams on Elastic Foundation}

Beams on an elastic foundation were first examined by Winkler in 1867 to determine the stress in a railroad track bed foundation. The foundation restrains rail deformation and the deflected shape of the rail is a damped sine wave. The beam, which may be considered infinite or finite in length, can be subjected to a distributed or concentrated load. The foundation can be composed of any elastic medium, which could include soil or fluid. Railroad rails, laterally loaded piles, highway slabs, and floating structures all can be adequately modeled using the Winkler model. The Winkler model makes use of the assumption that a beam deflects only under an area near the load location (Figure 3.1), the beam is linearly elastic and of a constant cross-section, contact between the beam and foundation is not broken, and the applied loads are static. The actual response, however, resembles the first mode of a sine wave. The Winkler foundation can be idealized as a series of springs supporting an elastic component. The Winkler model has become the basis for track modulus measurement used in characterizing track strength and stiffness, and is useful to predict track performance. In Figure 3.1, the deflection of the rigid block is equal for both systems and considers vertical load only. Figure 3.2 shows the theoretical basis for a beam on an elastic foundation (Boresi et al., 1993). 


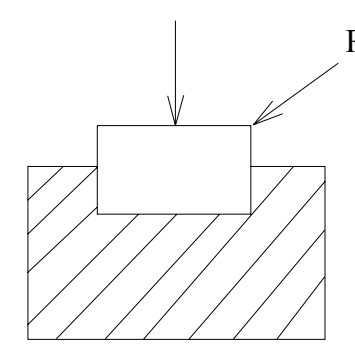

Winkler Idealization
Rigid Block

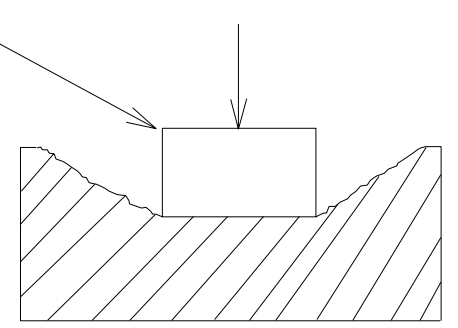

Actual System Response

Figure 3.1. Foundation Response of Rigid Block Comparing the Winkler Idealization to the Actual Response

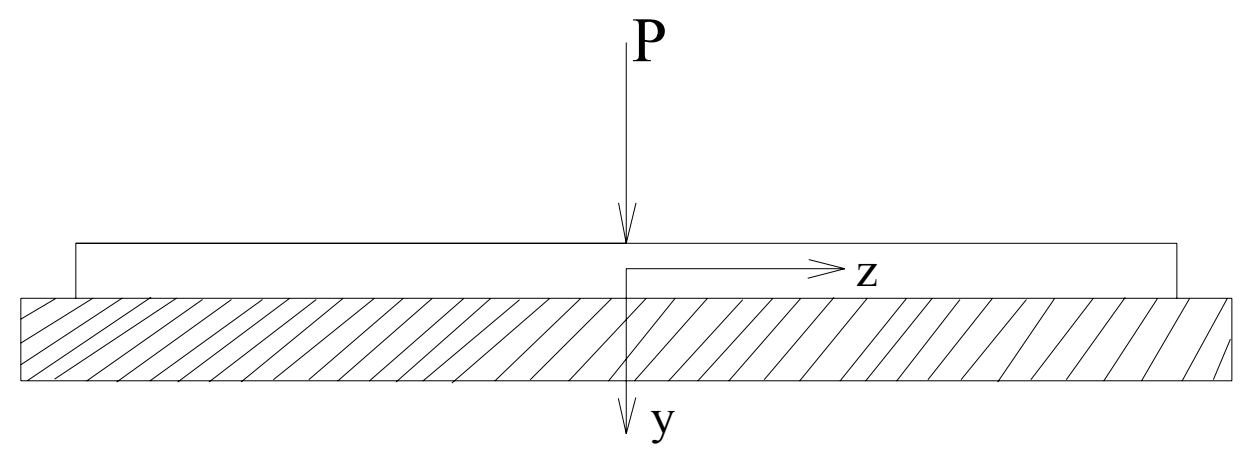

Figure 3.2. Infinite Beam on Elastic Foundation

The effect of the load (see Figure 3.2) is expected only near the loading location, i.e. $y=0$ as $z$ approaches infinity, where $y$ is the deflection. A free-body diagram of the beam is shown in Figure 3.3. 


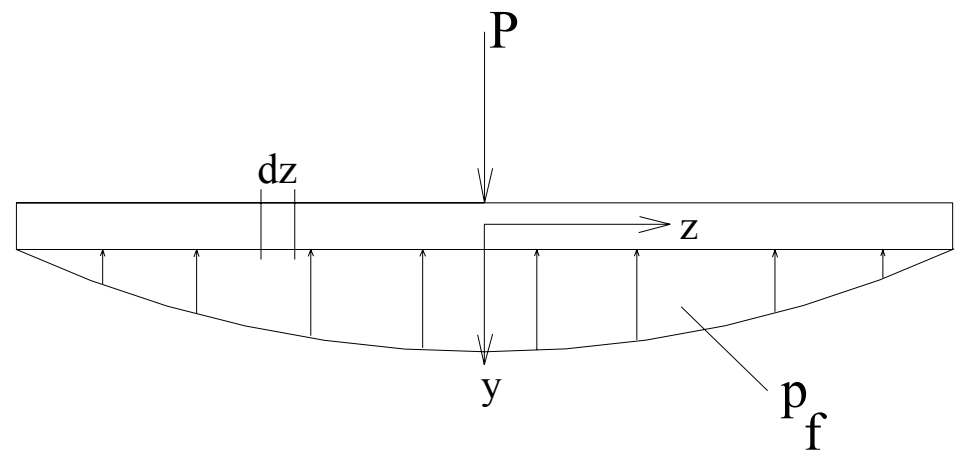

Figure 3.3. Free-Body Diagram of Beam on Elastic Foundation

Let $k_{\mathrm{o}}$ be the foundation parameter and " $\mathrm{b}$ " be with width of the beam at the location of contact with the foundation. Then, $k$, the spring coefficient can be expressed as

$$
k=k_{\mathrm{o}} \mathrm{b}
$$

The pressure on the foundation, $\mathrm{p}_{\mathrm{f}}$, can be expressed as

$$
\mathrm{p}_{\mathrm{f}}=\mathrm{ky}
$$

where $\mathrm{y}$ is the deflection.

An isolation of segment $\mathrm{dz}$ is shown in Figure 3.4. 


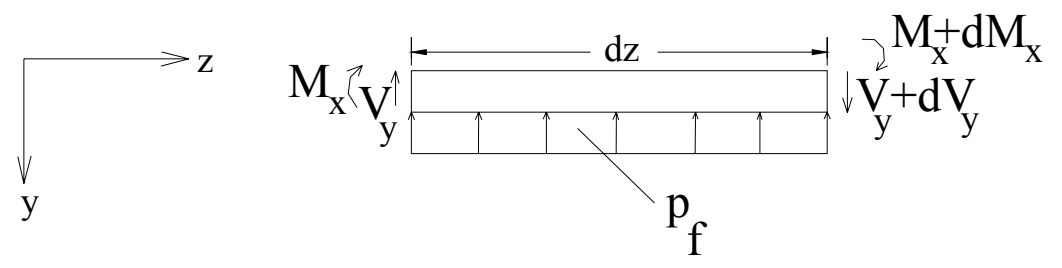

Figure 3.4. Segment dz of Beam on Elastic Foundation

Summation of the forces in the y-direction yield

$$
\mathrm{p}_{\mathrm{f}}=\mathrm{dV}_{\mathrm{y}} / \mathrm{dz}
$$

and

$$
\mathrm{V}_{\mathrm{y}}=\mathrm{dM}_{\mathrm{x}} / \mathrm{dz}
$$

From mechanics of materials:

$$
\operatorname{EId}^{2} \mathrm{y} / \mathrm{dz}^{2}=-\mathrm{M}_{\mathrm{x}}
$$

and that the shear force is:

$$
\operatorname{EId}^{3} \mathrm{y} / \mathrm{dz}^{3}=-\mathrm{V}_{\mathrm{y}}
$$

and the pressure is:

$$
\operatorname{EId}^{4} y / d z^{4}=-p_{f}
$$

The negative sign is used because positive moment is associated with negative curvature. The governing equation can be expressed as

$$
\operatorname{EId}^{4} \mathrm{y} / \mathrm{dz}^{4}+\mathrm{ky}=0
$$


Differentiating the shear force expression and rearranging for the deflection, $\mathrm{v}$, the displacement has the general form of

$$
y=e^{\beta x}\left(C_{1} \sin \beta x+C_{2} \cos \beta x\right)+e^{-\beta x}\left(C_{3} \sin \beta x+C_{4} \cos \beta x\right)
$$

where

$$
\beta=[k / 4 \mathrm{EI}]^{0.25}
$$

$\mathrm{C}_{1}, \mathrm{C}_{2}, \mathrm{C}_{3}$, and $\mathrm{C}_{4}$ are constants of integration. It can be observed that the deflection is composed of damped sine and cosine waves.

The procedure for analysis of a beam on an elastic foundation is to (1) solve for the constants of integration by applying the boundary conditions, (2) differentiate the resulting deflected shape curve to obtain $\mathrm{V}$ and $\mathrm{M}$, and (3) compute the bending stress using the elastic flexure equation (Boresi et al., 1993).

Using symmetry, only half of the beam is considered and integrated yielding the deflection as

$$
\mathrm{y}(\mathrm{z})=(\mathrm{P} \beta / 2 k) \mathrm{e}^{-\beta z}(\sin \beta \mathrm{z}+\cos \beta \mathrm{z})
$$

Since the deflection is maximum when $\mathrm{z}=0$, the maximum deflection can be expressed as

$$
\mathrm{y}_{\max }=\mathrm{P} \beta / 2 k
$$

where $\mathrm{P}$ is the applied load.

\subsection{Beam on Elastic Foundation Software}

The experimental deflections obtained from the laboratory tests in this research are compared to the results provided by the program Enercalc. Enercalc is a general-purpose program that has the ability to analyze structures with different loading conditions. One feature of this program is that it has the ability to analyze beams on elastic foundations subjected to vertical static loads. To verify that the Enercalc program yielded accurate solutions, it was 
validated against the solutions found from the general equation of the Winkler model. The deflections provided by Enercalc are shown graphically in Appendix A.

The beam had the following characteristics:

$\mathrm{f}^{\prime} \mathrm{c}=10,000 \mathrm{psi}$

$\mathrm{b}=10.625 \mathrm{in}$.

$\mathrm{h}=5 \mathrm{in}$.

$\mathrm{k}_{0}=310 \mathrm{lb} / \mathrm{in}^{3}$

The moment of inertia for a rectangular cross-section is:

Therefore,

$$
\mathrm{I}=\mathrm{bh}^{3} / 12
$$

$$
\mathrm{I}=(10.625)(5)^{3} / 12=110.68 \mathrm{in}^{4}
$$

The modulus of elasticity can be found from:

$$
E=57,000 \sqrt{f^{\prime} c}
$$

yielding

$$
E=57,000 \sqrt{10,000}=5.7 \times 10^{6} \mathrm{psi}
$$

The spring coefficient, $\mathrm{k}$, is given by the equation:

$$
\begin{gathered}
k=\mathrm{bk}_{0} \\
=(10.625 \mathrm{in})\left(310 \mathrm{lb} / \mathrm{in}^{3}\right)=3294 \mathrm{lb} / \mathrm{in}^{2}
\end{gathered}
$$

The magnitude of the $\beta$ parameter is given by:

$$
\beta=\sqrt[4]{k / 4 E I}
$$

Solving Equation (3.7) yields a $\beta$ value of 0.0338 in $^{-1}$

The maximum deflection of the beam, given by the Winkler model, is given by

$$
\mathrm{y}=\mathrm{P} \beta / 2 k
$$

Using the maximum wheel load of 10 kips and substituting in equation (3.17), the equation becomes 


$$
\mathrm{y}=(10,000 \mathrm{lb})\left(0.0338 \mathrm{in}^{-1}\right) /\left(2 * 3294 \mathrm{lb} / \mathrm{in}^{2}\right)=51 \times 10^{-3} \text { in }
$$

The graphs provided in Appendix A show typical output from the Enercalc program. The graph provided in Appendix A, page 142 shows the result from a single point load at midspan with the same beam characteristics shown above. It shows that the deflection of the beam is $50 \times 10^{-3}$ in, suggesting that the Enercalc program yields accurate solutions for beams subjected to loads on an elastic foundation.

\subsection{Finite Element Analysis for Beam on Elastic Foundation}

The results were also compared to Finite Element Analysis. Finite Element Analysis was conducted using the program NASTRAN. Twenty-nine (29) elements and twenty-two (22) nodal locations were used to analyze the panel. The input properties and materials for analysis are provided in Appendix B. Solid elements were used to model the concrete beams. Inputting the same information as was used for the Winkler model and Enercalc program, the analysis yielded

a deflection of $50 \times 10^{-3}$ in at the load location, which agrees well with the calculated value based upon the Winkler model. The following tables show the results of the Enercalc and NASTRAN output for the indicated pad location for two tests conducted at midspan. Table 3.1 shows the deflections for a single point load at midspan and Table 3.2 gives the values of deflection for a double point load applied centrally over midspan. All of the Enercalc and NASTRAN deflection values at given pad locations are provided in Chapter 4 as a comparison against the experimental measurements.

Table 3.1. Deflections for Single Point Load at Midspan Using Respective Analysis

\begin{tabular}{|c|c|c|}
\hline Pad \# & FEA $\left(10^{-3}\right.$ in $)$ & Enercalc $\left(10^{-3}\right.$ in $)$ \\
\hline 1 & -3 & -1 \\
\hline 2 & 11 & 8 \\
\hline 3 & 30 & 32 \\
\hline 4 & 42 & 50 \\
\hline 5 & 30 & 32 \\
\hline 6 & 11 & 8 \\
\hline 7 & -3 & -1 \\
\hline
\end{tabular}


Table 3.2. Deflections for Double Point Load at Midspan Using Respective Analysis

\begin{tabular}{|c|c|c|}
\hline Pad \# & FEA $\left(10^{-3}\right.$ in $)$ & Enercalc $\left(10^{-3}\right.$ in $)$ \\
\hline 1 & 5 & -11 \\
\hline 2 & 33 & 34 \\
\hline 3 & 53 & 65 \\
\hline 4 & 57 & 66 \\
\hline 5 & 53 & 65 \\
\hline 6 & 33 & 34 \\
\hline 7 & 5 & -11 \\
\hline
\end{tabular}

Tables 3.1 and 3.2 show that the respective methods of analysis yield results that are very similar. There is some discrepancy for pad numbers 1 and 7 for the case of double point loads at midspan. This could be due to the FEA having a slightly larger stiffness, however.

Interrail, Inc. also provided the Constructed Facilities Center with Finite Element Analysis. The results obtained by Interrail, Inc. are given in SI units in Appendix C. However, a descriptive report was not provided at the time of this research. 


\section{CHAPTER 4 - LABORATORY TESTING AND ANALYSIS}

\subsection{Prestressed Concrete Panels - Introduction}

This chapter presents laboratory simulation test information from the tests conducted on two (2) full-size prestressed concrete panels, one (1) half-size prestressed concrete panel, and two (2) resilient railpads. In addition, this chapter presents the testing procedure and data of a new and improved FRP panel. The tests include a simulated track bed and static and dynamic loads.

\subsection{Full-Size Prestressed Concrete Panel 1}

The first full-size modular track panel was tested for bending behavior and load sharing characteristics.

\subsubsection{Modular Track Panel Fabrication and Test Set-up}

The modular track panel consists of two (2) parallel post-tensioned concrete beams interconnected at discrete intervals by steel cross-ties. A steel mold was fabricated and was used to form the concrete modular panel which incorporates steel shoulders to be used for Pandrol Mineclips. The steel crossties were placed in positions welded specially for them and held down with steel wedges hammered in under the mold. A single 5/8-in diameter Dywidag high strength steel bar $\left(f_{y}=150 \mathrm{ksi}\right)$ was concentrically placed in each beam to provide the required prestress force. Stirrups were also placed at 4-in spacing. After pouring, curing, and lifting the concrete panel, several cracks were noticed on one of the beams. The panel was cured for twenty-eight (28) days by sprinkling water on it twice a day and covering it with burlap. The panel was lifted from the mold by welding one of the steel tee rails to the crossties and using the crane to pull it out of the mold. The concrete strength after twenty-eight (28) days was approximately 3500 psi, which is significantly lower than the expected 6000 psi. Since this is a ballastless application, the foundation for the full-scale panel tests was constructed using gravel placed in a large (6 ft wide $\mathrm{x}$ $18 \mathrm{ft}$ long x $1.25 \mathrm{ft}$ deep) steel bin to simulate a mine foundation.

Strain gages and load cells were used to monitor the response of the beam during the post-

tensioning process. Since one of the concrete beams had several cracks (Figure 4.2.1), varying force levels between the two beams were required to achieve equal stress levels in each beam. The beam that was not cracked was post-tensioned using $10 \mathrm{kips}$, which produced a strain of 
$74 \times 10^{-6} \mathrm{in} / \mathrm{in}$. The cracked beam was post-tensioned using $20 \mathrm{kips}$, which produced a strain of $53 \times 10^{-6} \mathrm{in} / \mathrm{in}$. The cracked section resulted in a reduced moment of inertia, which significantly reduced the beam stiffness.

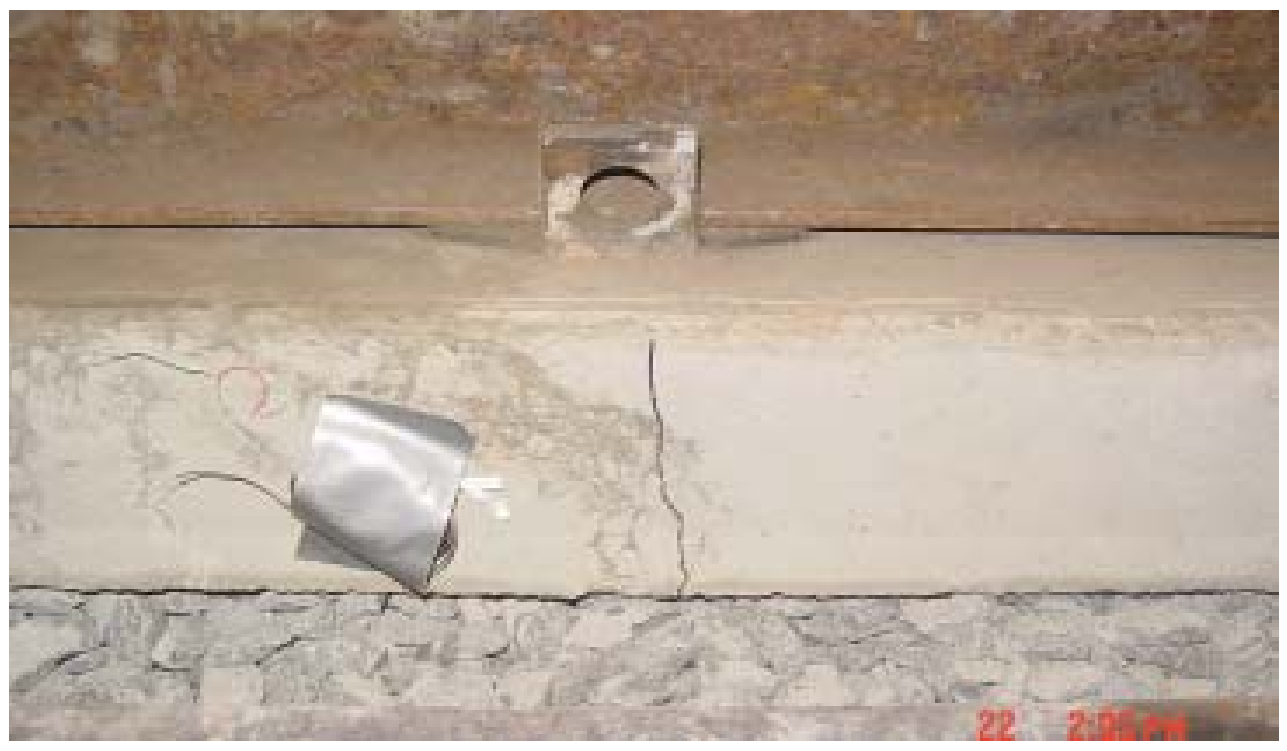

Figure 4.2.1. Crack located at 4'3" from Midspan

The next task was to place and attach the steel rails on the concrete beams. The shoulders on the cross-ties were found to be welded "too close" to each other, which did not allow the rail to set properly on the beams. A grinder was used to grind the shoulders and the rail until it fit properly inside the shoulders. Pandrol Mineclips were then hammered into place to attach the rail (Figure 4.2.2). 


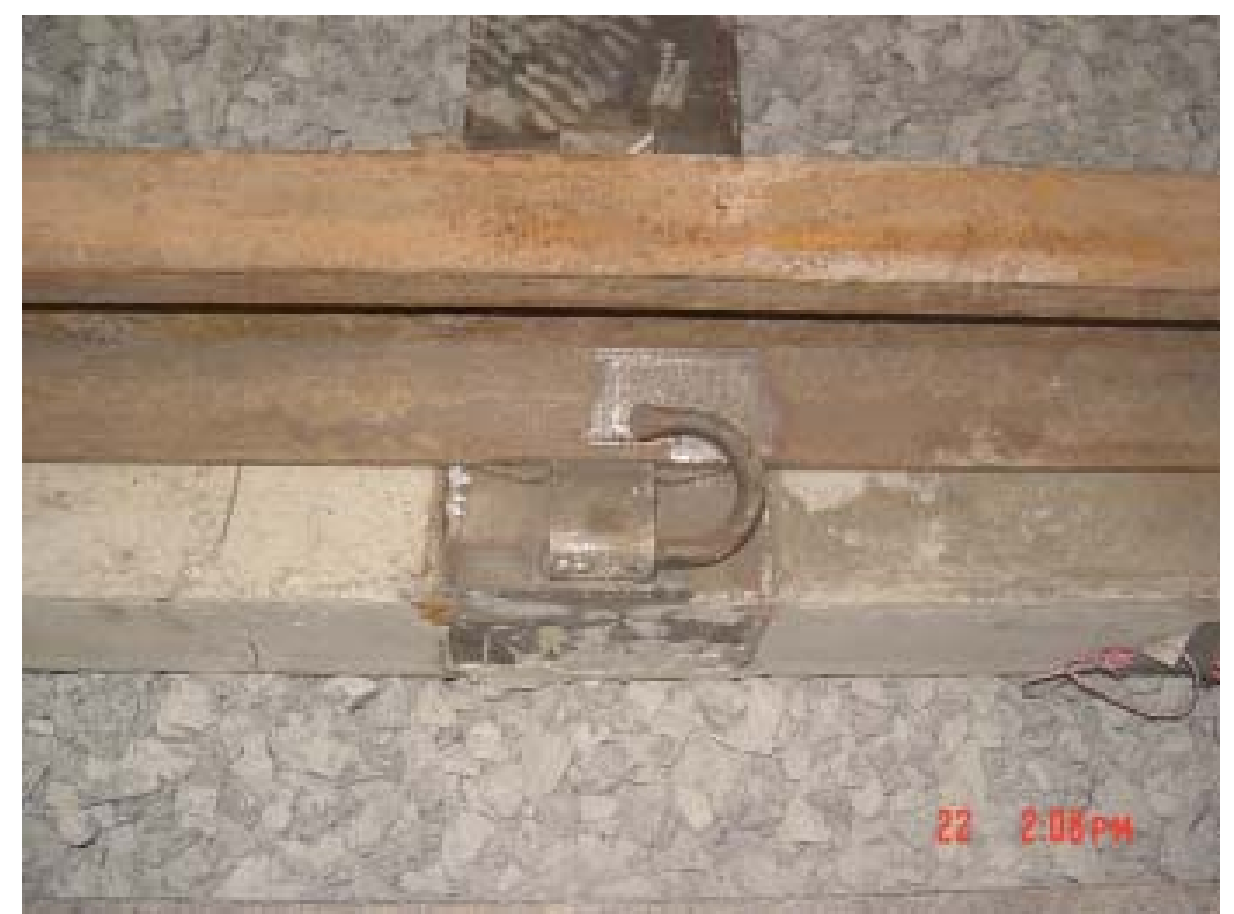

Figure 4.2.2. Pandrol Mineclip 7100 Series used to Attach Rail

Steel channels were used to fabricate the steel bin. The bin was filled with gravel (13" deep) to produce a bearing capacity comparable to that found in a typical coal mine (personal communication with CONSOL). The panel was then moved to the testing load frame as shown in Figure 4.2.3.

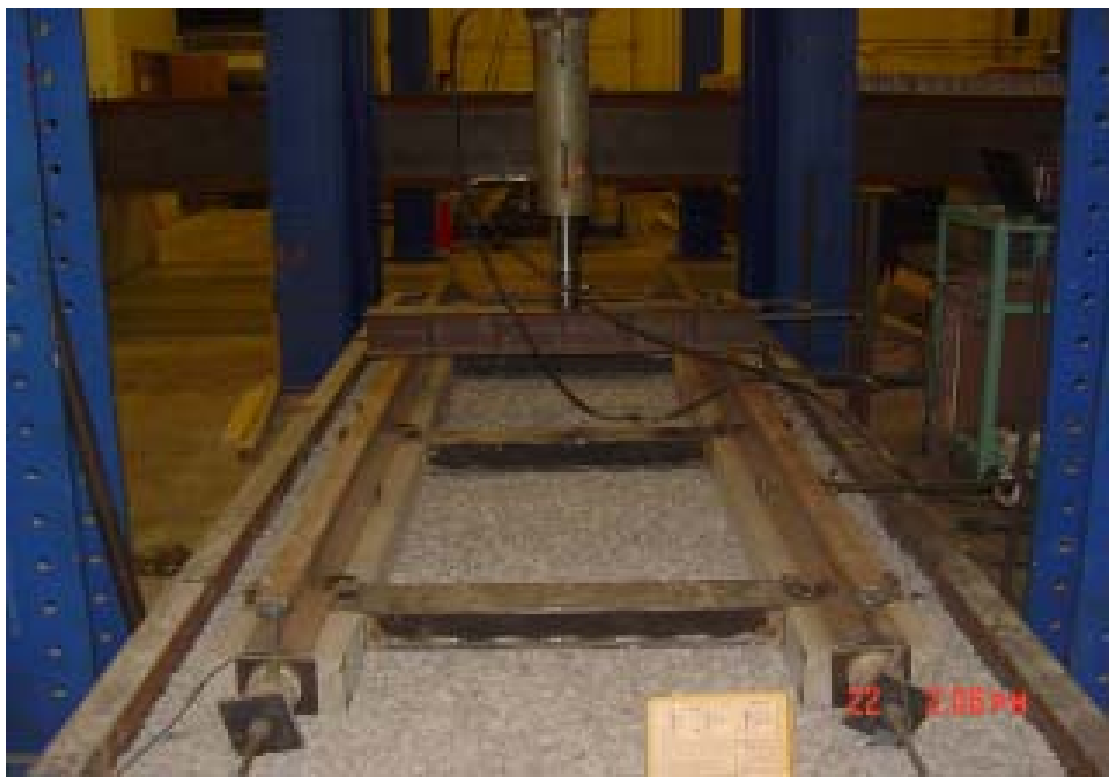

Figure 4.2.3. Test Set-up For Panel 
Fourteen (14) strain gages were mounted on several locations to measure the strain at/or near the pads. Dial gages were also placed at several locations to measure deflections as shown in Figure 4.2.4. A data acquisition system was used to acquire all strain and load data.

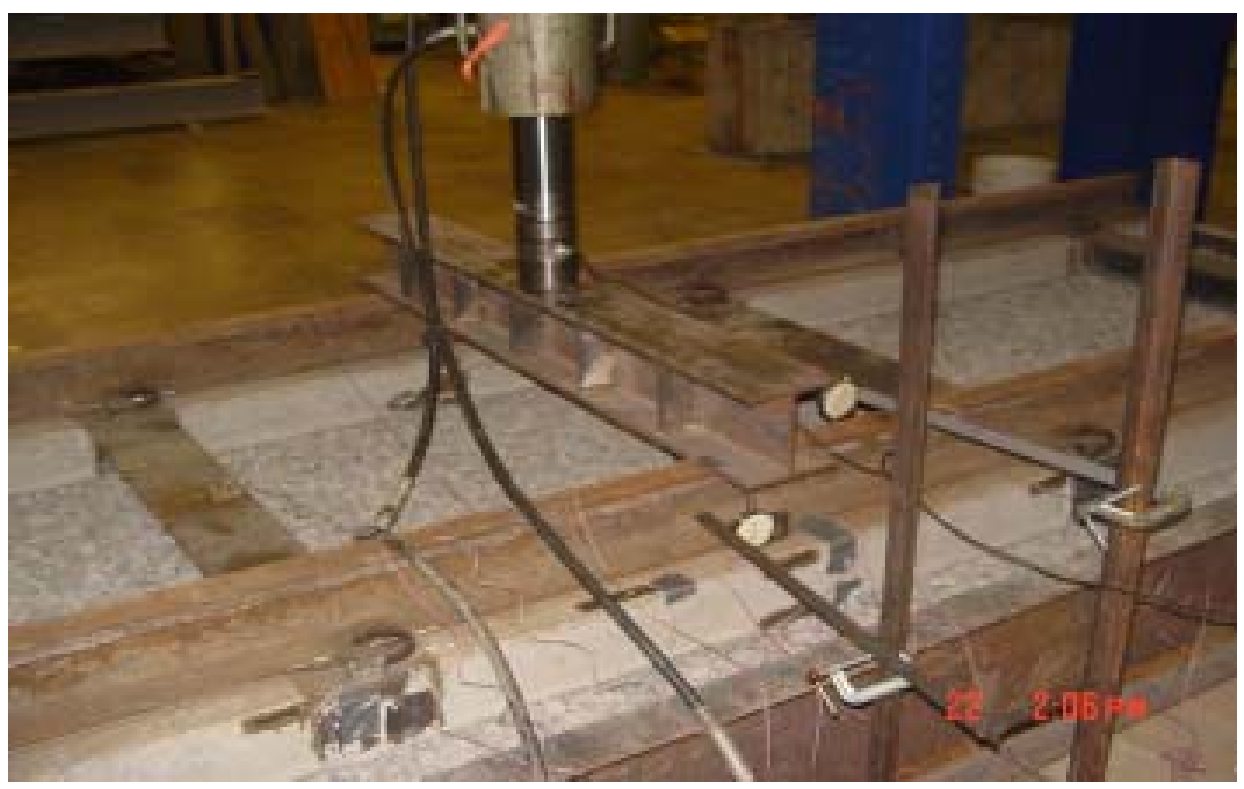

Figure 4.2.4. Dial Gages and Strain Gages on Test Specimen

\subsubsection{Testing}

The static tests conducted on the first modular track panel consisted of single point loads on each beam at midspan, cross-tie locations, and in between cross-ties. Tests were also conducted using two point loads on each beam at midspan and cross-tie locations.

With one of the beams being cracked, the first objective was to determine the amount of load being distributed to each beam. For this, a single point load test at midspan was conducted. The results showed that the beams had nearly equal deflection and therefore, experienced equal loading. 


\subsubsection{Load at Midspan}
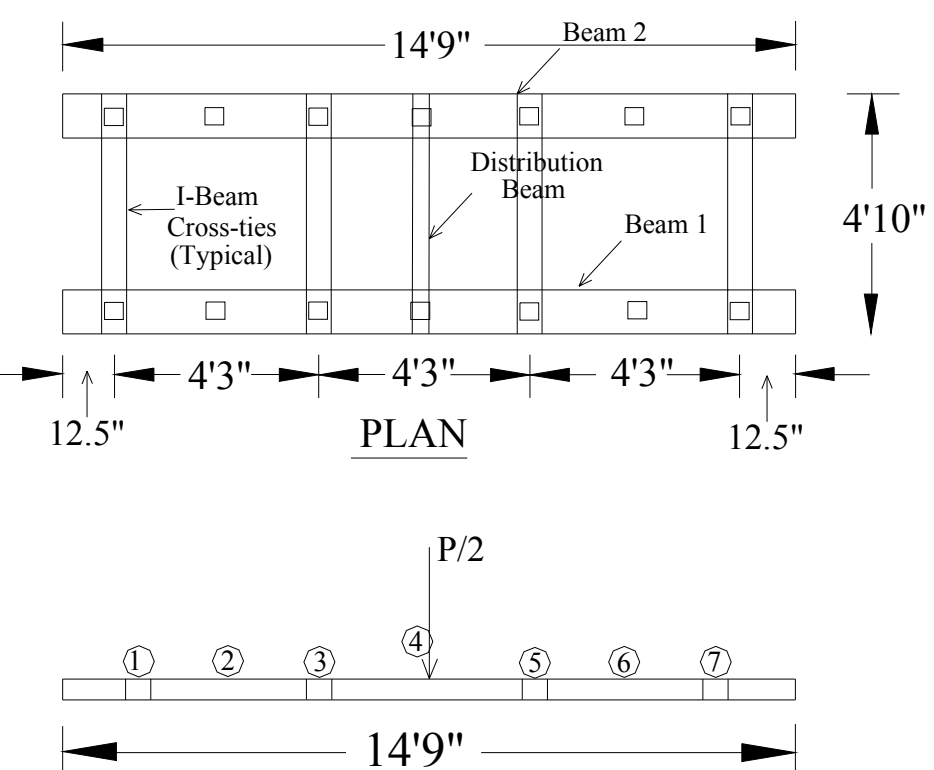

\section{ELEVATION}

Figure 4.2.5 Test Set-Up for Single Point Load at Midspan

The first test conducted was under a single point load at midspan. The maximum load was 40 kips, which produced a load of 20 kips on each beam. Load cells were used beneath the loading beams to ensure equal load distribution to both sides of the panel. Dial gages were placed on the top surface of the concrete beams and also on the rail. Strain gages were mounted on the concrete beam along the top of the vertical face and also on the rail and cross-ties. Figure 4.2.6 shows the deflected shape of the beams at 20 kips. 


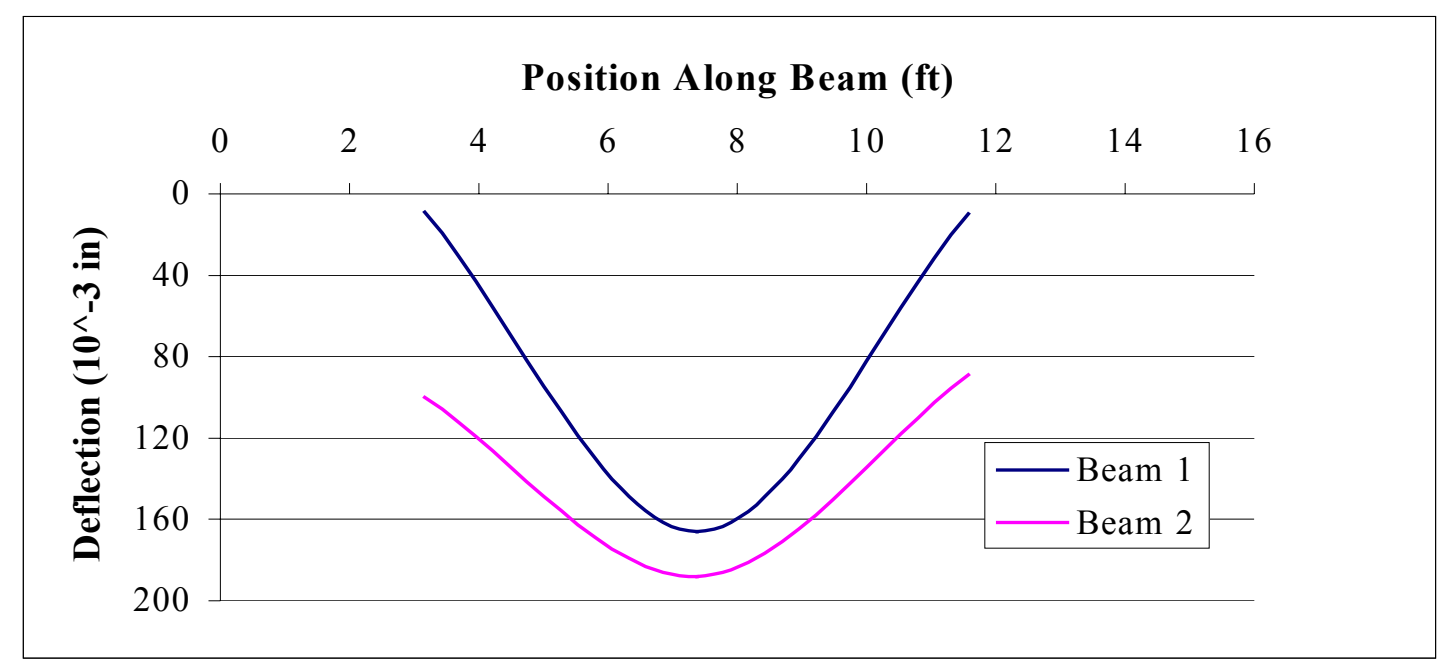

Figure 4.2.6. Deflected Shape of Beams at Maximum Load of 20 kips

Figure 4.2.7 shows the strains for Beam 1 at a load of 10 and 20 kips. The ends of the beam experience little change in the strain at 10 kips compared to 20 . The location that experiences significant strain differences from the two loading conditions is at or near the loading location.

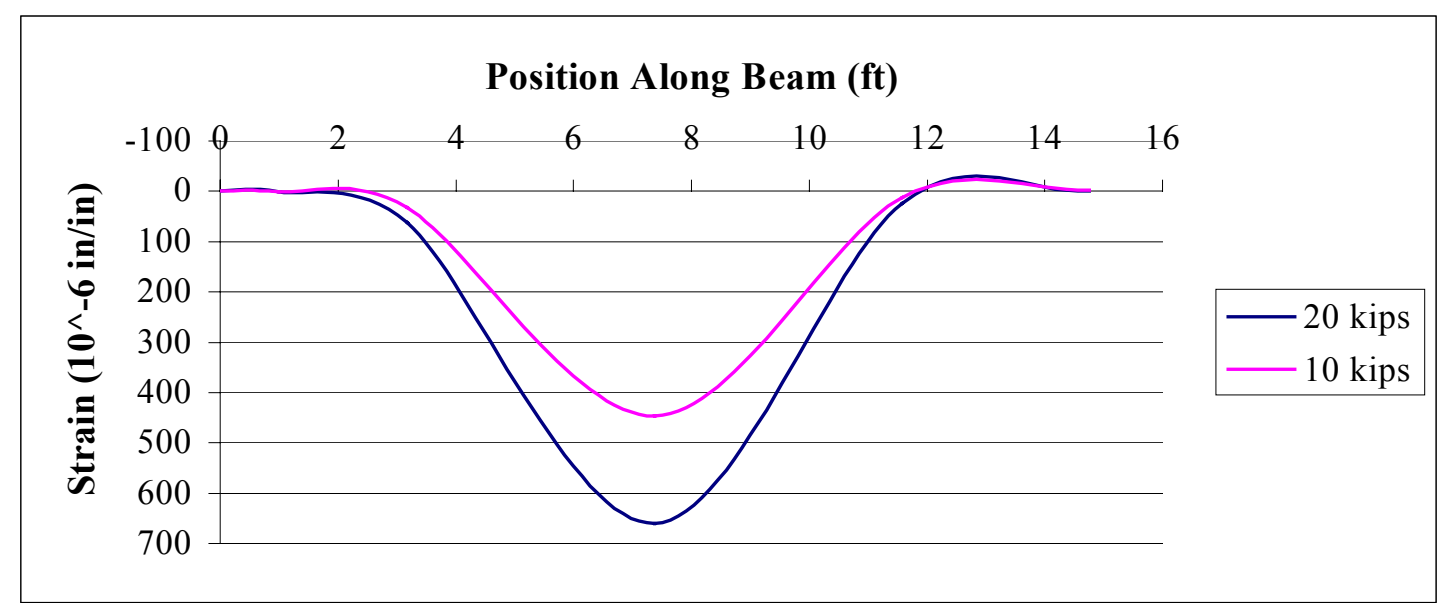

Figure 4.2.7. Strain vs. Position for Beam 1 at Indicated Loads

Figure 4.2.8 shows the strain distribution of Beam 1 for a single point load applied at midspan. It shows that $71 \%$ of the load acts at the point of application. 


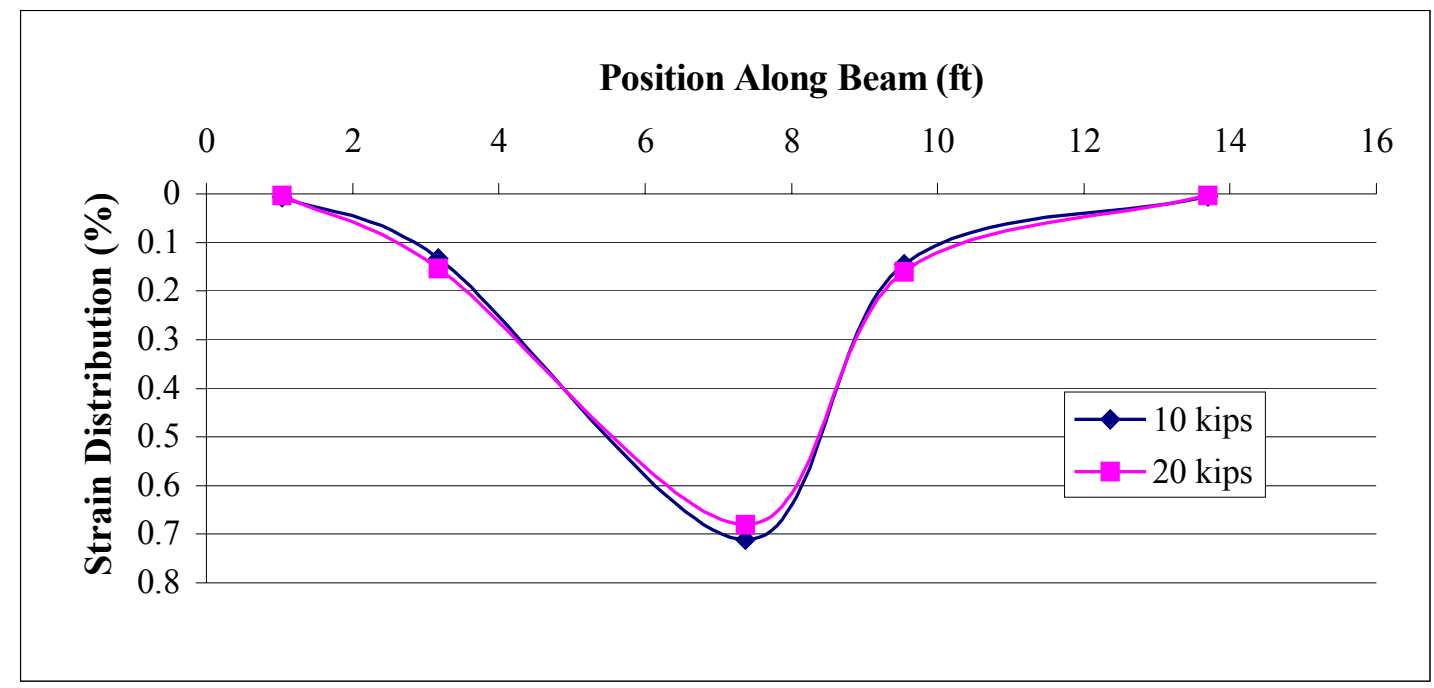

Figure 4.2.8. Strain Distribution Along Beam 1 for Indicated Loads for Point Load at Midspan

\subsubsection{Single Point Load at Interior Crosstie}

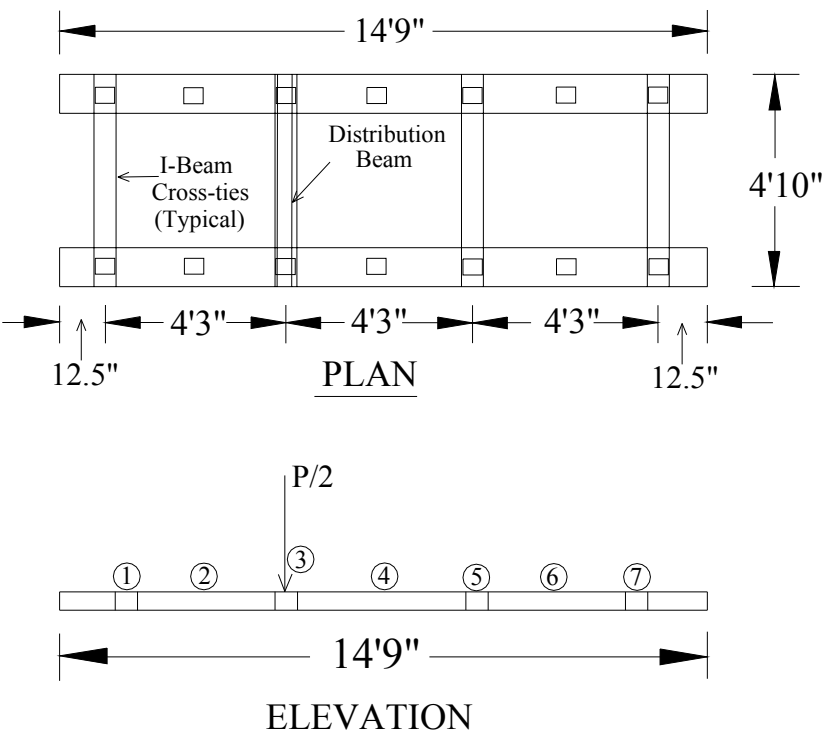

Figure 4.2.9. Test Set-Up for Single Point Load Applied Over Left Crosstie

A single point load was applied over the interior cross-tie of the panel, which is 5'3 $1 / 2$ ' from the end. Figure 4.2.10 shows the deflection of the two beams at a load of 20 kips. Figure 4.2.10 shows that there is an uneven load distribution between the two beams. This behavior needs to be further investigated in the next specimen to confirm that it is not an erroneous data. 


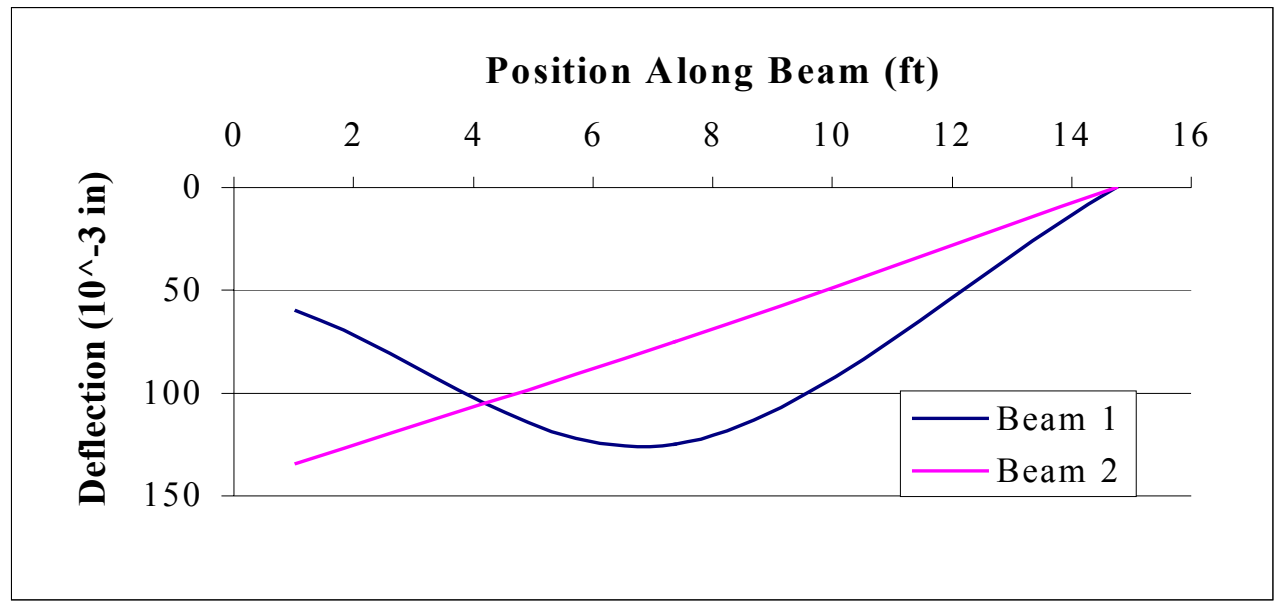

Figure 4.2.10. Deflected Shapes of Beams at Maximum Load of 20 kips for Interior Crosstie Loading

Figure 4.2.11 shows the strain distribution for 10 and 20 kips. This plot shows how the load is distributed over the panel's length for the two loads. It shows that the strain distribution at midspan is about $75 \%$ of the load while the strain distribution at the left end is only about $3 \%$.

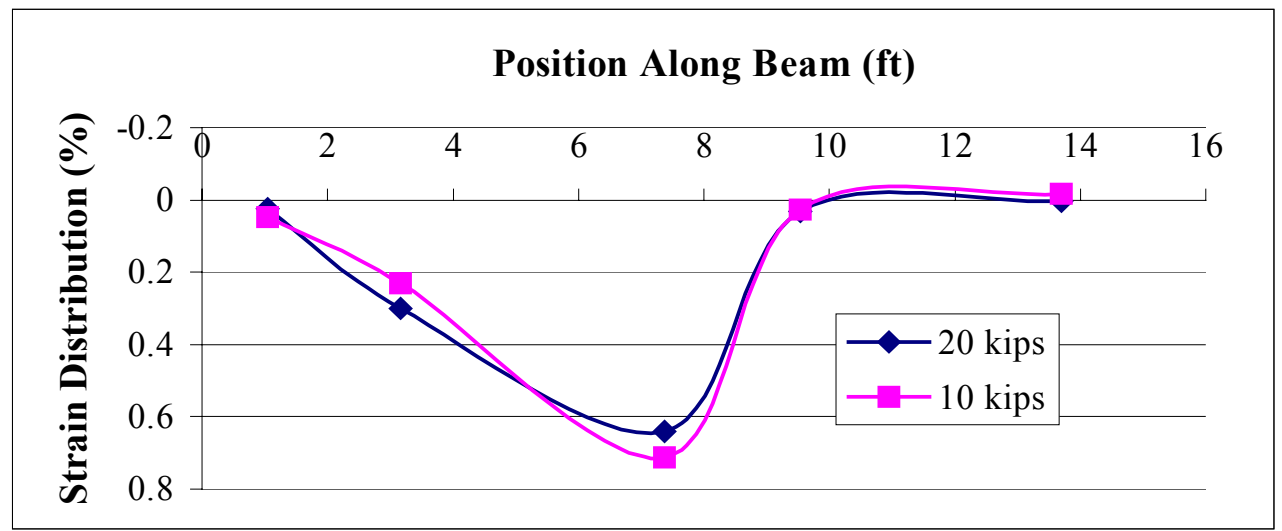

Figure 4.2.11. Strain Distribution Along Beam 1 for Indicated Loads at Interior Crosstie

Figure 4.2.12 shows the strains for Beam 1 at 10 and 20 kips. 


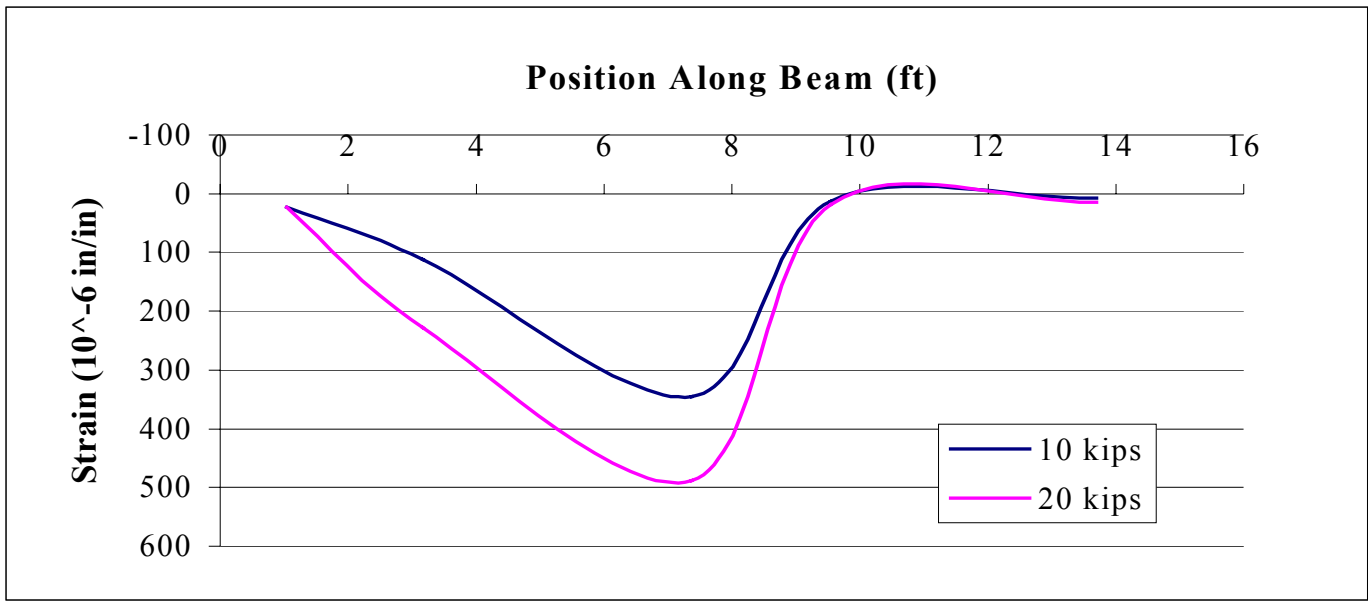

Figure 4.2.12. Strain vs. Position for Beam 1 at Indicated Loads

\subsubsection{Load in Middle of Outer Crossties}
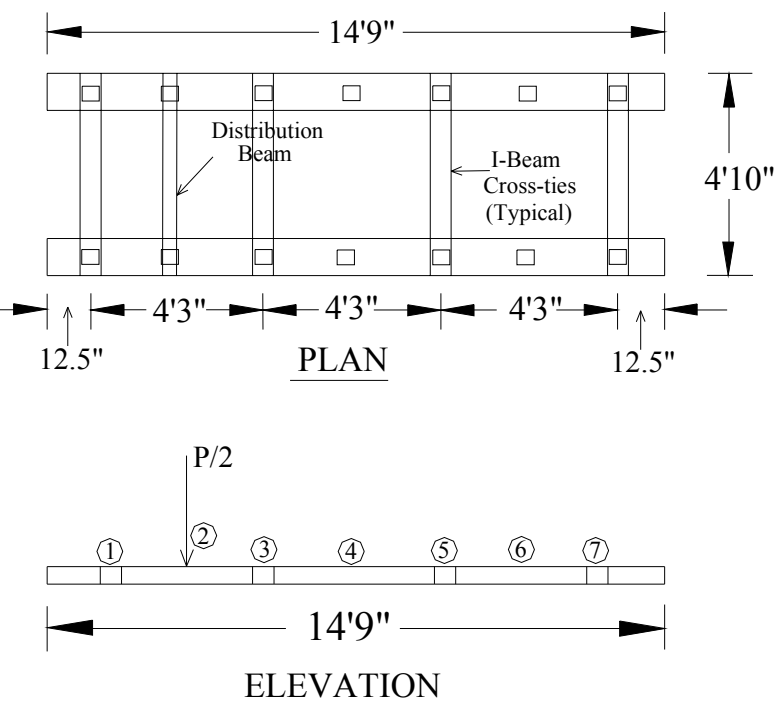

Figure 4.2.13. Test Set-Up for Single Point Load Applied At Midspan of Outer Left Crossties

Figures 4.2.14 and 4.2.15 show the results from a test conducted in the middle of the outer cross ties. 
Once again, there is an uneven load distribution between the two beams. Further observation in the next specimen is required.

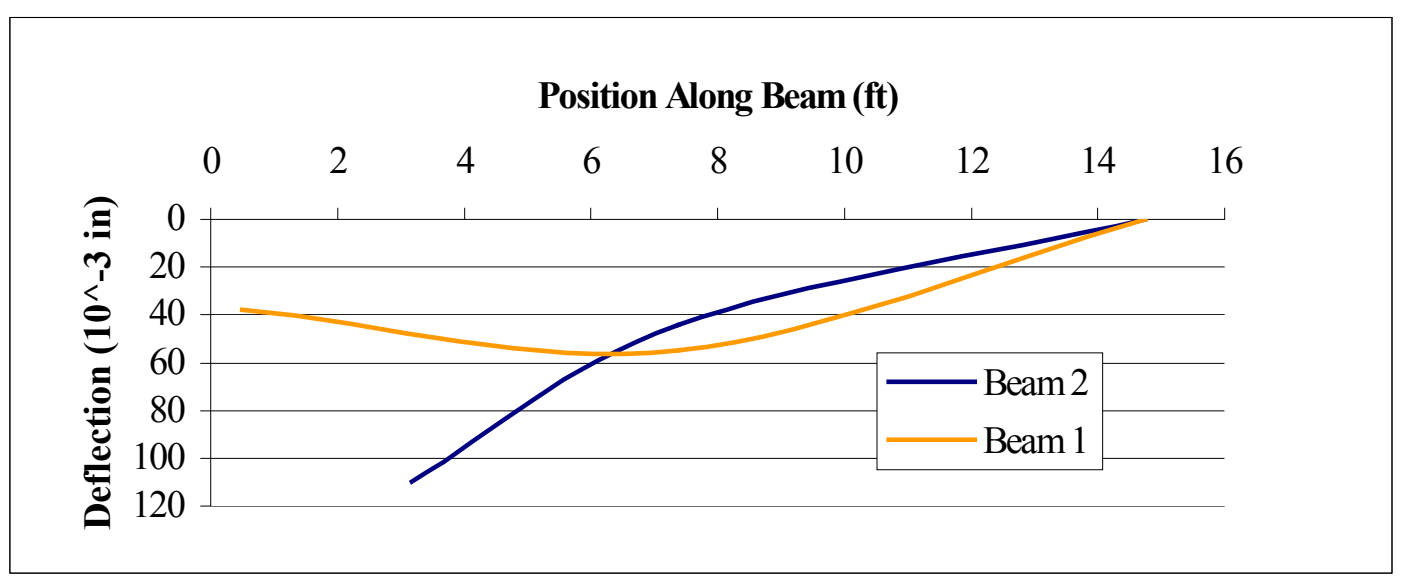

Figure 4.2.14. Deflected Shapes of Beams at Maximum Load of 20 kips for Load in Middle of Outer Crossties

Figure 4.2.15 shows the strain distribution at 10 and 20 kips. The strain distribution at the point of application is $80 \%$.

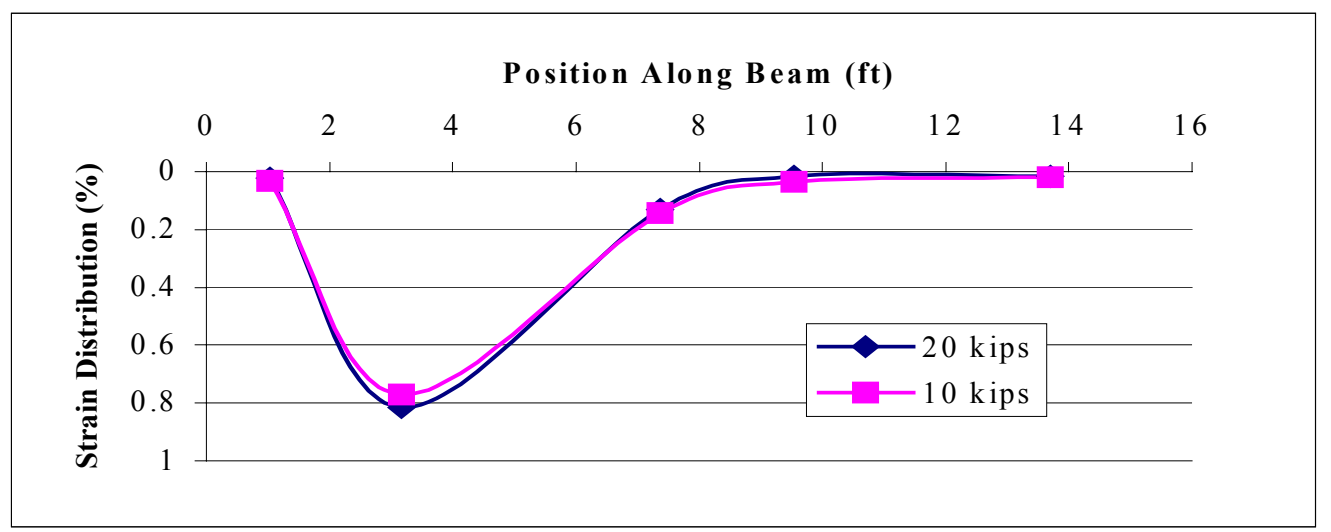

Figure 4.2.15. Strain Distribution for Beam 1 at Indicated Loads for Load Applied In Middle of Outer Crossties 
Figure 4.2.16 shows the strains for Beam 1 at 10 and 20 kips.

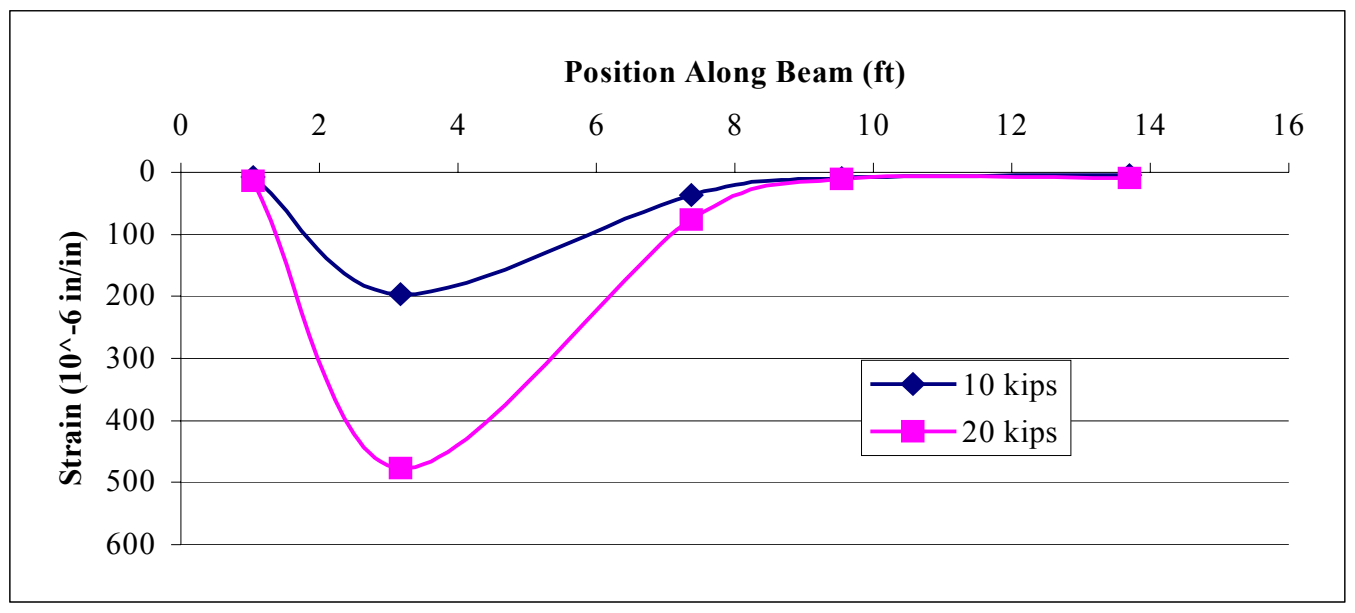

Figure 4.2.16. Strain vs. Position for Beam 1 at Indicated Loads 


\subsubsection{Two Point Loads at Midspan}

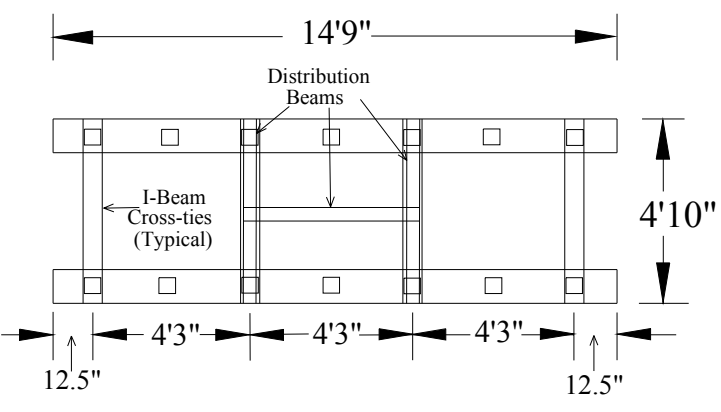

PLAN

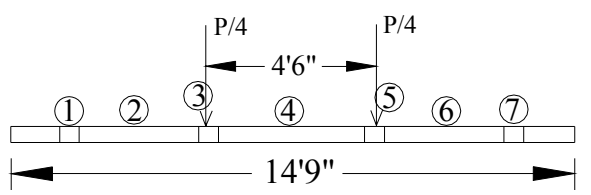

ELEVATION

Figure 4.2.17. Test Set-Up for Double Point Loads Applied Centrally At Midspan

The next test consisted of two vertical point loads at midspan. The two point loads are designed to simulate the two axles of a "mine car." A total load of 40 kips was applied and assuming equal distribution, each point load is equal to $\mathrm{P} / 4$. Deflection and strain were only measured on Beam 1. Figure 4.2.18 shows the deflection curve. As can be seen from Figure 4.2.18, the end of the beam deflects upward. The maximum deflection occurs at the location of the load, as expected. This indicates that more of the load is distributed to the right end.

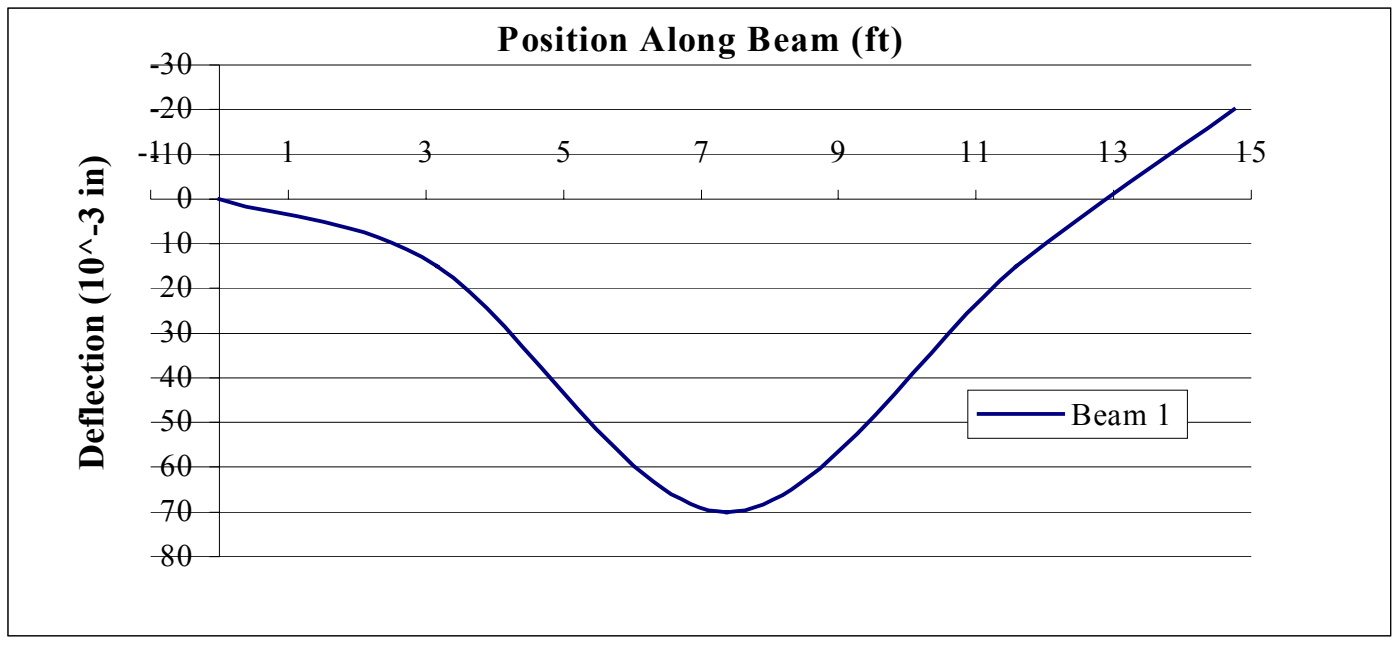

Figure 4.2.18. Deflection of Beam 1 at Maximum Load of 20 kips for Two Point Loads at Midspan (10 kips Each Point) 
Figure 4.2.19 shows the strain distribution for Beam 1 at 10 and 20 kips. $75 \%$ of the load acts over a $5 \mathrm{ft}$ section of the beam (midspan).

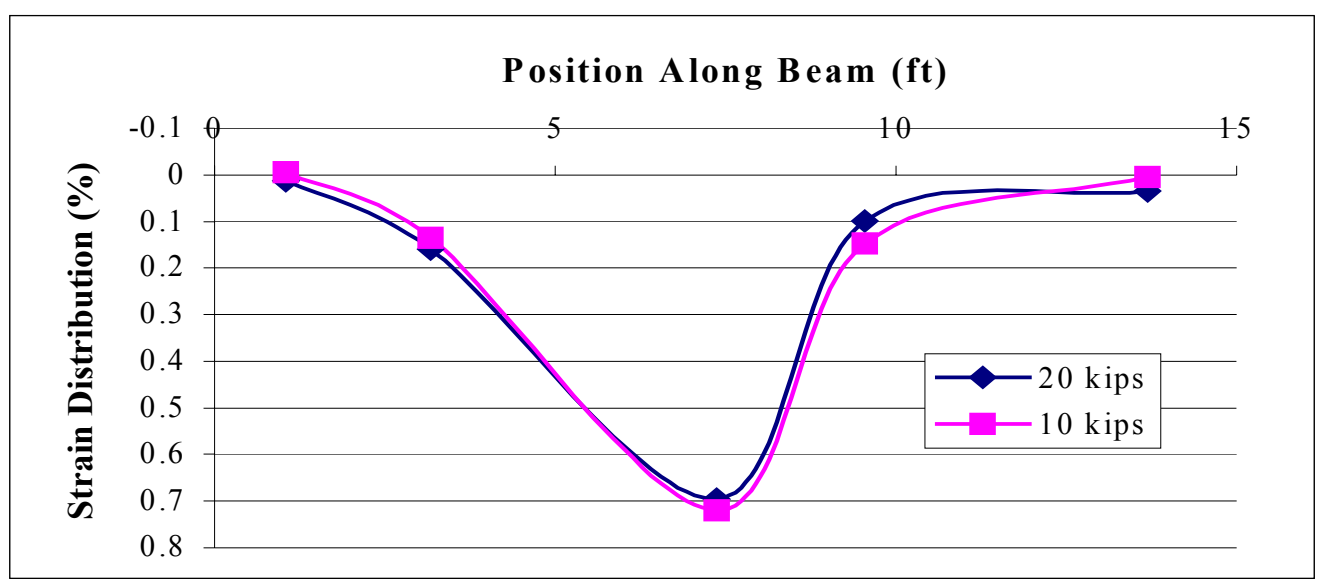

Figure 4.2.19. Strain Distribution for Beam 1 at Indicated Loads for Two-Point Loads at Midspan (Load is Total Load Applied to Each Beam)

Figure 4.2.20 shows the strains for Beam 1 at 10 and 20 kips.

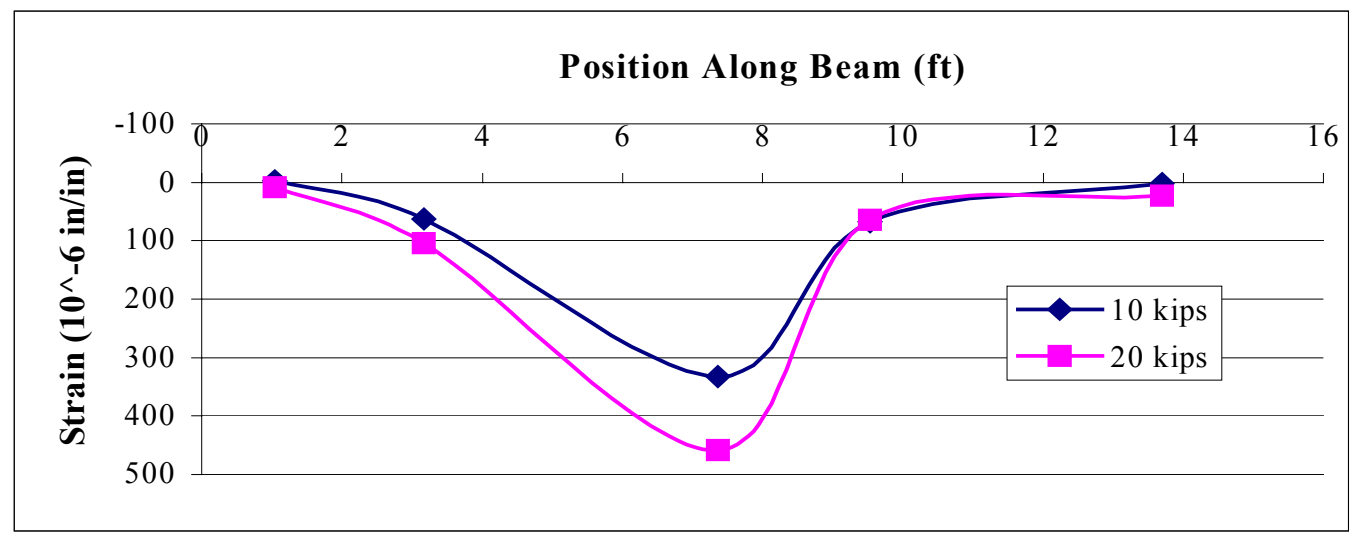

Figure 4.2.20. Strain vs. Position for Beam1 at Indicated Loads. 


\subsubsection{Two Point Loads Over Interior Crosstie (Left)}

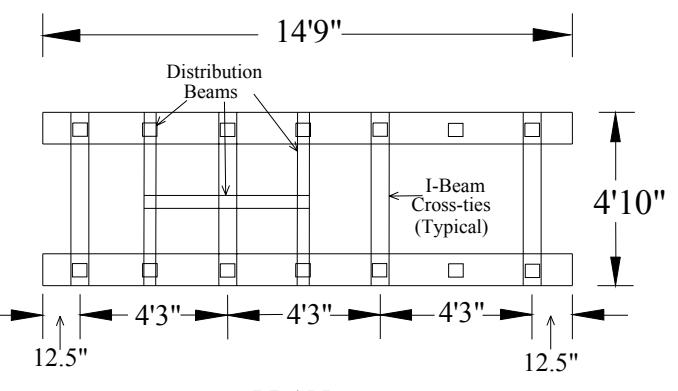

$\underline{\text { PLAN }}$

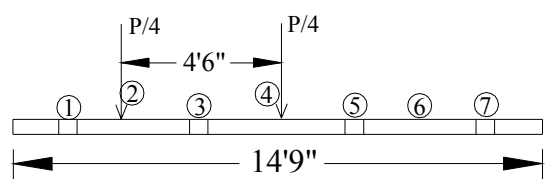

ELEVATION

Figure 4.2.21. Test Set-Up for Double Point Loads Applied Over Left Crosstie

A test of two point loads over the interior cross-tie was conducted next. The results from this test are shown in Figures 4.2.22 and 4.2.23. Once again, only the deflection and strain on Beam 1 were measured and a load of $\mathrm{P} / 4$ is again assumed.

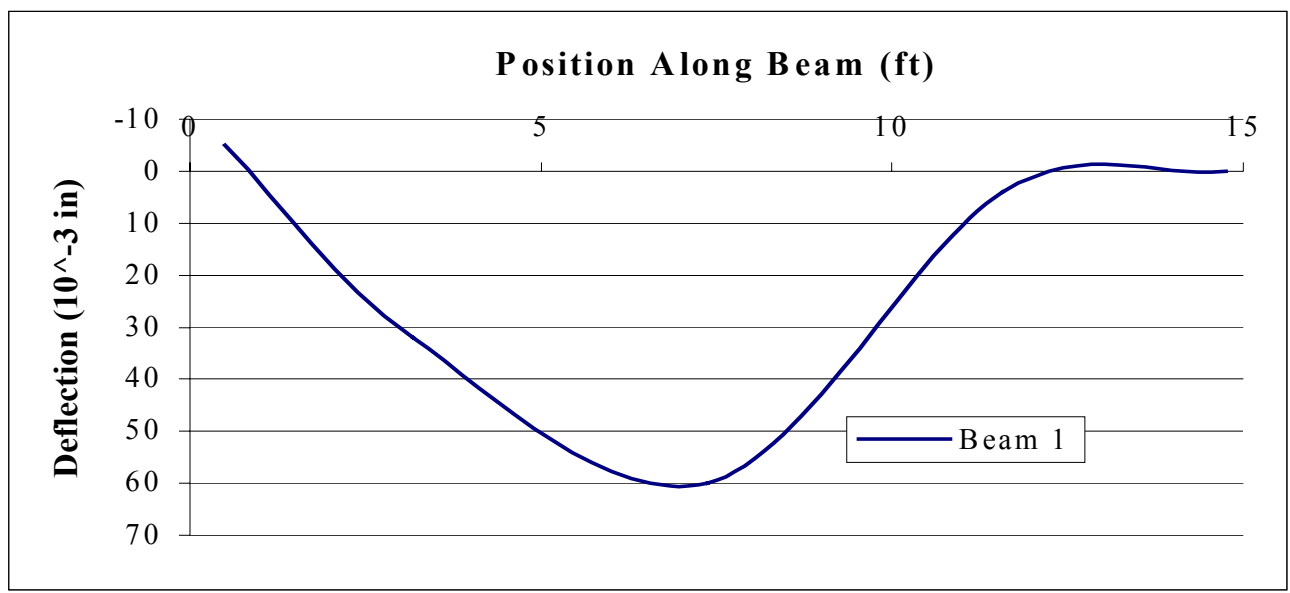

Figure 4.2.22. Deflected Shape of Beam 1 at Maximum Load of 20 kips for Two Point Loads at Inner Crosstie (10 kips at Each Point) 
Figure 4.2.23 shows the strain distribution for this test.

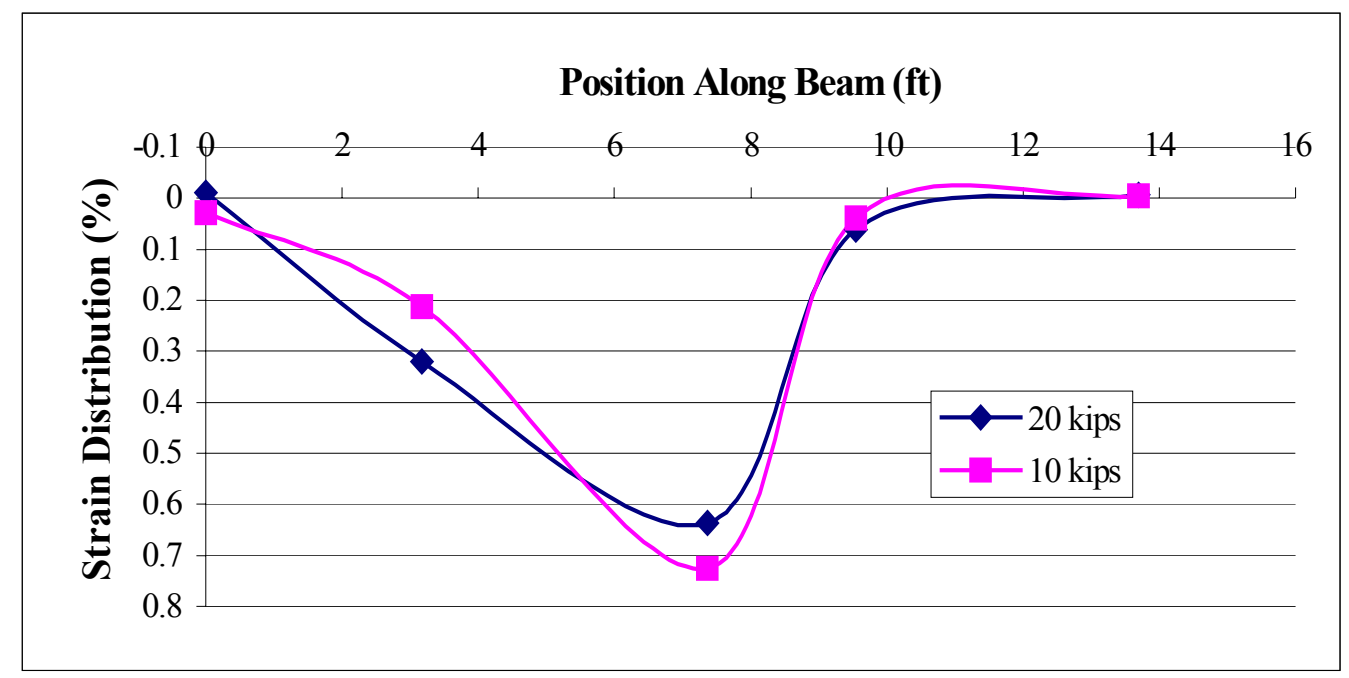

Figure 4.2.23. Strain Distribution for Beam 1 at Indicated Loads for Two-Point Loads at Interior Crosstie

Figure 4.2.24 shows the strains for Beam 1 at 10 and 20 kips.

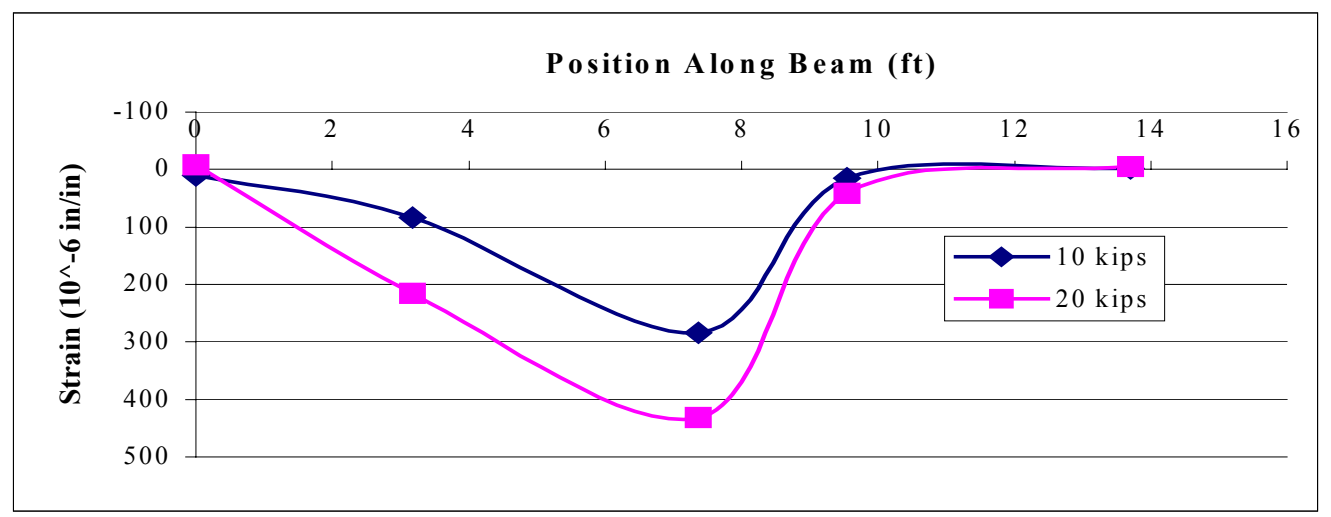

Figure 4.2.24. Strain vs. Position for Beam 1 at Indicated Loads 


\subsubsection{Two Point Loads at Interior Crosstie (Right)}
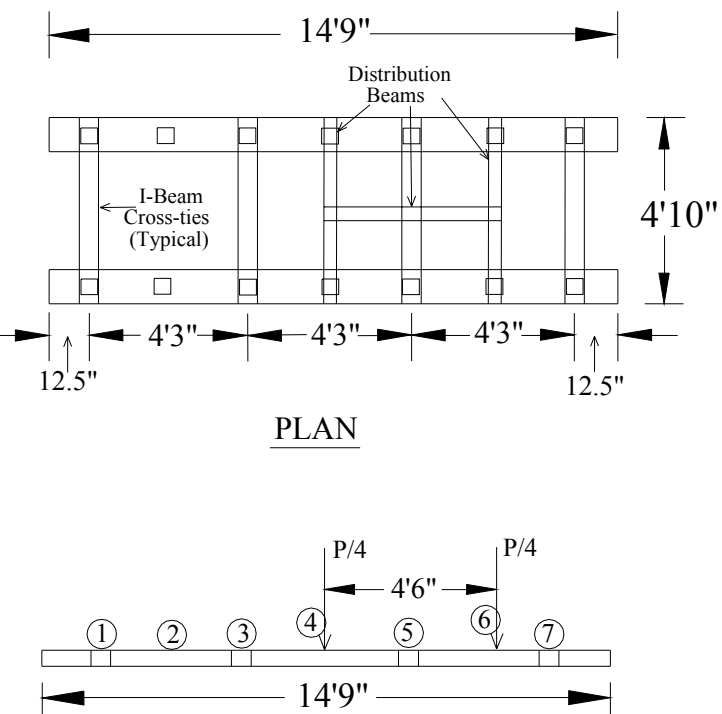

ELEVATION

Figure 4.2.25. Test Set-Up for Double Point Loads Applied Over Right Crosstie

A test was also conducted on the other inner cross-tie to compare the results to the previous test. The beam should act in a symmetric fashion. The deflected shape is shown in Figure 4.2.26 and strain distribution in Figure 4.2.27.

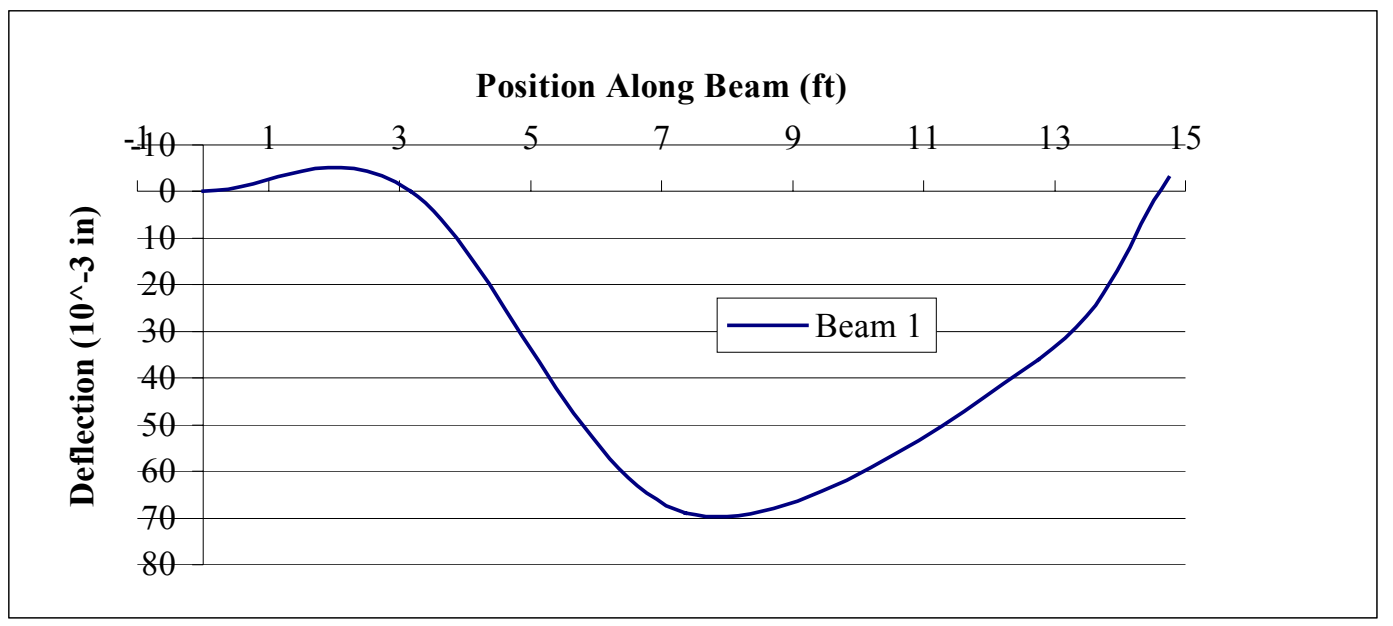

Figure 4.2.26. Deflected Shape of Beam 1 at Maximum Load of 20 kips for Load at Inner Crosstie (10 kips at Each Point) 
Figure 4.2.27 shows the strain distribution along Beam 1 for two point loads at inner cross-tie. The strain distribution at midspan is $69 \%$.

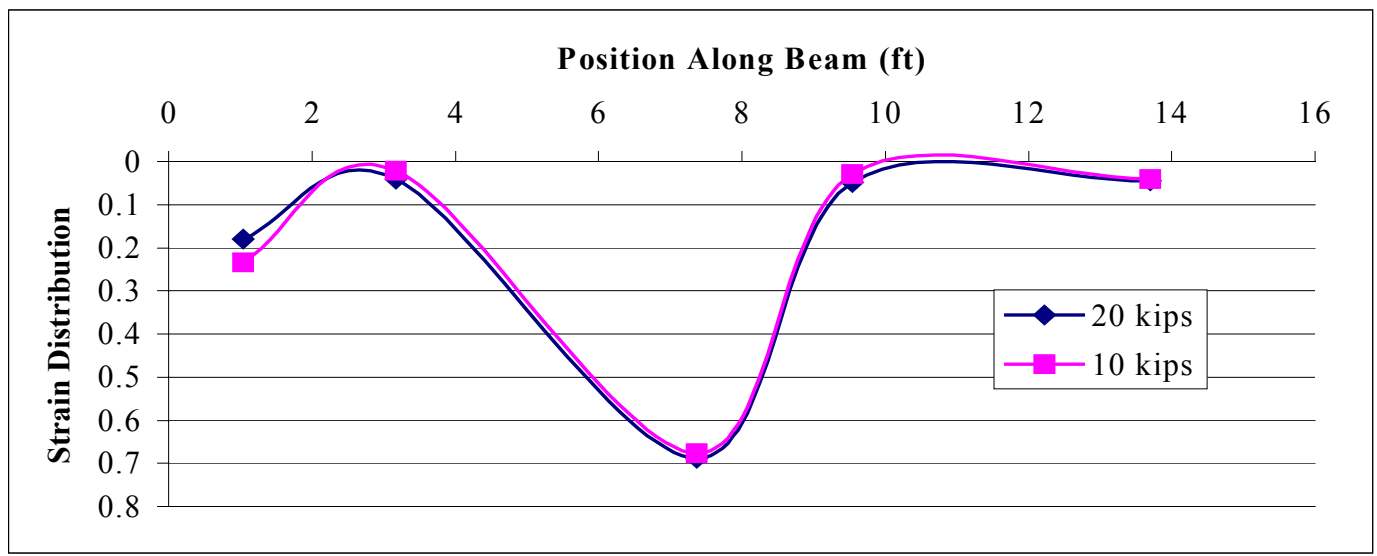

Figure 4.2.27. Strain Distribution for Beam 1 at Indicated Loads for Load At Inner Crosstie

Figure 4.2.28 shows the strain for Beam 1 at 10 and 20 kips.

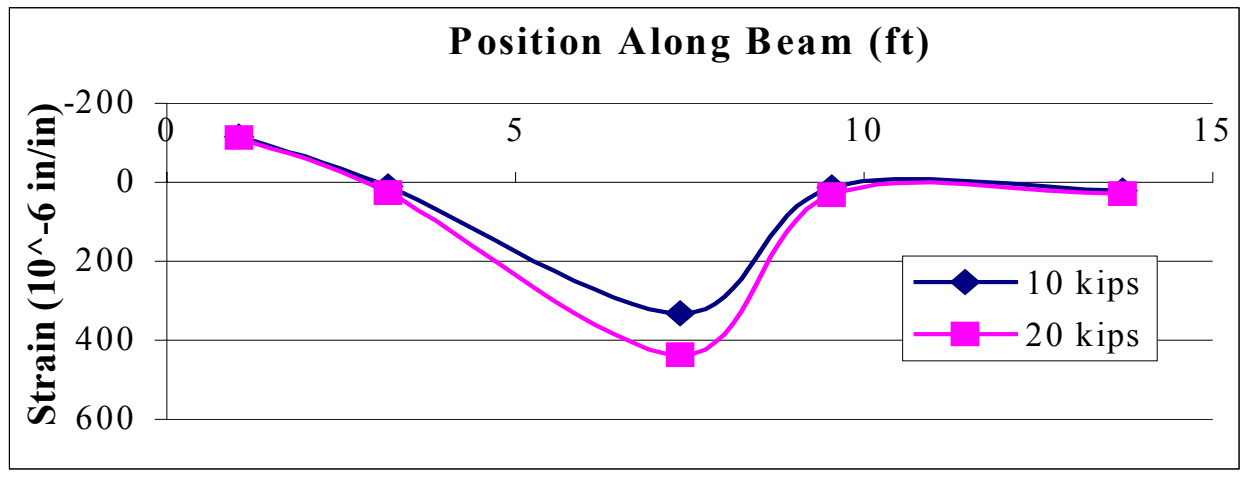

Figure 4.2.28. Strain vs. Position for Beam 1 At Indicated Loads

\subsubsection{Conclusion and Summary for Full-Size Prestrssed Concrete Panel 1}

Based on the first panel tests, the following preliminary conclusions are drawn:

- Based on strain measurements, the load distribution along the span of Beam 1 is found to be in the range of $70-80 \%$ under the load. Further, the load appears to be distributed within a $5 \mathrm{ft}$ segment. 
- The maximum strains are found to be in the range of $600-800 \mu$ s on the top surface of the concrete beam using a maximum load of $20 \mathrm{kips} / \mathrm{beam}$.

- Beam-to-beam load sharing appears to be evenly distributed based on deflection measurements.

- The prestress force of 10 kips for the uncracked beam seems to be satisfactory. The prestress force was doubled in the cracked beam to achieve equal stress in the two beams.

- The cracked beam caused a significant reduction in the moment of inertia, which in turn, caused a larger deflection. This situation needs to be avoided.

- A plate test to determine the subgrade modulus was also conducted. Preliminary calculations indicate a value of 300 pci.

- Pad deflections were measured at midspan for all the load conditions. Pad stiffness was calculated for the different load conditions and was in the range of $0.6-0.7 \mathrm{kip} / \mathrm{in}$. 


\subsection{Full-Size Prestressed Concrete Panel 2}

\subsubsection{Introduction}

The second modular track panel was tested under static and fatigue loading to determine its bending behavior, load sharing characteristics, maximum deflections under single and double point load conditions, and stiffness change after being fatigued.

\subsubsection{Testing Set-Up}

The modular track panel consists of two (2) parallel post-tensioned concrete beams interconnected at discrete intervals by steel crossties. A steel mold was fabricated and was used to form the concrete modular panel, which incorporates steel shoulders to be used with Pandrol Mineclips. A single 5/8-in diameter Dywidag high strength steel bar $\left(\mathrm{f}_{\mathrm{y}}=150 \mathrm{ksi}\right)$ was concentrically placed in each beam to provide the required prestress force. A prestress force of 10 kips was placed on each beam. Stirrups were used at 4-in spacing. The concrete strength at twenty-eight (28) days was 8500 psi.

Eleven (11) strain gages and twelve (12) dials gages were used (Figure 4.3.1) to monitor the response of the beam during the testing process. Dial gages were used to measure deflection on the concrete beam and were placed near the seven (7) pad locations. An additional three (3) dial gages were used to measure deflection in the steel rail. Dial gages are represented in Figure 4.3.1 by a circle with the corresponding number inside the circle and strain gages are represented as the rectangles with corresponding numbers. Dial gages 8-10 were mounted on the steel rail. The rest were located on the top side of the prestressed concrete beam. Load cells were placed under the distribution beam to measure the load being distributed to each concrete beam. A data acquisition system was used to acquire all load and strain data. A plate test was conducted before testing began and a subgrade modulus of 310 pci was found. A pressure cell was placed under the beam at midspan to measure the change in pressure experienced by the foundation. The pressure cell was placed approximately three inches below the surface of the gravel. The cross-section of the prestressed beam is shown in Figure 4.3.2. Numbers on the figures in this section correspond to their respective pad numbers. 


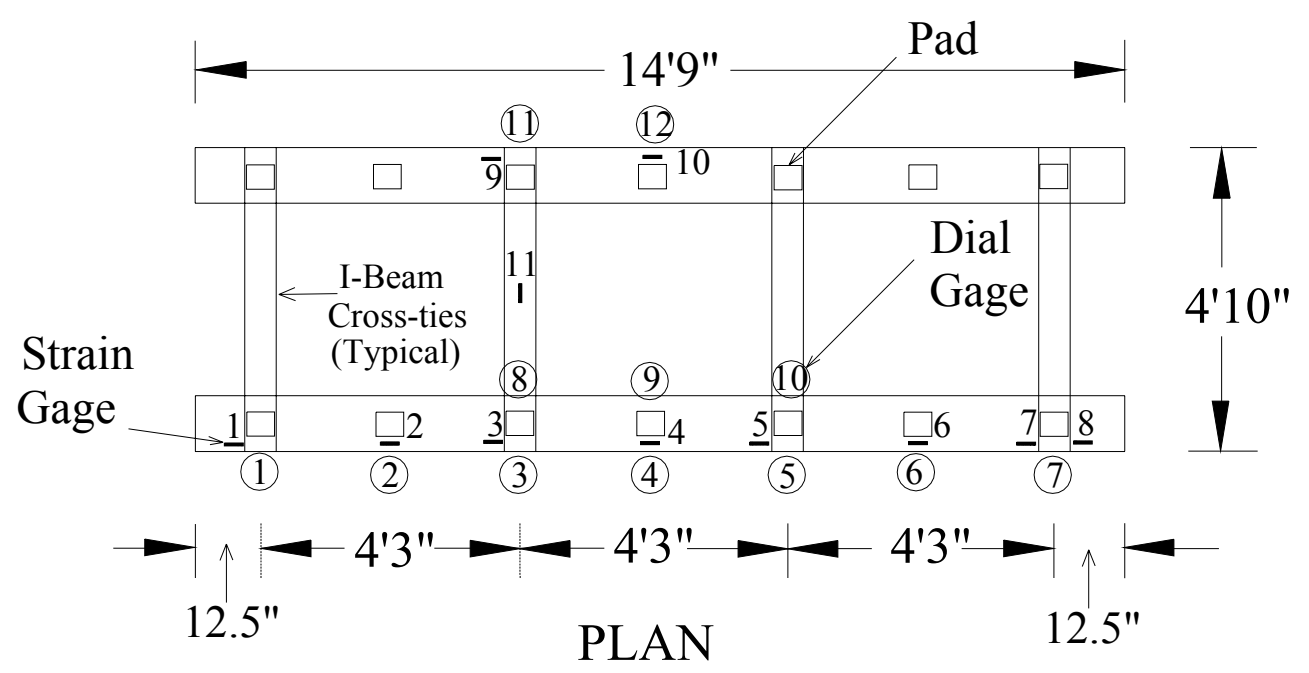

Figure 4.3.1. Strain Gage and Dial Gage Location on Prestressed Concrete Panel

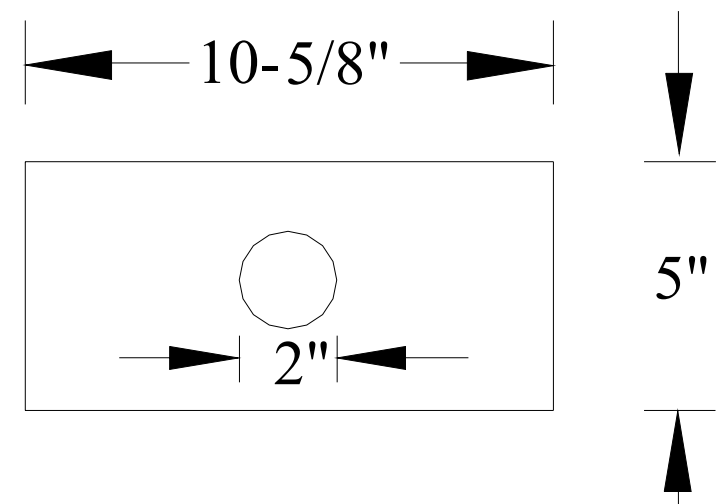

Figure 4.3.2. Post-Tension Concrete Beam Cross-Section

\subsubsection{Static Load Testing}

The following sections describe the single and double point load tests conducted the midspan and cross-tie locations.

\subsubsection{Single Point Load At Midspan}

The first test conducted was under a single point load at midspan using a load distribution beam shown in Figure 4.3.3. The maximum load applied was 20 kips, which produced a load of 10 kips on each beam. 


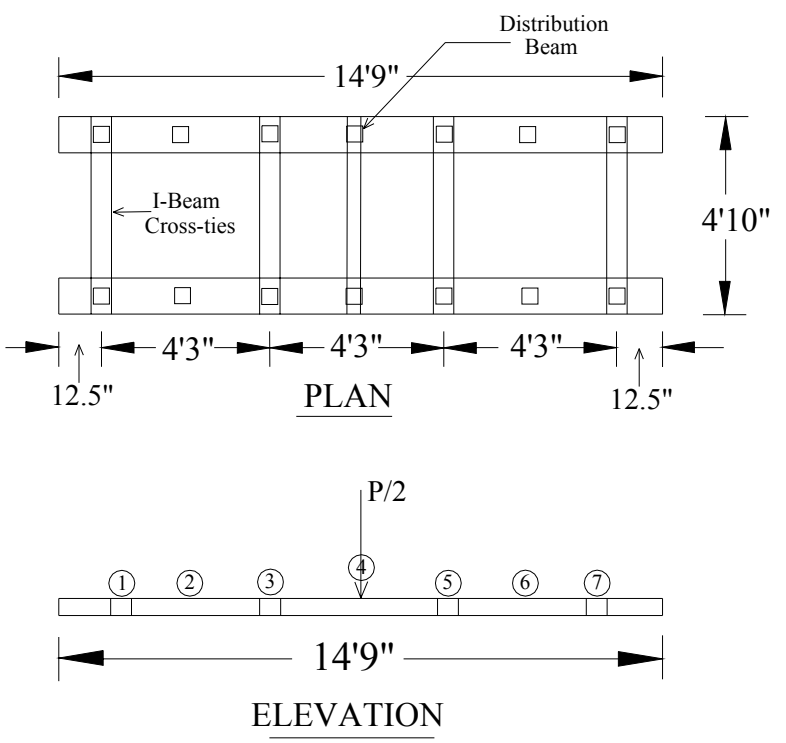

Figure 4.3.3. Schematic for Single Point Load at Midspan

Figure 4.3.4 shows the deflection of the beam at 5 and 10 kips. As can be seen from Figure 4.3.4, the maximum deflection is at the center and is $65 \times 10^{-3}$ in for the $10 \mathrm{kip}$ load and $40 \times 10^{-3}$ in for a load of 5 kips. This indicates that stiffness of the foundation increased with load, meaning deflection does not increase linearly. This is probably due to the gravel compacting under the concrete beam.

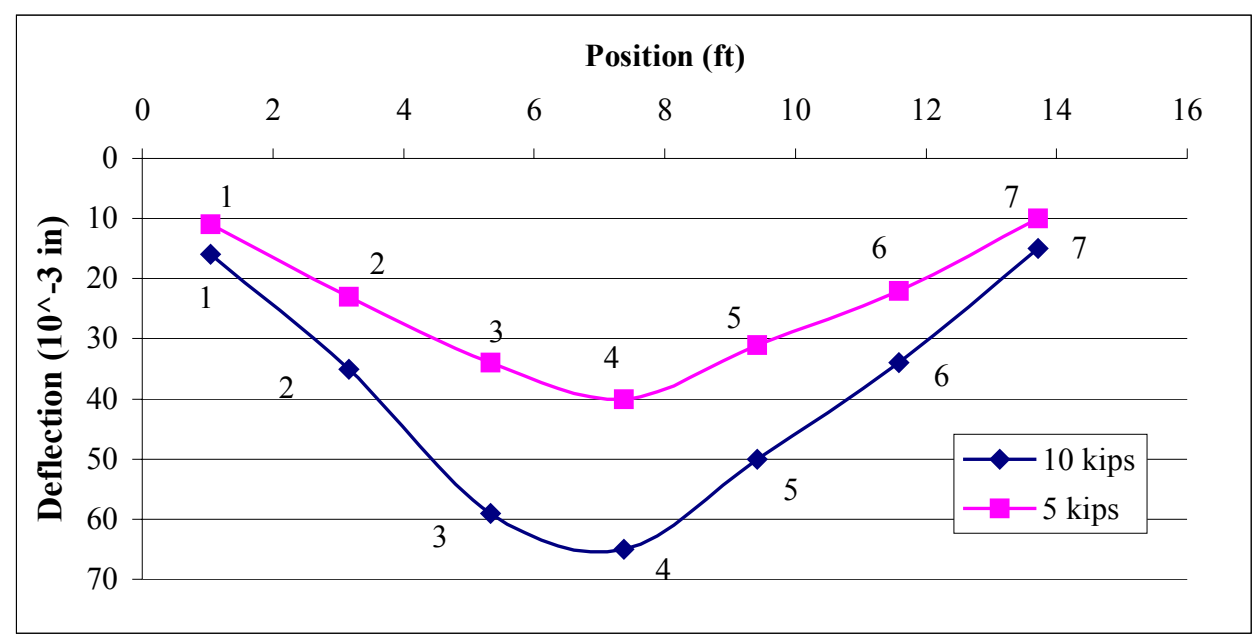

Figure 4.3.4. Deflected Shape of Beam at 5 and 10 kips Loading.

Figure 4.3.5 shows the load distribution based on deflection for the beam under a single point load at midspan at the maximum load of 10 kips. It shows that $64 \%$ of the load is carried by the middle three pads ( $\mathrm{Pad} 3$ carries 22\%, Pad 4 carries 24\%, and Pad 5 carries 18\%). 


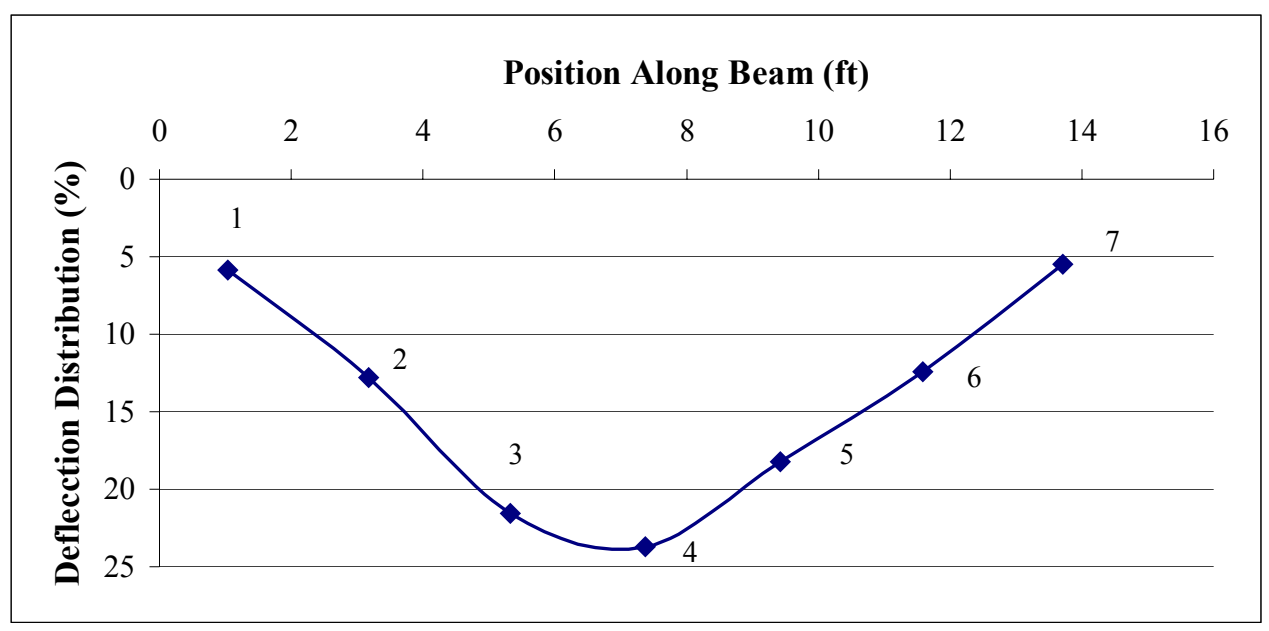

Figure 4.3.5. Deflection Distribution vs. Position for Load of 10 kips

Figure 4.3.6 shows the strains for the beam at the maximum load of 10 kips. The largest strain value is at the midspan and is $218 \times 10^{-6} \mathrm{in} / \mathrm{in}$.

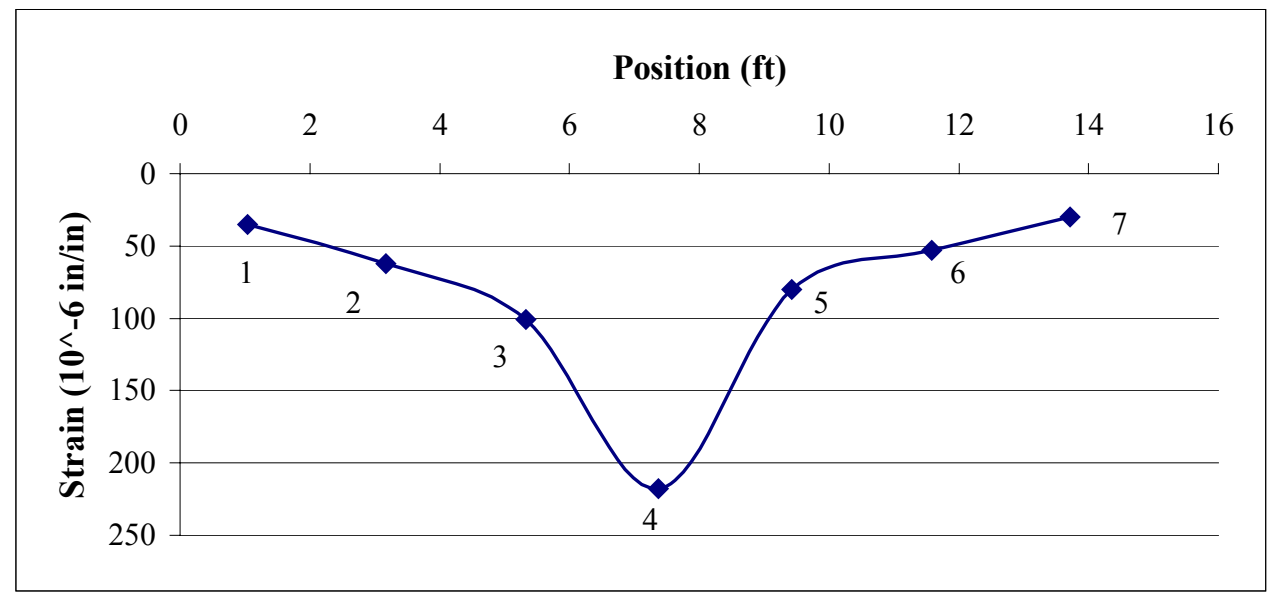

Figure 4.3.6. Strain vs. Position at Maximum Load of 10 kips

Figure 4.3.7 shows the strain distribution for the single load at midspan. Based on strain, 67\% of the load is distributed to the middle three pads, which agrees very well with the $64 \%$ distribution based on deflection. However, the gage under the load (Gage 4) carries almost 37\% of the load from a strain point of view, while the dial gage at the same location carries approximately $24 \%$ of the load. This indicates that the deflection measurements are global in nature and give a more accurate global distribution estimate. 


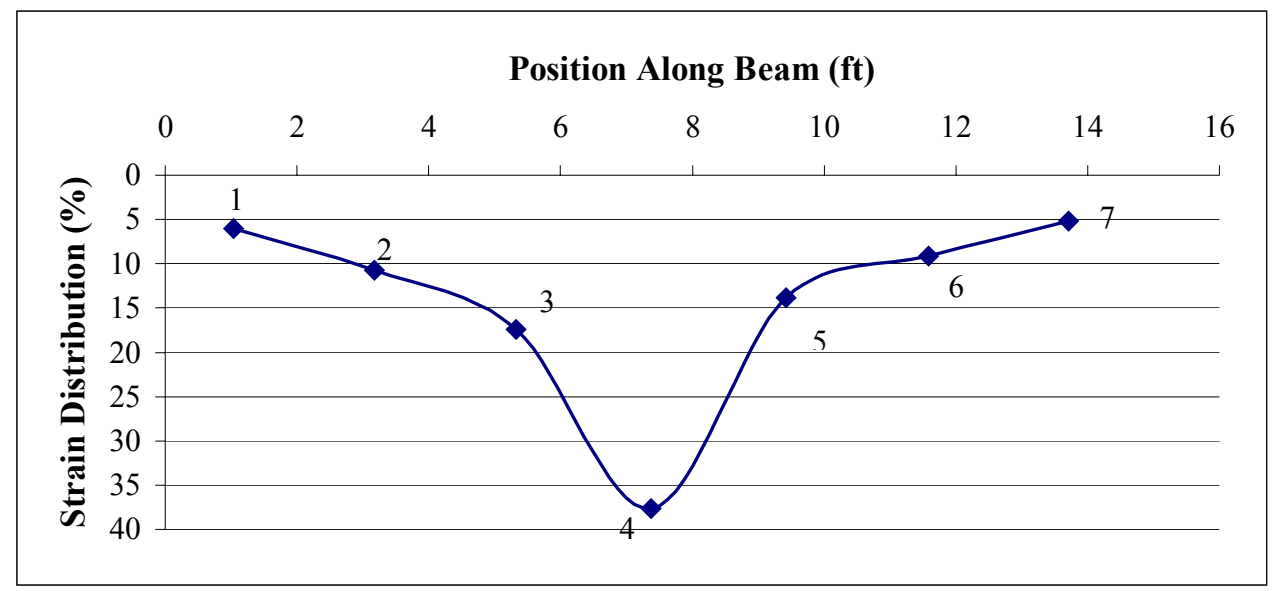

Figure 4.3.7. Strain Distribution vs. Position at Load of 10 kips

Figure 4.3.8 shows the change in pressure versus increasing load experienced by the foundation under the panel. The maximum load of 20 kips produced a pressure of 7.6 psi. The pressure cell was located at midspan.

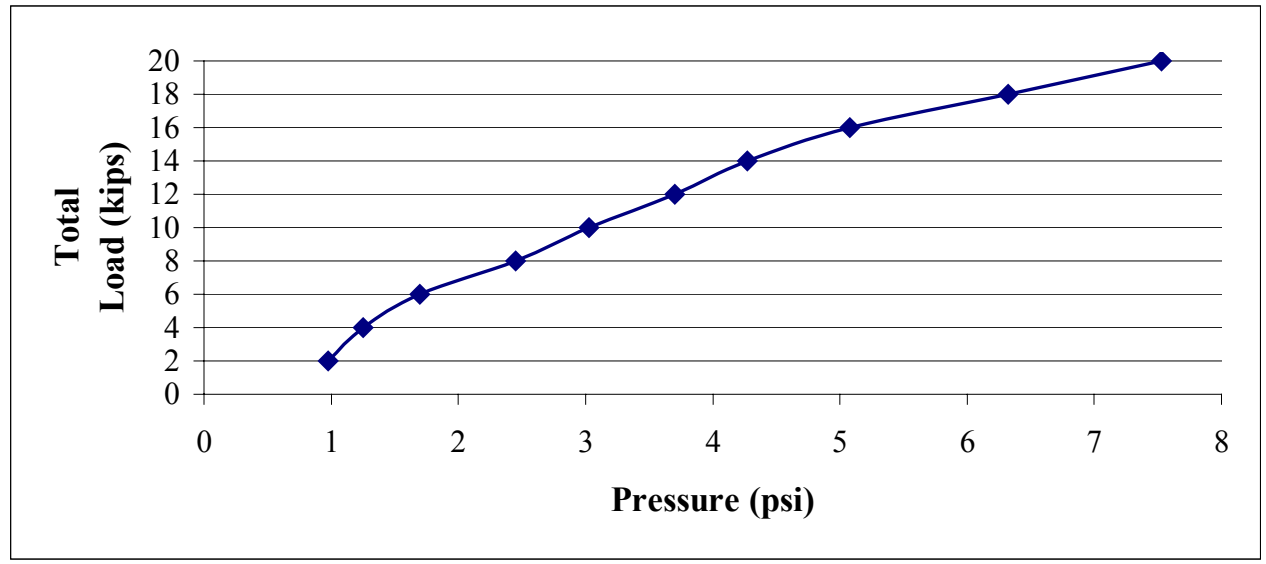

Figure 4.3.8. Load vs. Pressure for Single Point Load at Midspan

\subsubsection{Single Point Load at Interior Crosstie}

A single point load was applied with a distribution beam over the interior crosstie of the panel as shown in Figure 4.3.9. 


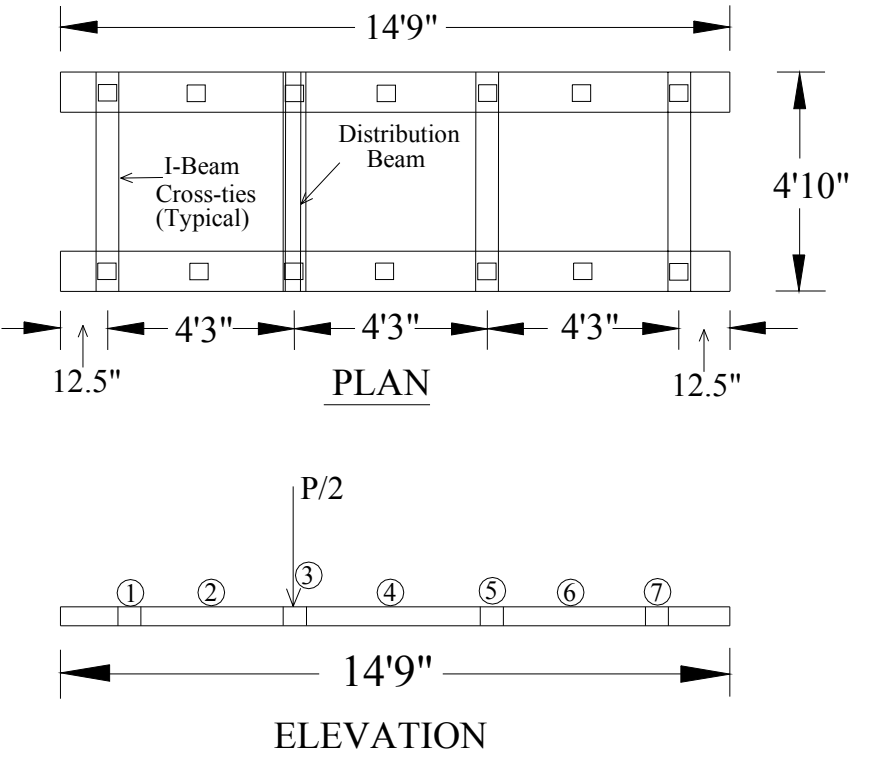

Figure 4.3.9. Schematic for Interior Cross-Tie Loading

Figure 4.3.10 shows the deflected shape of the beams at 5 and 10 kips. Figure 4.3 .10 shows that the maximum deflection is at the location of the load and is $76 \times 10^{-3}$ in for the $10 \mathrm{kip}$ load. The deflection at a load of 5 kips was $38 \times 10^{-3}$ in.

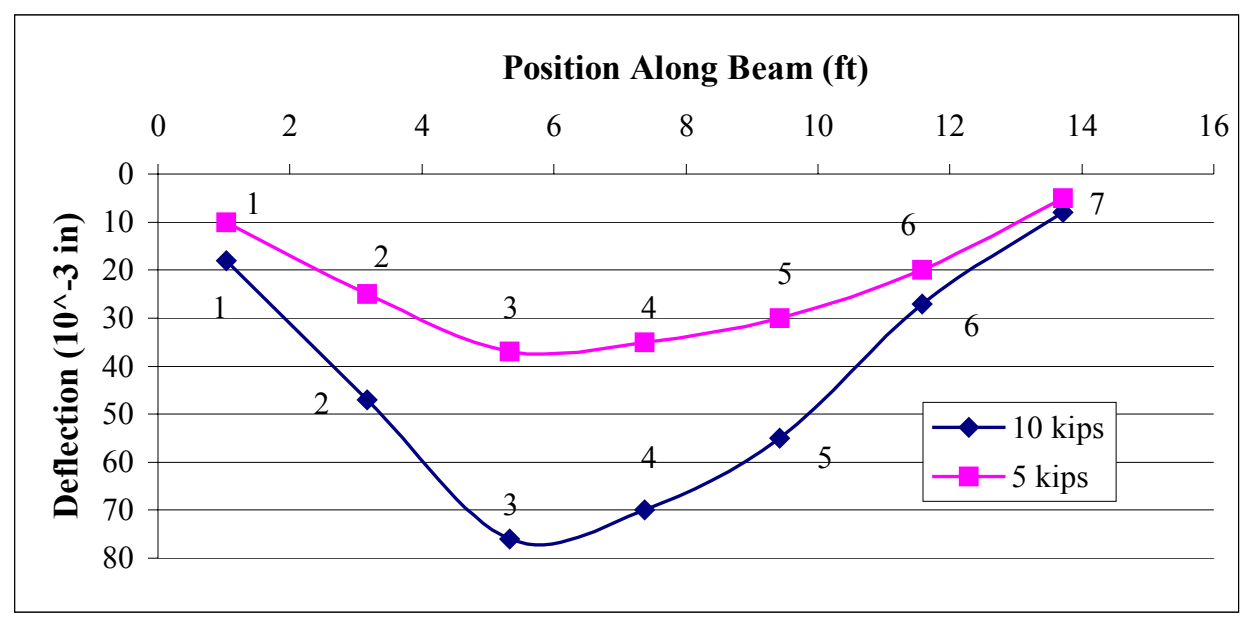

Figure 4.3.10. Deflected Shape of Beams at Indicated Loads for Interior Crosstie Loading 
Figure 4.3.11 shows the distribution of load based on deflection. The pad at the location of the applied load ( $\mathrm{Pad} 3$ ) carried $25 \%$ of the load, while $63 \%$ of the total load is distributed to the pad at the load location and the two adjacent pads (i.e. Pads 2, 3, and 4).

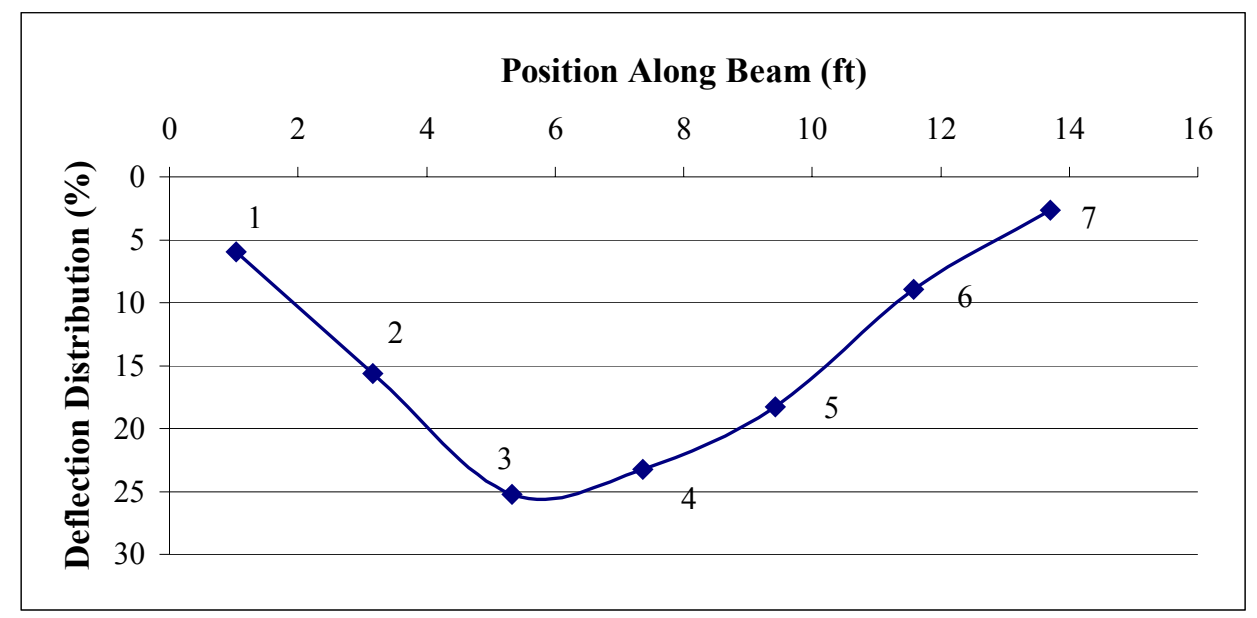

Figure 4.3.11. Deflection Distribution vs. Position at Maximum Load of 10 kips For Loading at Interior Crosstie

Figure 4.3.12 shows the strains for the beams at the maximum load of 10 kips. The maximum strain occurs at the load location $(\operatorname{Pad} 3)$ and is $260 \times 10^{-6} \mathrm{in} / \mathrm{in}$.

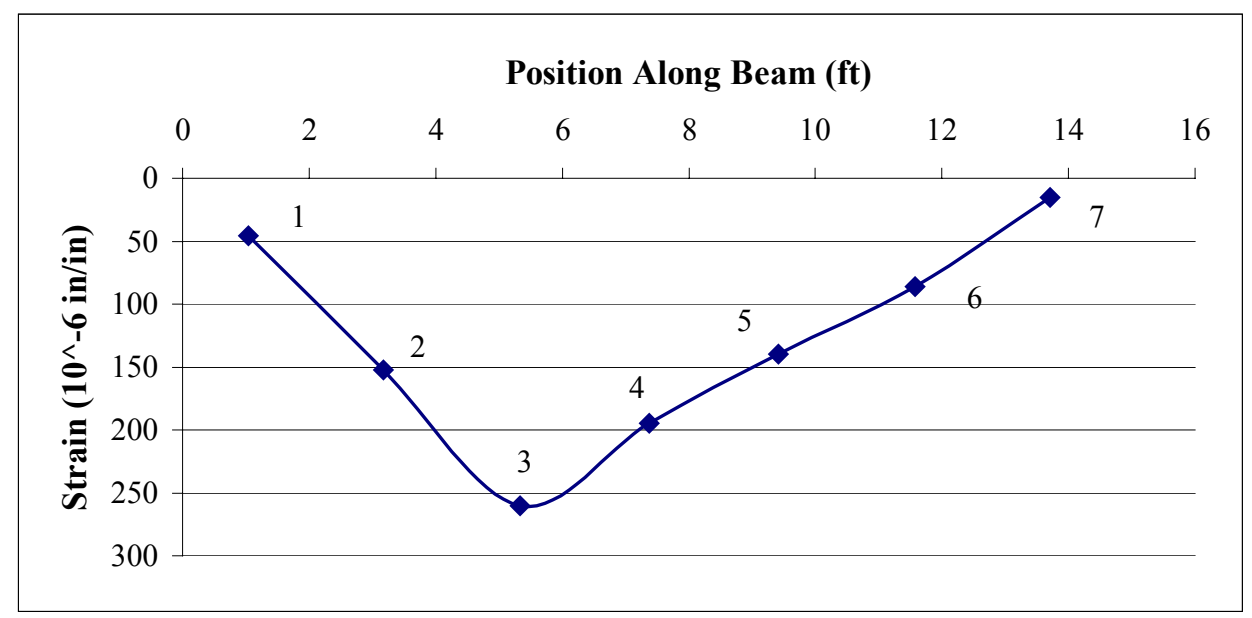

Figure 4.3.12. Strain vs. Position for Maximum Load of 10 kips

Figure 4.3.13 shows the strain distribution for the loading at the interior cross-tie. It shows that $67 \%$ of the load is carried by the pad under the load and the adjacent two pads compared to $63 \%$ based on deflection. 


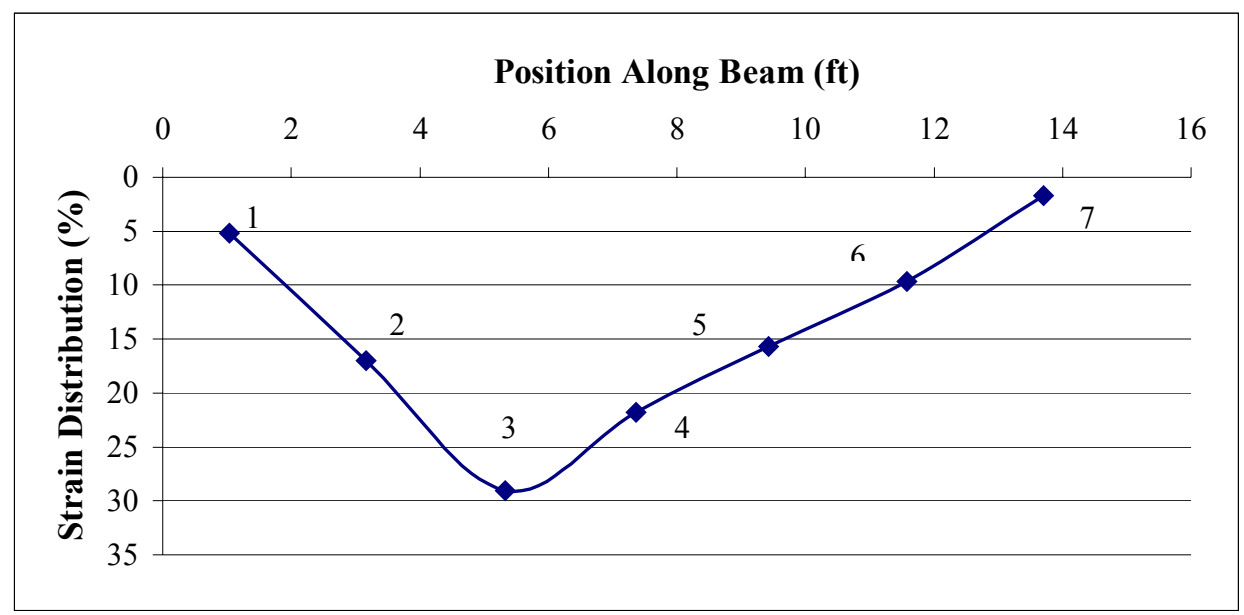

Figure 4.3.13. Strain Distribution vs. Position for Maximum Load of 10 kips

Figure 4.3.14 shows the change in pressure for the foundation for a single point loading at the interior cross-tie. This loading was approximately $2 \mathrm{ft}$ from the pressure cell location. The maximum load of 20 kips produced a pressure on the foundation at midspan of 8.1 psi.

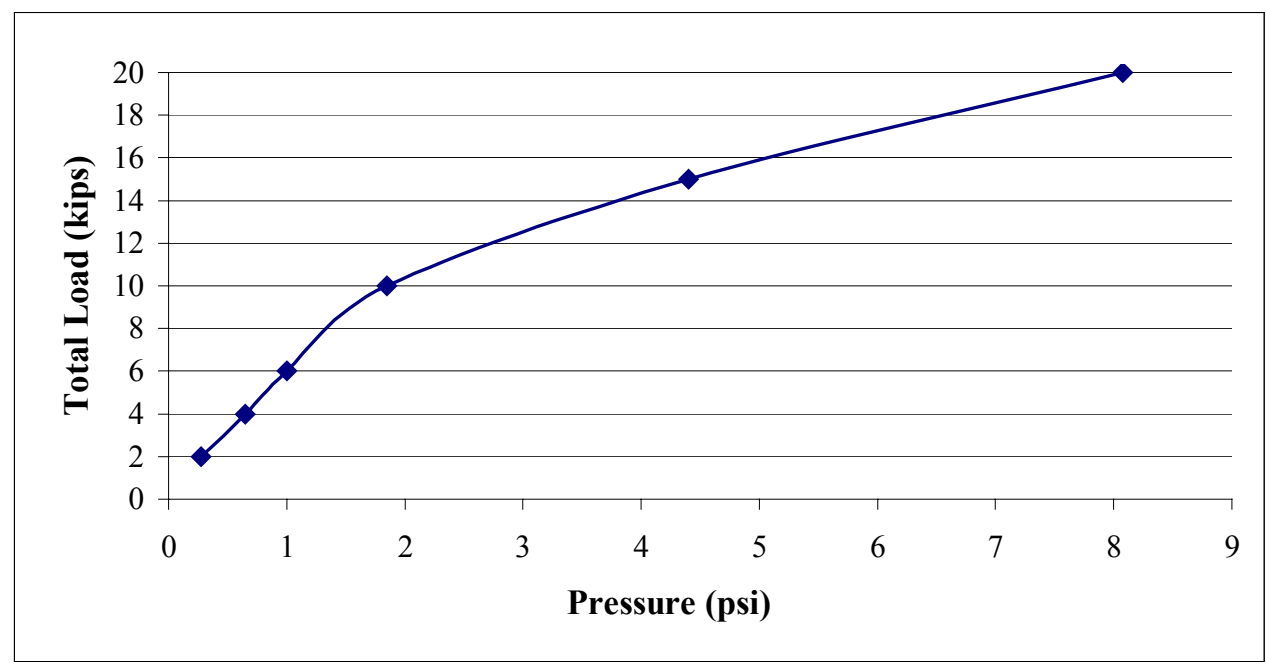

Figure 4.3.14. Total Load vs. Pressure for Single Point Load At Interior Crosstie 


\subsubsection{Single Point Load In Middle of Outer Crossties (Left)}

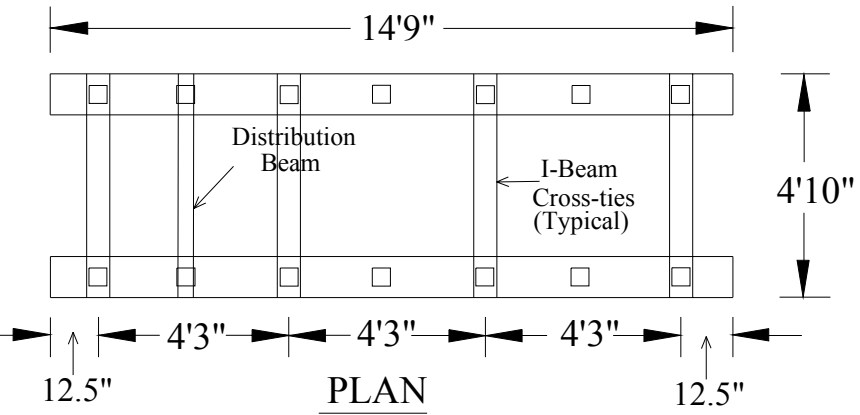

$\mathrm{P} / 2$

\begin{tabular}{lllllllll}
1 & $v^{2}$ & 3 & 4 & 5 & 6 & 7 \\
\hline & $14^{\prime} 9^{\prime \prime}$ & & &
\end{tabular}

ELEVATION

Figure 4.3.15. Schematic for Application of Load in Middle of Outer Crossties

Figures 4.3.16 and 4.3.17 show the results from a test conducted in the middle of the outer crossties. The maximum deflection was obtained at the load location and was equal to $65 \times 10^{-3}$ in for the 10 kip loading.

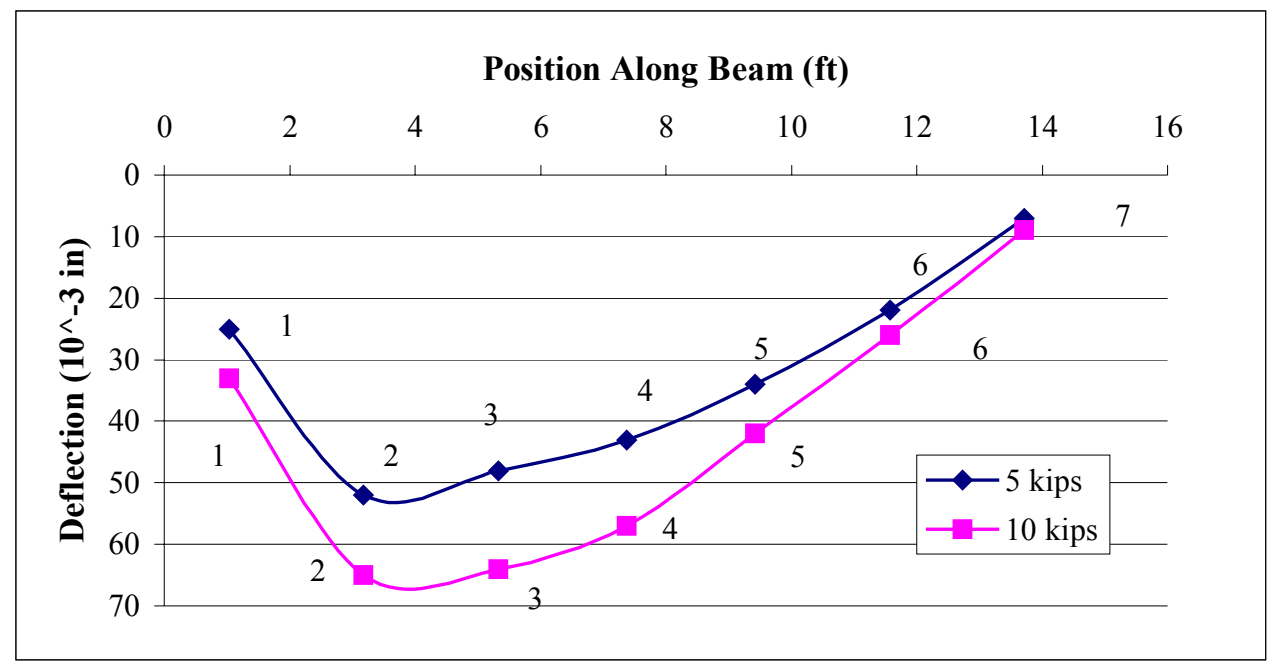

Figure 4.3.16. Deflection vs. Position for Load in Middle of Outer Crossties 
Figure 4.3 .17 shows that $53 \%$ of the load is distributed to the pad location under the load $(\operatorname{Pad} 2)$ and the adjacent two pads (one on each side). There is also significant deflection (19\%) at midspan or near the location of Pad 4.

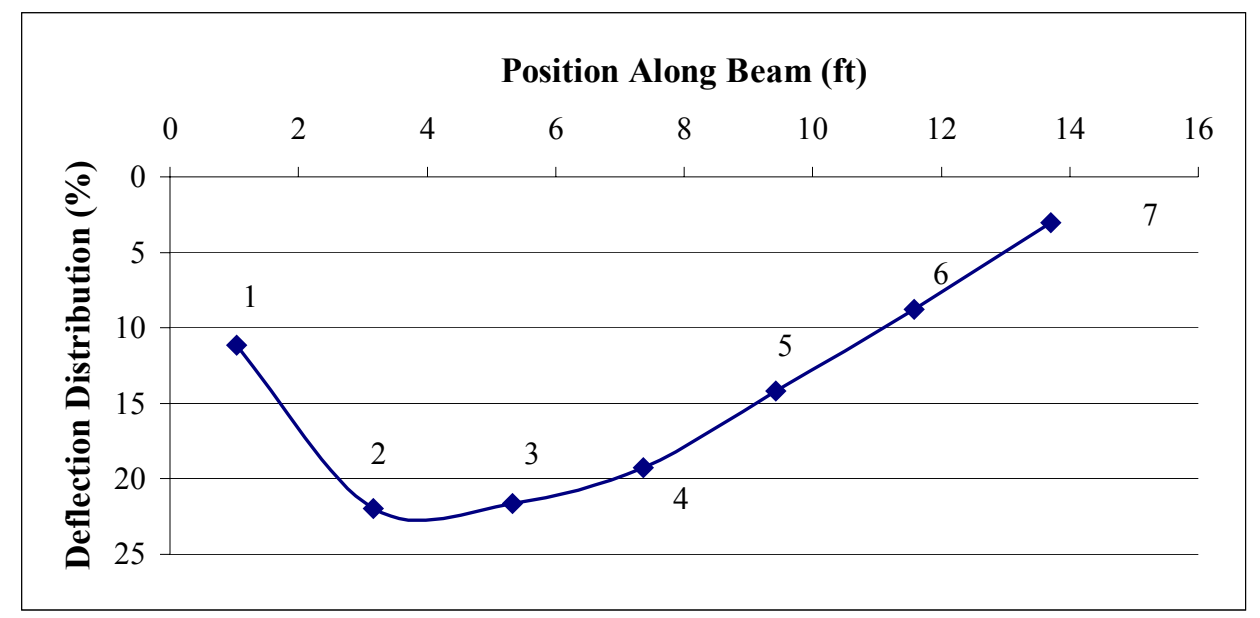

Figure 4.3.17. Deflection Distribution for Single Point Load in Middle of Outer Crossties

Figures 4.3.18 and 4.3.19 show the results from strain analysis. The maximum strain value is $350 \times 10^{-6}$ in/in and located at the point of load application.

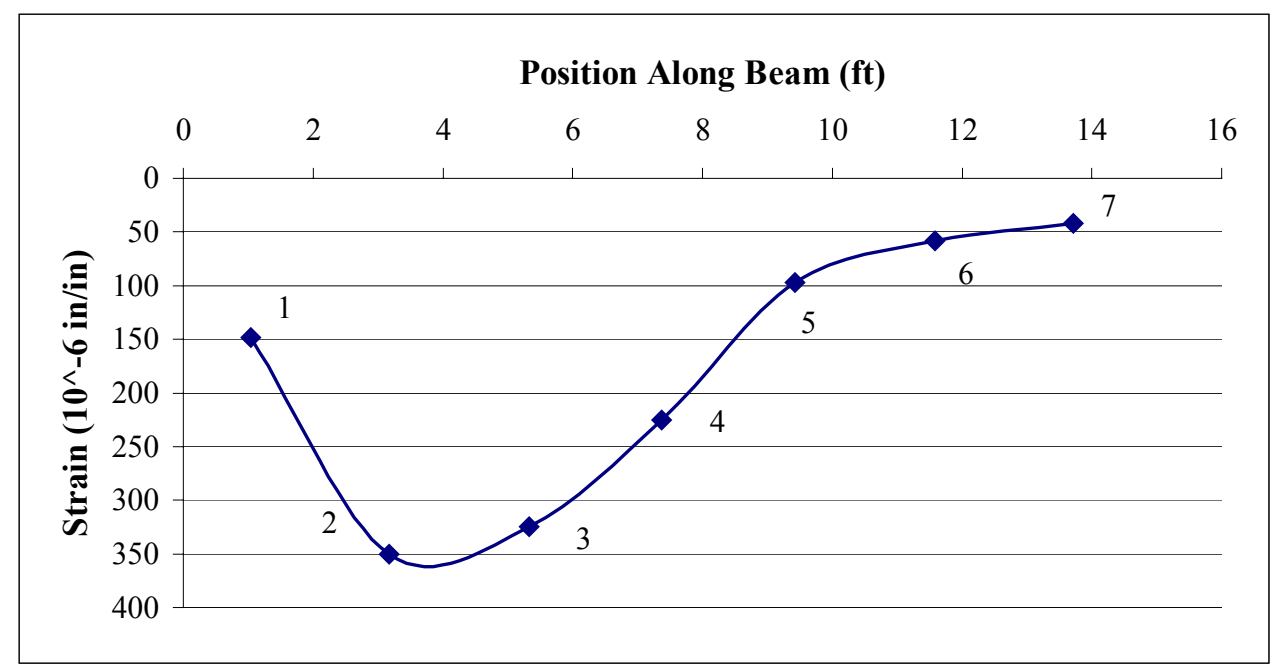

Figure 4.3.18. Strain vs. Position for Single Point Load in Middle of Outer Crossties

Figure 4.3 .19 shows that $64 \%$ of the load is distributed to the pad under the load and the adjacent two pads based on strain, compared to $53 \%$ based on deflection. This behavior is similar to the previous tests. The deflection response is in global terms while the strain response is localized. 


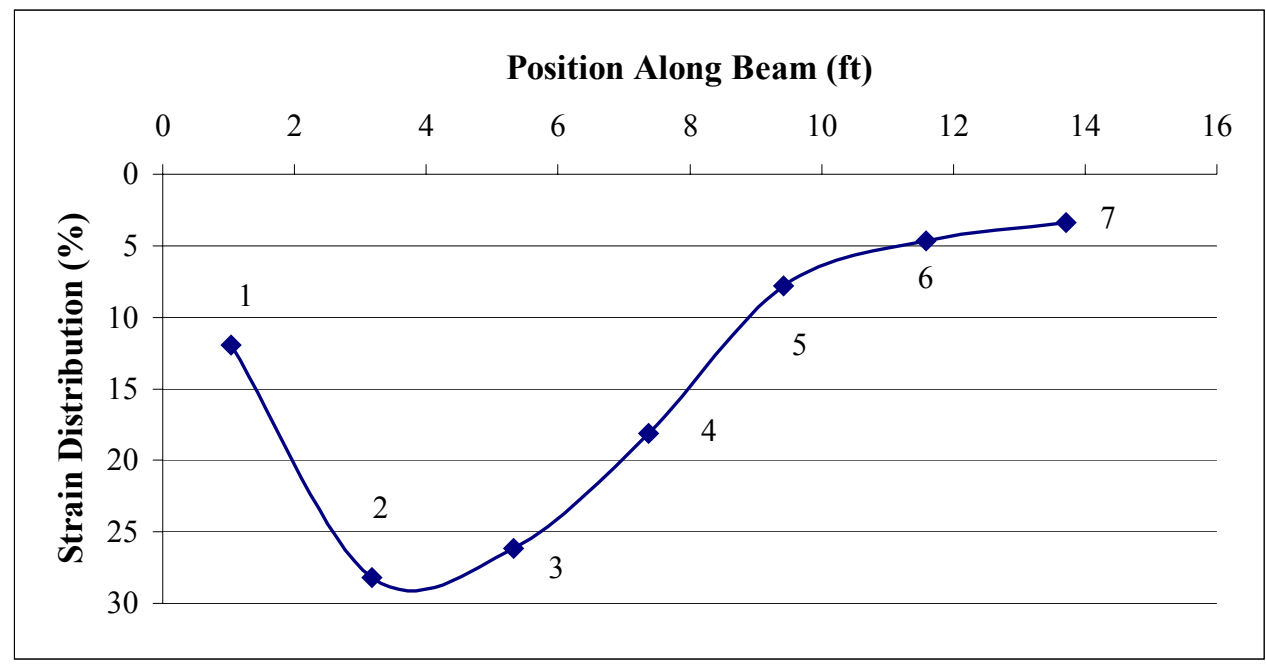

Figure 4.3.19. Strain Distribution for Load Applied in Middle of Outer Crossties

Figure 4.3.20 shows the change in pressure for the foundation for a single point loading in the middle of the outer crossties. This loading was approximately $4 \mathrm{ft}$ from the pressure cell location. The maximum load of 20 kips produced a pressure on the foundation at midspan of 1.85 psi.

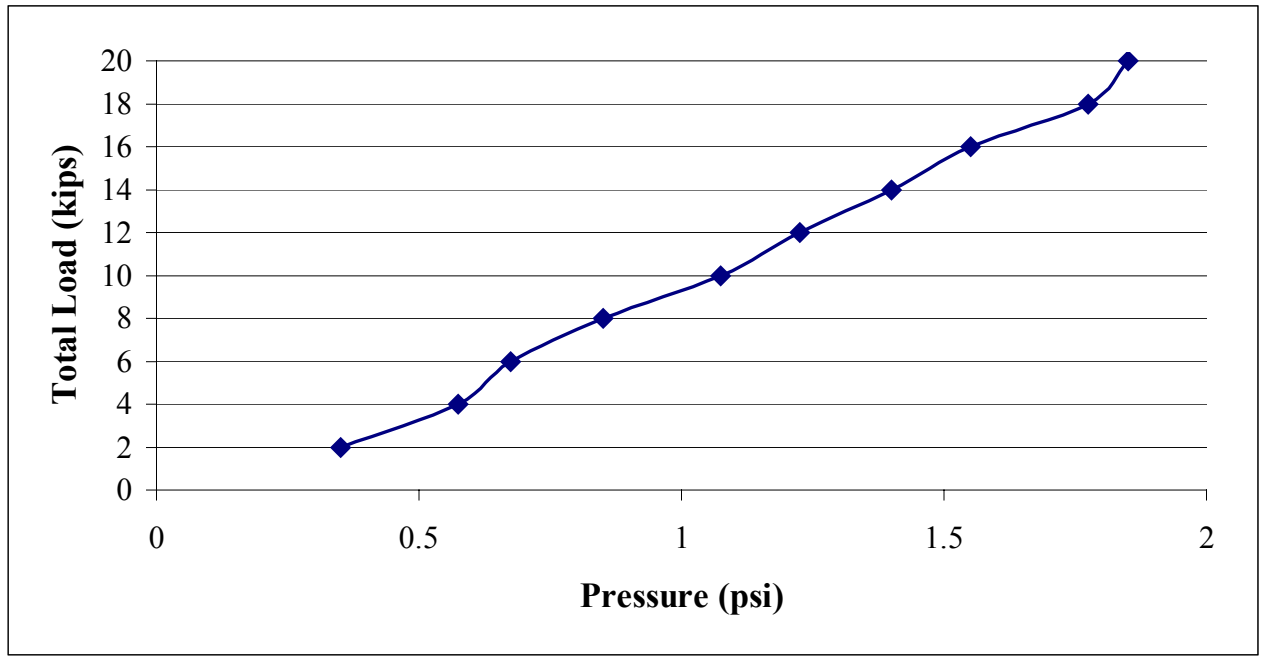

Figure 4.3.20. Load vs. Pressure for Load in Middle of Outer Crossties 


\subsubsection{Two Point Loads at Midspan}

The next series of tests consisted of two vertical point loads at midspan. The two point loads are designed to simulate the two axles of a "coal mine car" and are shown in Figure 4.3.21.
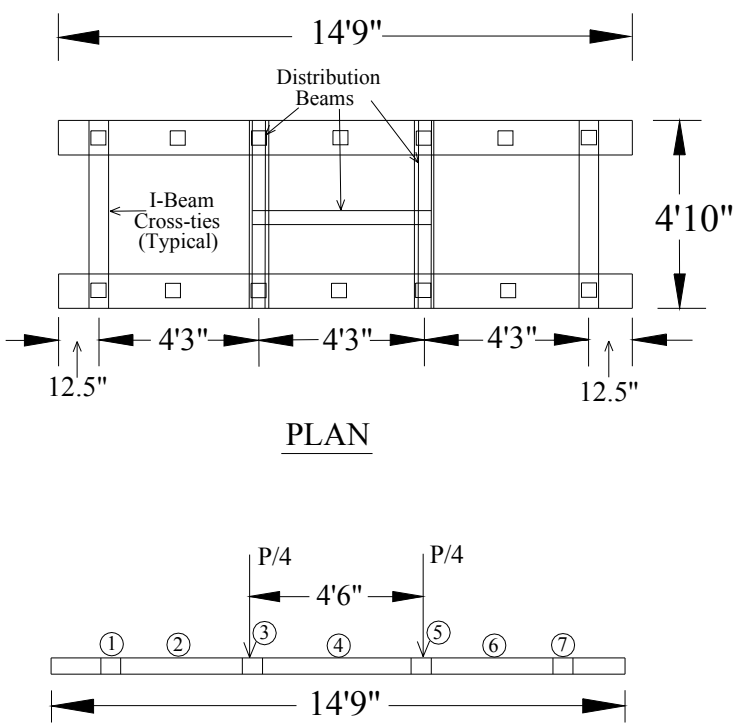

ELEVATION

Figure 4.3.21. Schematic for Application of Two Central Point Loads

A total load of 40 kips was applied and assuming equal distribution, each point load is equal to $\mathrm{P} / 4$. The maximum deflection was $93 \times 10^{-3}$ in for the 20 kip load per beam, while the deflection for 10 kips per beam was $58 \times 10^{-3}$ in. The beam response is shown in Figure 4.3.22.

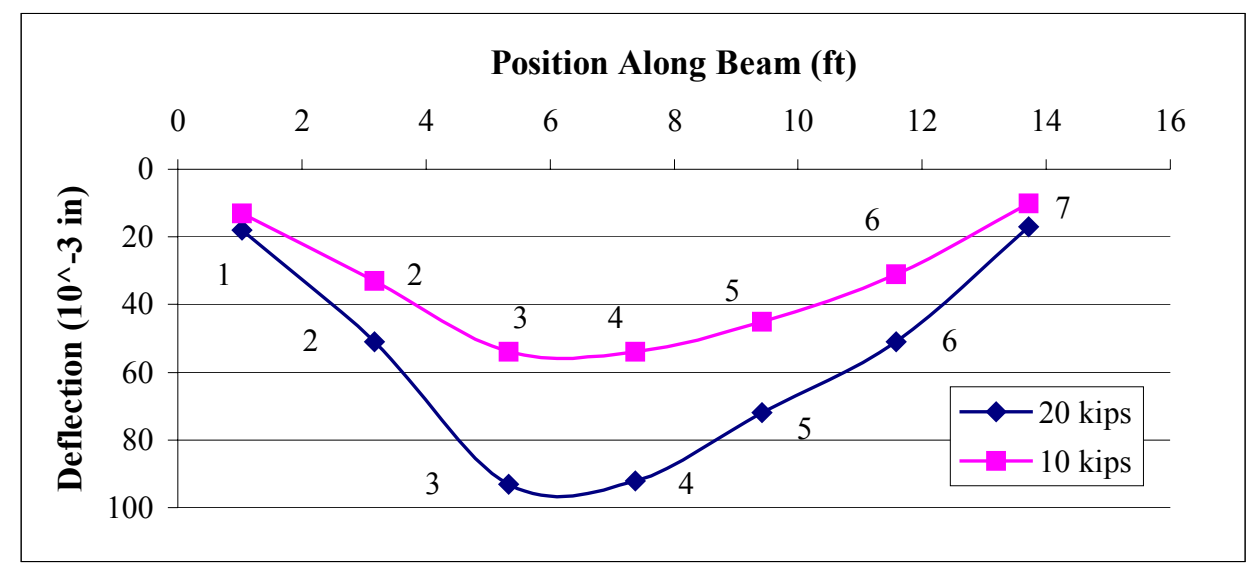

Figure 4.3.22. Deflection vs. Position at Indicated Loads for Two Point Loads At Midspan 
Figure 4.3.23 shows the load distribution based on deflection of the concrete beam at the maximum load on the beam (20 kips). Figure 4.3 .23 shows that $64 \%$ of the load acts at the central three pads (Pads 3, 4, and 5).

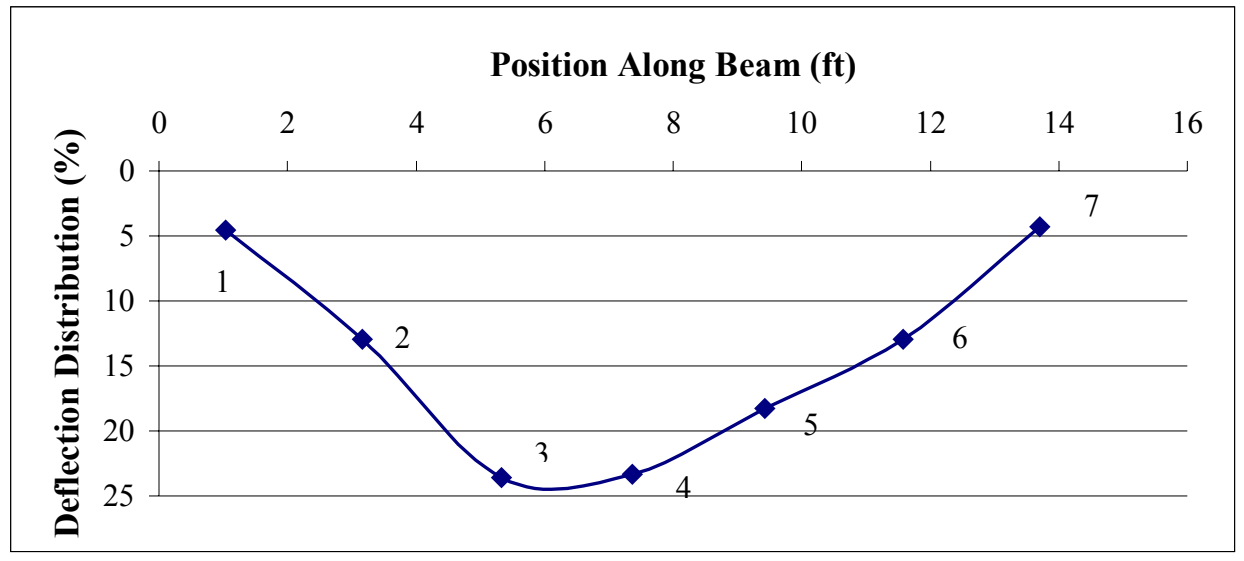

Figure 4.3.23. Deflection Distribution vs. Position for Two Point Loads at Midspan

Figures 4.3.24 and 4.3.25 show the results from the strain analysis. Figure 4.3.24 shows that the strain at midspan is less than at the load application points. Also, the beam exhibits nearly perfect symmetry under two-point loading. The maximum strain was $225 \times 10^{-6} \mathrm{in} / \mathrm{in}$ at the location of Pad 3.

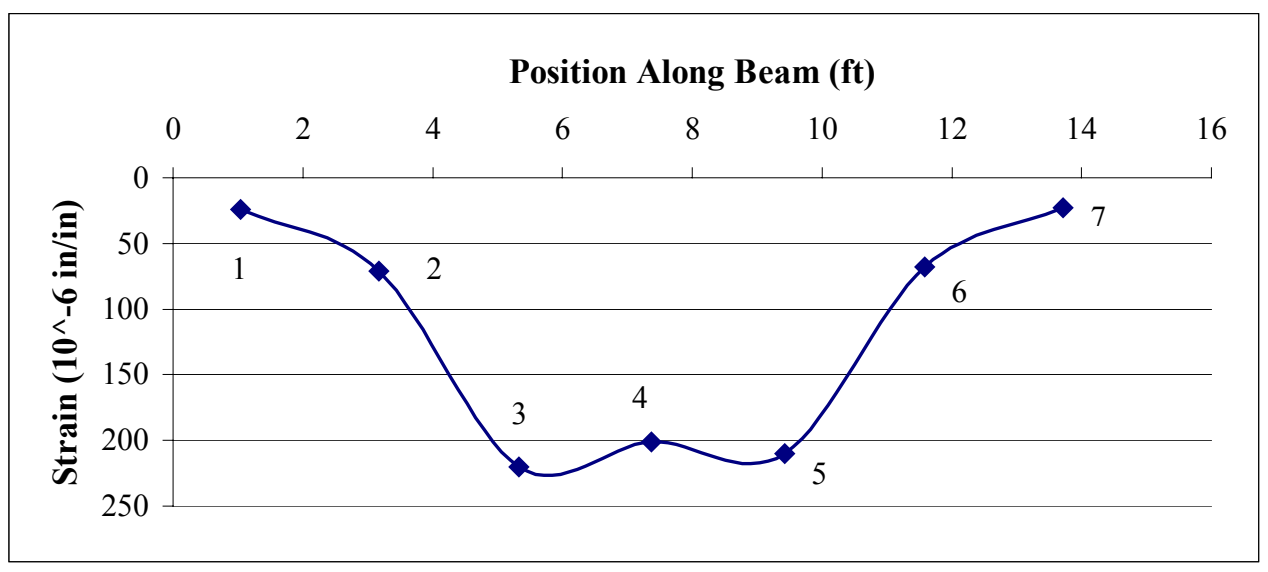

Figure 4.3.24. Strain vs. Position for Two Point Loads at Midspan 
Figure 4.3.25 shows that $77 \%$ of the load is distributed over the central three pads (Pads 3,4 , and $5)$.

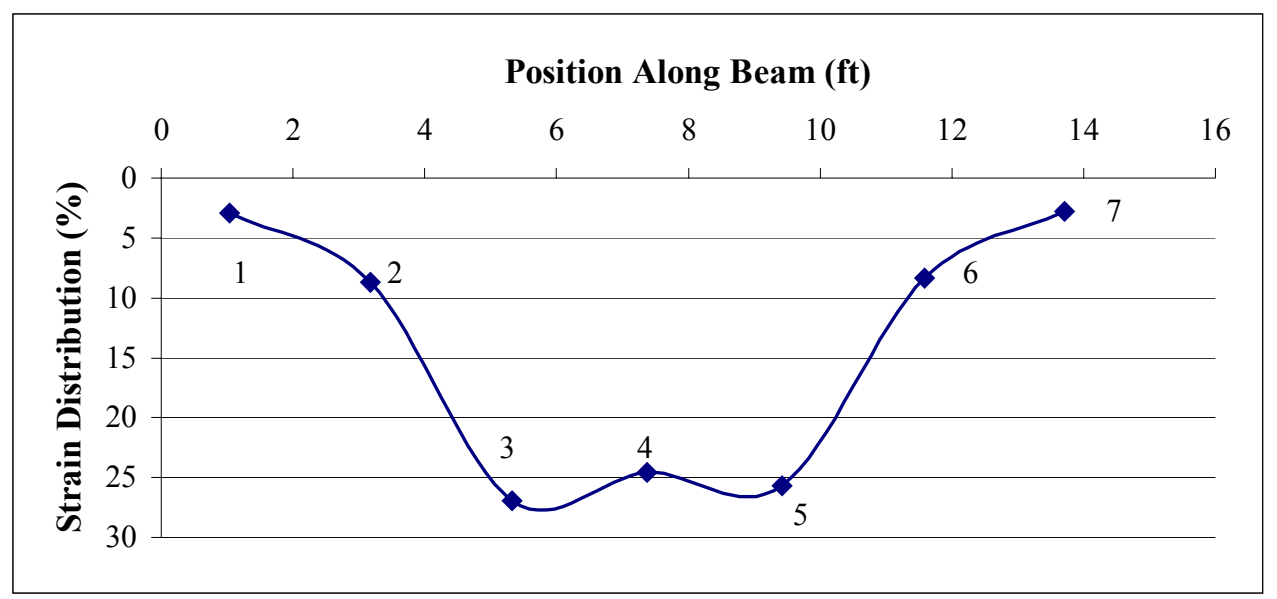

Figure 4.2.25. Strain Distribution for the Application of Two Point Loads At Midspan

Figure 4.3.26 shows the change in pressure experienced by the foundation under the panel. The maximum load of 40 kips produced a pressure of 45 psi.

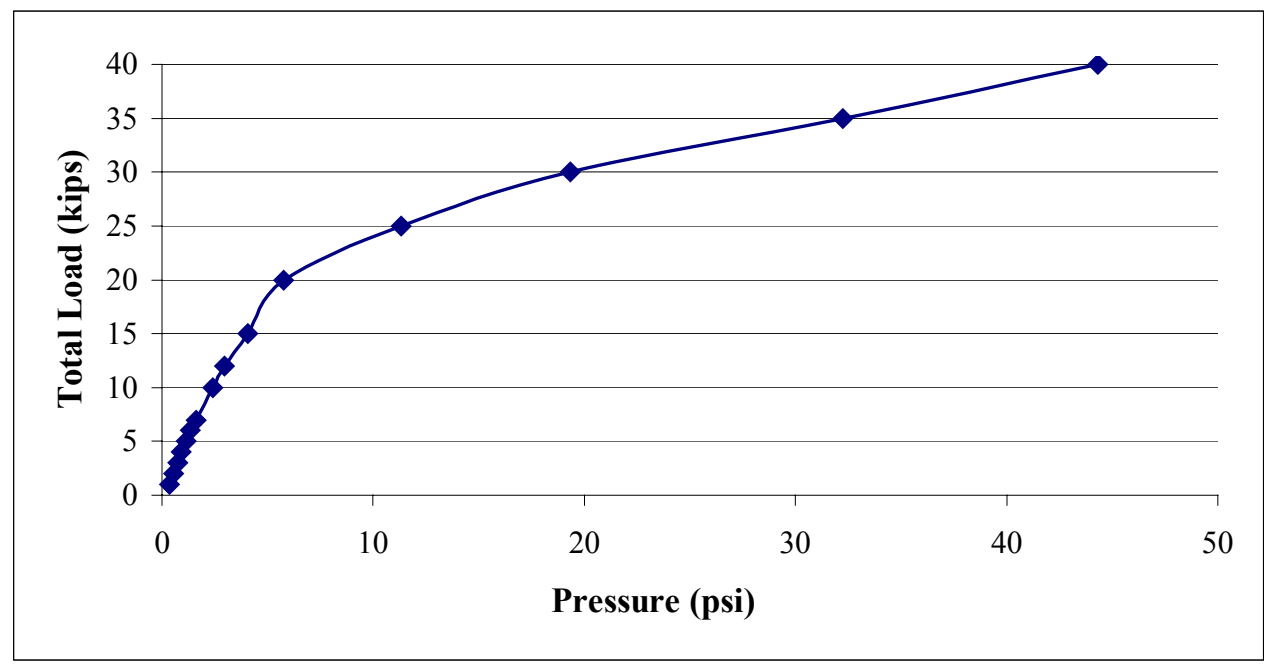

Figure 4.3.26. Load vs. Pressure for Two Point Loads Applied at Midspan

\subsubsection{Two Point Loads Over Left Interior Crosstie}

A test of two point loads over the left interior cross-tie was conducted next with distribution beams shown in Figure 4.3.27. 

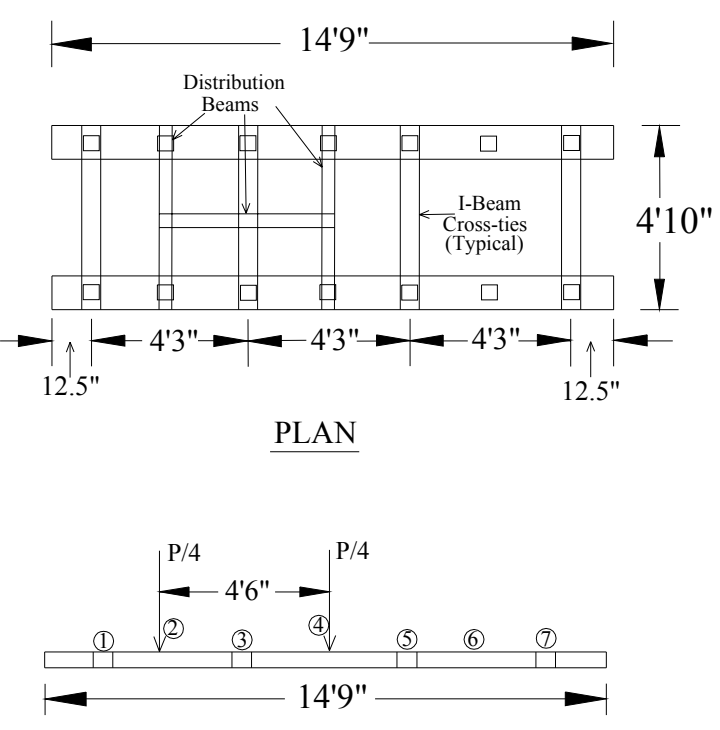

ELEVATION

Figure 4.3.27. Schematic of Interior Crosstie Two Point Load Application

The results from this test are shown in Figures 4.3.28 and 4.3.29. The maximum deflection at 20 kips on each beam was $95 \times 10^{-3}$ in and $80 \times 10^{-3}$ in for the $10 \mathrm{kip}$ loading, indicating the foundation acts like a nonlinear spring.

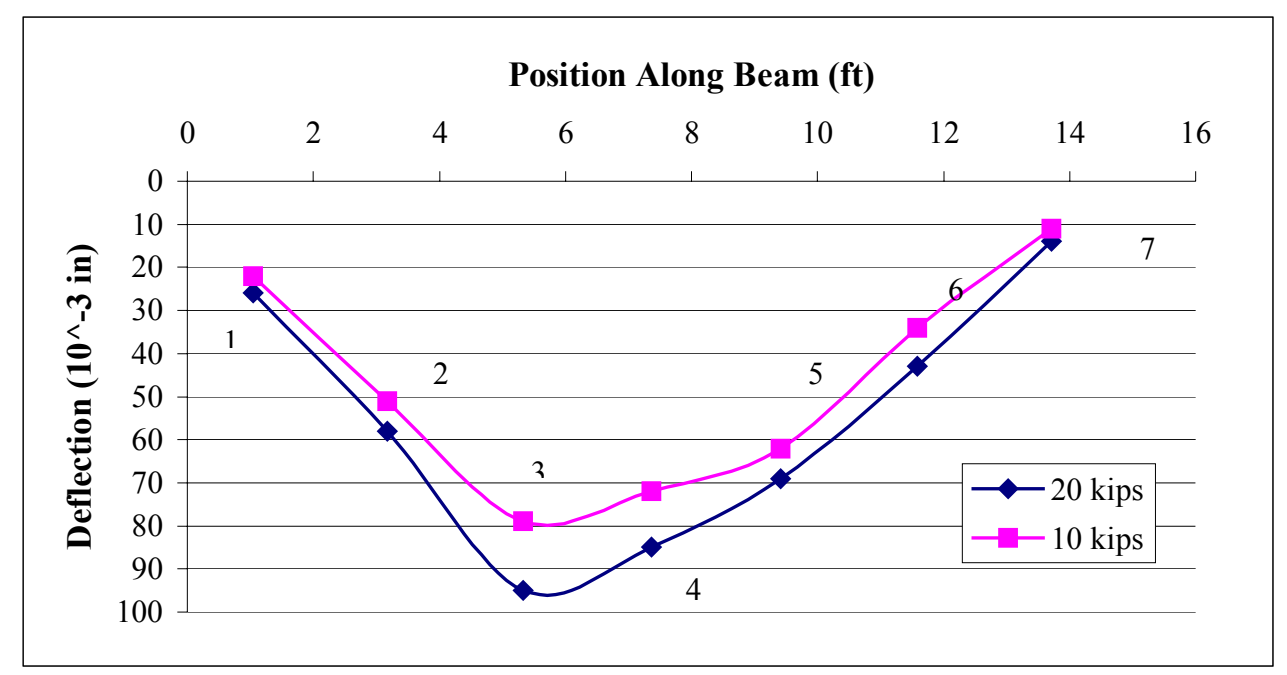

Figure 4.3.28. Deflection vs. Position for Two Point Loads Applied Over Left Interior Crosstie

Figure 4.3.29 shows the load distribution based on deflection for two points load applied over the left interior crosstie. Figure 4.3.29 shows that $59 \%$ of the load is distributed over the location of Pad 3 and the adjacent two pads (Pads 2 and 4). 


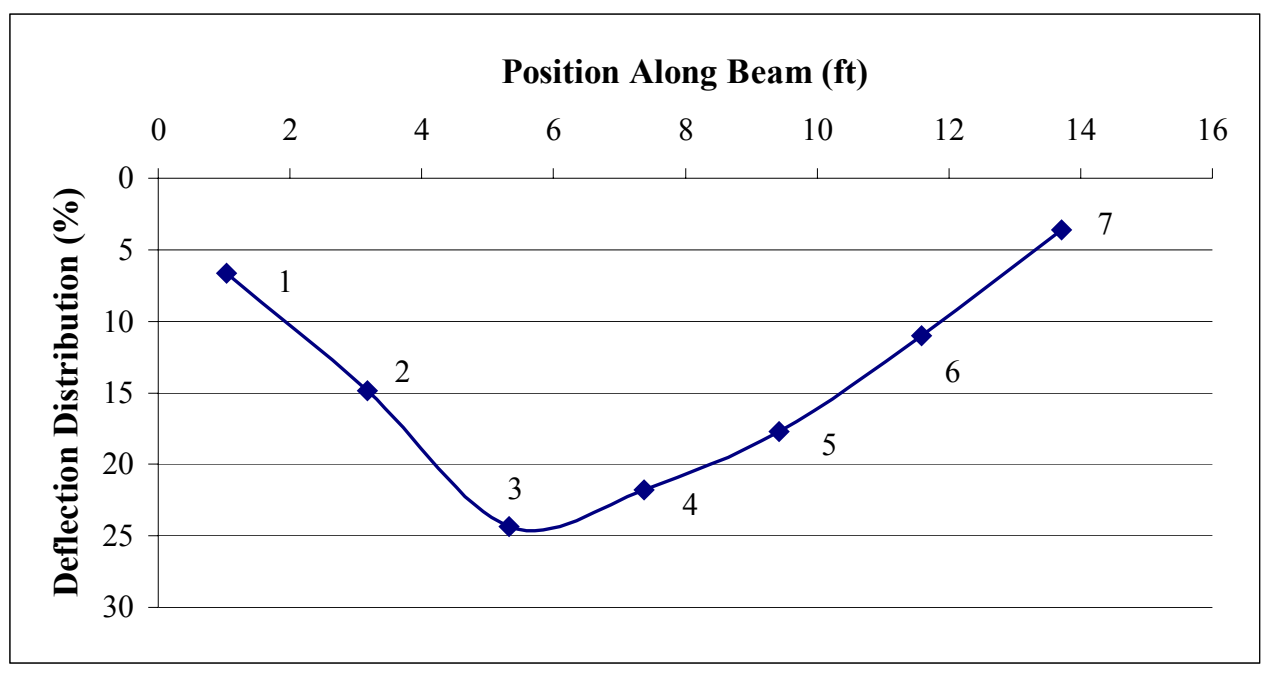

Figure 4.3.29. Deflection Distribution vs. Position for Two Point Loads Applied Over the Left Interior Crosstie

Figures 4.3.30 and 4.3.31 show the results of the strain analysis for the application of two point loads over the left interior crosstie. The maximum strain was $248 \times 10^{-6} \mathrm{in} / \mathrm{in}$ at or near the location of Pad 3.

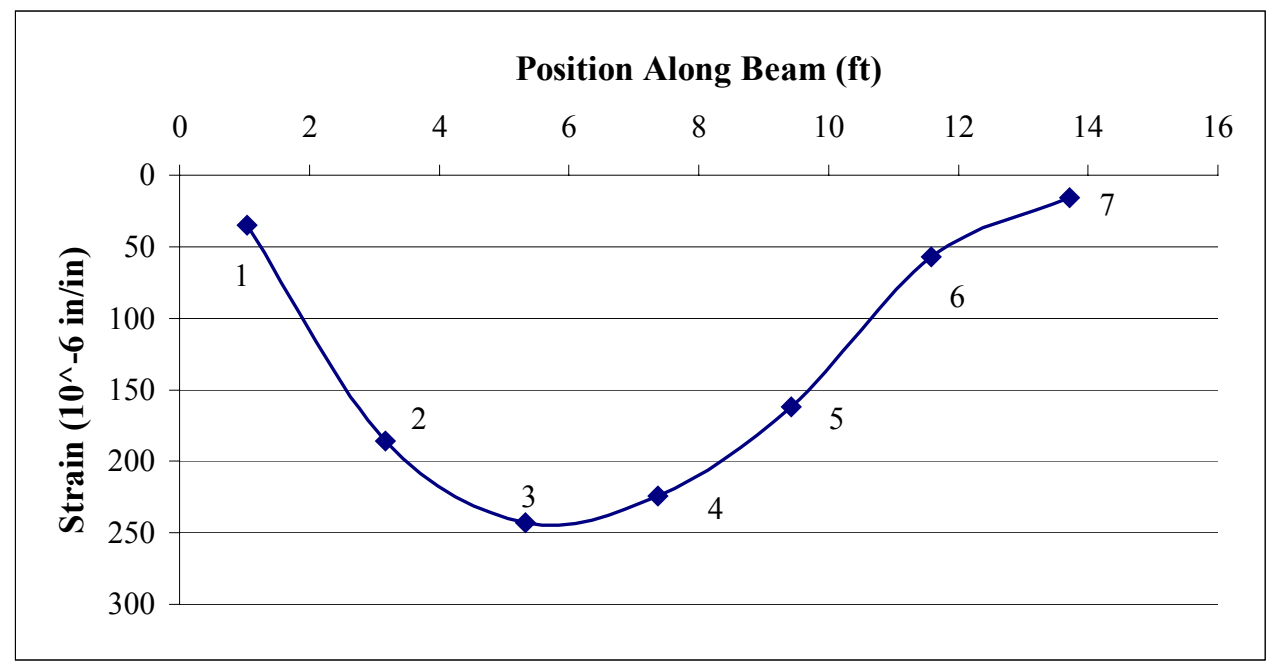

Figure 4.3.30. Strain vs. Position for Two Point Loads Applied At Left Interior Crosstie 
Figure 4.3 .31 shows that $69 \%$ of the load is distributed to the pad under the load and the adjacent two pads.

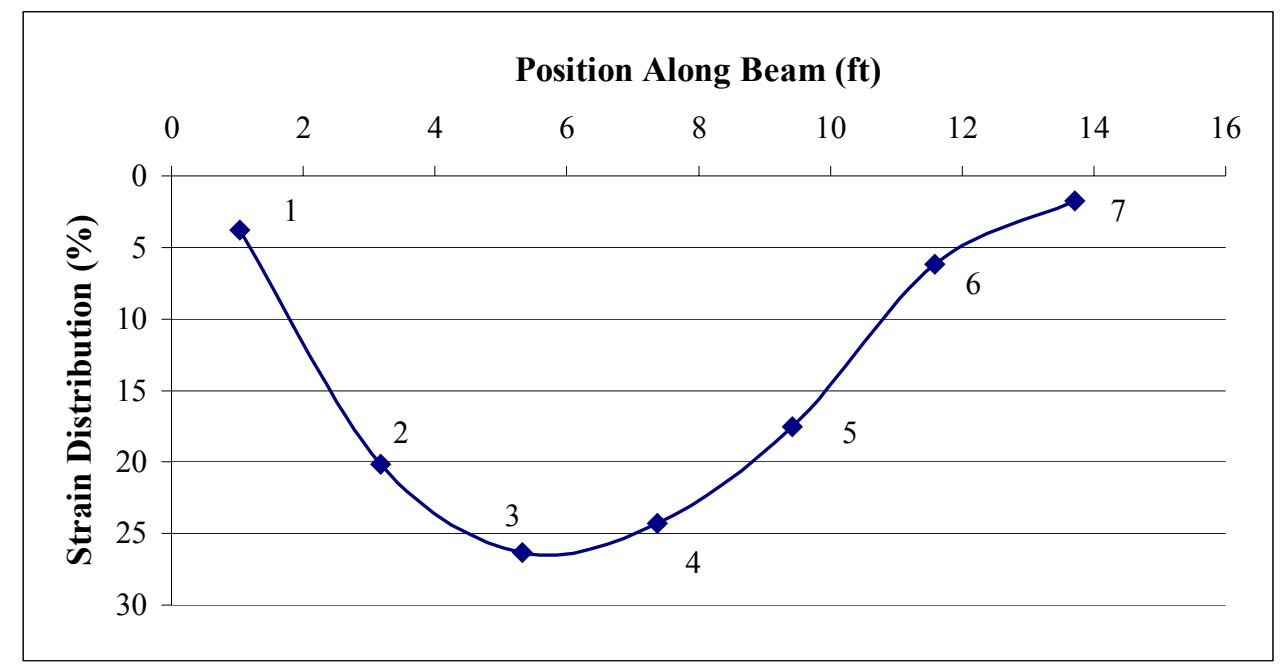

Figure 4.3.31. Strain Distribution vs. Position for Two Point Loads Applied At Left Interior Crosstie

Figure 4.2.32 shows the change in pressure experienced by the foundation under the panel. The maximum load of 40 kips produced a pressure of 48 psi. The pressure exhibits a nearly bilinear behavior.

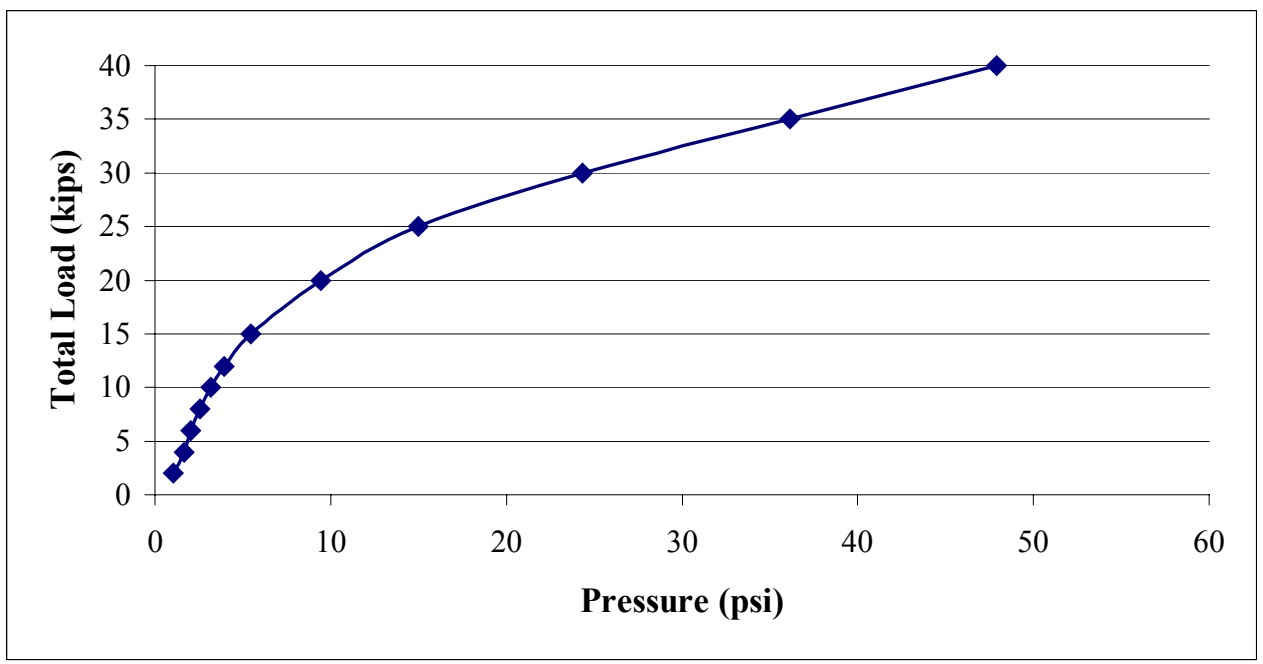

Figure 4.3.32. Load vs. Pressure Experienced by Foundation at Maximum Load for Application of Two Point Loads at Interior Crosstie 


\subsubsection{Two Point Loads Over Right Interior Crosstie}

Figure 4.3.33 shows the test set-up for a double point load of 10 kips each conducted over the right interior crosstie.
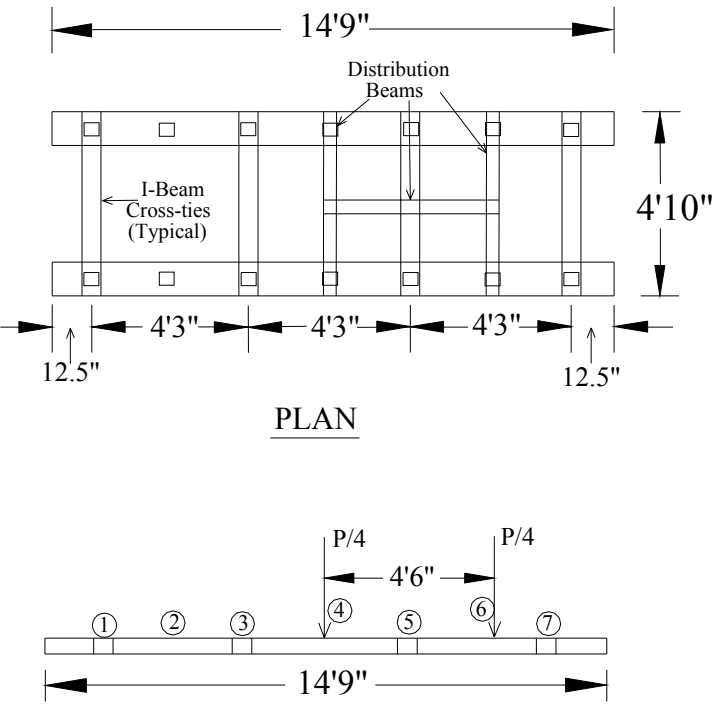

ELEVATION

Figure 4.3.33. Schematic of Interior Crosstie Two Point Load Application

Figures 4.3.34 and 4.3.35 show the deflection results of a test conducted over the right interior crossties. Figure 4.3.34 shows that the maximum deflection was $125 \times 10^{-3}$ in at or near the location of Pad 5 for the 20 kip loading.

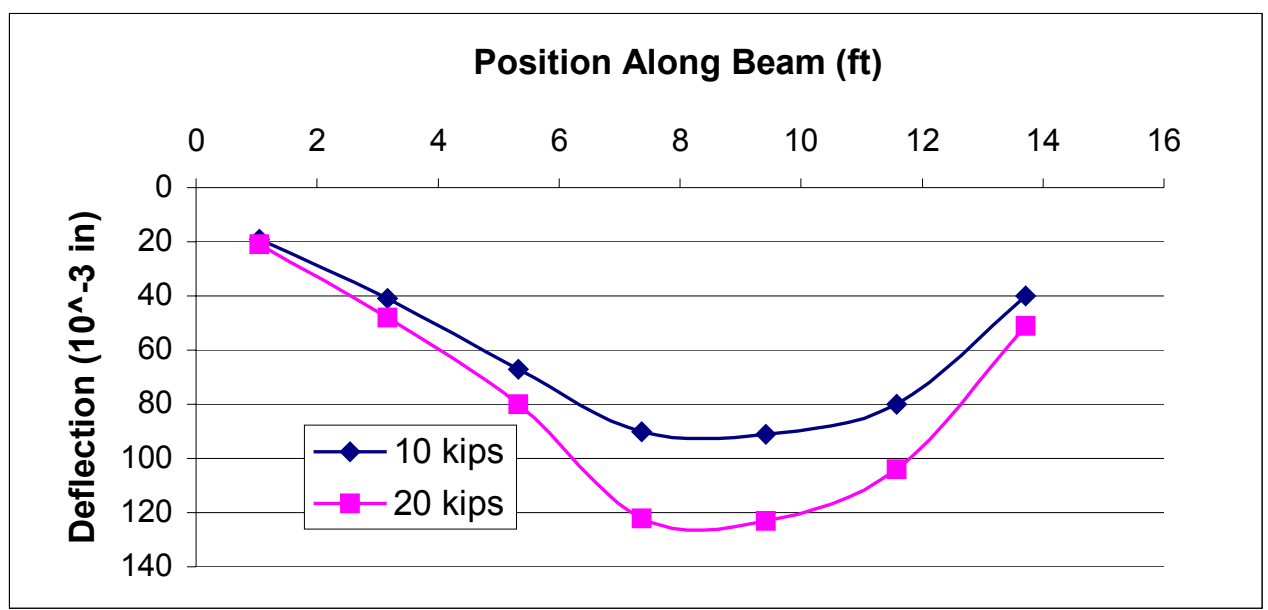

Figure 4.3.34. Deflection vs. Position for Two Point Loads Applied At Right Interior Crosstie 
Figure 4.3 .35 shows that $64 \%$ of the load is distributed to the pad under the load and the adjacent two pads (Pads 4, 5, and 6).

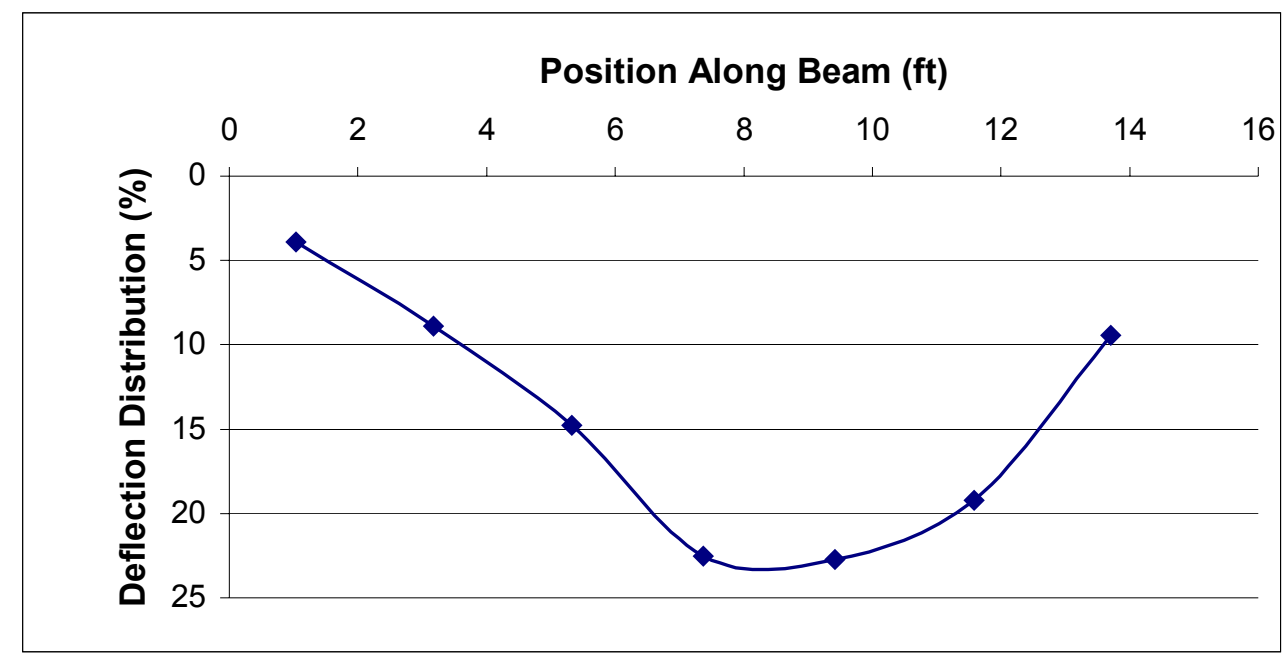

Figure 4.3.35. Load Distribution Based on Deflection for Application of Two Point Loads at Right Interior Crosstie

Figures 4.3.36 and 4.3.37 show the results of the experimental strain analysis for the application of two point loads over the right interior crosstie.

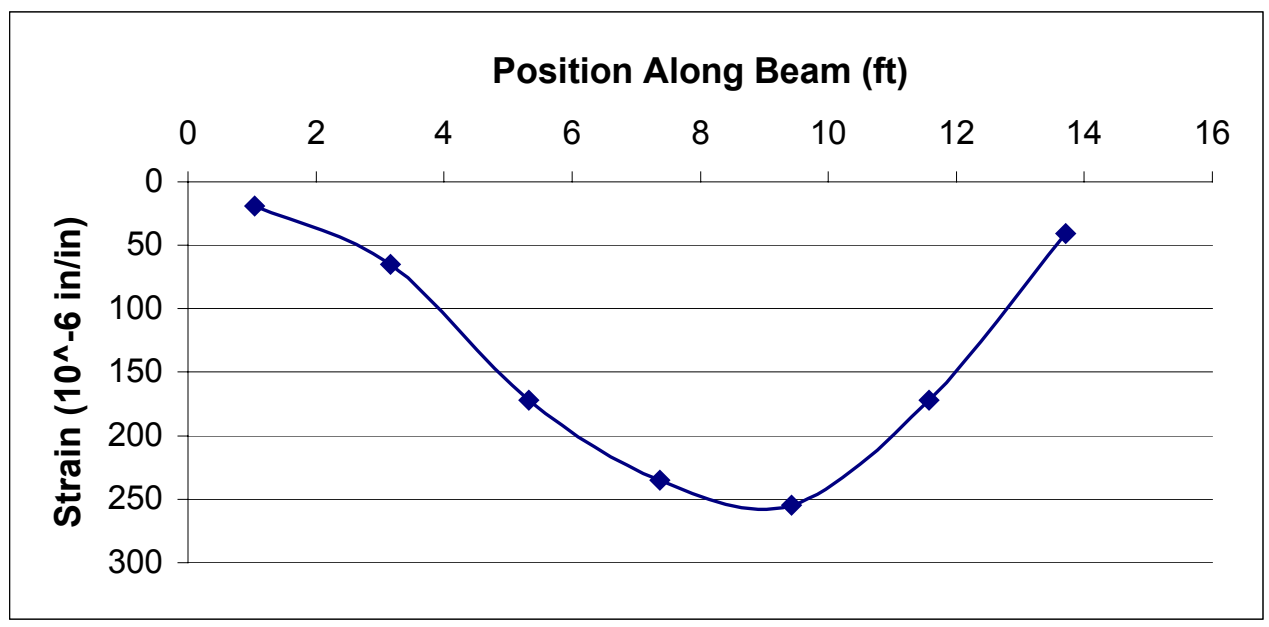

Figure 4.3.36. Strain vs. Position for Two Point Loads Applied At Right Interior Crosstie

The values from Figure 4.3.37 show that $69 \%$ of the load is distributed to the pad under the loading location and the adjacent two pads (Pads 4, 5, and 6). The strain distribution curve shape closely follows that of the deflection distribution curve shape. 


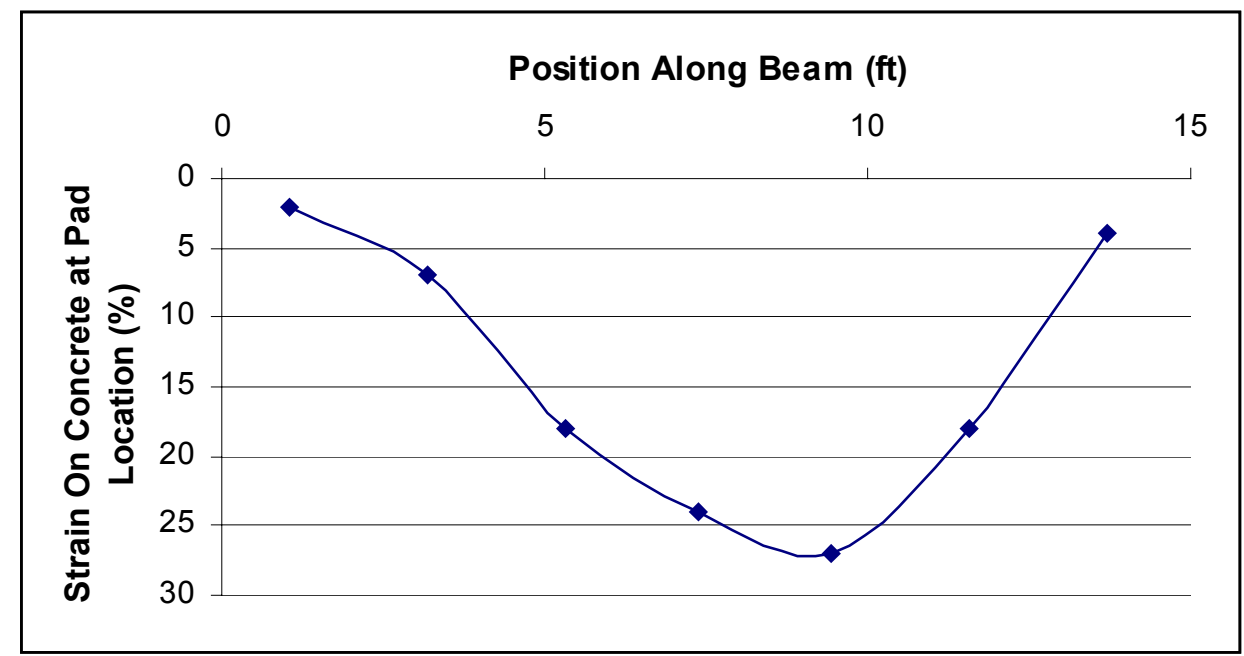

Figure 4.3.37. Strain Distribution vs. Position for Two Point Loads Applied At Right Interior Crosstie

The pressure for this test was exactly the same as for the static test conducted with double point loads applied over the left crosstie.

\subsubsection{Theoretical Comparisons}

The following tables and figures provide experimental deflection values along the length of the prestressed concrete beam and are compared to theoretical and finite element analysis. The theoretical values were obtained from the program Enercalc (see Section 3.3 for detail on Enercalc and Appendix A for deflection values). Enercalc has the ability to analyze beams on elastic foundations. The results of this program were verified for the test of a single point load at midspan by the beam on elastic foundation equations developed by Hetenyi (1946), which are based on the Winkler model. Finite element analysis was conducted on the prestressed concrete beams and the values are shown in Appendix C.

\subsection{Single Point Load at Midspan}

Tble 4.3.1 lists the values for each of the respective deflections at the maximum load of 10 kips per beam. Negative values of deflection indicate uplift. 
Table 4.3.1. Deflections at Pad Location for Respective Analysis.

\begin{tabular}{|c|c|c|c|}
\hline $\mathrm{Pad}$ & $\begin{array}{c}\text { Experimental } \\
\left(10^{-3} \mathrm{in}\right)\end{array}$ & $\begin{array}{c}\text { FEA } \\
\left(10^{-3} \mathrm{in}\right)\end{array}$ & $\begin{array}{c}\text { Theoretical } \\
\left(10^{-3} \text { in }\right)\end{array}$ \\
\hline 1 & 16 & -3 & -1 \\
\hline 2 & 35 & 11 & 8 \\
\hline 3 & 59 & 30 & 32 \\
\hline 4 & 65 & 42 & 50 \\
\hline 5 & 50 & 30 & 32 \\
\hline 6 & 34 & 11 & 8 \\
\hline 7 & 15 & -3 & -1 \\
\hline
\end{tabular}

The values in Table 4.3.1 are shown graphically in the Figure 4.3.38.

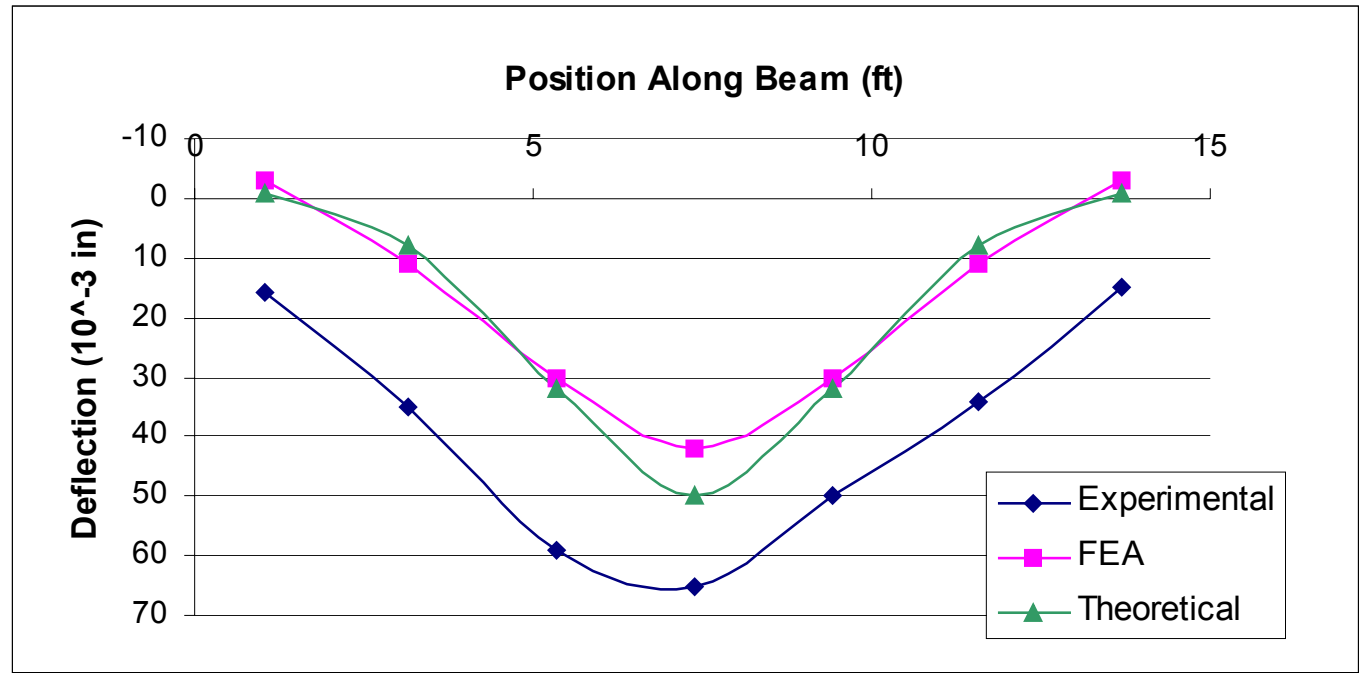

Figure 4.3.38. Deflection Results for Single Point Load at Midspan

The theoretical and FEA results compare very well. However, the experimental deflections are approximately 30\% higher, but follow the same trend. Given the order of magnitude, however, the experimental results compare reasonably well to the theoretical values, only 0.015 in higher. This is due to the subgrade modulus having a direct relationship to load. As the load increases, so does the subgrade modulus, yielding lesser deflection values.

\subsection{Single Point Load at Left Crosstie}

Table 4.3.2 lists the values of deflection for the indicated analysis at the maximum load of 10 kips per beam. Negative values indicate uplift. The reasons for the discrepancy of the deflection values could be due to dial gage errors and the subgrade modulus not being linear with load. 
Table 4.3.2. Deflection for Single Point Load at Left Interior Crosstie

\begin{tabular}{|c|c|c|c|}
\hline Pad & $\begin{array}{c}\text { Experimental } \\
\left(10^{-3} \mathrm{in}\right)\end{array}$ & $\begin{array}{c}\text { FEA } \\
\left(10^{-3} \mathrm{in}\right)\end{array}$ & $\begin{array}{c}\text { Theoretical } \\
\left(10^{-3} \mathrm{in}\right)\end{array}$ \\
\hline 1 & 18 & 8 & 5 \\
\hline 2 & 47 & 35 & 36 \\
\hline 3 & 76 & 41 & 54 \\
\hline 4 & 70 & 25 & 32 \\
\hline 5 & 55 & 15 & 10 \\
\hline 6 & 27 & 4 & 1 \\
\hline 7 & 8 & -3 & -2 \\
\hline
\end{tabular}

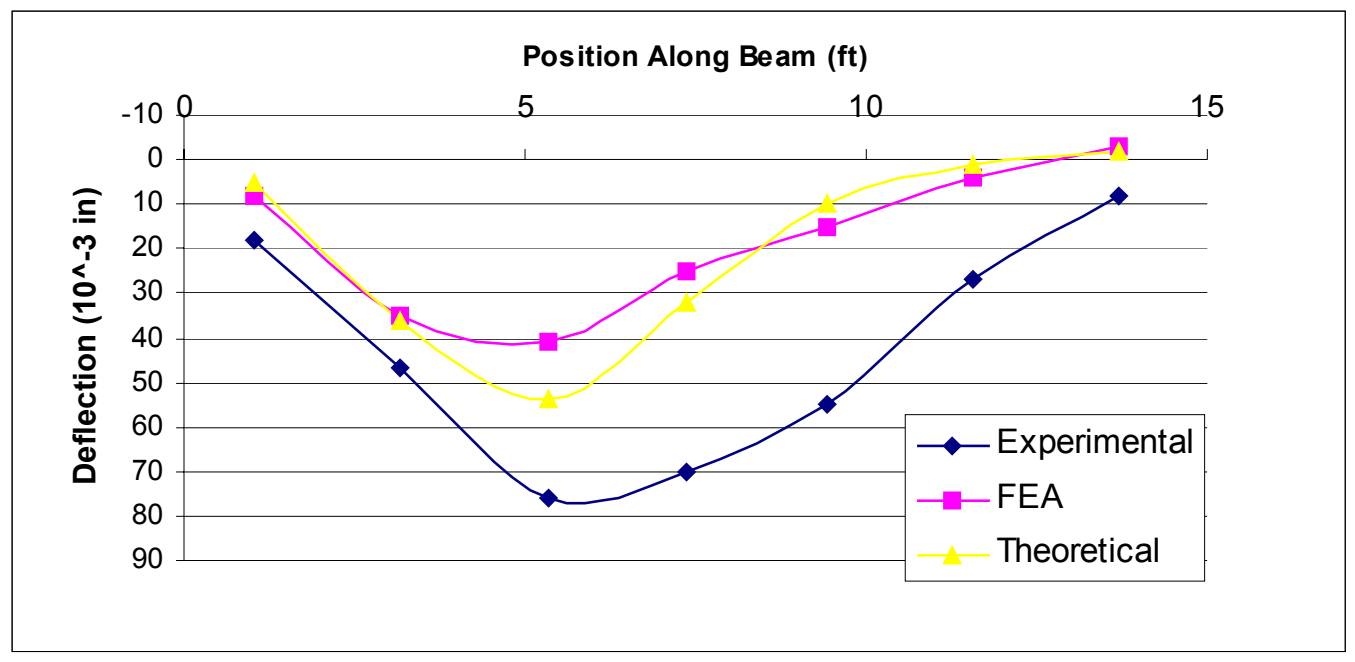

Figure 4.3.39. Deflection for Indicated Analysis for Single Point Load at Left Interior Crosstie

Figure 4.3.39 shows the deflected shape of the beam for the indicated analysis type. At the loading point, the experimental deflection is 0.022 in (29\%) higher than the theoretical value.

\subsection{Single Point Load in Middle of Outer Crossties}

Table 4.3.3 lists the values for deflections for a single point load in the middle of the outer crossties at the maximum load of 10 kips per beam. 
Table 4.3.3. Deflections for Single Point Load in Middle Of Outer Crossties

\begin{tabular}{|c|c|c|c|}
\hline Pad & $\begin{array}{c}\text { Experimental } \\
\left(10^{-3} \mathrm{in}\right)\end{array}$ & $\begin{array}{c}\text { FEA } \\
\left(10^{-3} \mathrm{in}\right)\end{array}$ & $\begin{array}{c}\text { Theoretical } \\
\left(10^{-3} \mathrm{in}\right)\end{array}$ \\
\hline 1 & 33 & 37 & 32 \\
\hline 2 & 65 & 55 & 52 \\
\hline 3 & 64 & 36 & 34 \\
\hline 4 & 57 & 28 & 25 \\
\hline 5 & 42 & 12 & -1 \\
\hline 6 & 26 & -2 & -2 \\
\hline 7 & 9 & -4 & -1 \\
\hline
\end{tabular}

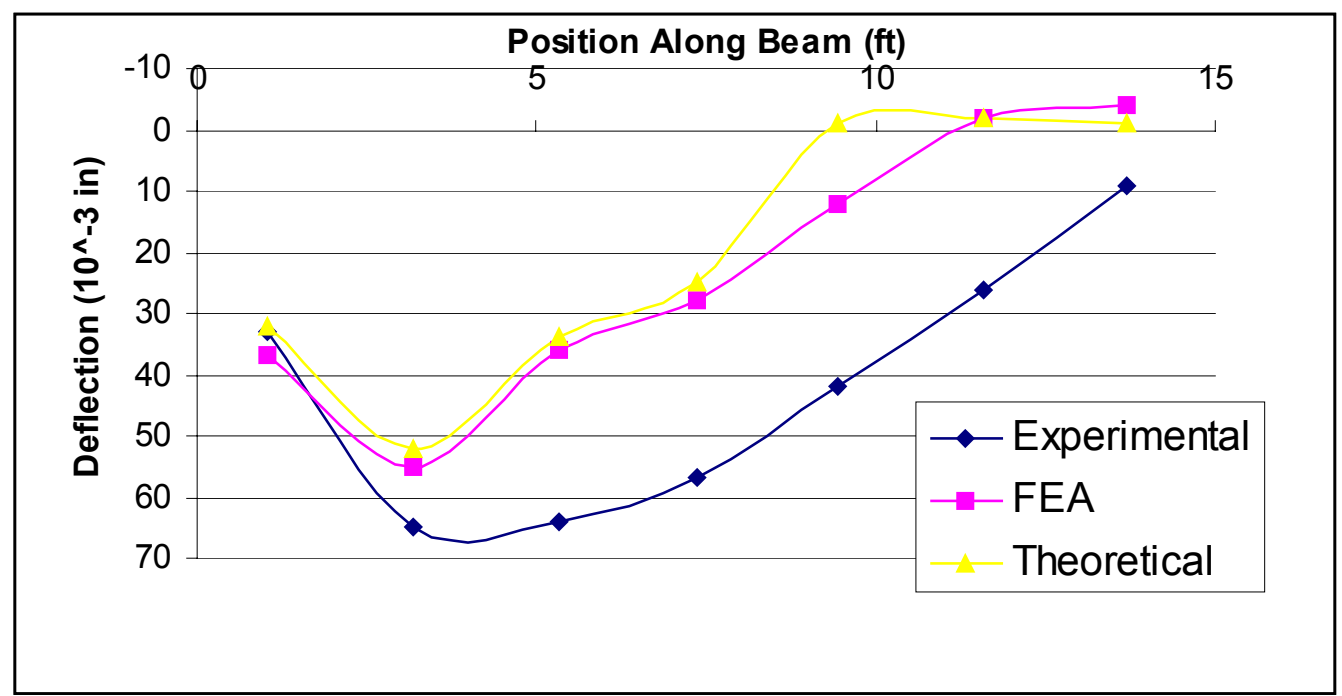

Figure 4.3.40. Deflection for Indicated Analysis for Single Point Load in Middle Of Outer Crossties

Figure 4.3.40 shows the deflected shape of the beams when the load is applied between the outer crossties. The experimental deflection obtained is 0.010 in higher $(15 \%)$ than the theoretical and FEA values.

\subsection{Two Point Loads at Midspan}

Table 4.3.4 lists the values for deflections for two point loads centered at midspan at the maximum load of 20 kips per beam. Negative values indicate uplift. 
Table 4.3.4. Deflections for Two Point Loads at Midspan

\begin{tabular}{|c|c|c|c|}
\hline Pad & $\begin{array}{c}\text { Experimental } \\
\left(10^{-3} \mathrm{in}\right)\end{array}$ & $\begin{array}{c}\text { FEA } \\
\left(10^{-3} \mathrm{in}\right)\end{array}$ & $\begin{array}{c}\text { Theoretical } \\
\left(10^{-3} \mathrm{in}\right)\end{array}$ \\
\hline 1 & 18 & 5 & -11 \\
\hline 2 & 51 & 33 & 34 \\
\hline 3 & 93 & 53 & 65 \\
\hline 4 & 92 & 57 & 66 \\
\hline 5 & 72 & 53 & 65 \\
\hline 6 & 51 & 33 & 34 \\
\hline 7 & 17 & 5 & -11 \\
\hline
\end{tabular}

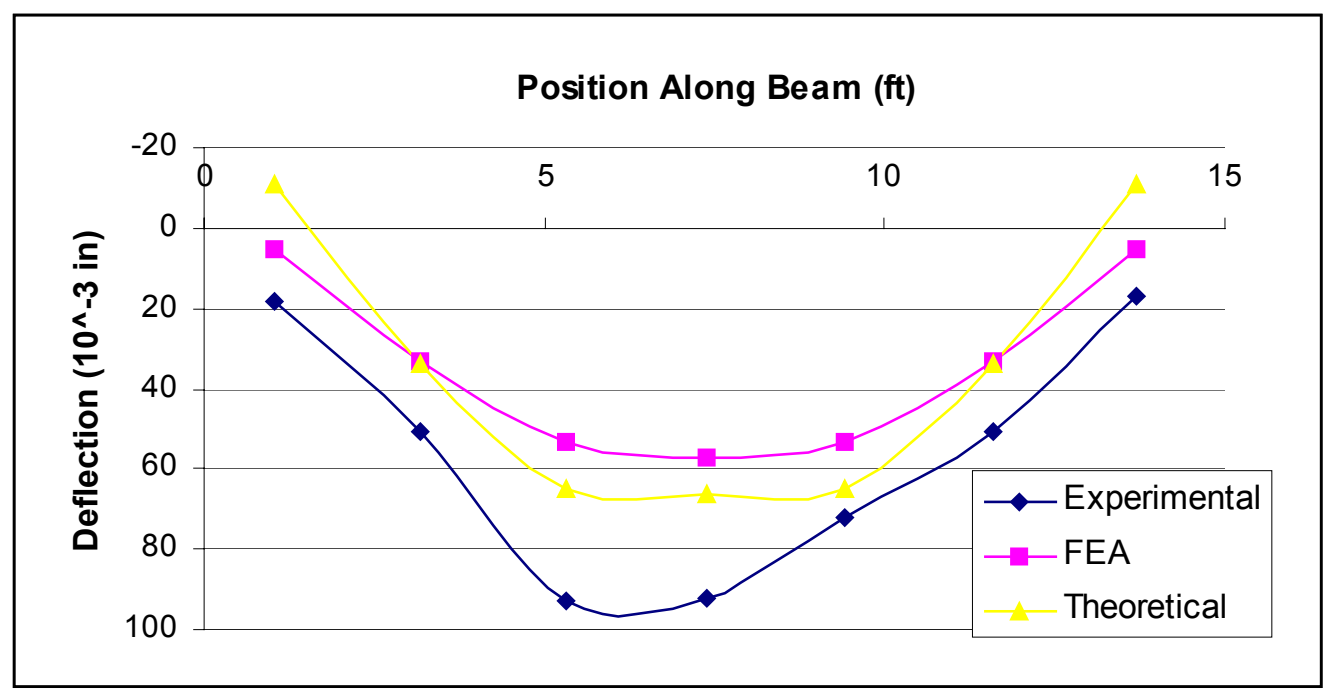

Figure 4.3.41. Deflections for Indicated Analysis for Two Point Loads at Midspan

Figure 4.3.41 shows the deflected shape of the beam when the two loads are applied over the center of the panel. The experimental deflection obtained is 0.026 in (28\%) higher than the theoretical value.

\subsection{Two Point Loads at Left Interior Crosstie}

Table 4.3.5 lists the values of deflection for the applied double load being at the left interior cross-tie at the maximum load of 20 kips per beam. 
Table 4.3.5. Deflections for Two Point Loads at Left Interior Crosstie

\begin{tabular}{|c|c|c|c|}
\hline Pad & $\begin{array}{c}\text { Experimental } \\
\left(10^{-3} \mathrm{in}\right)\end{array}$ & $\begin{array}{c}\text { FEA } \\
\left(10^{-3} \mathrm{in}\right)\end{array}$ & $\begin{array}{c}\text { Theoretical } \\
\left(10^{-3} \mathrm{in}\right)\end{array}$ \\
\hline 1 & 26 & 36 & 22 \\
\hline 2 & 58 & 53 & 58 \\
\hline 3 & 95 & 65 & 62 \\
\hline 4 & 85 & 59 & 59 \\
\hline 5 & 69 & 41 & 44 \\
\hline 6 & 43 & 9 & 8 \\
\hline 7 & 14 & -5 & -4 \\
\hline
\end{tabular}

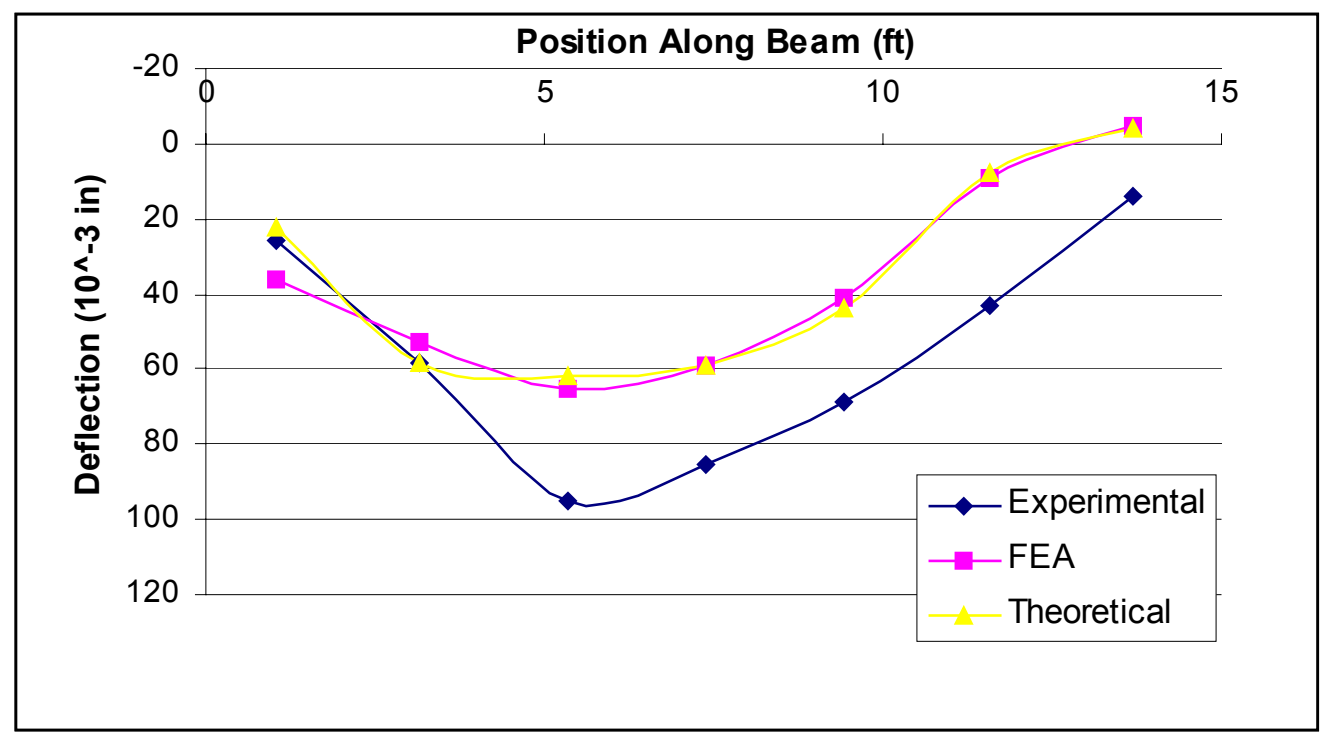

Figure 4.3.42. Deflection Analysis for Two Point Loads at Left Interior Crosstie

Figure 4.3.42 shows the deflected shape of the beam for the two point loads being applied over the left interior crosstie. The experimental deflection obtained is $0.030(31 \%)$ in higher than the theoretical and FEA values.

\subsubsection{Fatigue Testing}

The concrete panel was subjected to a dynamic loading cycle using a single point load at midspan at a frequency of $1 \mathrm{~Hz}$ and a load of $20 \mathrm{kips}$. The dynamic loading was conducted to determine the change in stiffness of the concrete beam due to simulated passage of "mine cars." Deflection was measured at every pad location and compared to the deflection to a static load 
test from a single point load at midspan test before applying the dynamic loading. Static tests were conducted after 250,000 and 500,000 cycles had been applied.

Figure 4.3.43 shows the deflection of the concrete beam after 250,000 and 500,000 cycles of applied load compared to the beam before fatigue testing.

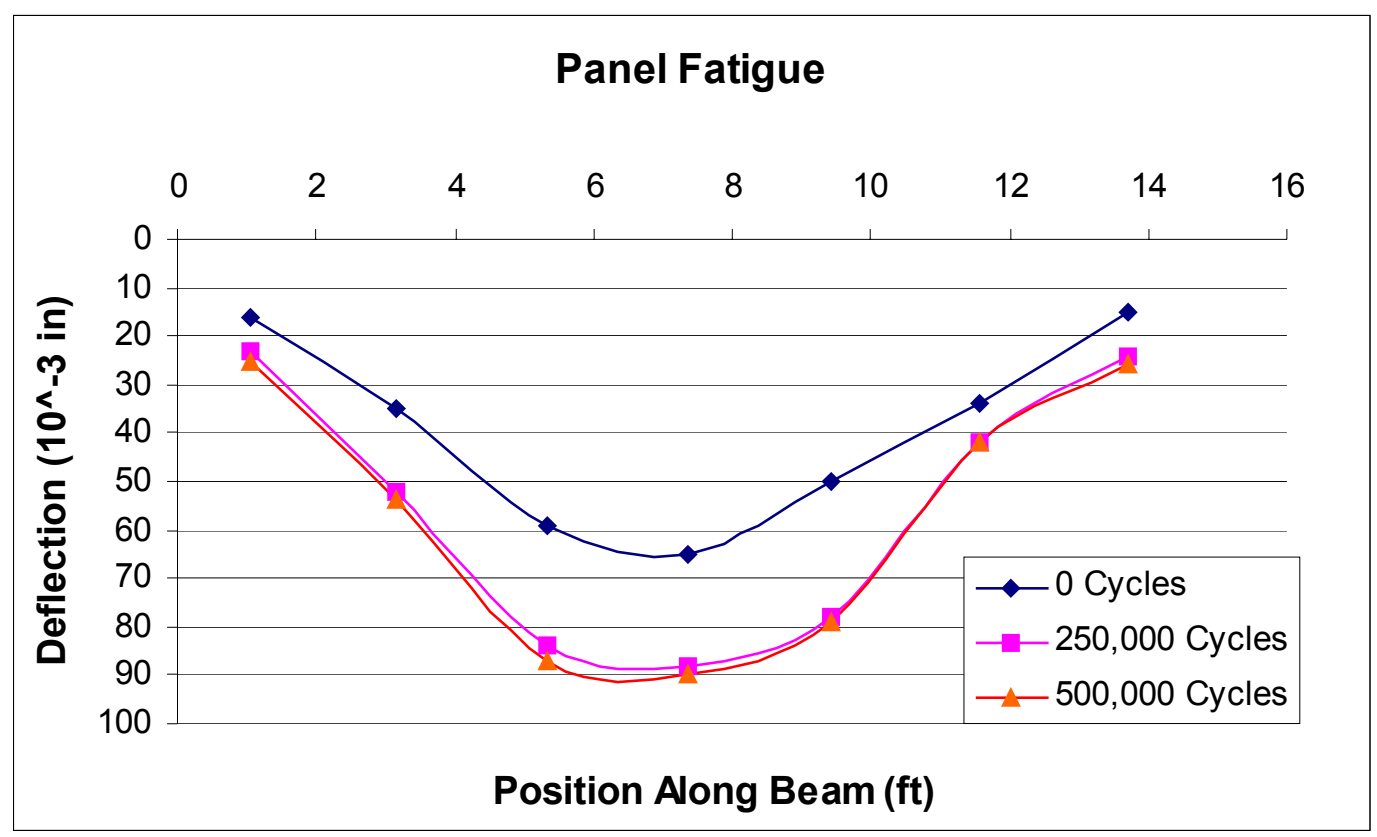

Figure 4.3.43. Deflection of the Concrete Beam after Indicated Fatigue Cycles

As can be seen from Figure 4.3.43, deflection increased significantly (38\%) after applying 250,000 cycles. After 500,000 cycles, however, deflection was nearly the same at every pad location. This may be an indication that the foundation was compacted during the initial 250,000 cycles.

Figure 4.3.44 shows the stiffnesses of the concrete beam for the static tests conducted after fatigue testing. 


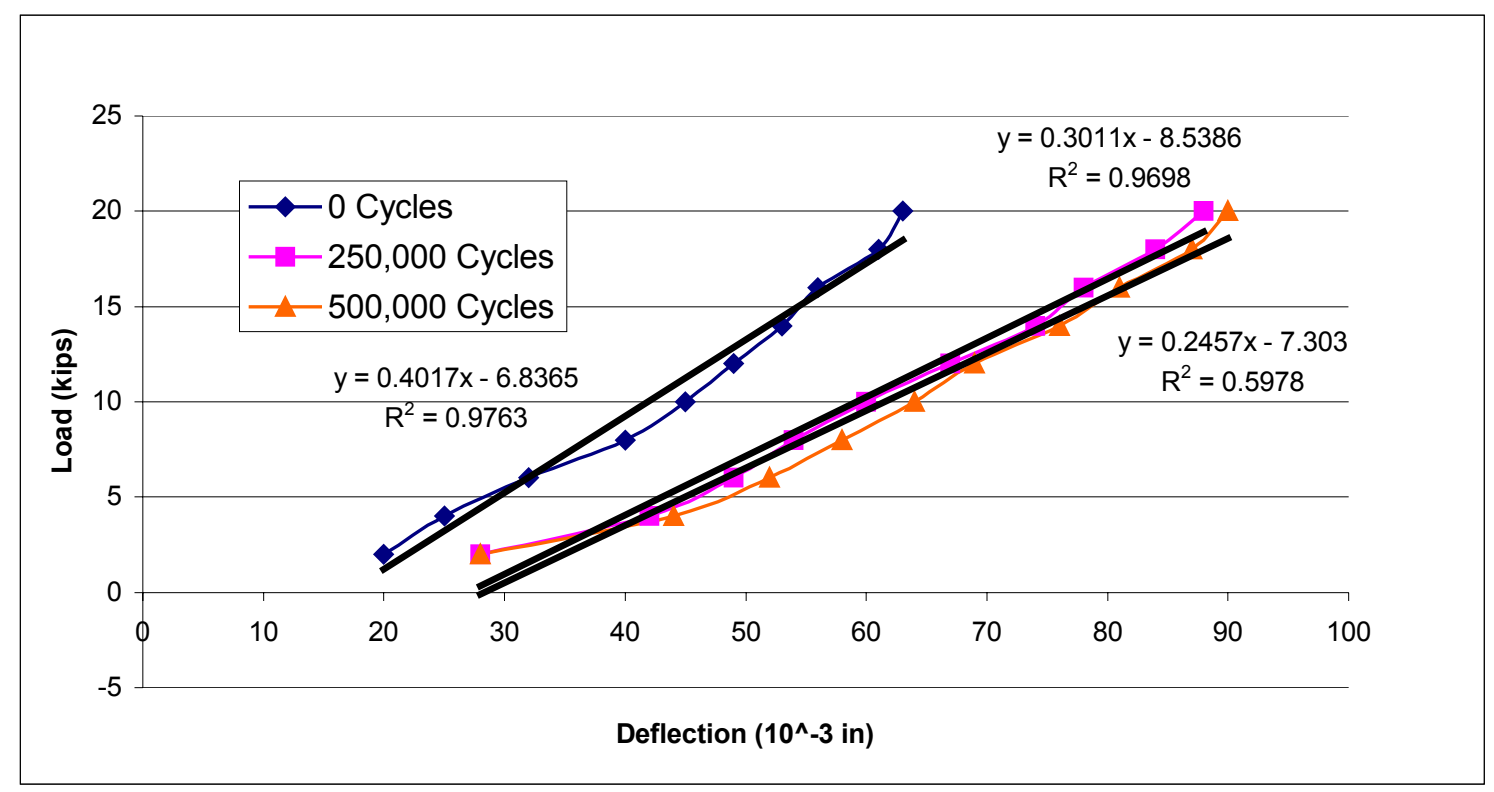

Figure 4.3.44. Stiffness of Concrete Beam after Indicated Fatigue Loading Cycles

Figure 4.3.44 shows that the stiffness of the beam before testing was calculated to be $402 \mathrm{lb} / \mathrm{in}$ using simple regression analysis. After 250,000 cycles, the stiffness was calculated to be 301 $\mathrm{lb} /$ in, a decrease of $25 \%$. The stiffness after 500,000 cycles was calculated to be $246 \mathrm{lb} / \mathrm{in}$, a decrease of $39 \%$ compared to the beam before fatigue testing began. However, the decrease in stiffness from 250,000 to 500,000 cycles is only $22 \%$, which is primarily due to compaction of the gravel foundation.

Table 4.3.6 presents deflection values for each pad at the indicated number of cycles at the maximum load of 20 kips.

Table 4.3.6. Deflection of Concrete Beam at Indicated Pad Location

\begin{tabular}{|c|c|c|c|}
\hline $\begin{array}{c}\text { Pad } \\
\text { Number }\end{array}$ & $\begin{array}{c}\text { Deflection Before } \\
\text { Fatigue Testing }\left(10^{-3} \text { in }\right)\end{array}$ & $\begin{array}{c}\text { Deflection After } \\
250,000 \text { Cycles }\left(10^{-3} \text { in) }\right.\end{array}$ & $\begin{array}{c}\text { Deflection After } \\
500,000 \text { Cycles }\left(10^{-3} \text { in }\right)\end{array}$ \\
\hline \hline 1 & 16 & 23 & 25 \\
\hline 2 & 35 & 52 & 54 \\
\hline 3 & 59 & 84 & 87 \\
\hline 4 & 65 & 88 & 90 \\
\hline 5 & 50 & 78 & 79 \\
\hline 6 & 34 & 42 & 42 \\
\hline 7 & 15 & 24 & 26 \\
\hline
\end{tabular}




\subsubsection{Summary and Conclusions of Full-Size Prestressed Concrete Panel 2}

- The deflection and strain distribution primarily occur in a $5 \mathrm{ft}$ band ( $2.5 \mathrm{ft}$ each direction) of the loading location. The deflection is in global terms while the strain is more localized.

- The maximum deflection for single point loads with a maximum load of 10 kips per beam is in the range of $75 \times 10^{-3}$ to $80 \times 10^{-3} \mathrm{in}$. The maximum deflection for double point loads with a maximum load of 20 kips per beam is in the range of $90 \times 10^{-3}$ to $95 \times 10^{-3} \mathrm{in}$. This small change in deflections from single point loads to double point loads is due to the subgrade behaving nonlinearly.

- Maximum strains for single point loads are in the range of $250 \times 10^{-6}$ to $350 \times 10^{-6} \mathrm{in} / \mathrm{in}$. Maximum strains for double point loads are in the area of $250 \times 10^{-6} \mathrm{in} / \mathrm{in}$.

- Significant changes in stiffness were calculated during the dynamic loading cycle testing, perhaps due to compaction of the foundation. 


\subsection{Jointed Prestressed Concrete Panels}

\subsubsection{Introduction}

During this testing period, two (2) half prestressed concrete panels were poured to test for bending behavior and load-sharing characteristics at the open joint of the modular track panels. The joint is the most critical location in the panels because there is no mechanism to transfer moment or shear from one panel to the next. The steel tee rail provides load transfer from one

panel to the next. Approximately five (5) inches of space was left between the panels to provide adequate room to prestress the beams, i.e. open joint.

Two experiments were conducted on this panel. One was a single point load over the joint and the other was a two-point load test applied centrally over the joint. Fatigue testing was also conducted with a single point load applied over the joint. Figure 4.4.1 shows the strain and dial gage locations for this series of testing. Dial gages, to measure deflections, are represented by circles with their corresponding numbers. Dial gages 7-10 are mounted on the steel rail.
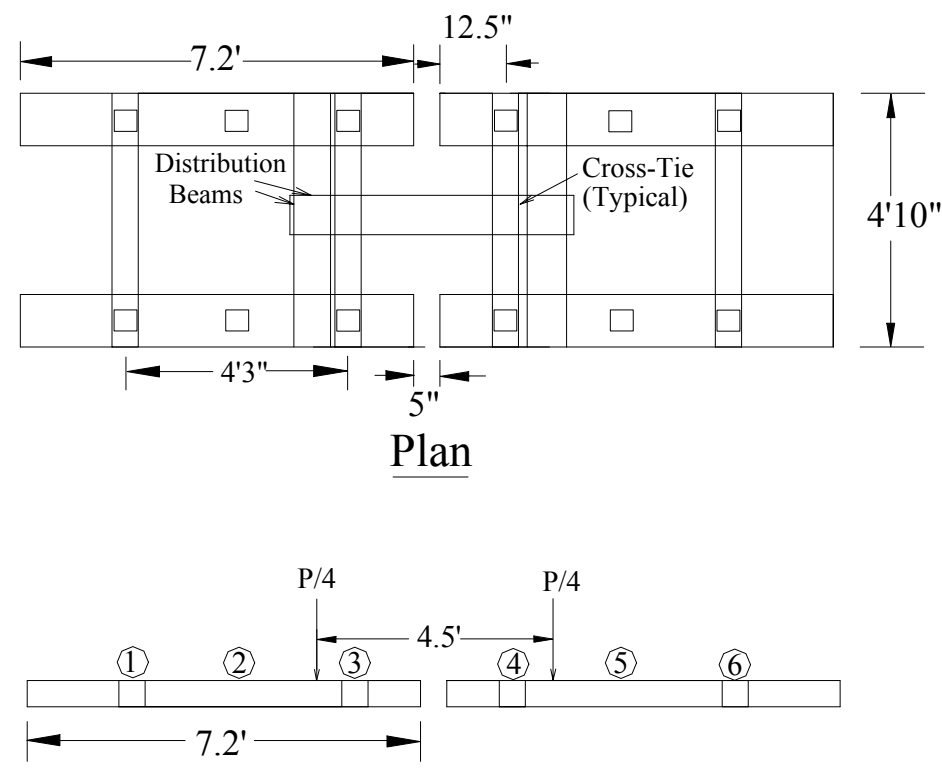

Elevation

Figure 4.4.1. Dial and Strain Gage Locations for Joint Testing

Three (3) strain gages, represented by solid dashes and five (5) dial gages were used on each of the panels to determine load- sharing characteristics. The experimental deflection obtained may not agree well with the actual deflection that would be obtained in the field because only a 
half panel was used. It is obvious that if a full panel were used, the deflection would have been less due the weight of the panel. In other words, if two fifteen (15) feet panels had been tested instead of the two seven and a half (7.5) feet panels (see Figure 4.4.1), deflection along the beam would have been less. Figure 4.4.2 shows the space between the two half panels.

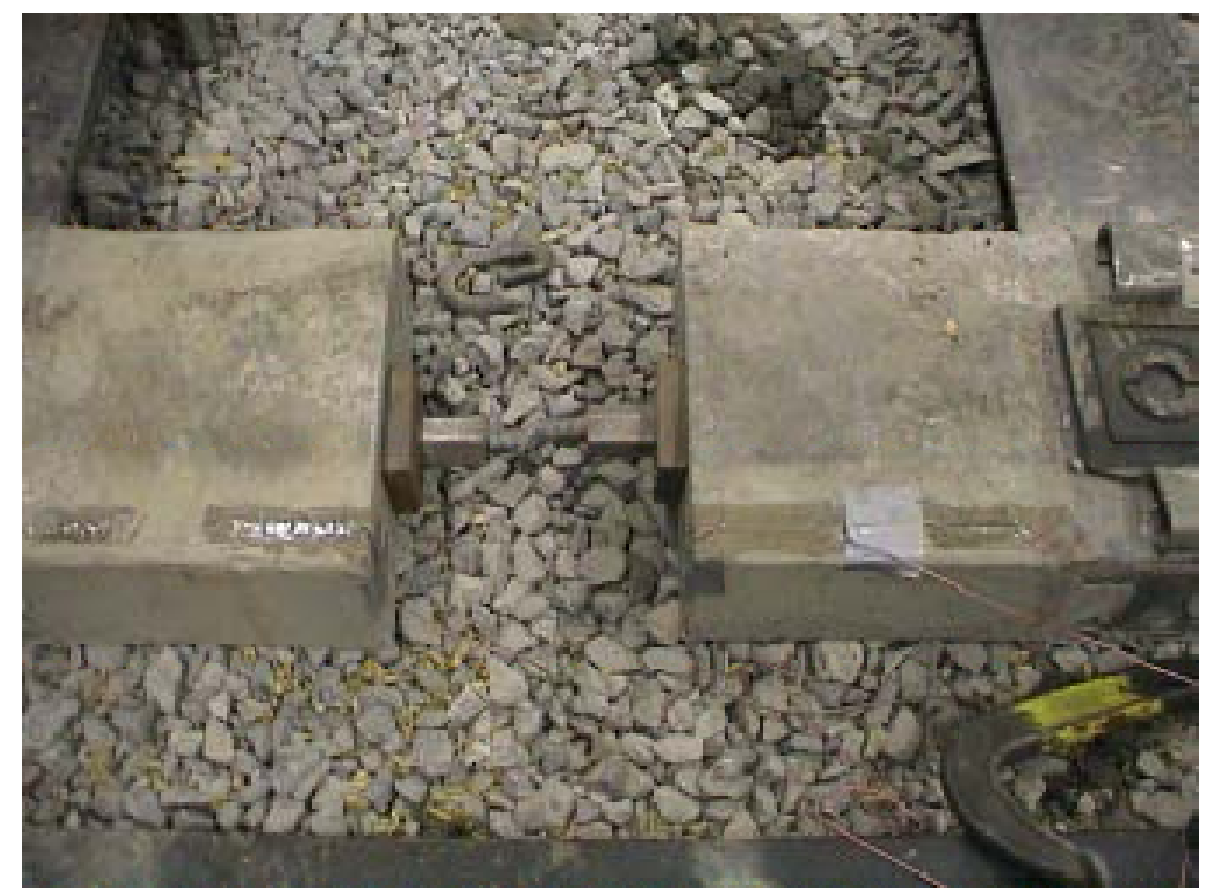

Figure 4.4.2. Spacing Between Half-Panels (Open Joint) 


\subsubsection{Single Point Load Applied Over Joint}

Figure 4.4.3 shows the experimental setup for this test. The steel tee rail is not shown. The pad numbers are shown, represented by circles in elevation view, and agree with the corresponding numbers in the deflection and strain plots.
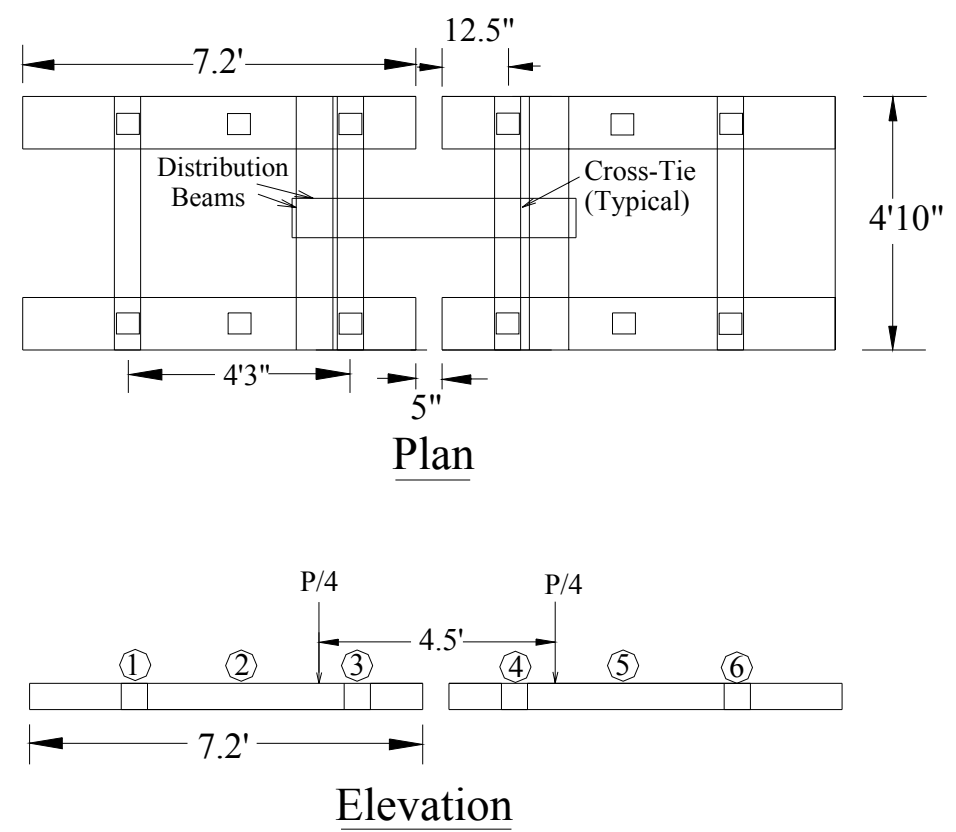

Figure 4.4.3. Experimental Setup for Single Point Load at Joint

Figure 4.4.4 provides the deflected shape of the beam. As can be seen, the deflections within a five (5) feet interval from the joint were measured. The deflected shape appears continuous over the open joint. 


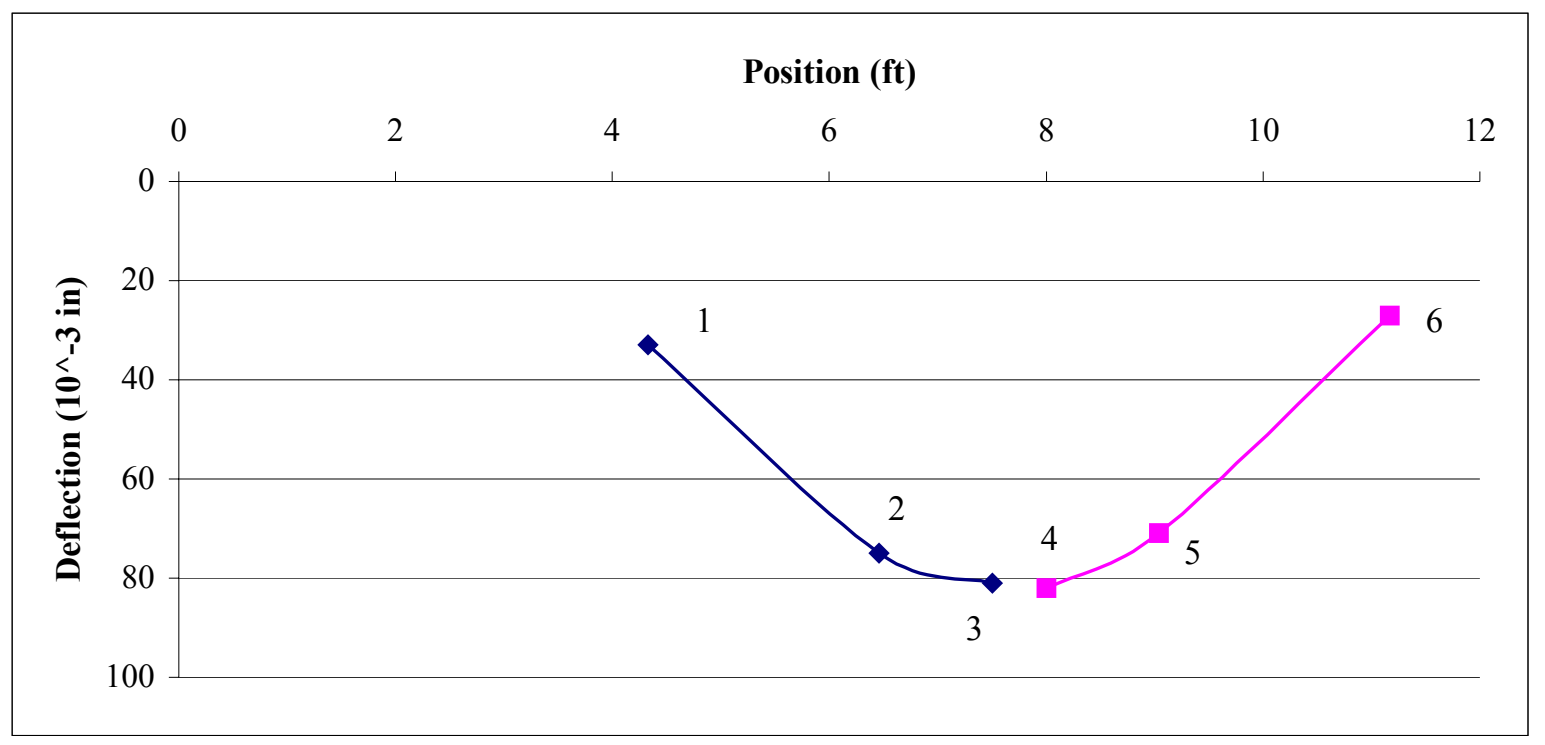

Figure 4.4.4. Deflected Shape of Beams for Single Point Load Applied Directly Over Joint

Figure 4.4.4 shows that the maximum deflection occurs at the point under the application of the load with a value of $82 \times 10^{-3}$ in. The maximum value obtained for the test that applied a single load at midspan of a full panel was $65 \times 10^{-3} \mathrm{in}$. The maximum value of deflection for the steel rail was found to be $95 \times 10^{-3} \mathrm{in}$. This higher value is expected since the panels are not connected.

Figure 4.4.5 shows the distribution of load based on deflection.

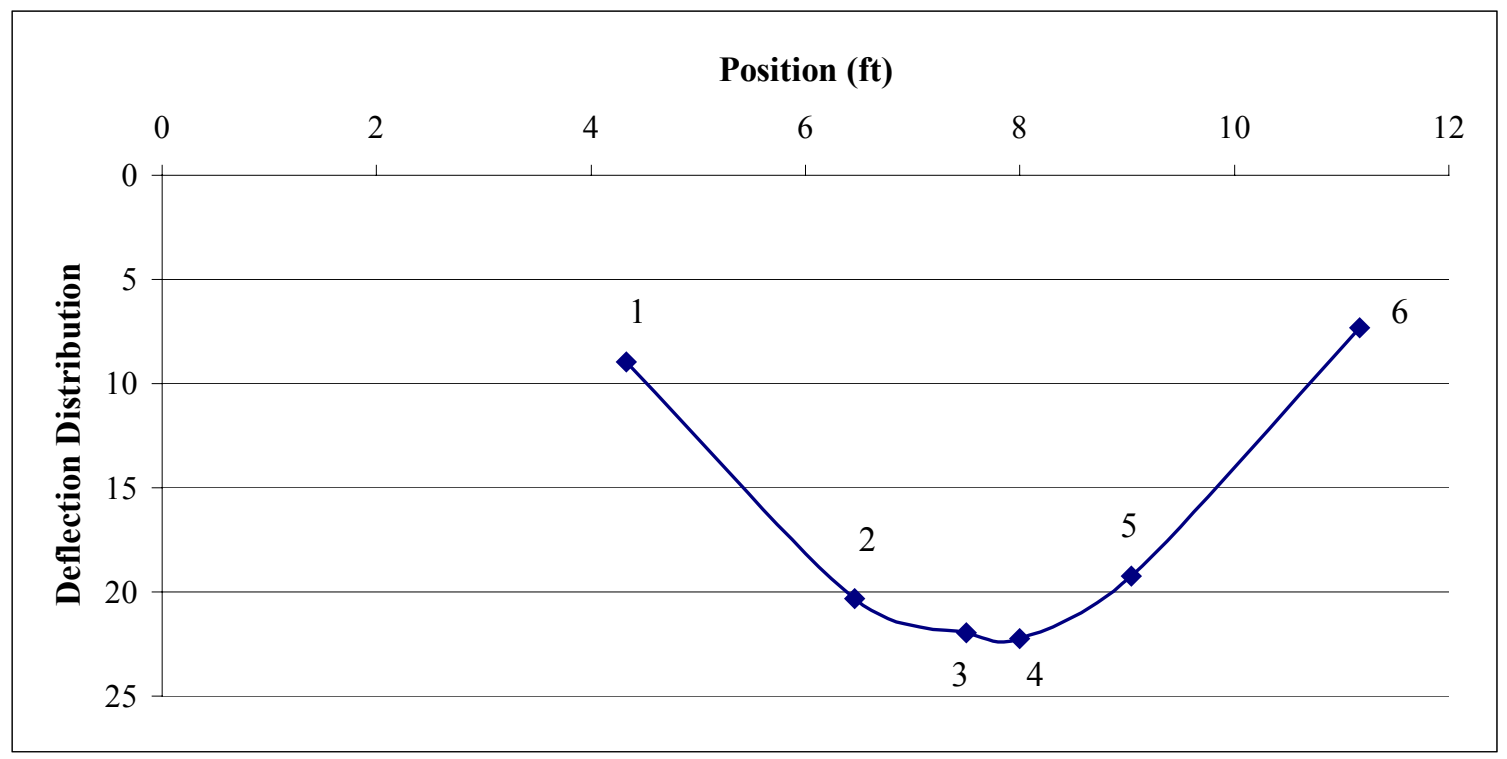

Figure 4.4.5. Load Distribution Based on Deflection for Single Point Load Applied Over Joint 
Figure 4.4.5 shows that the joints of each panel resisted $22 \%$ of the applied load, 10 kips on each beam. If compared to the single point load at midspan test, this value very closely resembles the $23 \%$ of load carried by the pad at midspan. This experiment shows that the load carried by the pads nearest the load over the joint is approximately $20 \%$ of the load.

Figure 4.4.6 shows the strains for the beam under a single point load applied over the joint.

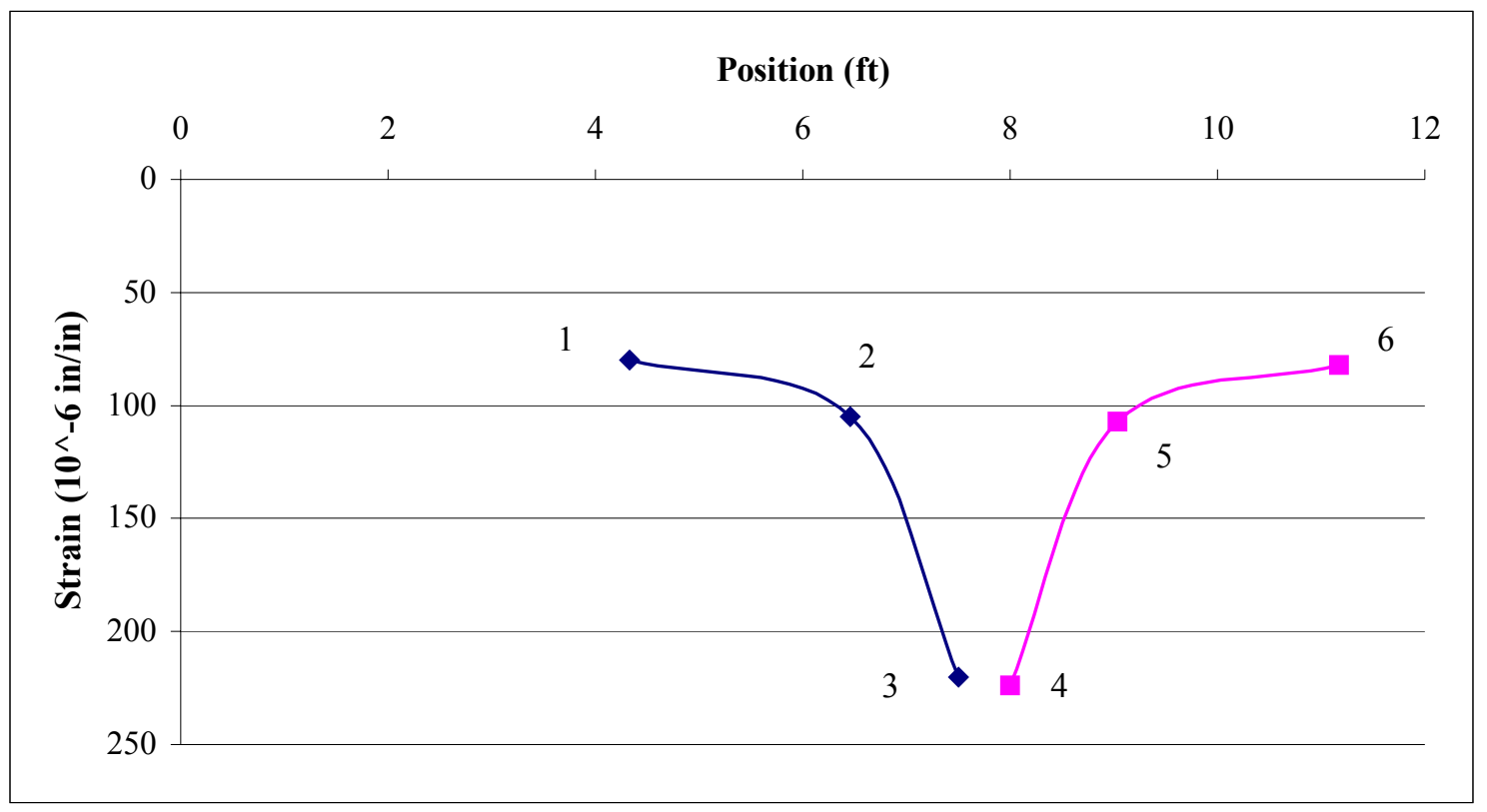

Figure 4.4.6. Strain vs. Position for Maximum Load of 10 kips

Figure 4.4.6 indicates the maximum strain value occurs under the load and is $224 \times 10^{-6} \mathrm{in} / \mathrm{in}$. The maximum value of strain obtained for the single point load at midspan was found to be $218 \times 10^{-6} \mathrm{in} / \mathrm{in}$. Although there is no joint mechanism to transfer the load, the strain values are reasonably close from one panel to another, indicating reasonably good load transfer, in terms of shear, through the steel tee rail. However, bending transfer is poor because of the formation of a hinge.

The following figure, Figure 4.4.7, indicates the load distribution based on strain. 


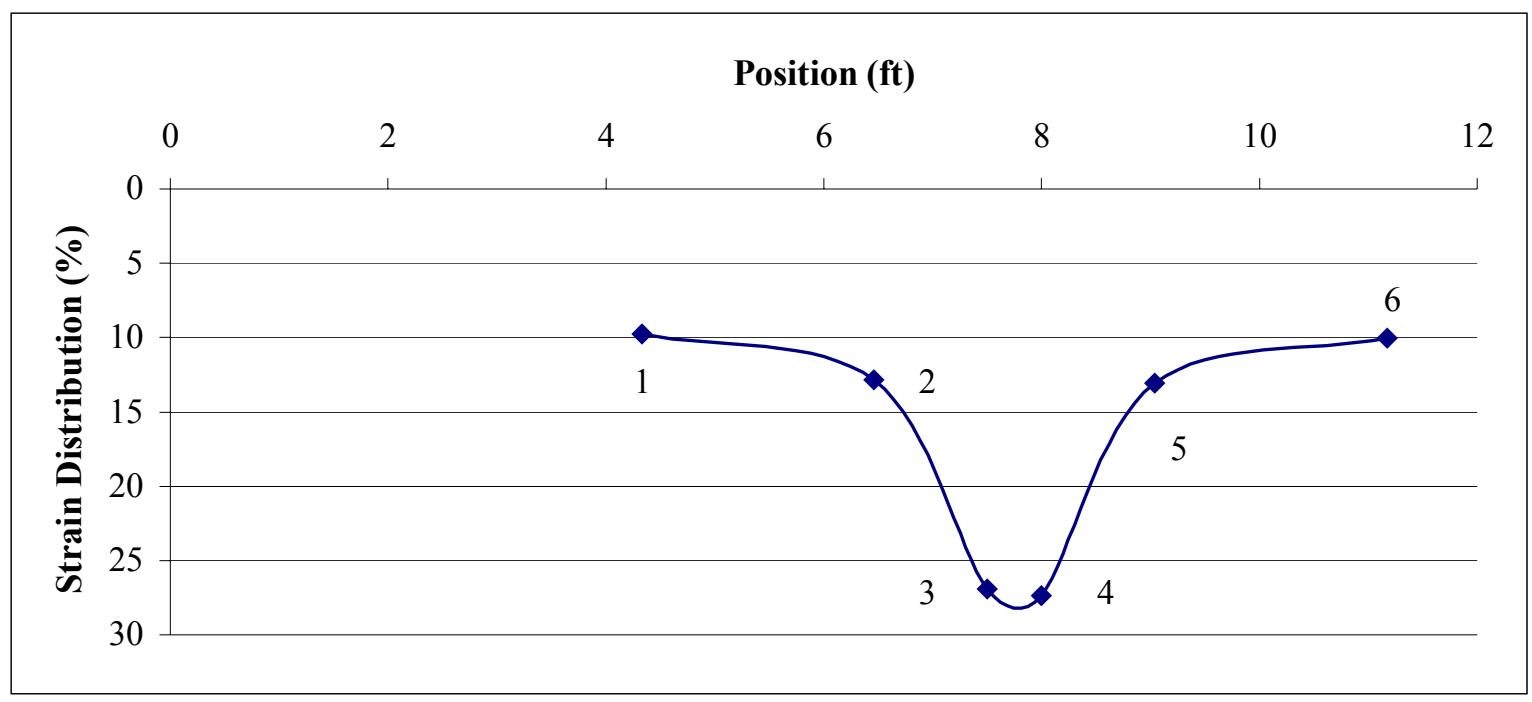

Figure 4.4.7. Load Distribution Based on Strain for Single Point Load Applied Over Joint

A pressure cell was again used to determine the pressure in the foundation under the jointed specimen. Figure 4.4 .8 shows the pressure under the joint.

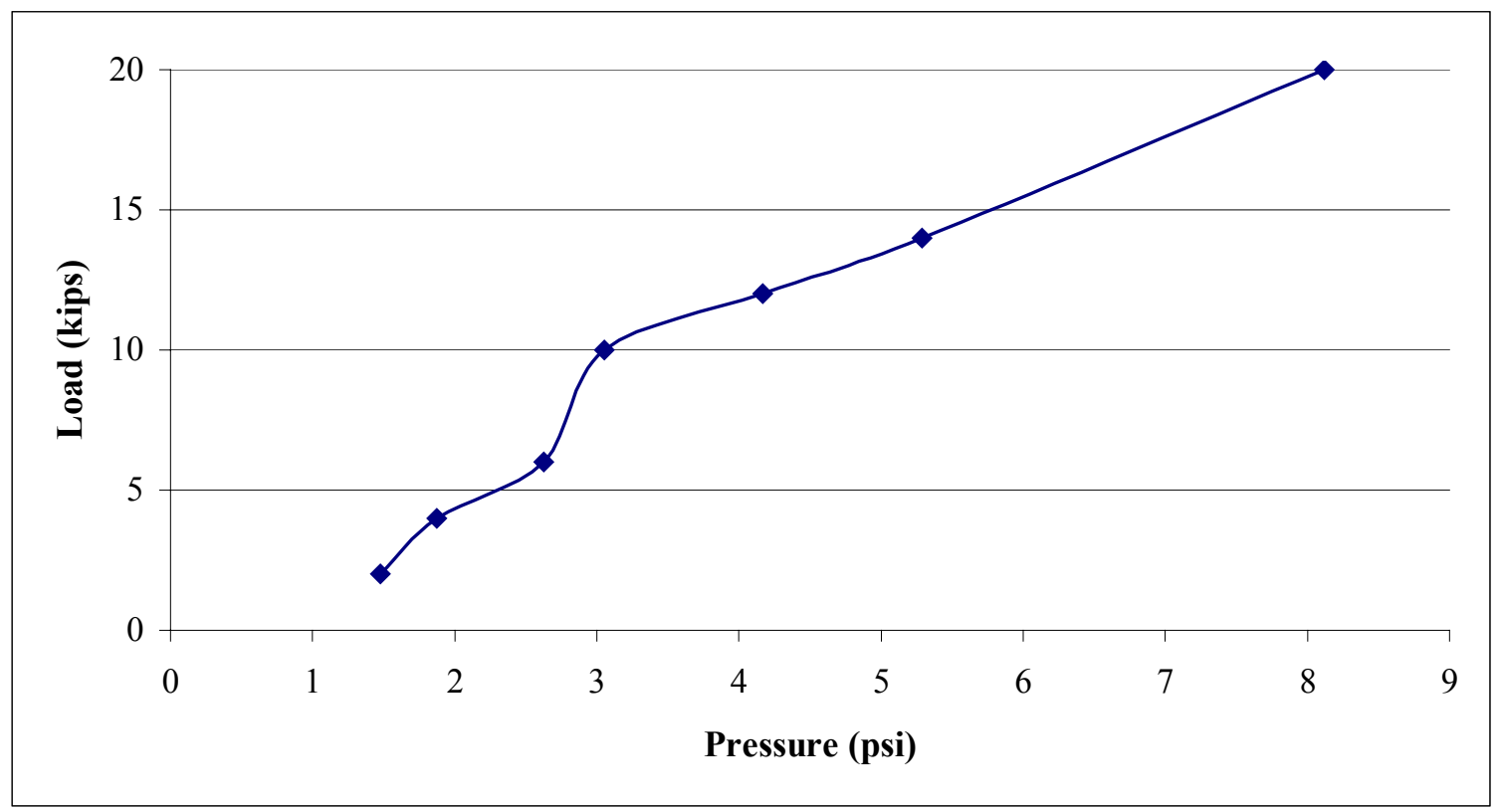

Figure 4.4.8. Pressure in the Foundation Under the Joint for a Single Point Load Applied over the Joint

As can be seen, the pressure was about 8 psi. The change in pressure for the midspan test was found to be 7.6 psi. 


\subsubsection{Two Point Loads Applied Centrally Over Joint}

Figure 4.4.9 shows the experimental setup for this testing phase.
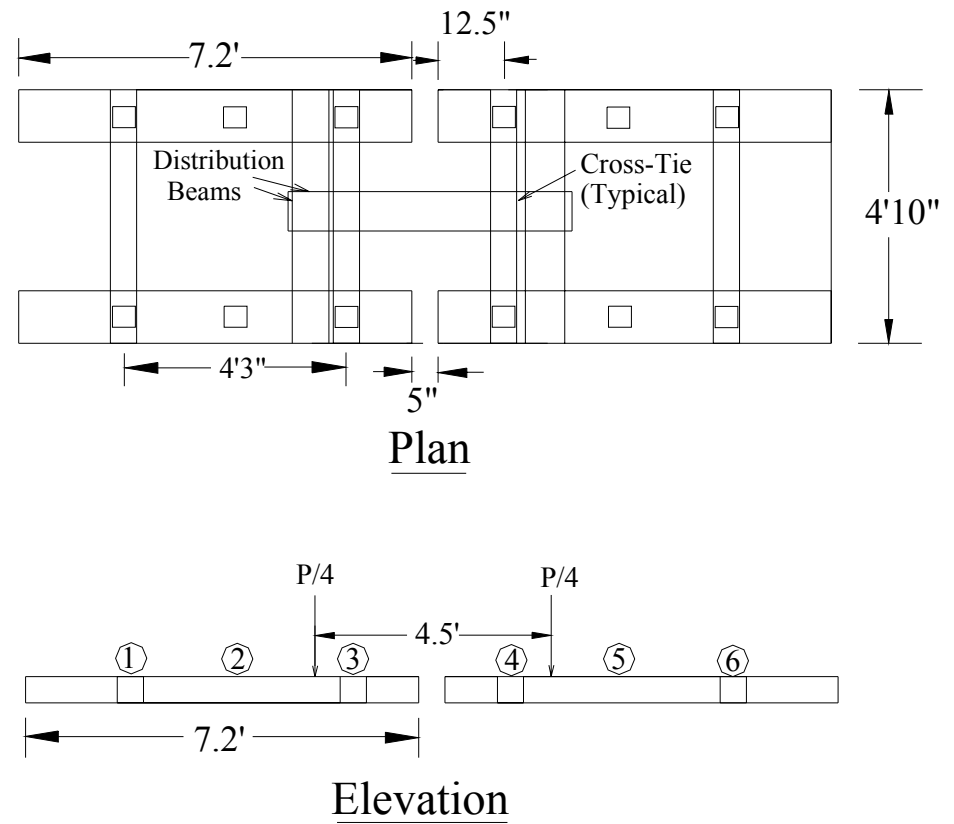

Figure 4.4.9. Experimental Setup for Two Point Loads Applied Centrally Over Joint

Once again, three (3) strain gages and five (5) dial gages were used to determine the distribution of load.

Figure 4.4.10 shows the deflected shape of the beams at the maximum load of 20 kips per beam. 


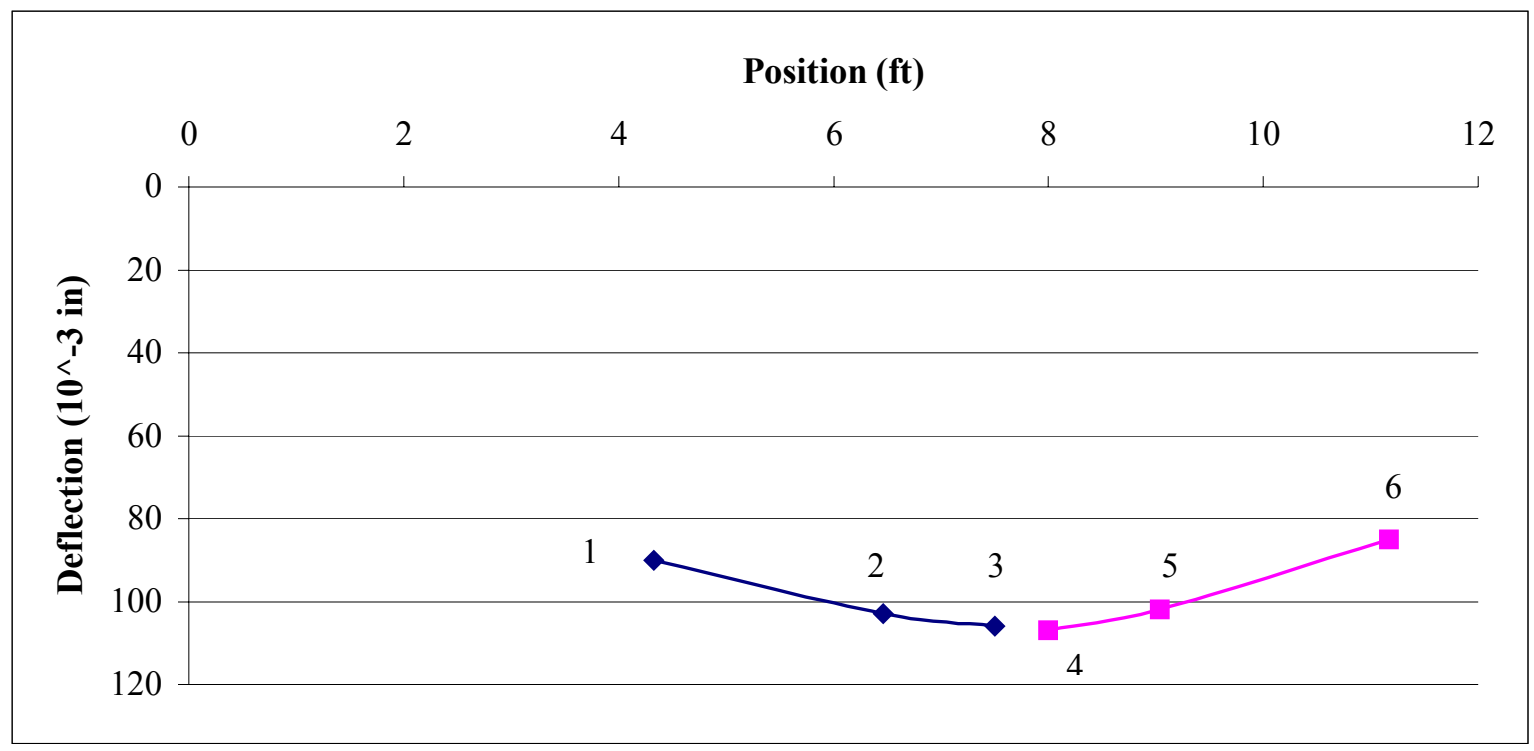

Figure 4.4.10. Deflected Shape of Beams At Total Load of 20 kips/beam

Figure 4.4.10 shows that the maximum value of deflection was obtained at the joint at a value of $107 \times 10^{-3}$ in. compared to the value of $93 \times 10^{-3}$ in. for the two central loads applied at midspan on the full panel. Once again, the jointed section had a higher deflection compared to a section with continuous concrete support, but showed reasonably good load transfer.

Figure 4.4.11 shows the distribution of load based on the deflection values.

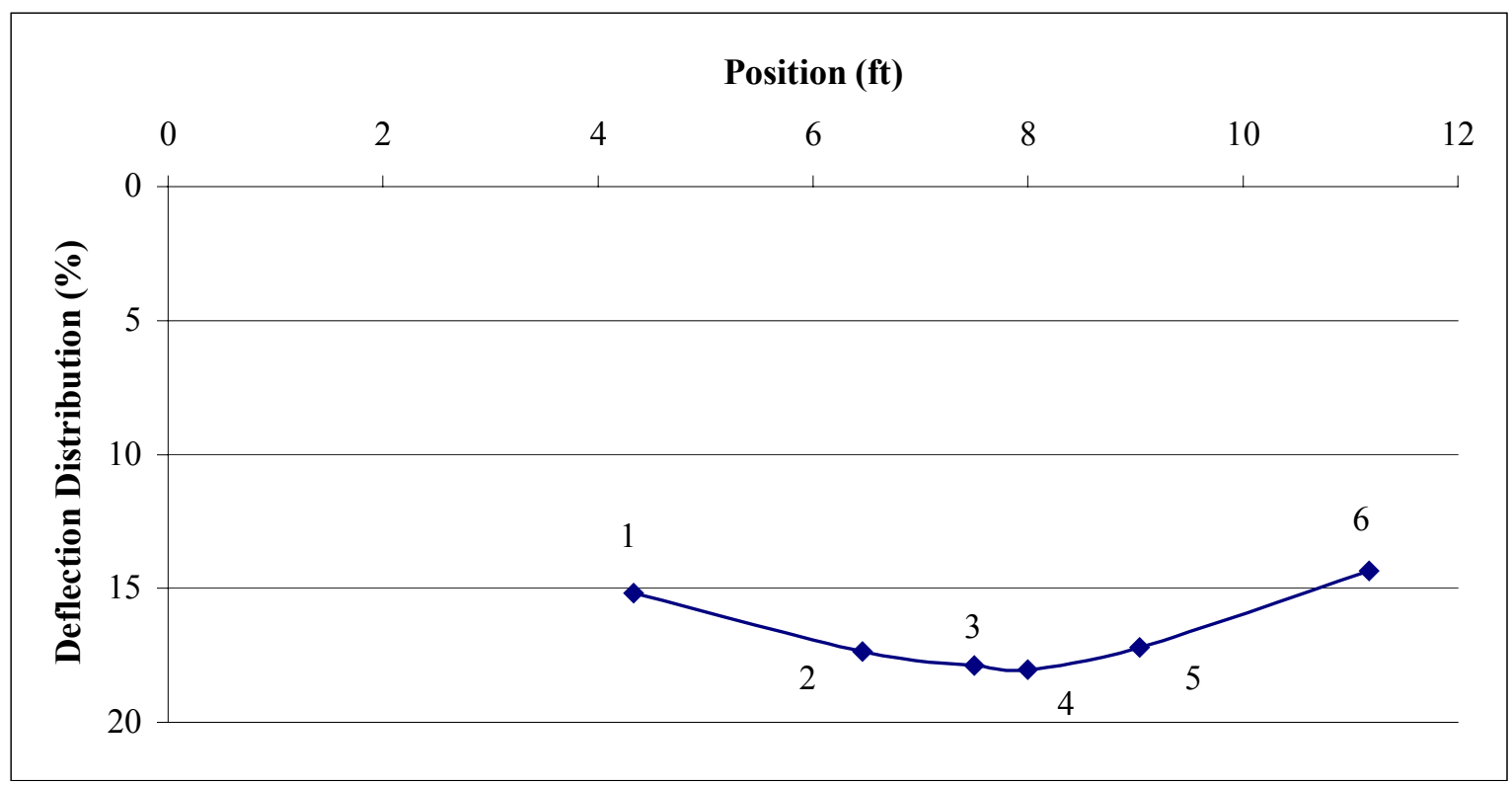

Figure 4.4.11. Load Distribution Based on Deflection for Double Point Load Applied Over Joint 
Figure 4.4.11 shows that the joint experienced approximately $18 \%$ of the load, while the pad nearest the application of the load experienced approximately $17 \%$ of the load. If compared to the two point load over midspan test on a full panel, the pads nearest the load experienced approximately $24 \%$ of the load.

Figure 4.4.12 shows the strain values obtained during this experiment.

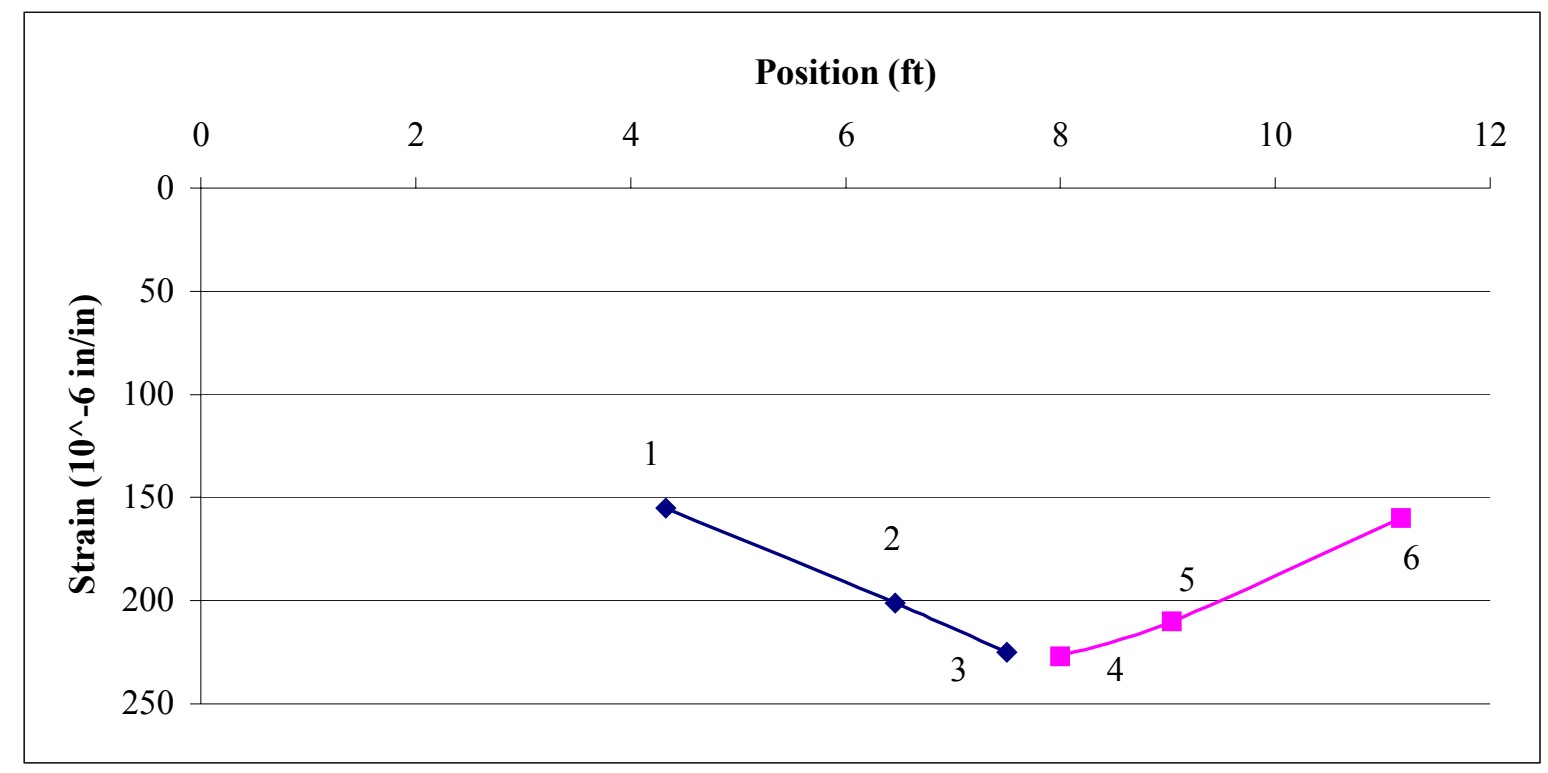

Figure 4.4.12. Strain vs. Position for Double Point Load Applied Centrally Over Joint

The maximum strain value was obtained at the locations of the joints and had a value of $227 \times 10^{-6} \mathrm{in} / \mathrm{in}$. The strain experienced at midspan on the full panels under the same loading condition was found to be $221 \times 10^{-6} \mathrm{in} / \mathrm{in}$, a $3 \%$ difference. From a strain point of view, i.e., a localized response, there appears to be good load sharing through the steel tee rail. The jointed panels show poor bending transfer because of the cantilever action.

Figure 4.4.13 shows the load distribution for the panels based on strain. It shows that $19 \%$ of the load is experienced at the joint locations and approximately $17 \%$ at the location of the nearest pads, which coincides with the deflection results. 


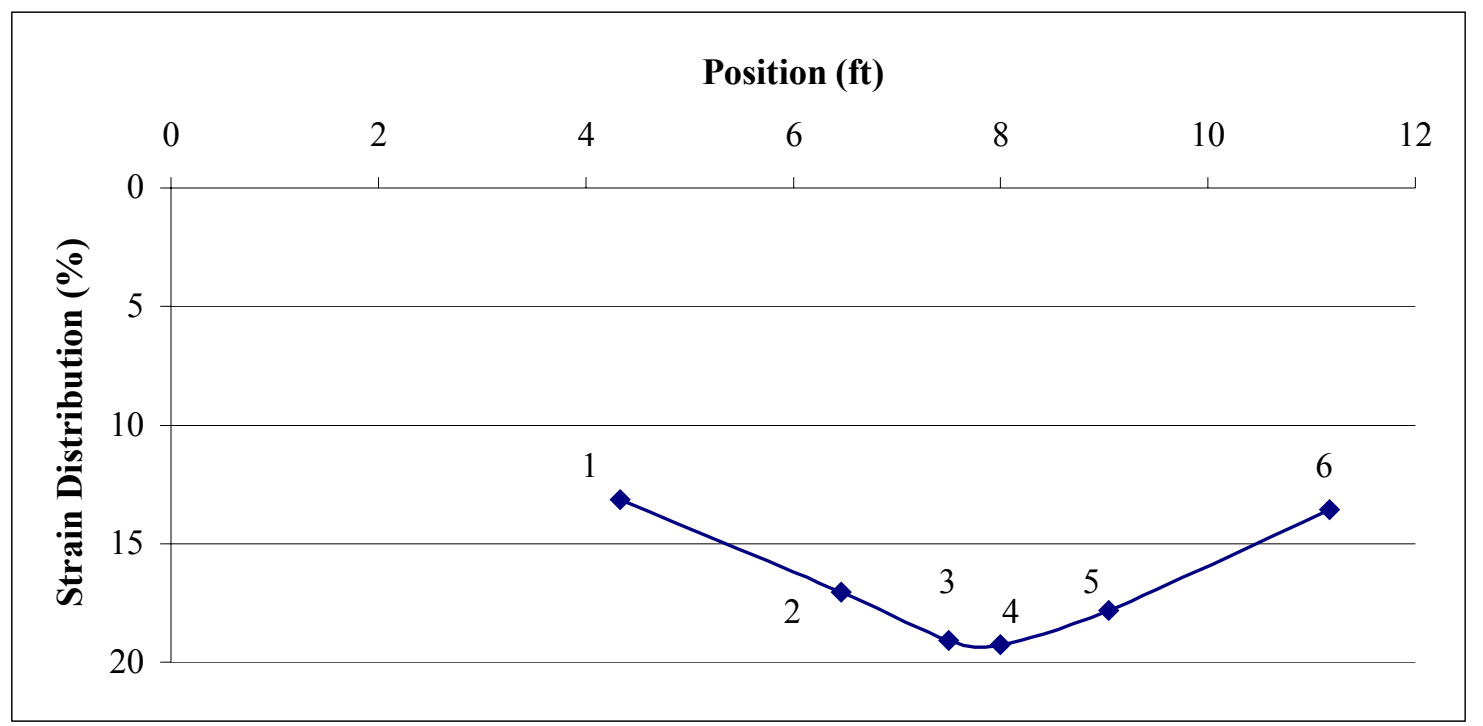

Figure 4.4.13. Load Distribution based on Strain for Double Point Loads Applied Centrally Over Joint

Figure 4.4.14 shows the pressure experienced by the foundation under the joints at the indicated load.

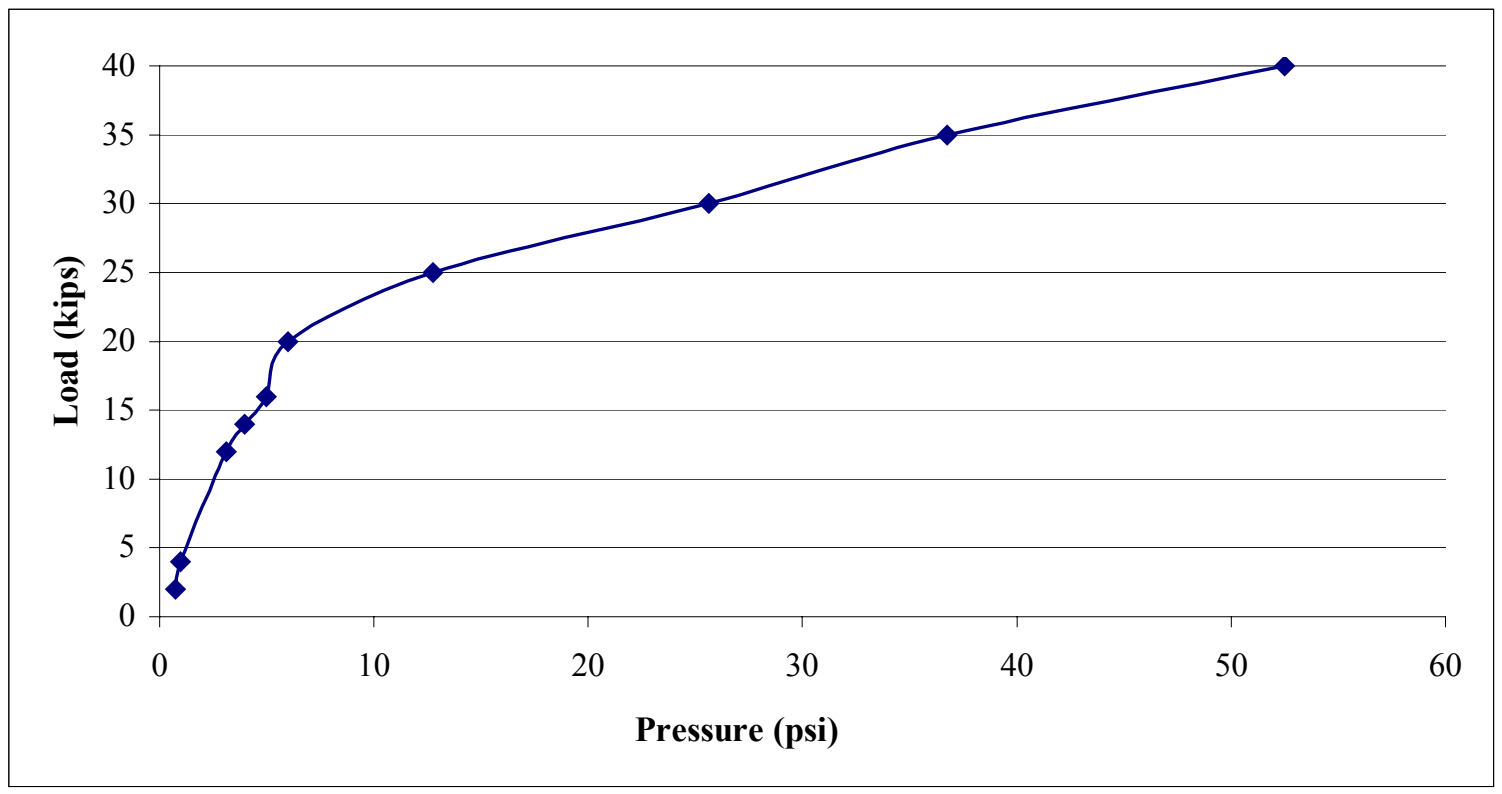

Figure 4.4.14. Pressure in the Foundation for Double Point Loads Applied Centrally Over the Joints

Figure 4.4.14 shows that the pressure at the maximum load was found to be $52.5 \mathrm{psi}$, compared to 45 psi for the midspan test of a full panel. 
These results show that there is a slightly larger value in all obtained data for the joint tests compared to a test of the full panel. Deflection, strain, and change in pressure are all greater at the joint.

\subsubsection{Fatigue Testing}

Dynamic load testing was conducted on the set of half panels at the joint location using a single point load of 20 kips. Static tests after 250,000 and 500,000 applied cycles were used to determine the change in stiffness of the panel.

Figure 4.4.15 shows the deflection along the length of the beam for the dynamic testing. The deflection before testing began is also provided as a comparison.

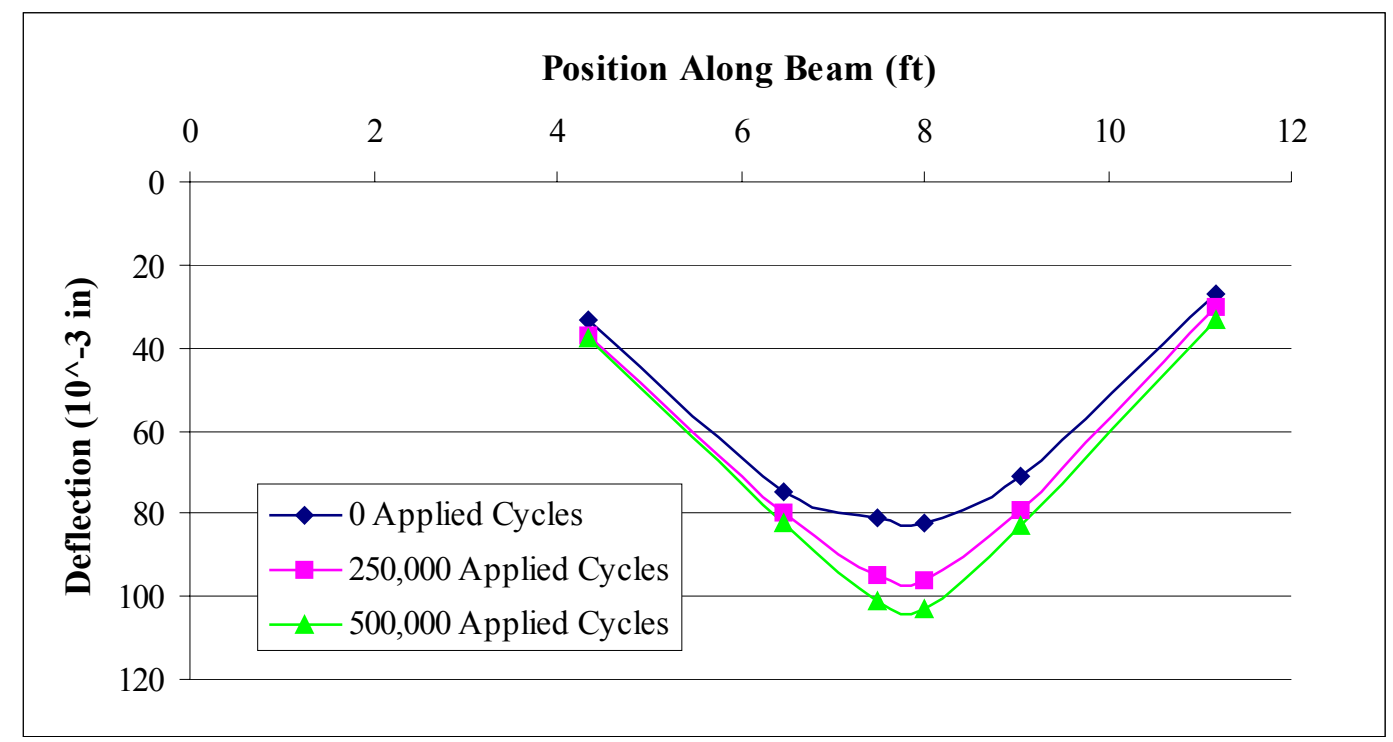

Figure 4.4.15. Deflection of Beam for Static Test Conducted After Indicated Applied Cycles

Figure 4.4.15 shows that the deflection increased from 0.081 in to 0.095 in after 250,000 applied cycles, an increase of 17\%. The deflection after 500,000 applied cycles was found to be 0.101 in, an increase of $25 \%$ compared to the value obtained before dynamic load testing began. The stiffness calculated before fatigue testing began was $241 \mathrm{lbs} / \mathrm{in}$. The stiffness calculated from the deflections at the joint location after 250,000 applied cycles was $207 \mathrm{lbs} / \mathrm{in}$, a decrease of 14\%. After 500,000 applied loading cycles, the stiffness was calculated to be $194 \mathrm{lbs} / \mathrm{in}$, a decrease of $20 \%$ from the value obtained before fatigue testing began. 


\subsubsection{Conclusions on Set of Half Prestressed Concrete Panels}

A set of half panels were fabricated and tested to determine the response of the joint locations. Tests of single and double point loads were applied centrally over the joint. The deflection of the joint closely resembles the deflection of the midspan of a full-size panel. Dynamic load testing was also conducted to determine the change in stiffness. No significant cracking was observed during any of the tests. The maximum deflection for the single point load test was 0.082 in at the joint location and 0.107 in for the double point load test also at the joint location. The maximum strain was $224 \times 10^{-6} \mathrm{in} / \mathrm{in}$ for the single point load test and $227 \times 10^{-6}$ in/in for the double point load test. Results from the dynamic loading analysis after 500,000 cycles showed that the stiffness dropped by $20 \%$, most likely due to compaction of the gravel. In summary, the "open joint" appears to function reasonably well in terms of transferring the load through the continuous steel tee rail. 


\subsection{Pad Testing}

\subsubsection{Introduction}

Load-deflection tests were conducted on two (2) 0.24 " resilient rubber pads (Figure 4.5.1), manufactured by Pandrol, using an Instron load testing machine. A static test was used to determine pad stiffness after a fatigue test. Cycles of 100,000, 250,000, 500,000 , and 1,000,000 were used for fatigue at a frequency of $0.5 \mathrm{~Hz}$. This low rate was used to prevent hysteresis. The secant modulus of the pad was also calculated for each static test. The secant modulus is defined between two points, which are representative of the toe load and the live load under the mine coal car. The toe load used was 3 kips and the live load used was 9 kips. The secant modulus was calculated as the difference between two loads divided by the difference in their respective deflections. Two steel plates (1/2" thick) were used to ensure the entire pad was loaded. Figure 4.5.2 shows the testing set-up in the Instron machine for the pad testing.

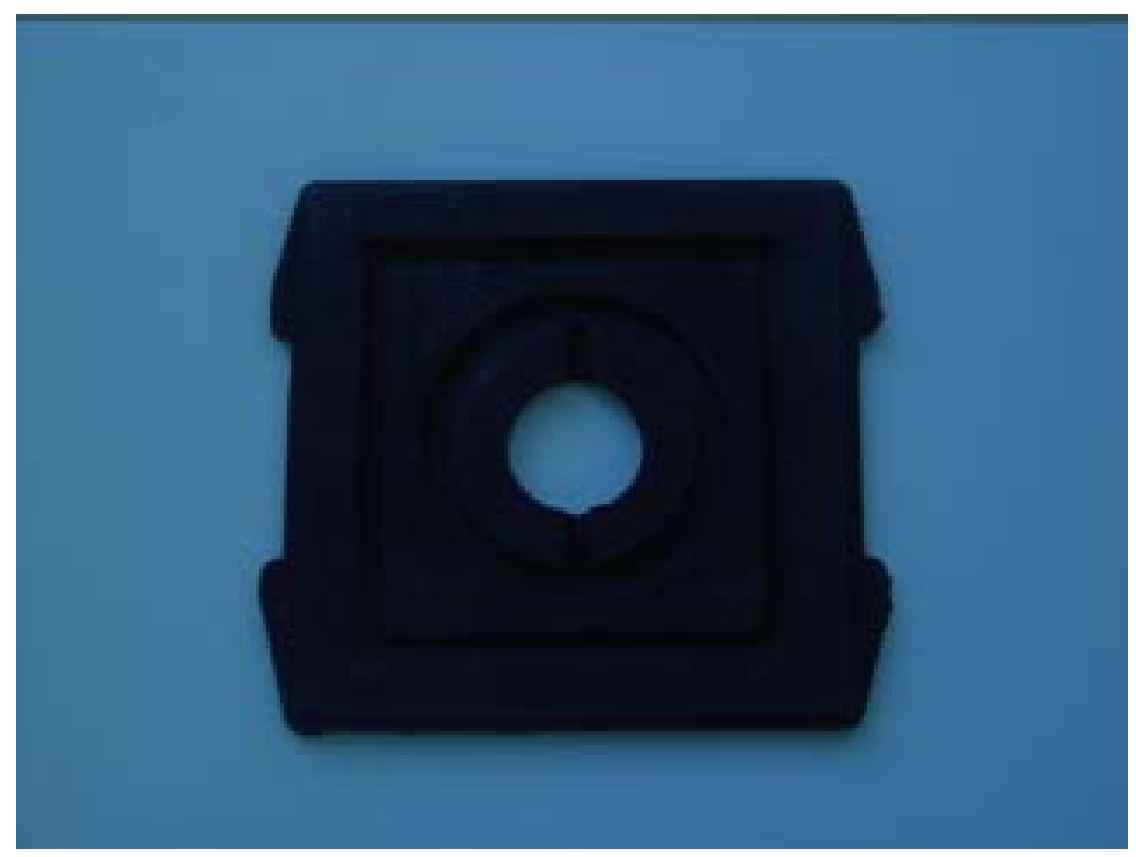

Figure 4.5.1. 0.24” Resilient Rubber Pad Used for Prestressed Concrete Panels 


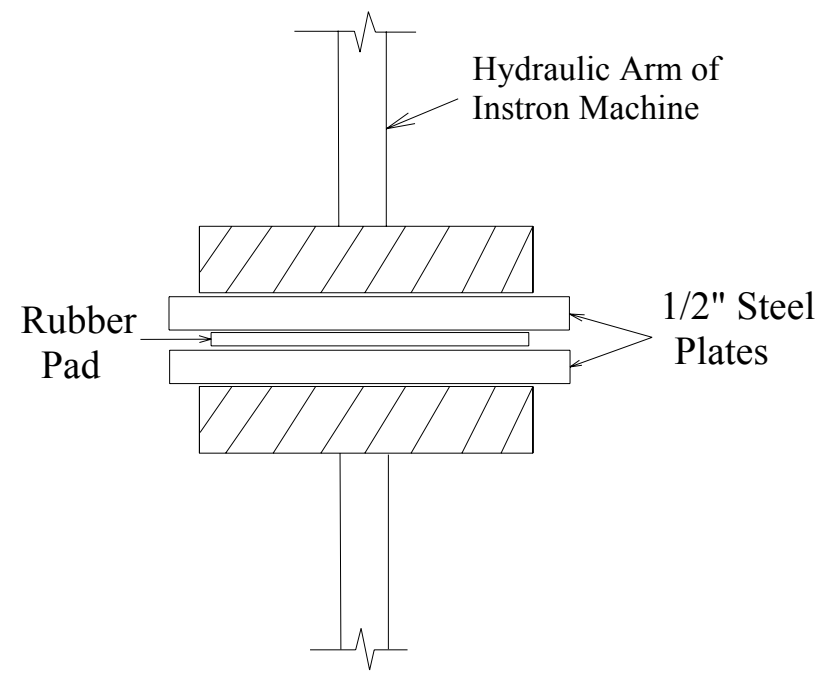

Figure 4.5.2. Test Set-up in Instron Machine for Pad Testing

\subsubsection{Pad I}

An initial static test was conducted to determine the stiffness of the pad before the fatigue testing began. The maximum load applied by the Instron machine was $10 \mathrm{kips}$. Figure 4.5.3 shows the stiffness of the pad. It shows that the maximum deflection was 0.11 in. The stiffness was calculated to be $127.1 \mathrm{kips} / \mathrm{in}$. The secant modulus for the pad was calculated to be $109.3 \mathrm{kips} / \mathrm{in}$. The pad exhibits a bi-linear behavior.

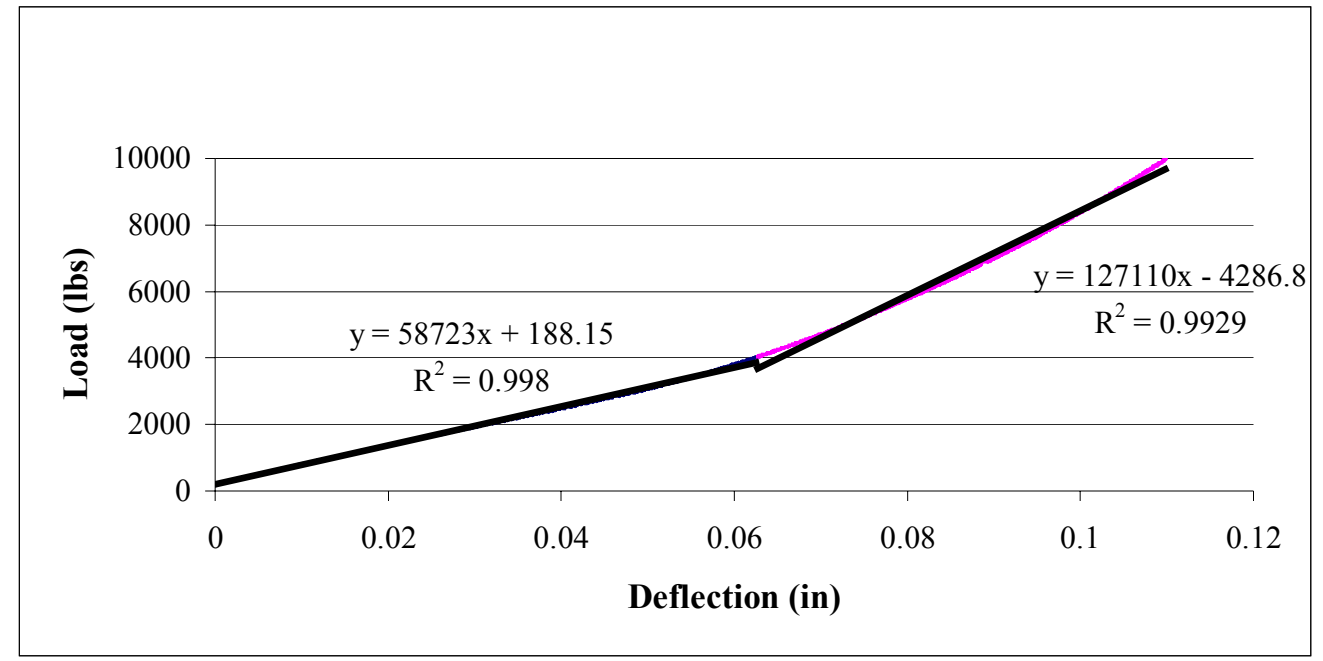

Figure 4.5.3. Pad Stiffness Before Fatigue Testing Began 
The first fatigue test involved applying 100,000 cycles to the pad. The Instron machine was set to apply a minimum load of 3 kips and a maximum load of 10 kips. Figure 4.5.4 shows the results of this test. It shows that the stiffness of the pad decreased by $1.5 \mathrm{kips} / \mathrm{in}$. to a value of $125.6 \mathrm{kips} / \mathrm{in}$. The maximum deflection was $0.103 \mathrm{in}$. The secant modulus was calculated to be $109.3 \mathrm{kips} / \mathrm{in}$.

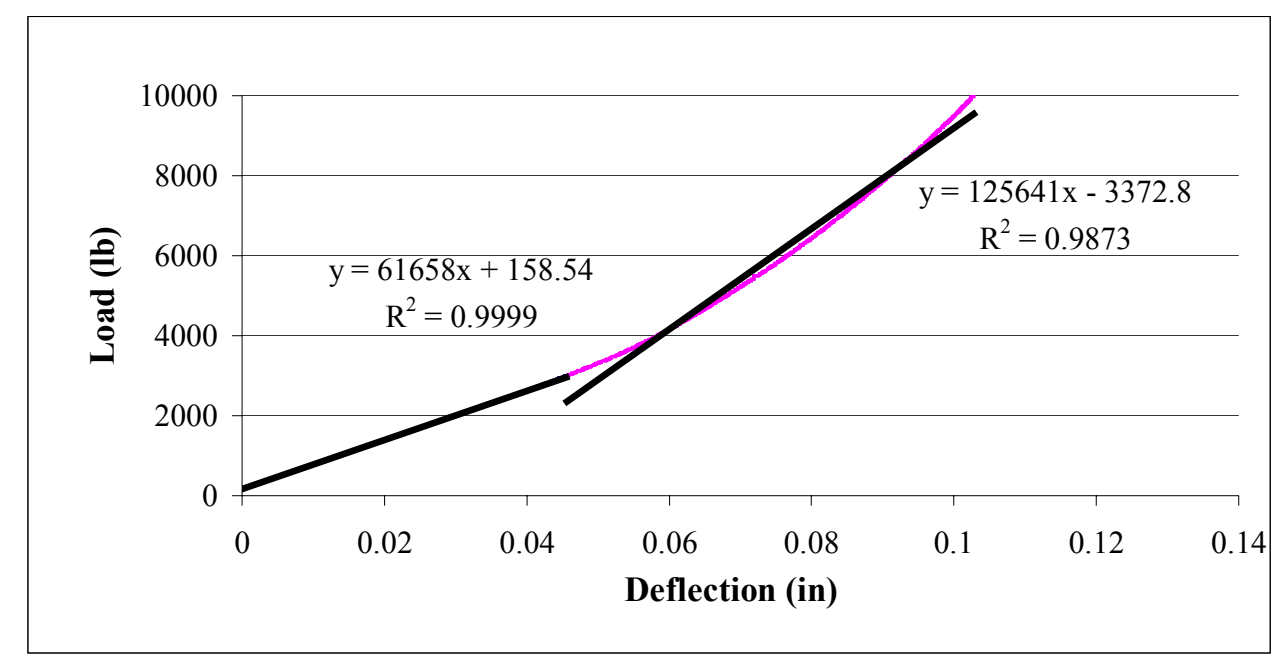

Figure 4.5.4. Pad Stiffness After 100,000 Cycles

The next test was conducted when the pad had a total value of 250,000 cycles applied. Figure 4.5.5 shows the results from this test. It shows that the stiffness decreased by $9.4 \mathrm{kips} / \mathrm{in}$, compared to the pad before fatigue testing began, to a value of $117.7 \mathrm{kip} / \mathrm{in}$. The maximum deflection was $0.127 \mathrm{in}$. The secant modulus was calculated to be $109.7 \mathrm{kips} / \mathrm{in}$. 


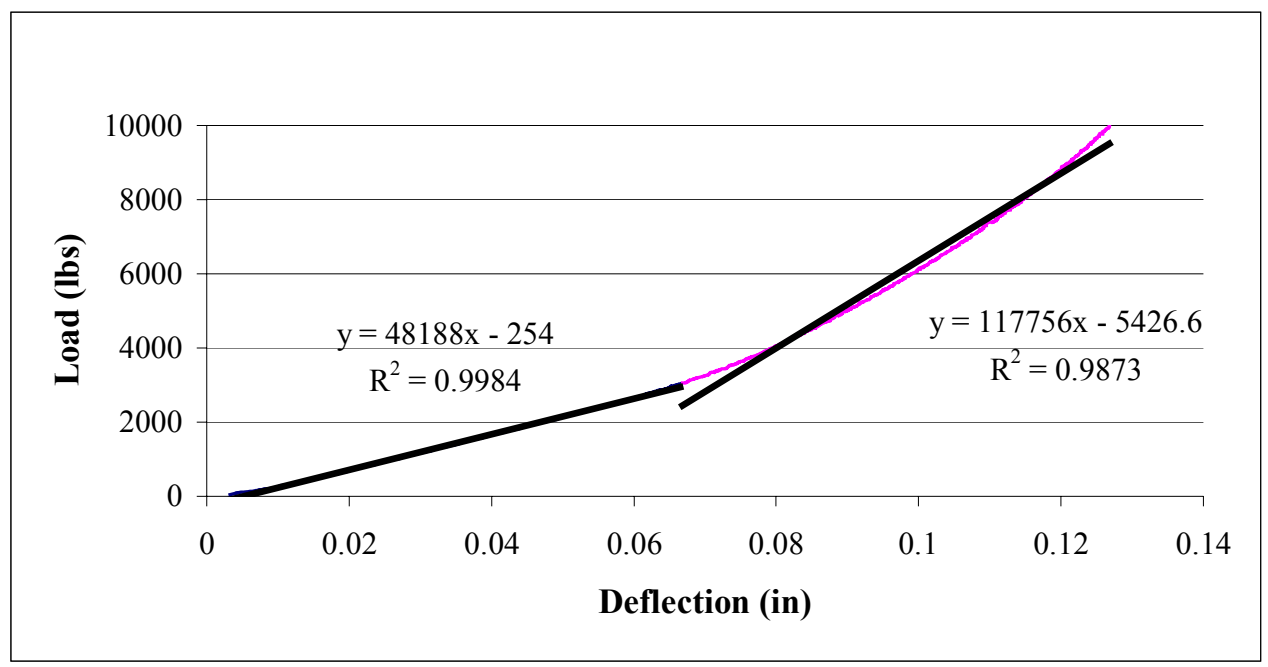

Figure 4.5.5 Pad Stiffness After 250,000 Cycles

The next test was conducted when the pad had a total value of 500,000 cycles applied. Figure 4.5.6 shows the results for this testing cycle. The stiffness was calculated to be $117.4 \mathrm{kips} / \mathrm{in}$., which is $9.7 \mathrm{kips} / \mathrm{in}$. less than before the pad was loaded. The maximum deflection was 0.137 in. The secant modulus was calculated to be 108.9 kips/in.

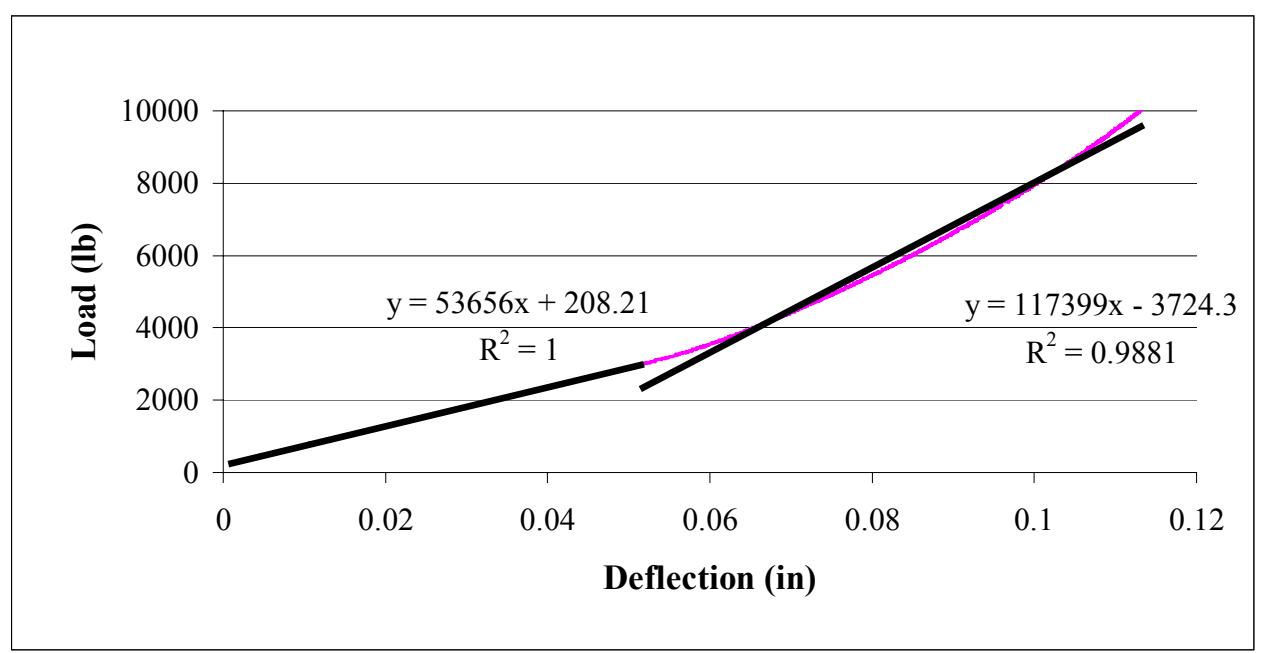

Figure 4.5.6. Pad Stiffness after 500,000 Cycles

The final test was conducted after 1,000,000 cycles had been applied. Figure 4.5.7 shows the results from the static test. The maximum deflection was 0.123 in. The pad stiffness was calculated to be $116.4 \mathrm{kip} / \mathrm{in}$., $10.7 \mathrm{kips} / \mathrm{in}$. less than the value obtained 
before fatigue testing began. This test shows that after 1,000,000 cycles are applied, the stiffness decreases by only $8.4 \%$. The secant modulus for this test was calculated to be 106.1 kips/in.

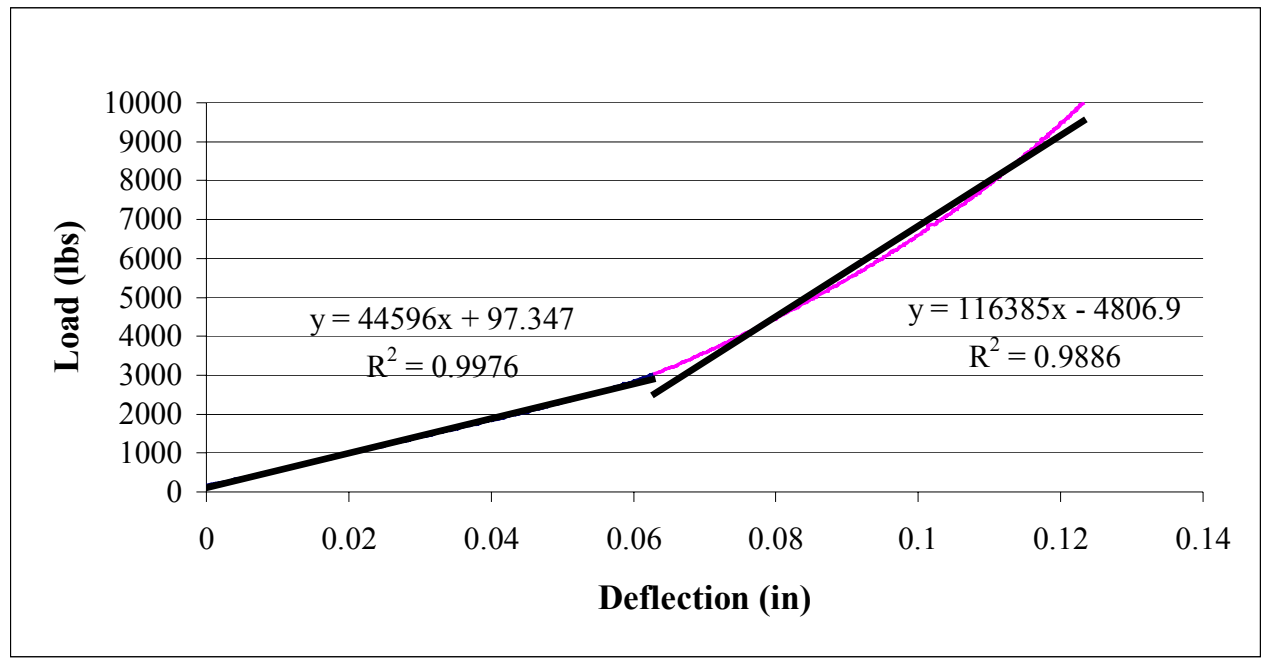

Figure 4.5.7. Pad Stiffness After 1,000,000 Cycles

Figure 4.5.8 shows the stiffness curves for each set of tests conducted.

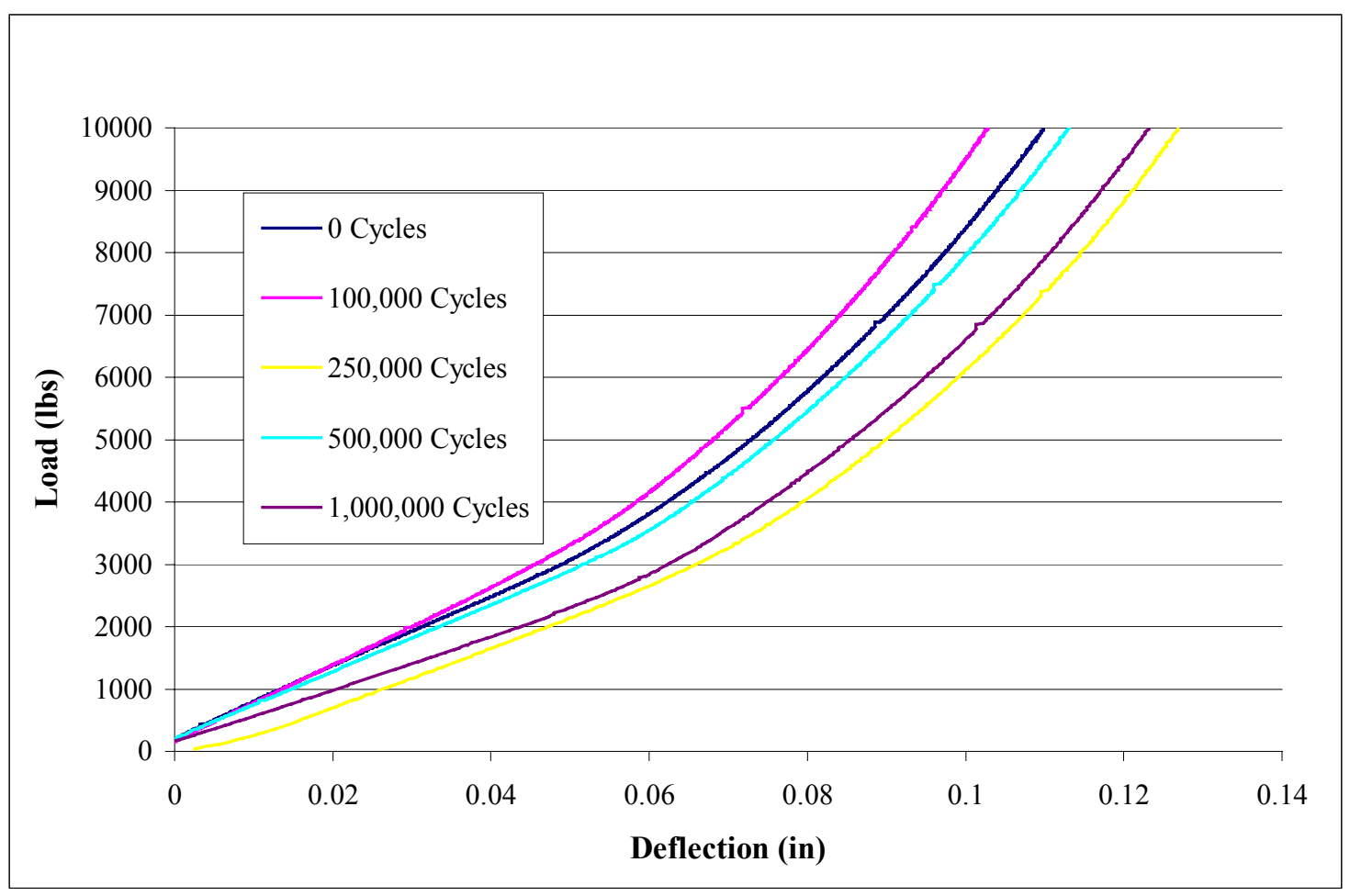

Figure 4.5.8. Load vs. Deflection Curves for Individual Tests 


\subsubsection{Pad II}

A second pad was tested to verify the results of the first pad. An initial static test was conducted to determine the stiffness of the pad. Figure 4.5.9 shows that the stiffness of the pad before fatigue testing began was calculated to be $123 \mathrm{kips} / \mathrm{in}$. The maximum deflection was 0.119 in. The secant modulus, once again calculated using the toe and live load, was calculated to be $112.3 \mathrm{kips} / \mathrm{in}$.

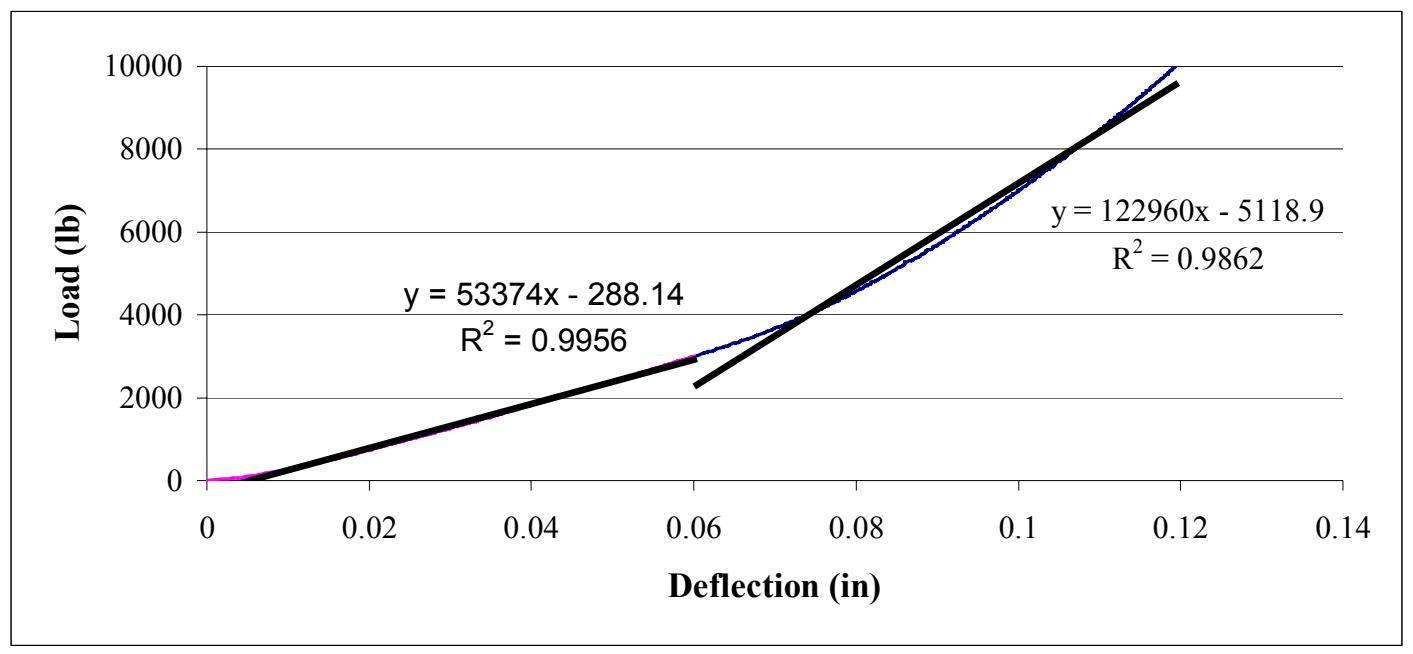

Figure 4.5.9. Stiffness of Pad 2 Before Fatigue Testing

The first fatigue test involved applying 100,000 cycles to the pad. Figure 4.5.10 shows that the stiffness was calculated to be $123 \mathrm{kips} / \mathrm{in}$, which is equal to the original value. The maximum deflection was 0.133 in. The secant modulus was calculated to be 112.4 kips/in.

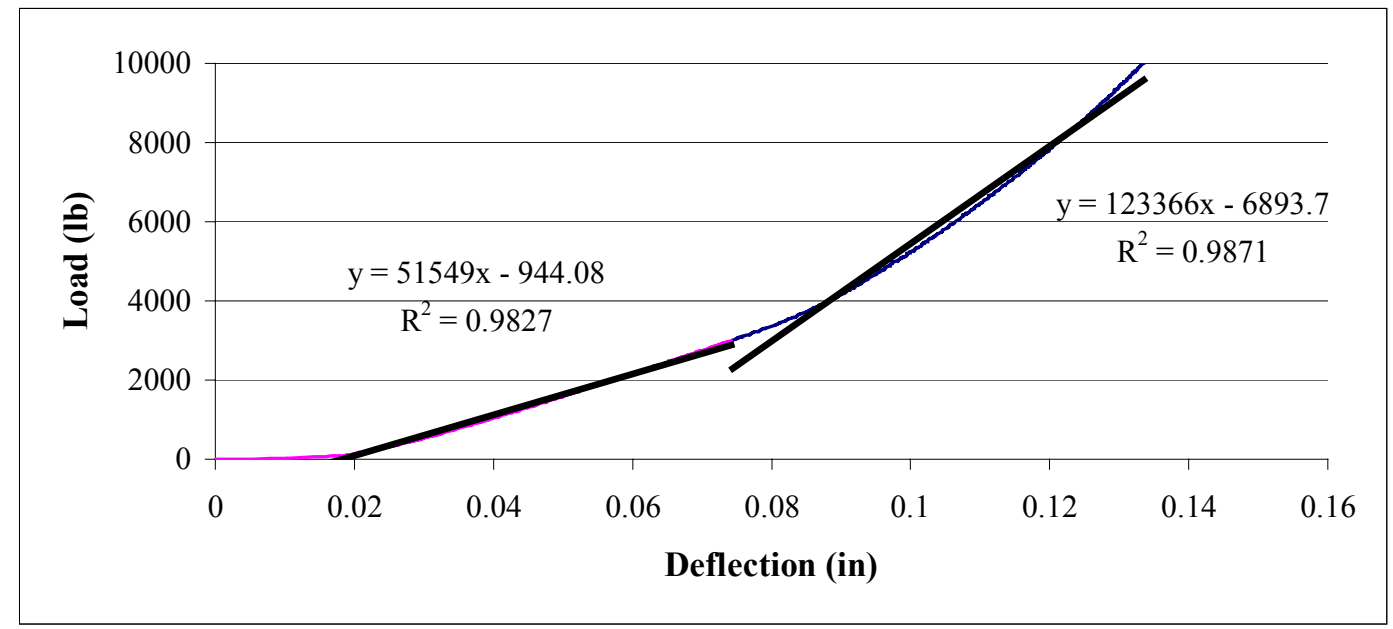

Figure 4.5.10. Stiffness of Pad 2 after 100,000 Cycles of Applied Load 
A total number of 250,000 cycles of applied load were next applied. Figure 4.5.11 shows that the stiffness was calculated to be $119 \mathrm{kips} / \mathrm{in}$. The maximum deflection was 0.156 in. The secant modulus after 250,000 cycles was calculated to be $110.4 \mathrm{kips} / \mathrm{in}$.

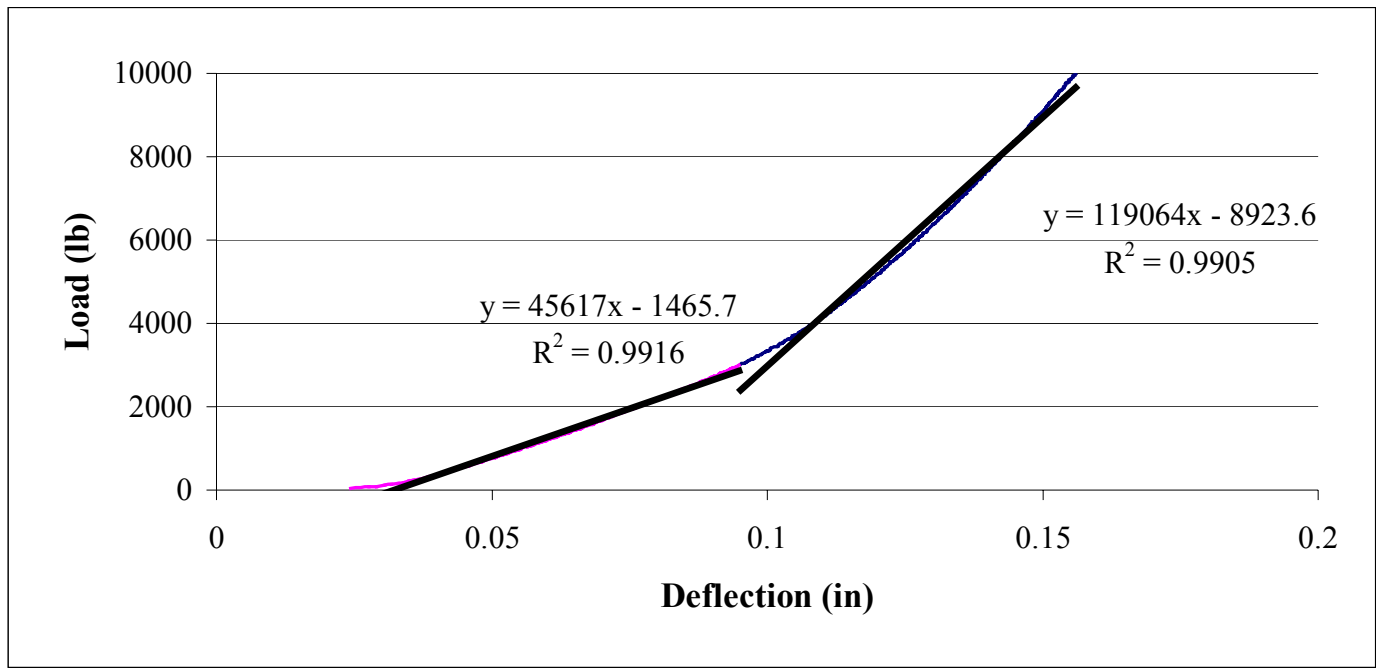

Figure 4.5.11. Stiffness of Pad 2 After 250,000 Cycles of Applied Load

500,000 cycles of applied load were next applied to Pad 2. Figure 4.5.12 shows the stiffness of Pad 2 to be 125.9 kips/in, which is $2 \mathrm{kip} / \mathrm{in}$ higher than the stiffness of the pad before fatigue testing began. The maximum deflection was 0.120 in. The secant modulus after 500,000 cycles was calculated to be $107.8 \mathrm{kips} / \mathrm{in}$.

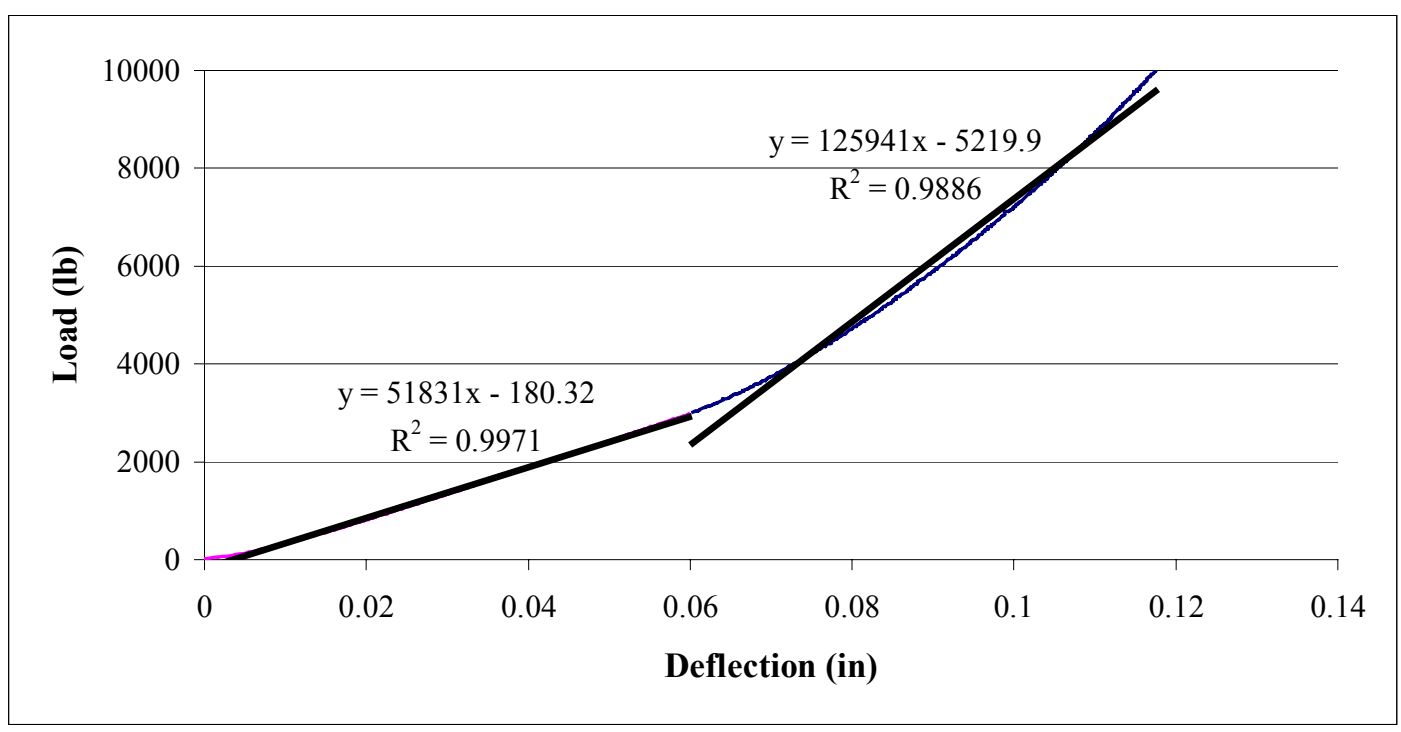

Figure 4.5.12. Stiffness of Pad 2 After 500,000 Cycles of Applied Load 
Although the stiffness value is higher than the original, the secant modulus decreased.

1,000,000 cycles of load were next applied. Figure 4.5.13 shows that the stiffness was calculated to be $117.3 \mathrm{kips} / \mathrm{in}, 5.7 \mathrm{kips} / \mathrm{in}$ less than the original. The maximum deflection was $0.125 \mathrm{in}$. The secant modulus was calculated to be $106 \mathrm{kips} / \mathrm{in}$.

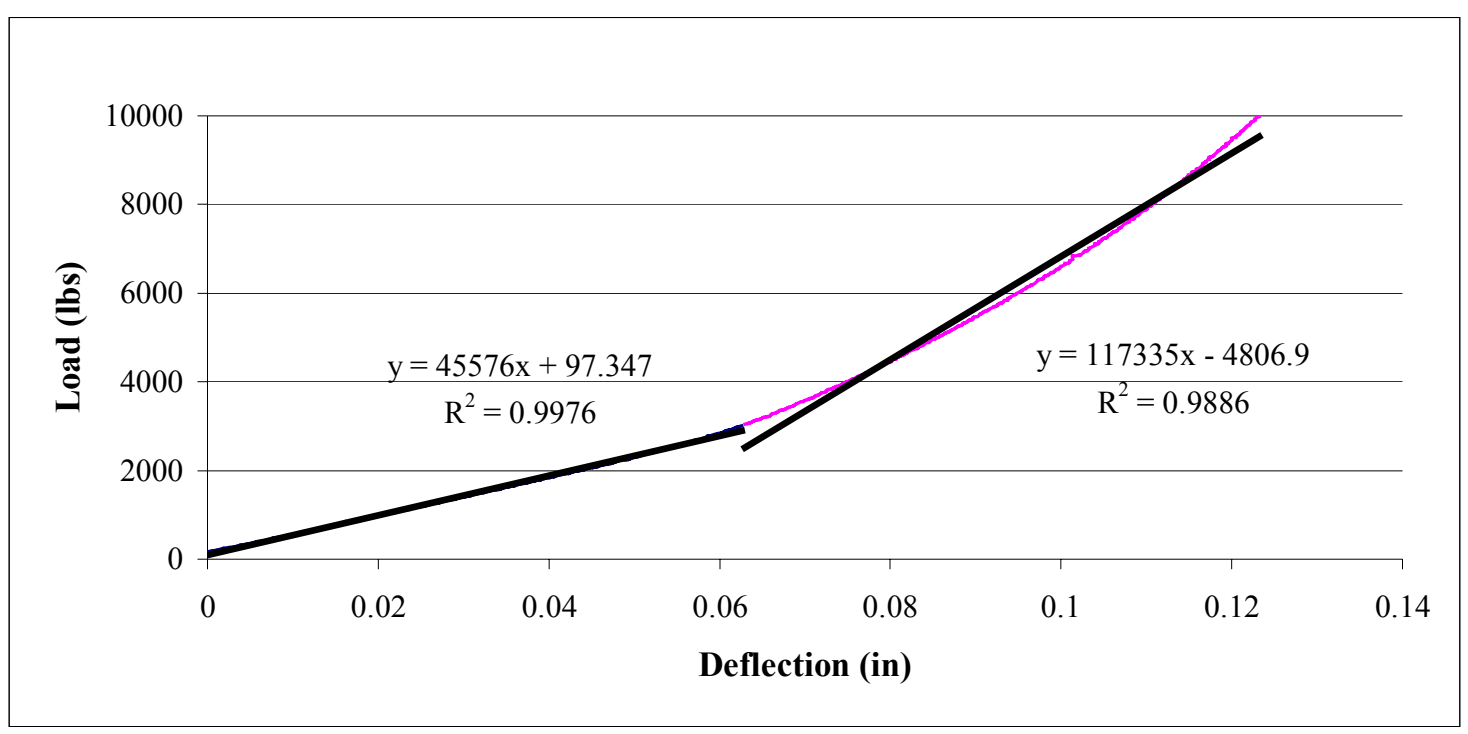

Figure 4.5.13. Stiffness of Pad 2 after 1,000,000 Cycles of Applied Load.

The following tables summarize the results of testing for the two pads.

Table 4.5.1. Stiffness and Secant Modulus for Each Pad at Indicated Number of Cycles

\begin{tabular}{|c|c|c|c|c|}
\hline $\begin{array}{c}\text { Number of } \\
\text { Cycles }\end{array}$ & $\begin{array}{c}\text { Pad } 1 \\
\text { Stiffness }\end{array}$ & $\begin{array}{c}\text { Pad } 2 \\
\text { Stiffness }\end{array}$ & $\begin{array}{c}\text { Pad } 1 \\
\text { Secant Modulus }\end{array}$ & $\begin{array}{c}\text { Pad } 2 \\
\text { Secant Modulus }\end{array}$ \\
\hline 0 & $127.1 \mathrm{kips} / \mathrm{in}$ & $123 \mathrm{kips} / \mathrm{in}$ & $109.3 \mathrm{kips} / \mathrm{in}$ & $112.3 \mathrm{kips} / \mathrm{in}$ \\
\hline 100,000 & $125.6 \mathrm{kips} / \mathrm{in}$ & $123 \mathrm{kips} / \mathrm{in}$ & $109.3 \mathrm{kips} / \mathrm{in}$ & $112.4 \mathrm{kips} / \mathrm{in}$ \\
\hline 250,000 & $117.7 \mathrm{kips} / \mathrm{in}$ & $119 \mathrm{kips} / \mathrm{in}$ & $109.7 \mathrm{kips} / \mathrm{in}$ & $110.4 \mathrm{kips} / \mathrm{in}$ \\
\hline 500,000 & $117.4 \mathrm{kips} / \mathrm{in}$ & $125.9 \mathrm{kips} / \mathrm{in}$ & $108.9 \mathrm{kips} / \mathrm{in}$ & $107.8 \mathrm{kips} / \mathrm{in}$ \\
\hline $1,000,000$ & $116.4 \mathrm{kips} / \mathrm{in}$ & $117.3 \mathrm{kips} / \mathrm{in}$ & $106.1 \mathrm{kips} / \mathrm{in}$ & $106.5 \mathrm{kips} / \mathrm{in}$ \\
\hline
\end{tabular}


Table 4.5.2. Maximum Deflections for Each Pad at Indicated Number of Cycles

\begin{tabular}{|c|c|c|}
\hline $\begin{array}{c}\text { Number of } \\
\text { Cycles }\end{array}$ & $\begin{array}{c}\text { Pad 1 } \\
\text { Deflection }\end{array}$ & $\begin{array}{c}\text { Pad } 2 \\
\text { Deflection }\end{array}$ \\
\hline 0 & 0.110 in & 0.119 in \\
\hline 100,000 & 0.103 in & 0.133 in \\
\hline 250,000 & 0.127 in & 0.156 in \\
\hline 500,000 & 0.137 in & 0.120 in \\
\hline $1,000,000$ & 0.123 in & 0.123 in \\
\hline
\end{tabular}

\subsubsection{Conclusions of Rubber Pad Testing}

After the application of 1,000,000 cycles, the pads exhibited a small decrease in stiffness (about 5\%). Deflections of the pads ranged from $0.110 \mathrm{in}$. to $0.156 \mathrm{in}$. The secant modulus was calculated for each test. The maximum change in the secant modulus was for Pad 2 and was about 6 kips/in. The secant moduli ranged from 106 kips/in to $112 \mathrm{kips} / \mathrm{in}$. There was little visual damage to the pads after 1,000,000 cycles. After $1,000,000$ cycles, the stiffness of Pad I decreased by only $8.4 \%$ and Pad II by only 4.6\%. The secant modulus of Pad I decreased by 3\% after 1,000,000 cycles and 5\% for Pad II. From an analysis viewpoint, pad degradation and loss of stiffness would not be an issue of concern in field applications. 


\subsection{Fiber Reinforced Polymer (FRP) Composite Panel}

\subsubsection{Introduction}

The response of the prestressed concrete panel to axle loads is not only localized to a $5 \mathrm{ft}$ length, but also its weight has limited the ability to install it in field situations. Therefore, a light fiber reinforced polymer (FRP) composite section was designed and tested. The FRP sections solved the weight problem and also exhibited better load distribution characteristics.

Several cross-sections were considered. A rectangular box with dimensions similar to the prestressed concrete section (i.e., 11" x 5") would have a shear (puncture) resistance concern. An I-shaped section would have a similar issue in the flange, as well as a concern with torsional stability. Finally, a two-cell box section was determined to be adequate. However, to fabricate the two-cell box section, two separate FRP box sections (6" $\mathrm{x} 4$ ") were bonded together using an epoxy type adhesive. Figures 4.6.1 and 4.6.2 show the two-cell box bonded together.

The beams were each fifteen (15) feet long. Three (3) high-strength Dywidag rods were used as crossties at discrete intervals. The rods were used to hold the beams in position and maintain the gauge length between rails. From previous experiments on the prestressed concrete panels, it was shown that there was little strain in the crossties during vertical static tests. Therefore, the rods were prestressed with only 500 pounds to hold the beams in place (Figure 4.6.3). A polyurethane adhesive "Pliogrip" manufactured by the Ashland Company was used to attach the steel tee rail to the FRP beams due to its demonstrated ductility and ability to transfer stresses. Twelve (12) strain gages and eight (8) dial gages were used to monitor strain and deflection, respectively. Once again, a plate test was conducted to determine the subgrade modulus and it was found to be $310 \mathrm{pci}$, which is the same as the subgrade modulus for the prestressed concrete panel tests. Therefore, the results from the FRP beams can be compared to the prestressed concrete panel. A cross-section of the beam with the steel rail attached is shown in Figure 4.6.1 and 4.6.3. Figure 4.6.4 shows the set-up of the FRP panel in the gravel bin and 4.6.5 shows the loading location for the first test, a single point load at midspan. 


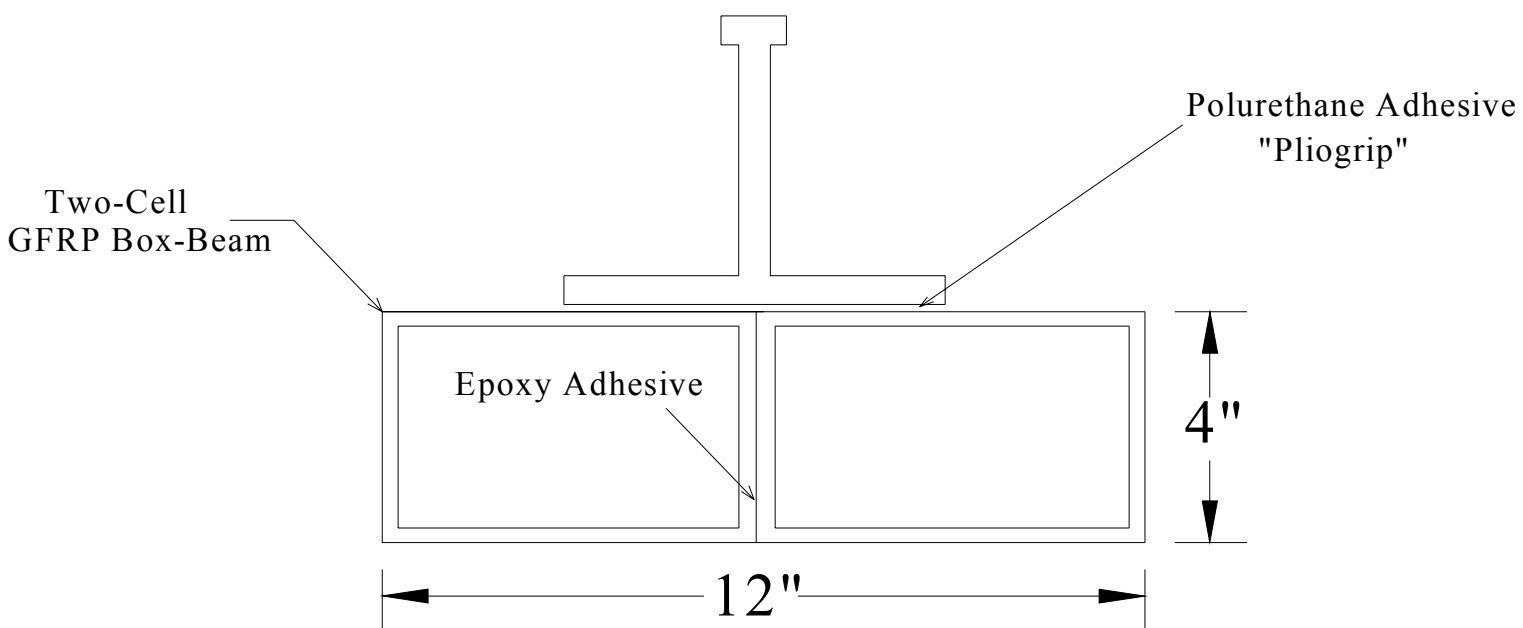

Figure 4.6.1. Cross-Section of FRP Beam with Rail Attached

Figure 4.6.2 shows the two FRP beams bonded together with epoxy. 5/8" high-strength dywidag rods were used to hold the beams together during the curing process.

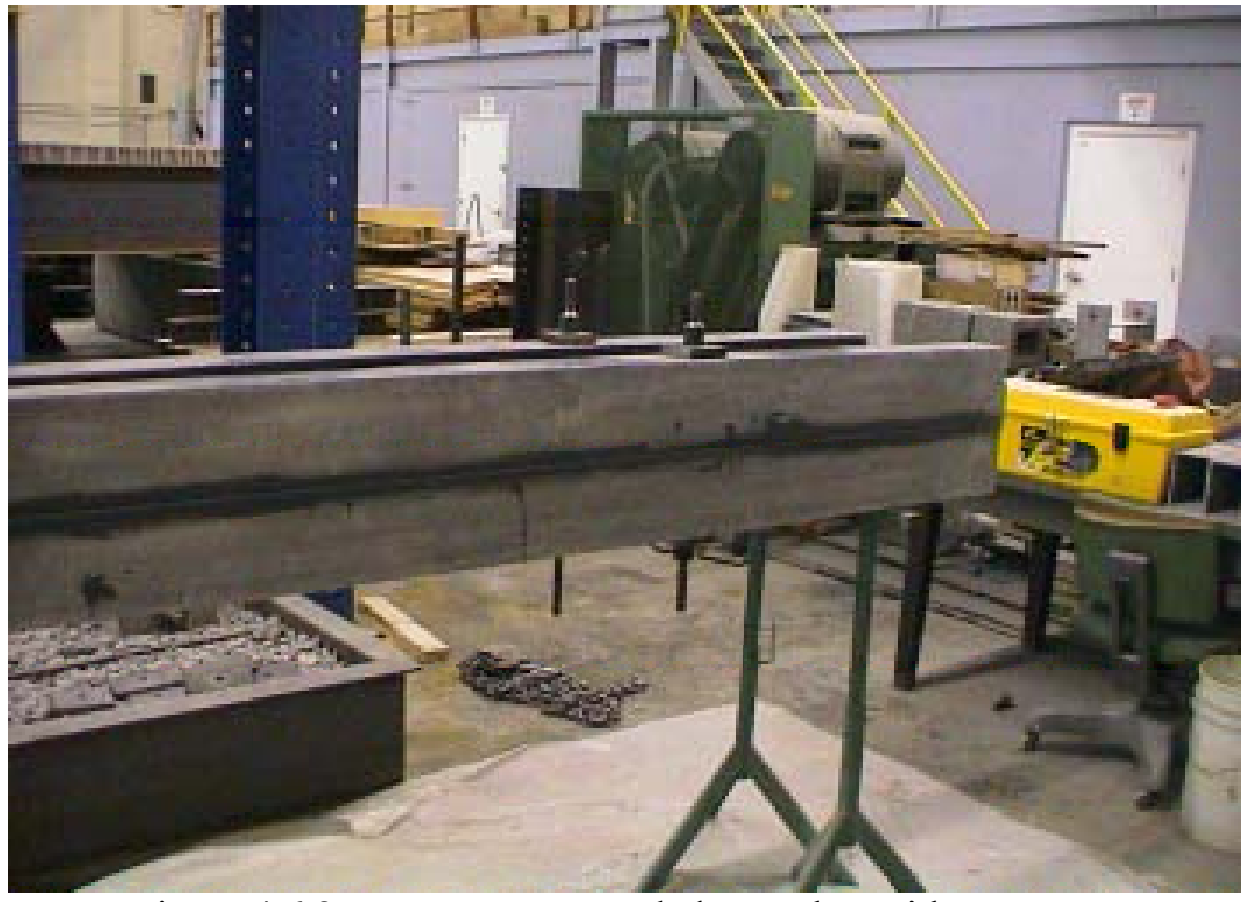

Figure 4.6.2. FRP Beams Bonded Together with Epoxy 


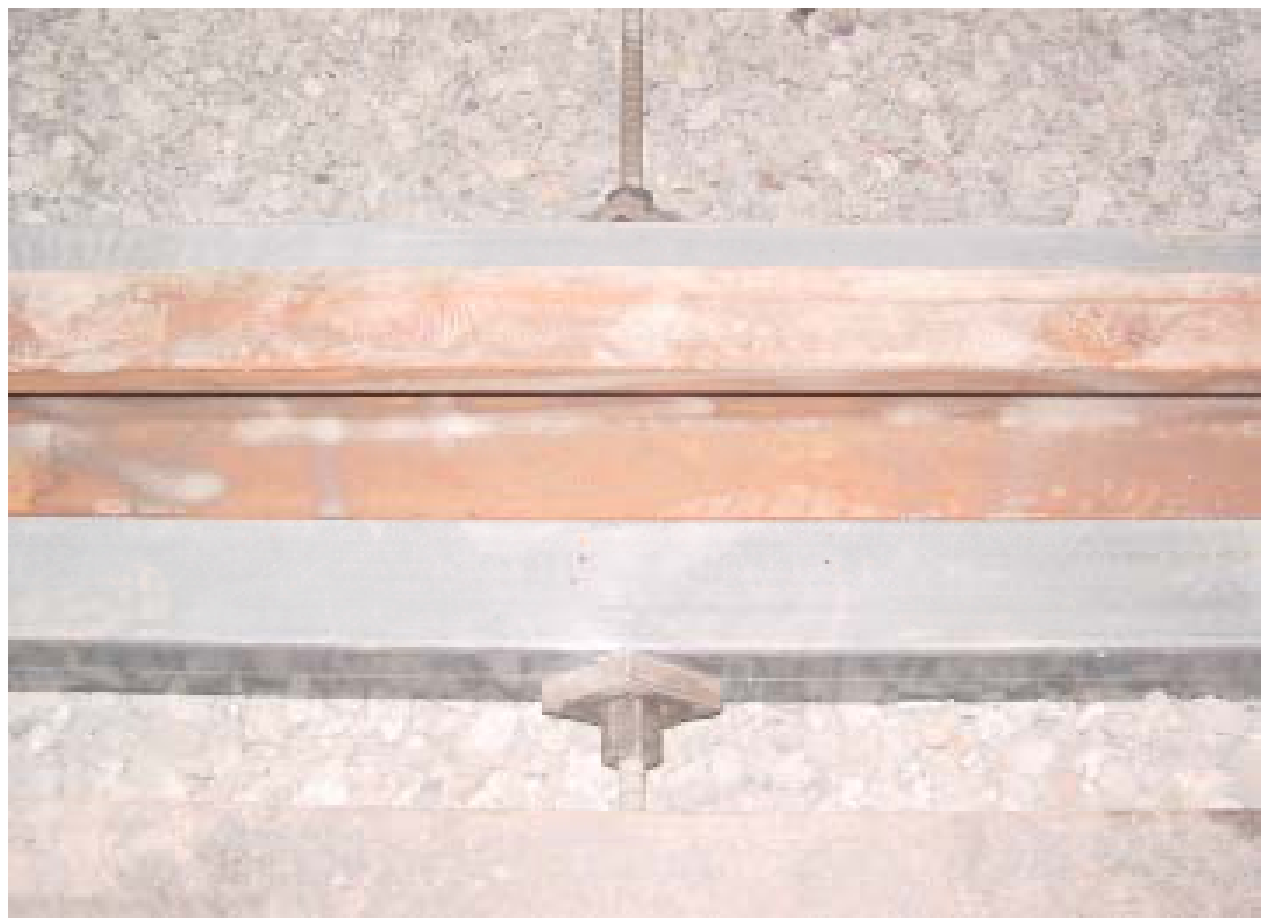

Figure 4.6.3. High-Strength Dywidag Rod Used as Crosstie

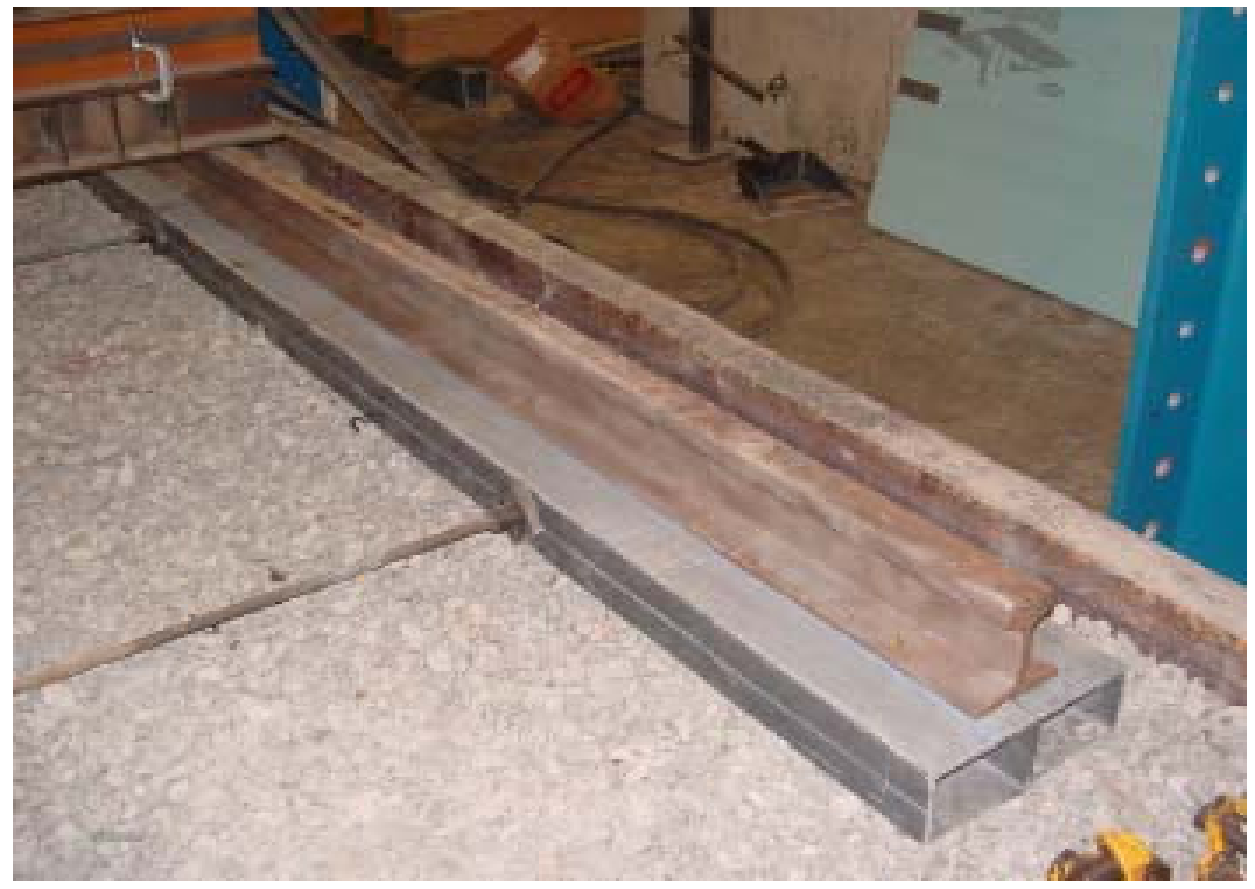

Figure 4.6.4. FRP Panel Set-Up in Gravel Bin 


\subsubsection{Single Point Load At Midspan}

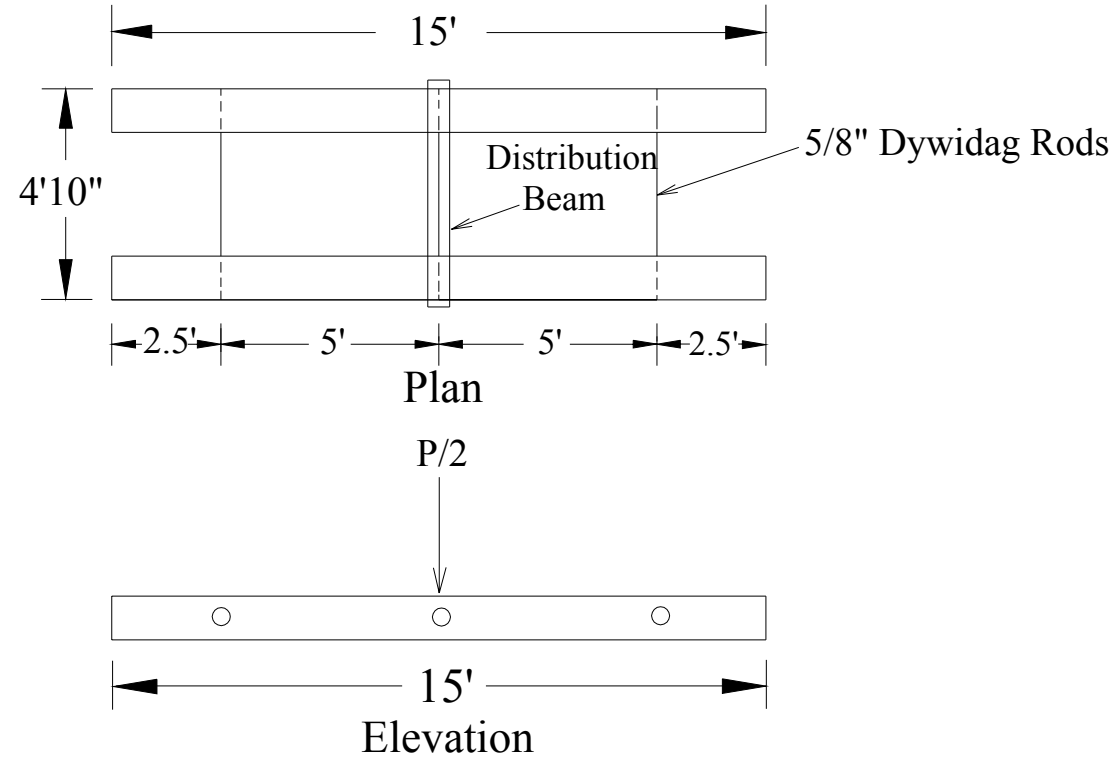

Figure 4.6.5. Schematic for Single Point Load at Midspan Test

The first test conducted was under a single point load at midspan. The maximum load applied was 20 kips, which produced a load of 10 kips on each beam. Two load cells under the distribution beam were used measure the load of each beam. Figure 4.6.6 shows the deflection of the beam at the load of 10 kips. From Figure 4.6.6, the maximum deflection is at the center and is 0.111 in, compared to 0.065 in for the prestressed concrete panel. The ends of the beam experienced an uplift of $0.020 \mathrm{in}$. The deflected shape indicates the beam acts very much in a symmetrical manner. 


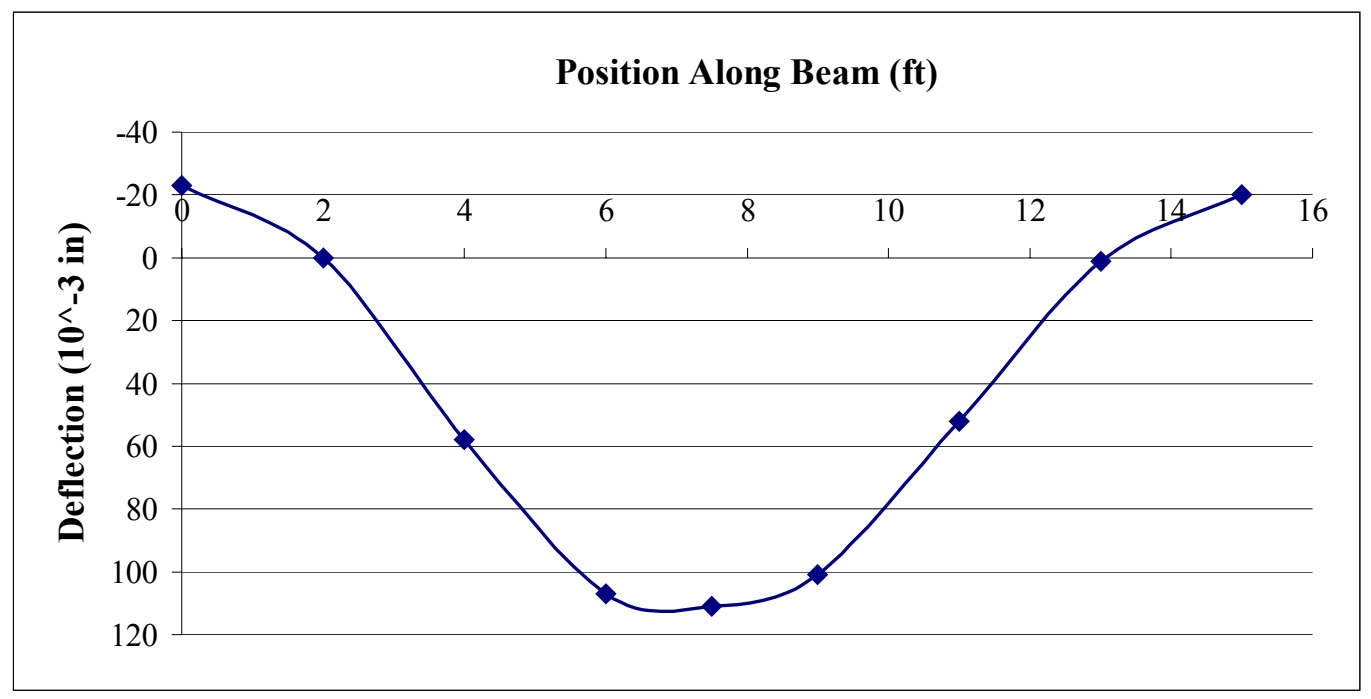

Figure 4.6.6. Deflection of Beam Under Single Point of 10 kips Load Applied At Midspan

Figure 4.6.7 gives the load distribution based on deflection. It was found from the previous tests that the three pads at midspan (middle third of beam) carried $64 \%$ of the load over a $5 \mathrm{ft}$ span. Results from the FRP beams show that $74 \%$ of the load is carried by the middle third of the beam. Only the positive values of deflection were used to determine the load distribution.

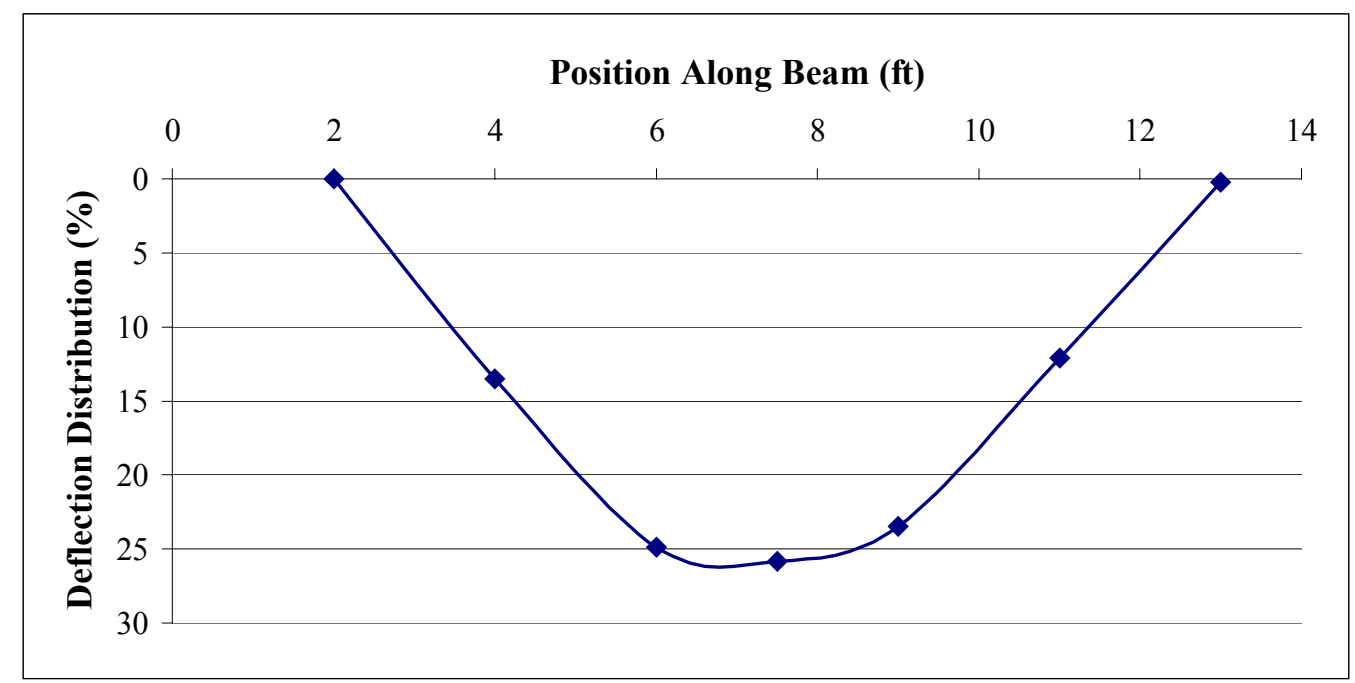

Figure 4.6.7. Load Distribution from Deflection for Single Load Applied At Midspan

Figure 4.6.8 shows the strain values for this set of tests. The highest strain value is at the center, as expected, and has a value of $147 \times 10^{-6} \mathrm{in} / \mathrm{in}$. The strain has a linear shape 
compared to the prestressed concrete panel results, which had a parabola. The reason for this may be the localized nature of strain measurements.

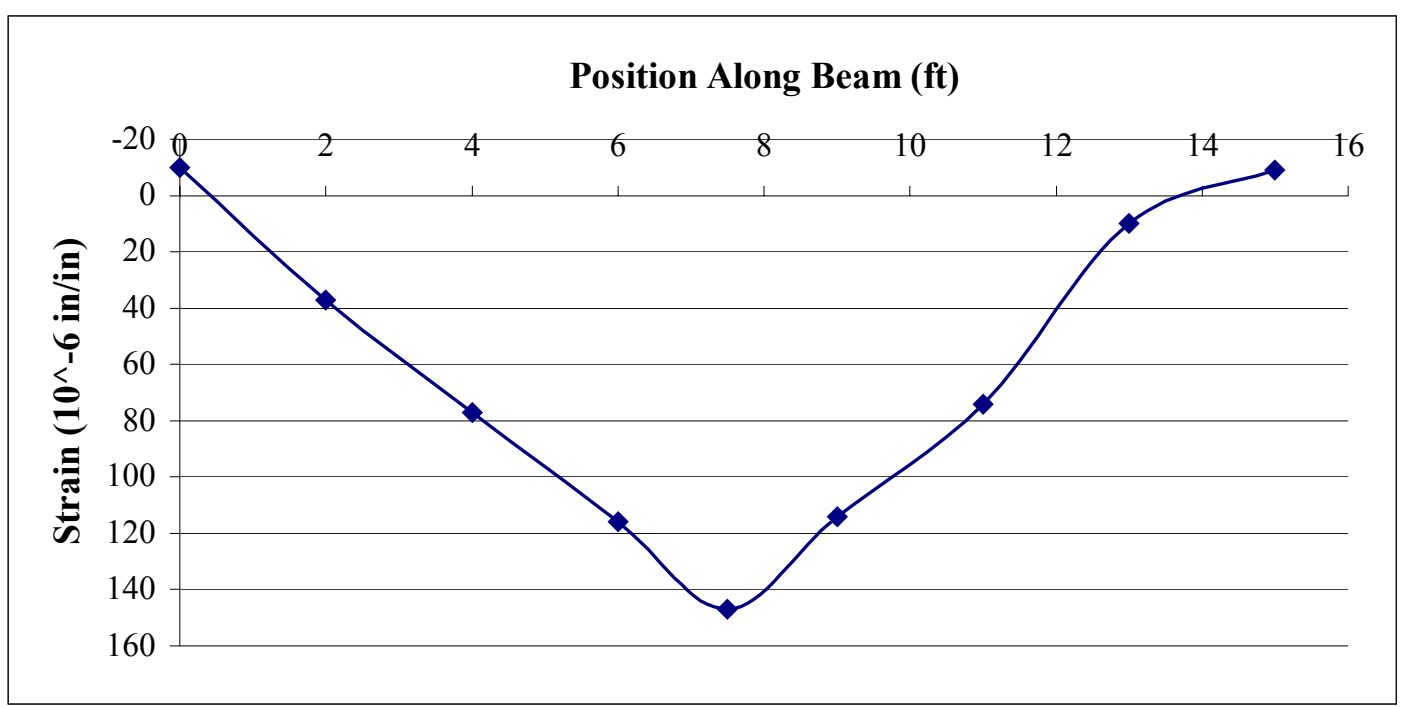

Figure 4.6.8. Strain of FRP Beam Under Single Point Load of 10 kips Applied at Midspan

Figure 4.6.9 shows the strain distribution for the beam under the single point load at midspan. It shows that $66 \%$ of the load is carried by the middle third of the beam. Compared to the prestressed concrete beam, the center of the FRP beam experiences $26 \%$ of the load, while the central pad of the prestressed concrete beam experienced $37 \%$ of the load. The strain distribution is very localized as compared to deflection, which is more global.

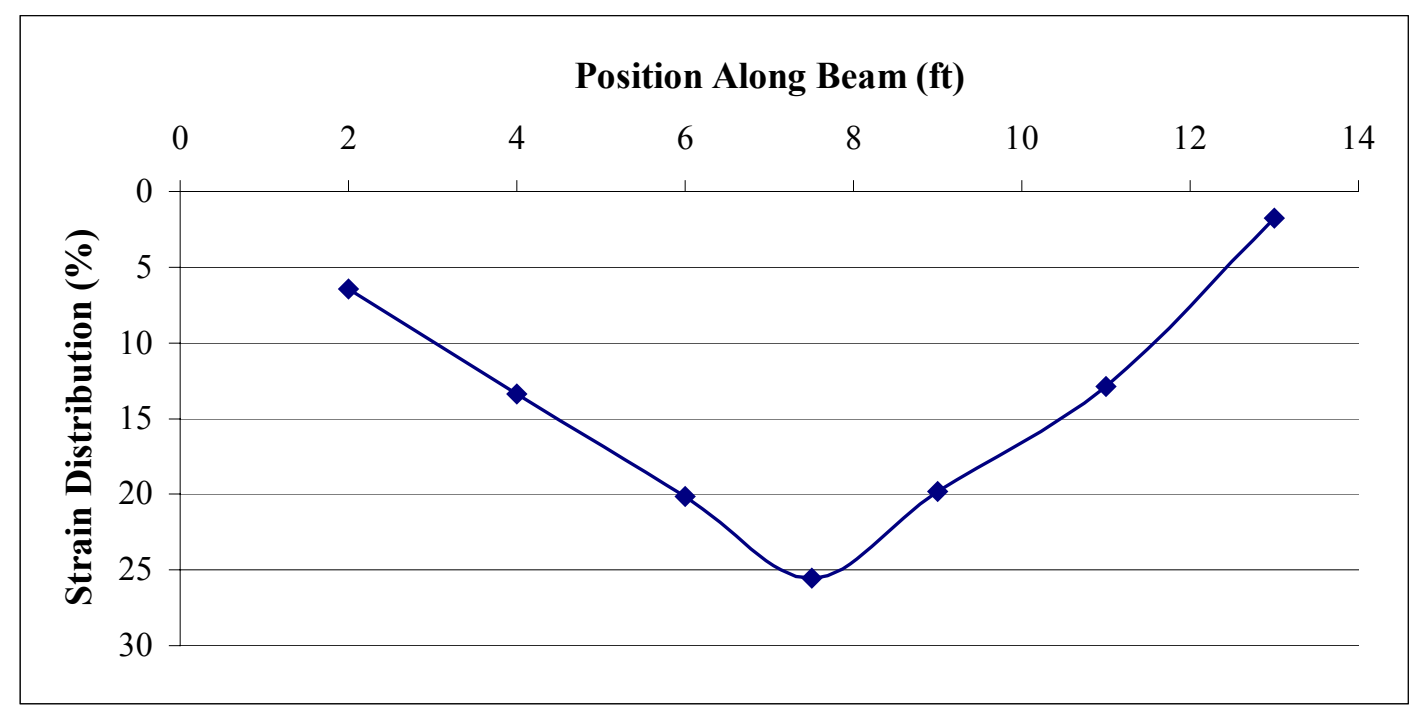

Figure 4.6.9. Strain Distribution for Single Point Load of 10 kips Applied at Midspan 
Figure 4.6.10 provides the load versus pressure in the foundation during static loading. The maximum pressure occurred at the maximum load and had a value of $47 \mathrm{psi}$. The maximum for the same test on the prestressed concrete panel was 7.6 psi. The pressure cell was located at the same location for both the FRP panel and prestressed concrete panel. The pressure is much higher for the FRP panel because the measured pressure is localized under the FRP panel, where it is better distributed under the prestressed concrete panel.

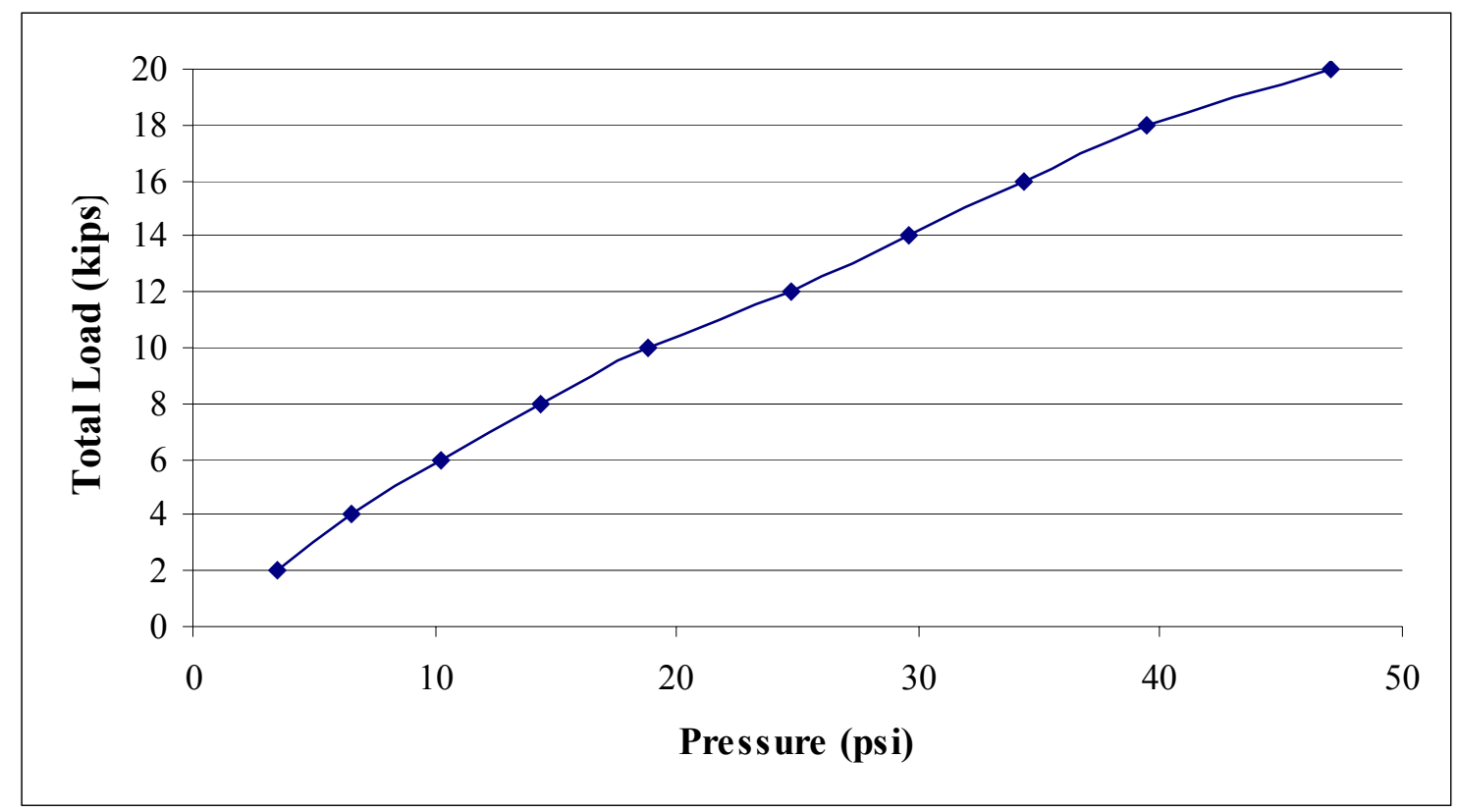

Figure 4.6.10. Pressure of Foundation for Single Point Load of 10 kips at Midspan 


\subsubsection{Single Point Load at Center of Midspan and Left Crossties}

The beam was next tested under a single point load statically applied at the center of the midspan and left cross-tie at a position of five feet from the left end (Figure 4.6.11). Figure 4.5.12 shows the deflection results from this test. The maximum deflection is 0.073 in at the location of the applied load, compared to 0.076 in for the prestressed concrete panel. It can be seen that the first six feet of the beam experiences nearly the same deflection. The right end of the FRP beam experienced an uplift of $0.040 \mathrm{in}$.

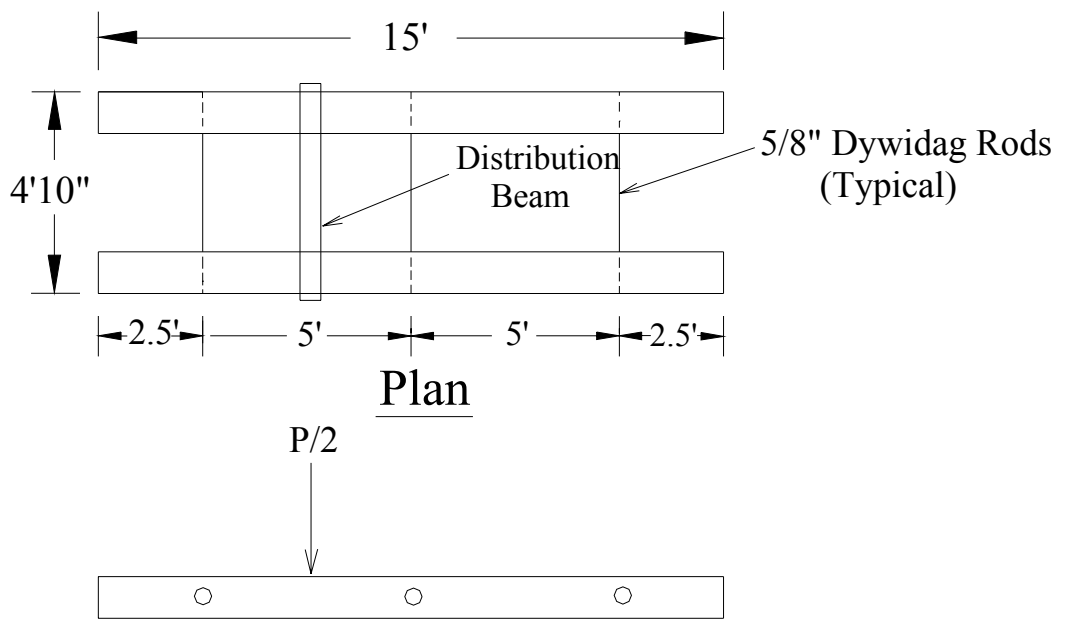

\section{Elevation}

Figure 4.6.11. Schematic for Single Point Load at Center of Midspan and Left Crossties 


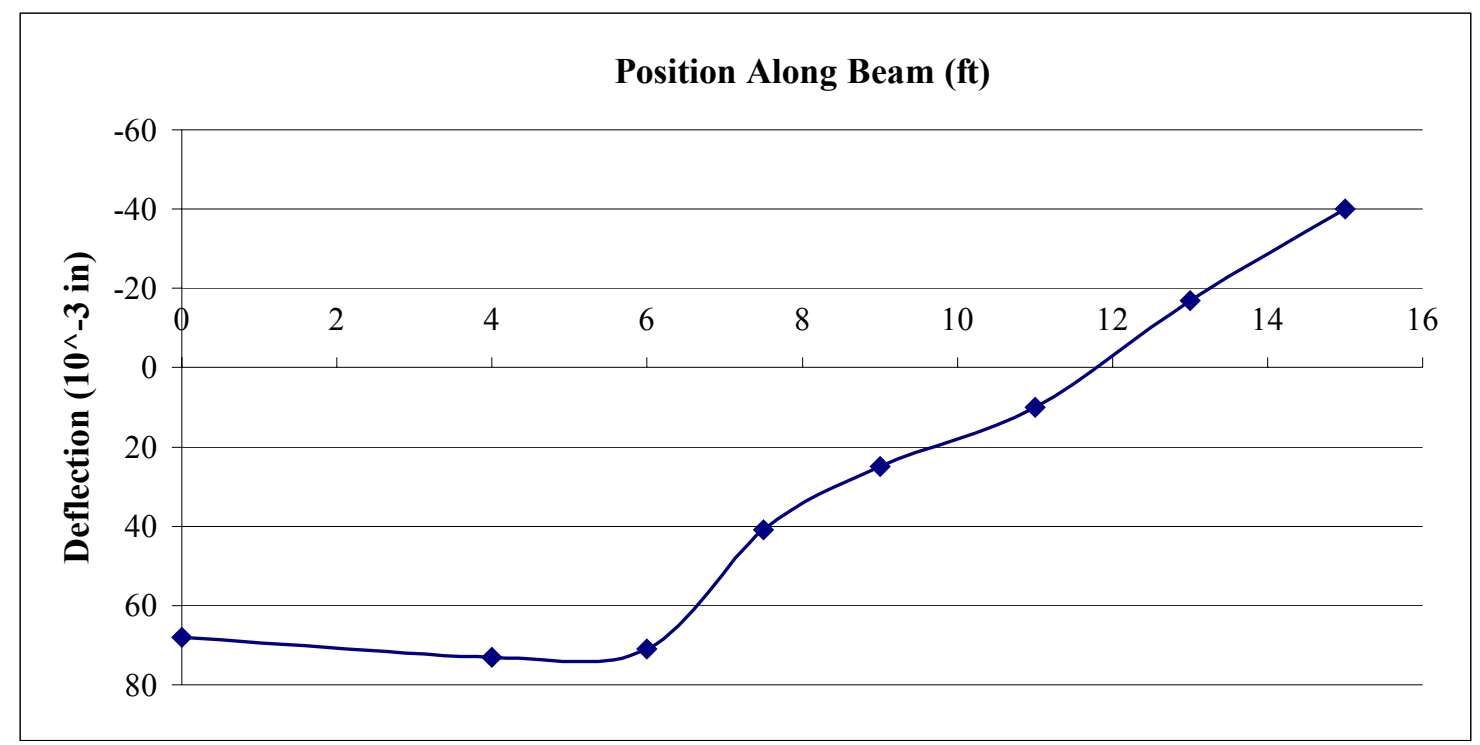

Figure 4.6.12. Deflection of FRP Beam Under Single Point Load of 10 kips Applied at Center of Midspan and Left Crossties

Figure 4.6.13 gives the load distribution based on deflection. It shows that $74 \%$ of the load is carried by the first six feet of the beam. The left end of the beam acted like a rigid body with a hinge at midspan.

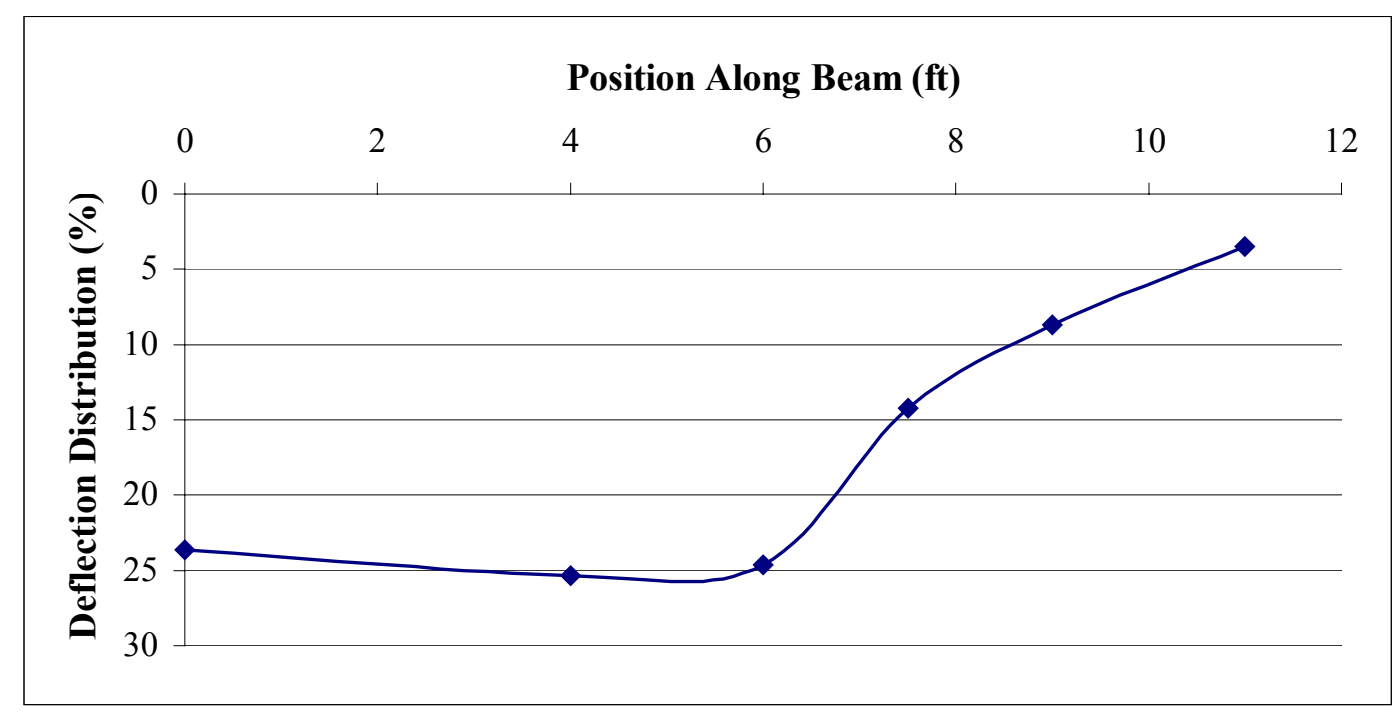

Figure 4.6.13. Load Distribution Based on Deflection for Single Point Load of 10 kips Applied at the Center of the Midspan and Interior Crossties

Figure 4.6.14 gives the values of strain for the test. The maximum strain value was found to be $135 \times 10^{-6}$ in/in. The shape of the strain values resembles the deflection results, except that the left end does not appear to be as significantly affected by the point load. 


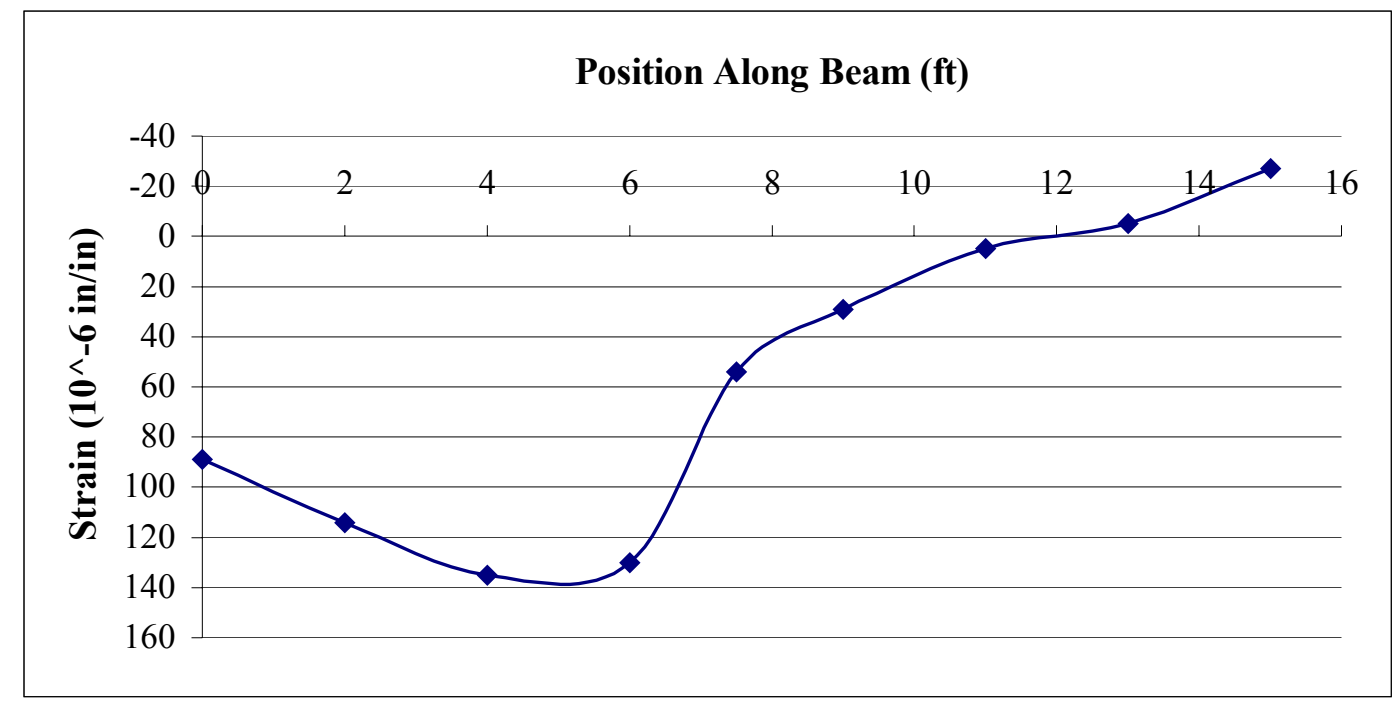

Figure 4.6.14. Strains in the FRP Beam Under a Single Point Load of 10 kips Applied at The Center of Midspan and Left Crossties

The load distribution based on strain is plotted in Figure 4.6.15. It shows that $84 \%$ of the load is carried from the left to the six feet mark.

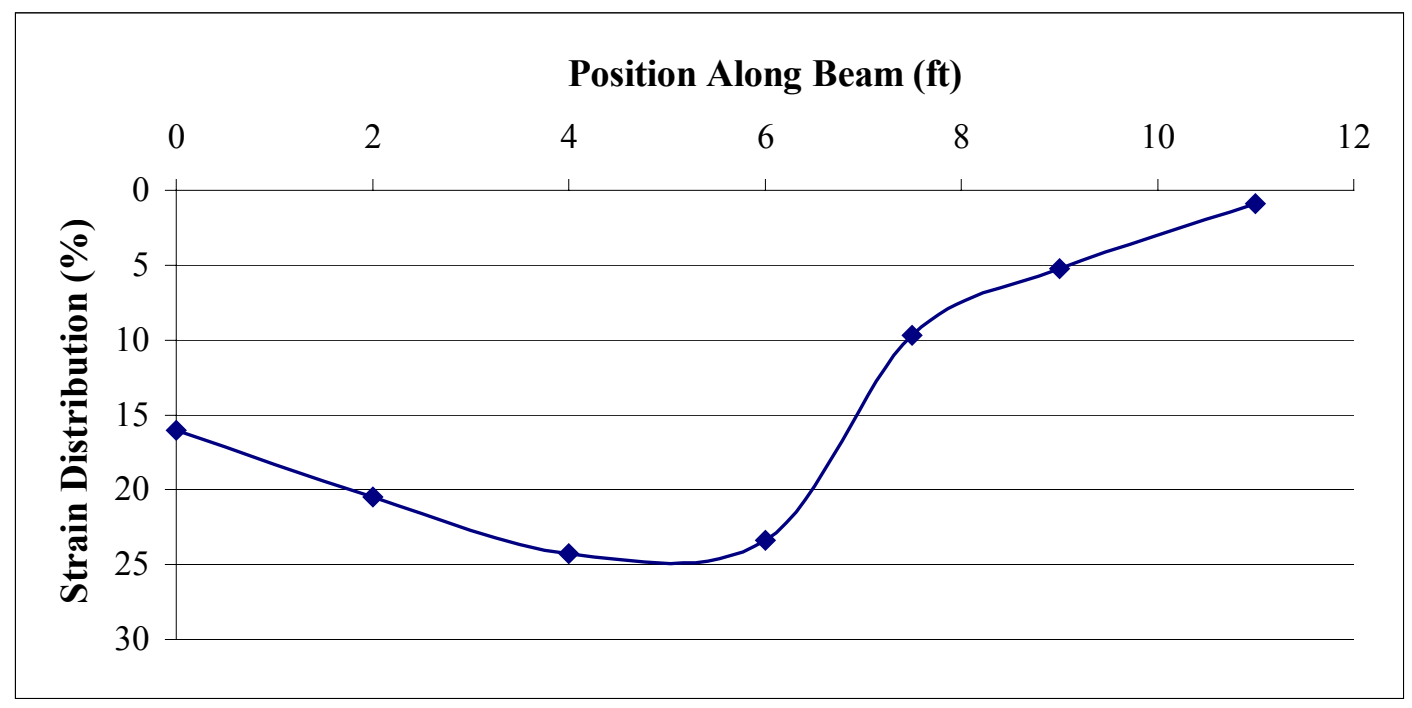

Figure 4.6.15. Load Distribution Based on Strain for Single Point Load of 10 kips Applied At The Center of Midspan and Left Crossties

Figure 4.6.16 shows the foundation pressure experienced for this test. It shows that the maximum pressure was 36 psi. The maximum pressure of the prestressed concrete panel for this test was 8.1 psi. 


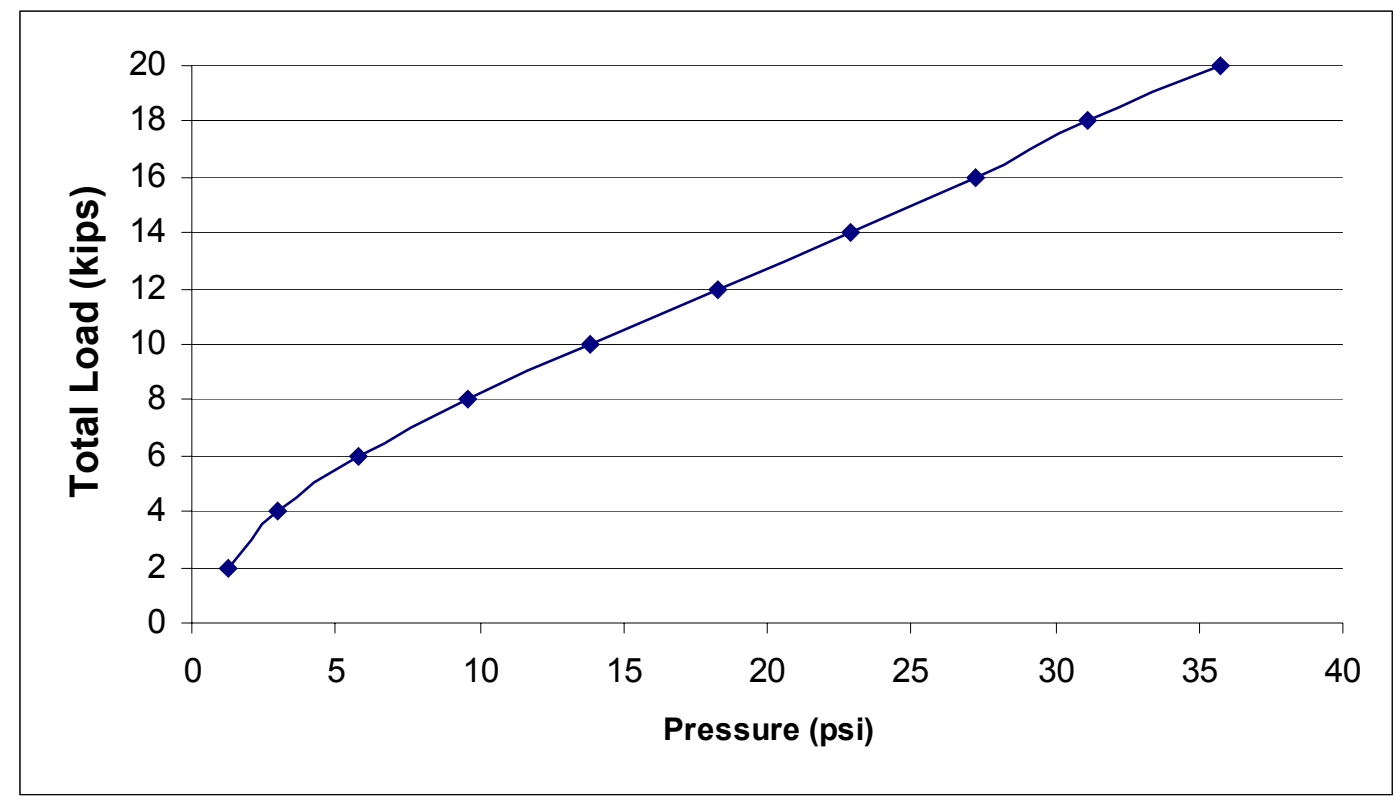

Figure 4.6.16. Pressure for Single Point Load of 10 kips Applied the Center of Midspan and Left Crossties

\subsubsection{Single Point Load at Center of Midspan and Right Crosstie}

The FRP beam was next tested at the center of the midspan and right cross-tie at a location of $10 \mathrm{ft}$. Figure 4.5 .18 shows the deflection results from this test. The maximum deflection is $0.076 \mathrm{in}$, compared with 0.073 in for the prestressed concrete panel. An uplift of 0.037 in was experienced by the left end of the FRP panel. This deflected shape resembles the deflected shape for the previous test when loaded at the opposite end, indicating the beam acts in a symmetric manner. 


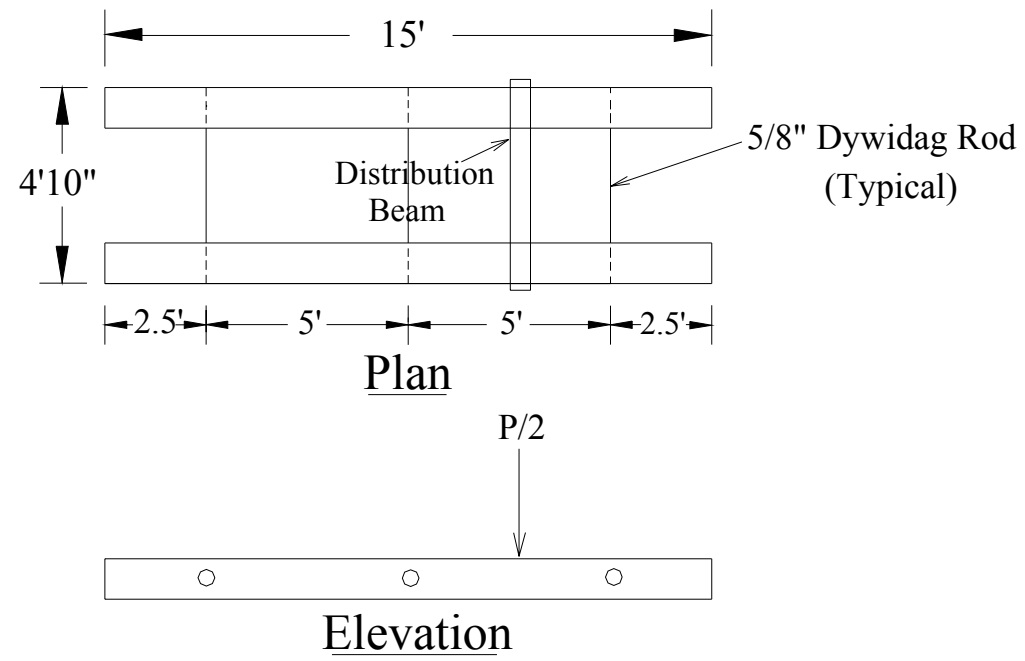

Figure 4.6.17. Schematic for Single Point Load at Center of Midspan and Right Crosstie

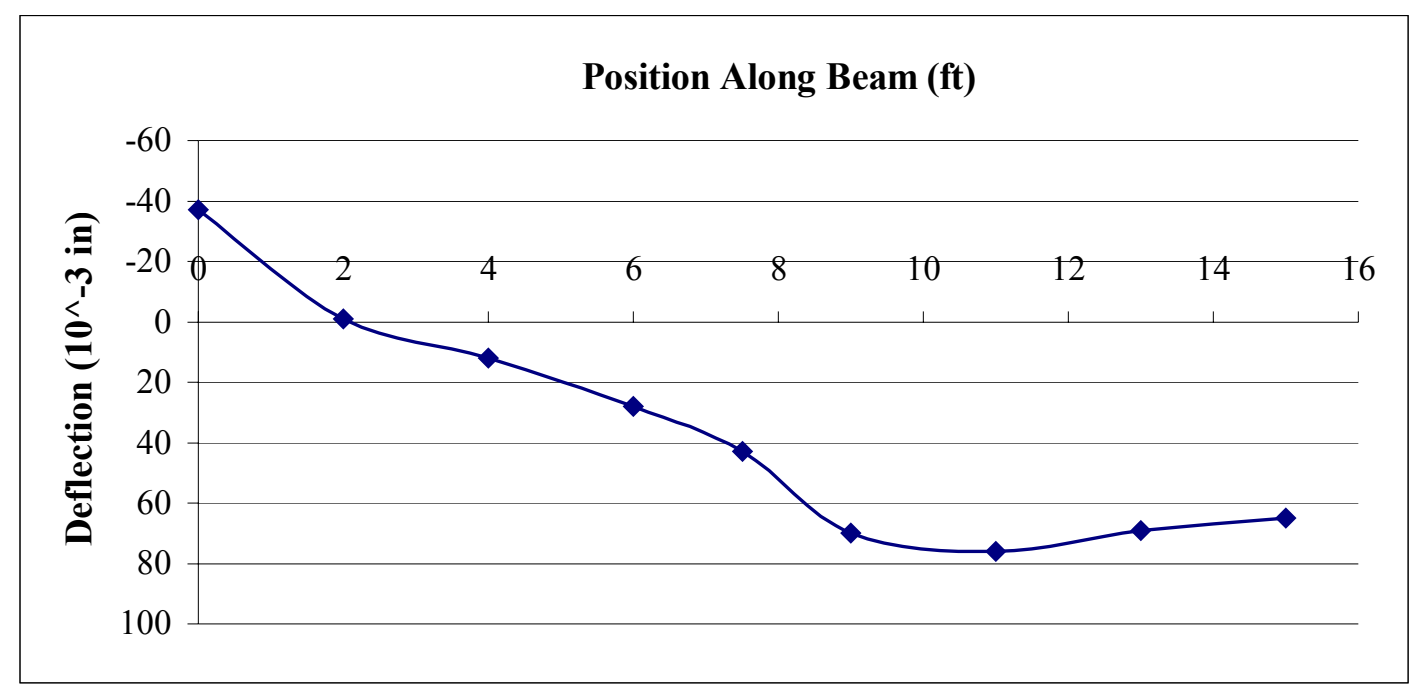

Figure 4.6.18. Deflection Values of FRP Beam Under Single Point Load of 10 kips Applied At Center of Midspan and Right Crosstie

Figure 4.6.19 shows the load distribution based on deflection. Once again, only positive values were taken for consideration. $77 \%$ of the load acts on the right $7 \mathrm{ft}$ of the beam. 


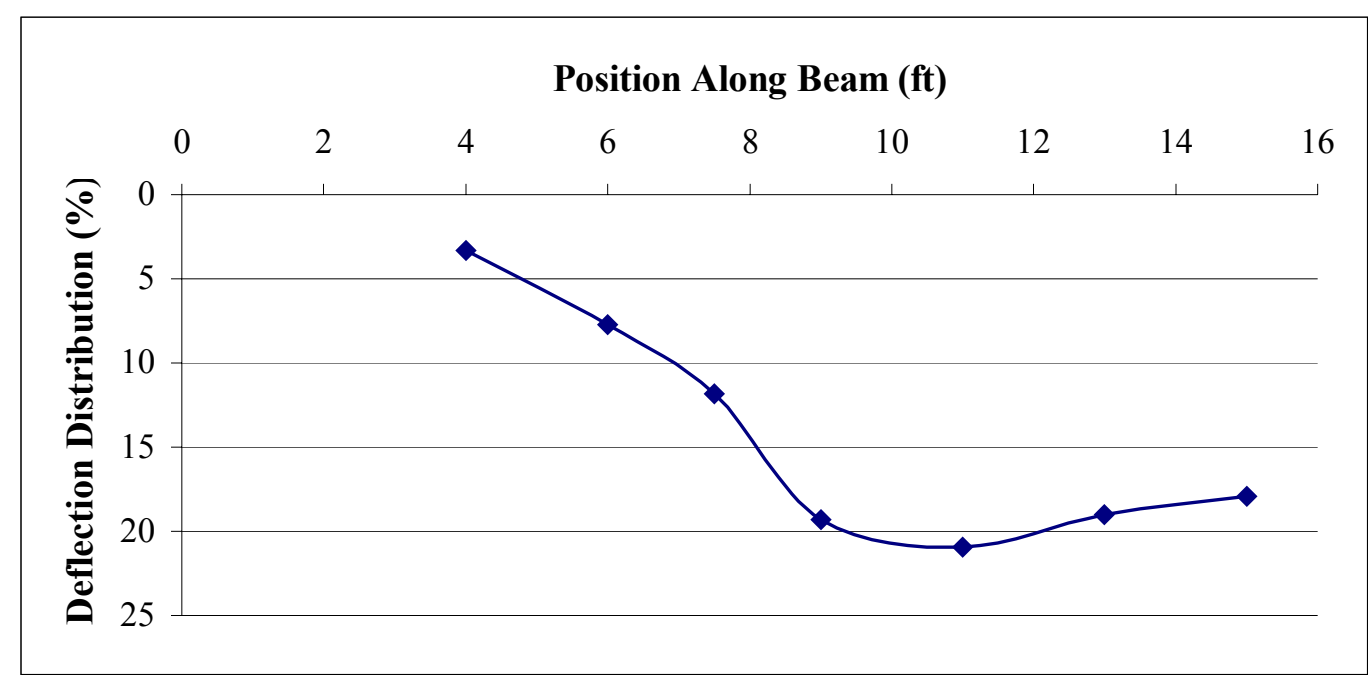

Figure 4.6.19. Load Distribution Based on Deflection for Single Point Load of 10 kips Applied at Center of Midspan and Right Crosstie

Figure 4.6.20 shows the strain values for this test. The maximum value was $145 \times 10^{-6}$ in/in. The plot of the strain values resembles the shape of the deflection.

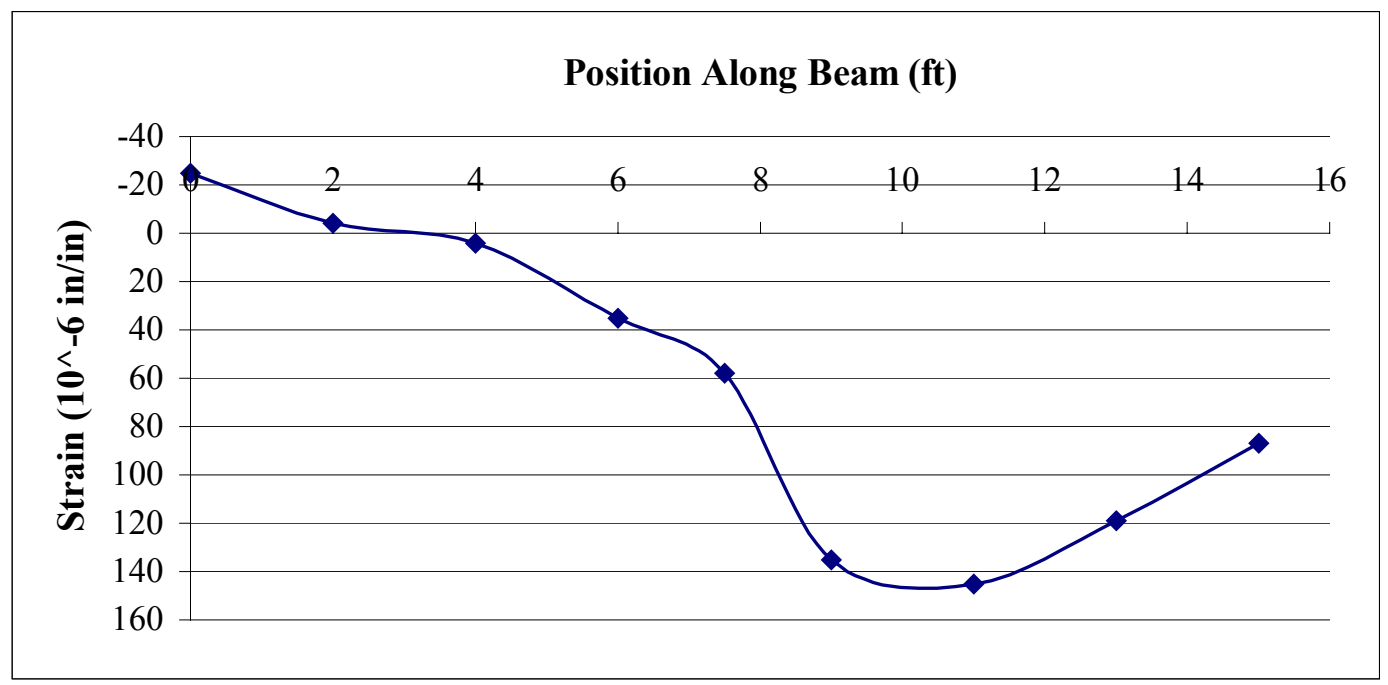

Figure 4.6.20. Strain Values FRP Beam Under Single Point Load of 10 kips Applied At Center of Midspan and Right Crosstie

Figure 4.6.21 shows the load distribution based on strain. It shows that $83 \%$ of the load is carried by the right end to the nine feet mark. 


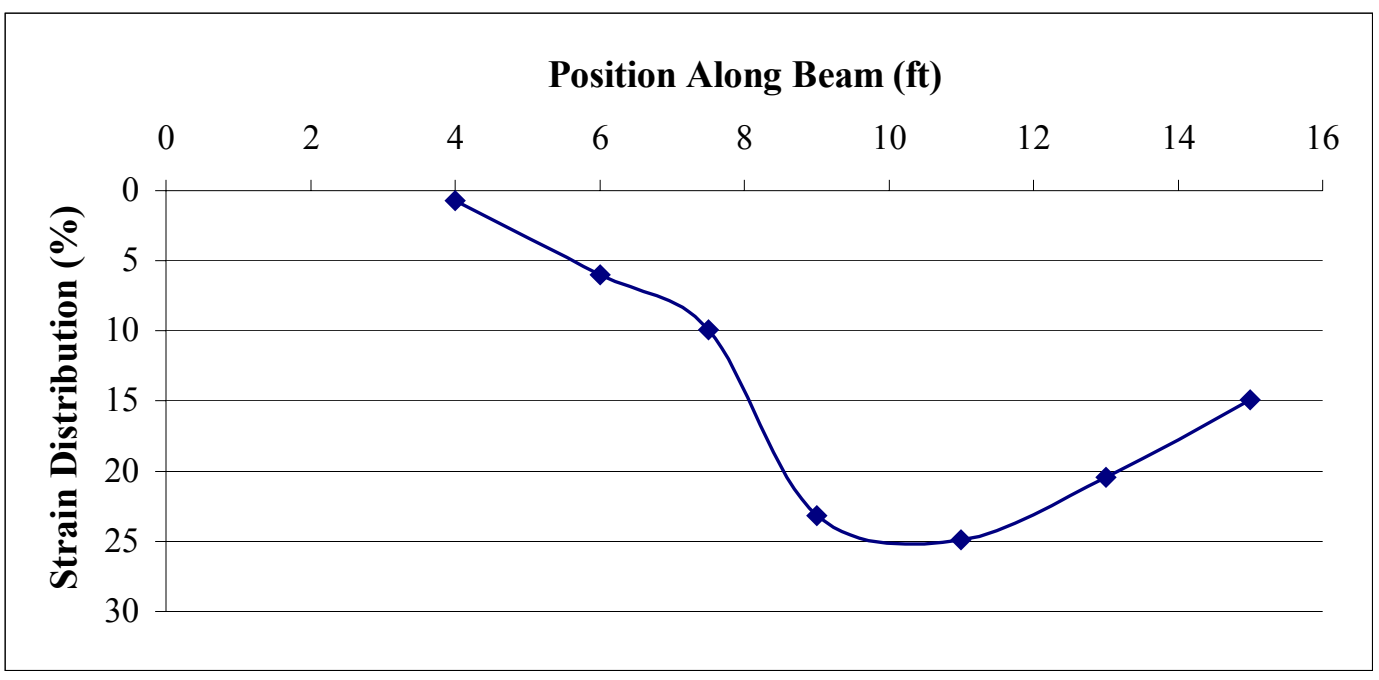

Figure 4.6.21. Load Distribution Based on Strain for Single Point Load of 10 kips Applied at Center of Midspan and Right Crosstie

Figure 4.6.22 shows the pressure of the foundation for this test. The maximum pressure was 38 psi. The same test on the prestressed concrete panel yielded a pressure of 1.85 psi.

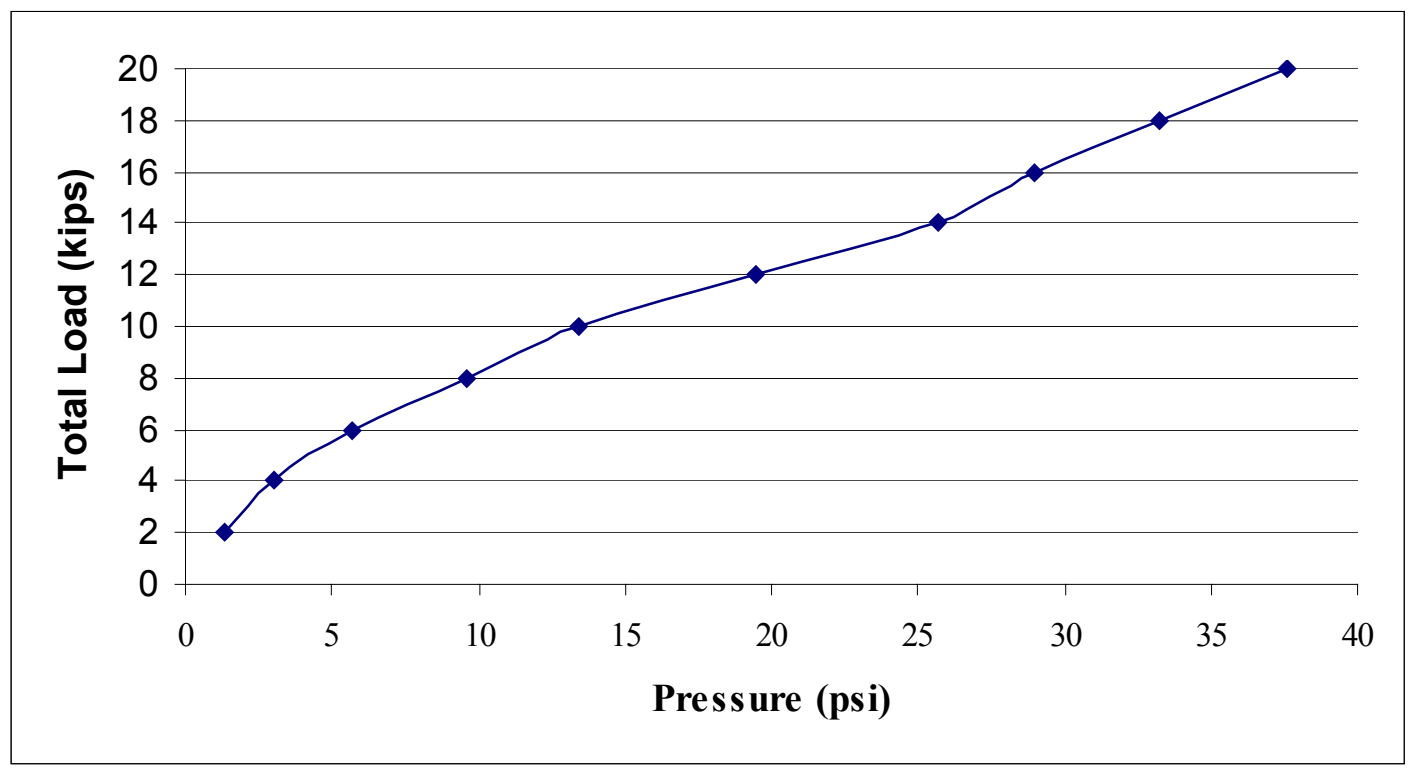

Figure 4.6.22. Pressure for Single Point Load of 10 kips Applied the Center of Midspan and Right Crossties 


\subsubsection{Two Point Loads Centrally Applied At Midspan}

The next series of tests consisted of two point loads on each beam as shown in Figure 4.6.23.

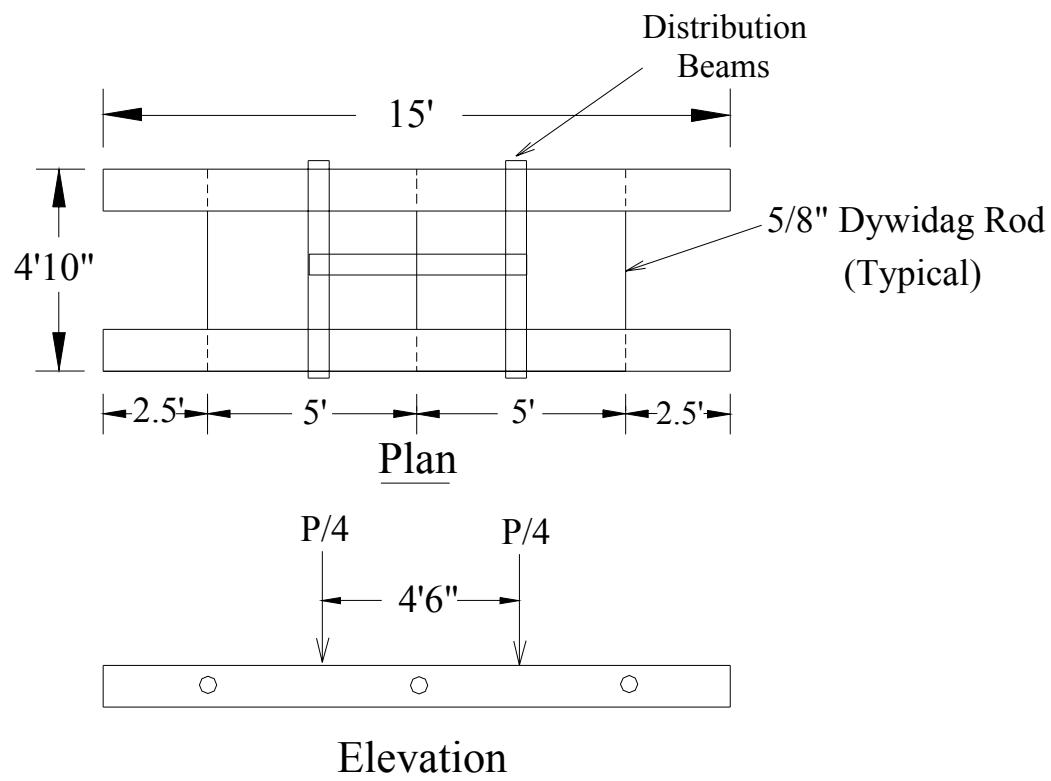

Figure 4.6.23 Schematic for Two Point Loads Centrally Loaded at Midspan

A total load of 40 kips was applied to simulate the load provided by a two-axle "mine car." Figure 4.6.24 shows the deflection result from this test. The two point load tests show that the FRP panel exhibits better load distribution compared to the prestressed concrete panel. The FRP beam had a maximum deflection of $0.100 \mathrm{in}$. This value is very close to the maximum deflection obtained from the prestressed concrete panel of 0.093 in. The deflection of the prestressed concrete panel almost entirely occurred within four or five feet of the loaded area. Observations of Figure 4.5.24, however, show that the deflection of the FRP beam has nearly the same values for seven feet (four feet mark to the eleven feet mark), i.e., a wider distribution width than the $5 \mathrm{ft}$ length of the prestressed concrete panel. 


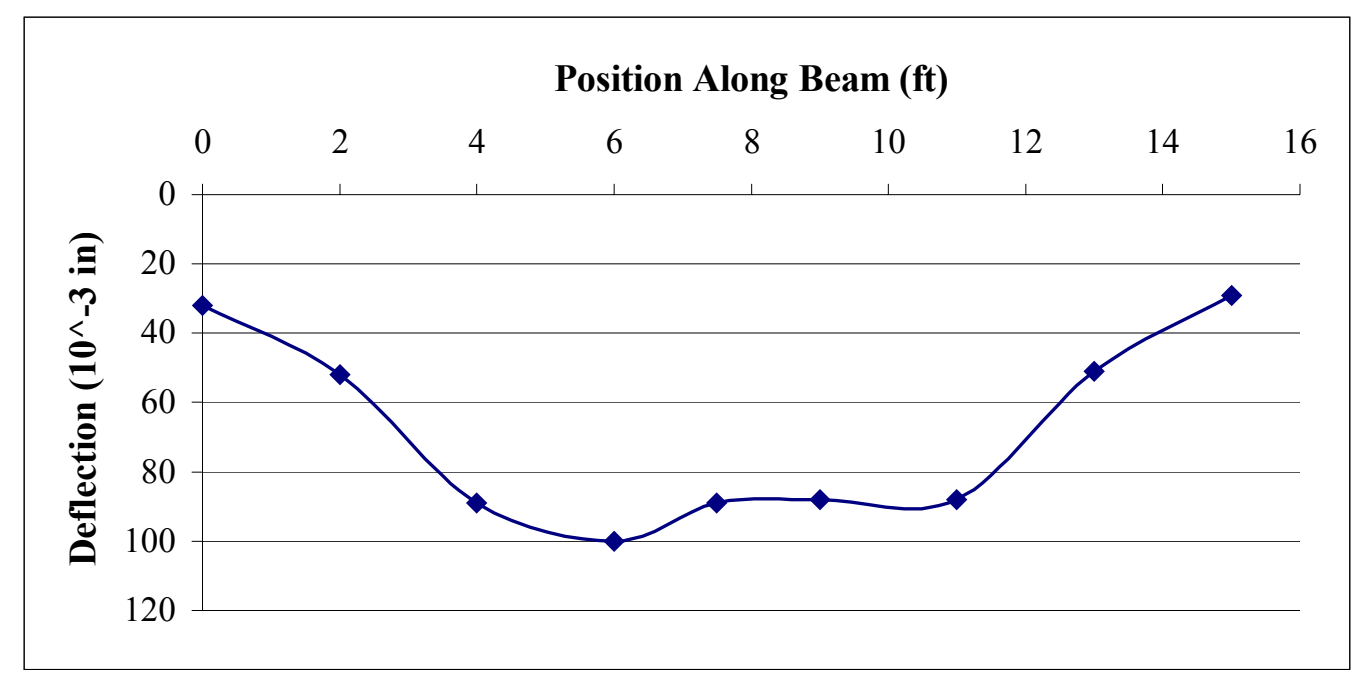

Figure 4.6.24. Deflection Values for Two Point Loads Applied Centrally At Midspan

Figure 4.6.25 shows the load distribution based on deflection. It is shown that $14-16 \%$ of the load is distributed to five different locations. These five location carry $73 \%$ of the load. Three pad locations on the prestressed concrete panel carried $64 \%$ of the load, where two pads alone carried $24 \%$ each. The highest value any location has for the FRP panel is $16 \%$.

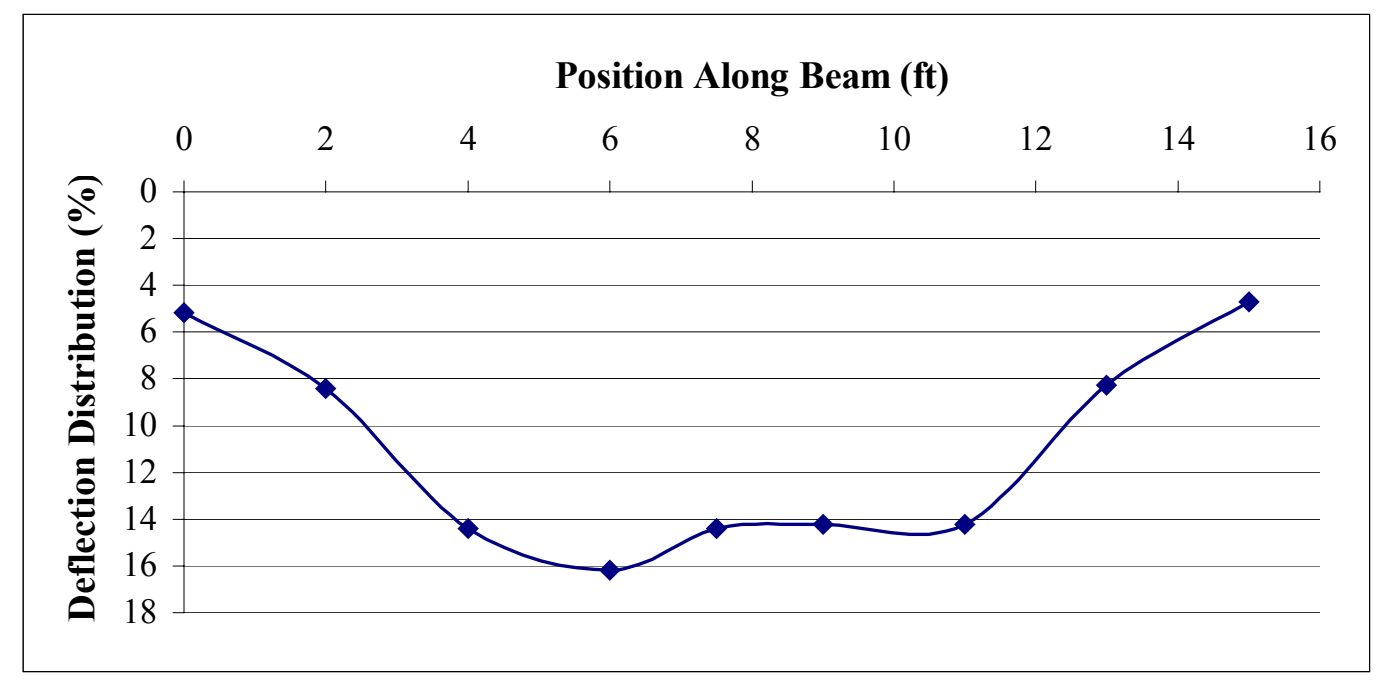

Figure 4.6.25. Load Distribution from Deflection for Two Point Loads Applied Centrally At Midspan

Figure 4.6.26 shows the strain values obtained during this test. The highest value of strain obtained was $91 \times 10^{-6} \mathrm{in} / \mathrm{in}$. The loading provided an almost perfect symmetric shape. 


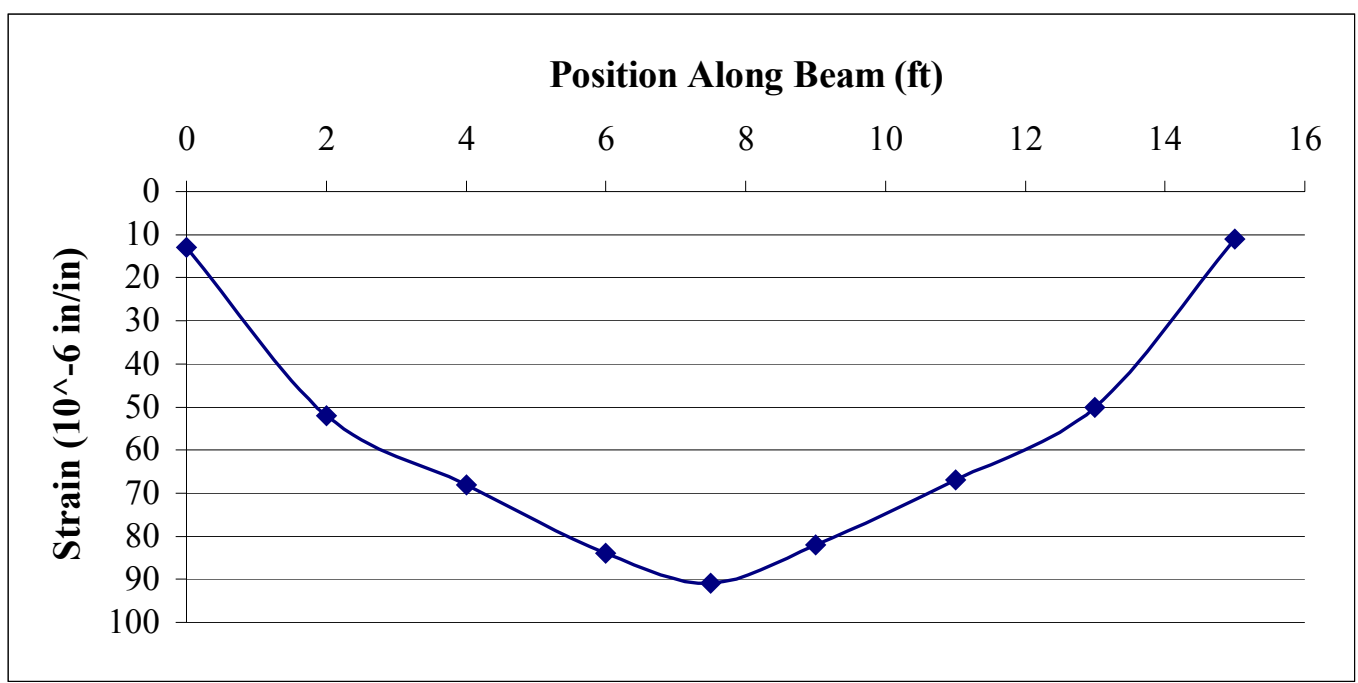

Figure 4.6.26. Strain Values for Two Point Loads Centrally Loaded At Midspan

Figure 4.6.27 shows the load distribution based on strain for this test. Once again, the beam distributes almost perfect load distribution. The same five locations as mentioned above in deflection consideration carry $75 \%$ of the load. The three central pad locations on the prestressed concrete panel carried $77 \%$ of the load.

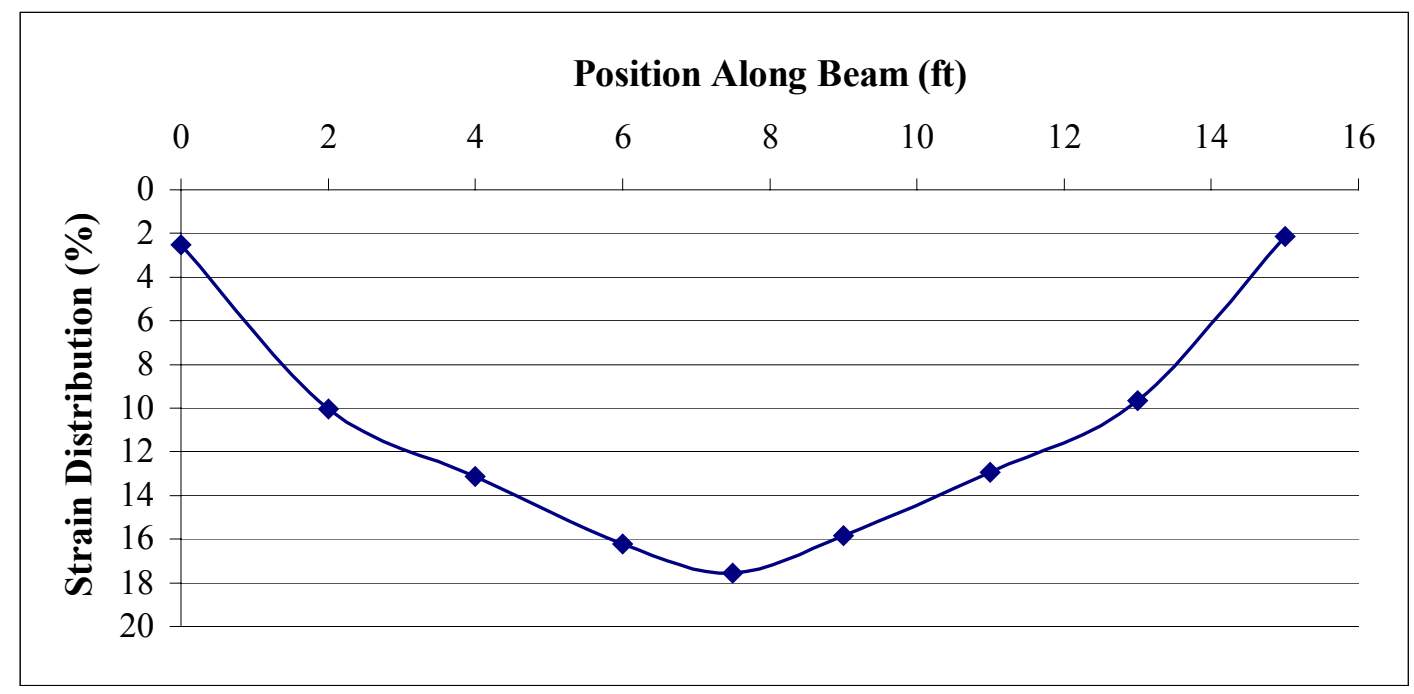

Figure 4.6.27. Load Distribution Based on Strain for Two Point Loads Applied Centrally At Midspan

Figure 4.6.28 shows the pressure experienced by the foundation during this test. The maximum pressure was 94 psi. For the same test on the prestressed concrete panel, the maximum pressure was 45 psi. 


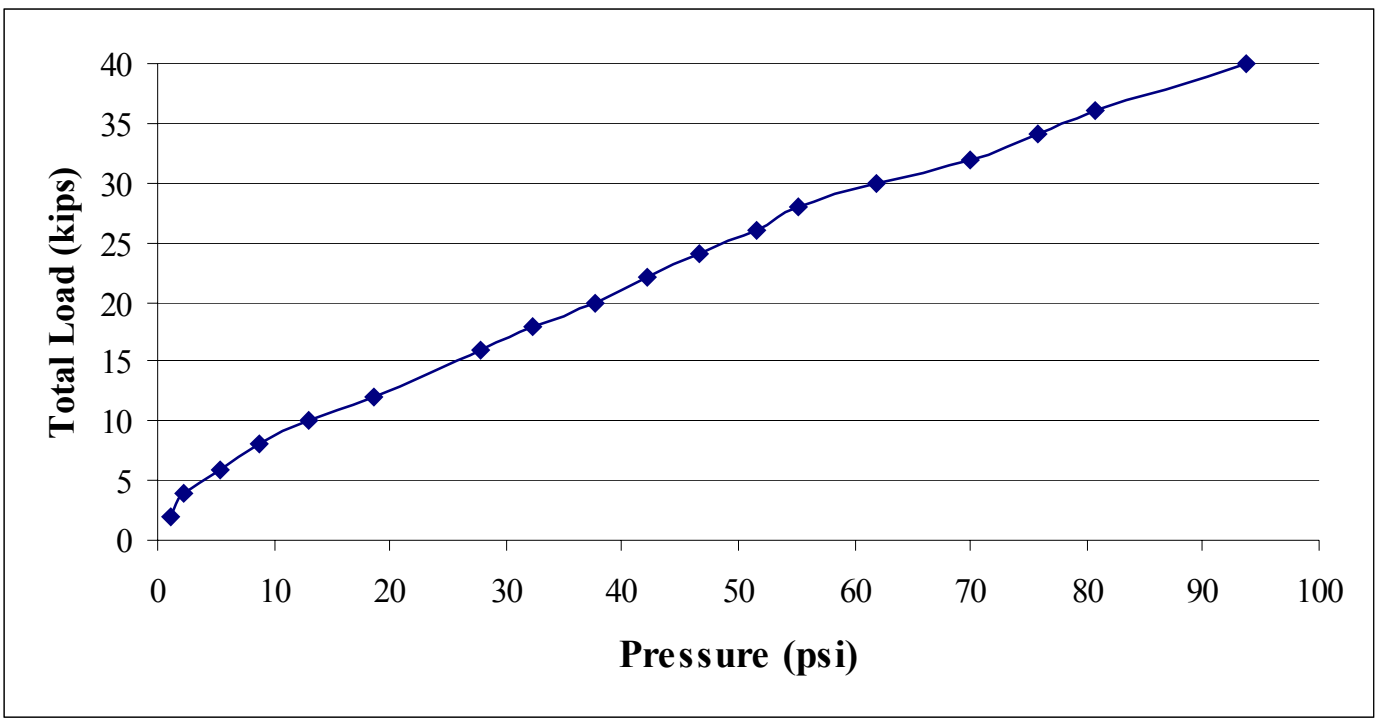

Figure 4.6.28. Pressure for Two Point Loads Applied Centrally At Midspan

\subsubsection{Two Point Loads Applied Centrally Between Left and Midspan Crossties}

Figure 4.6.29 shows the set-up for this test.

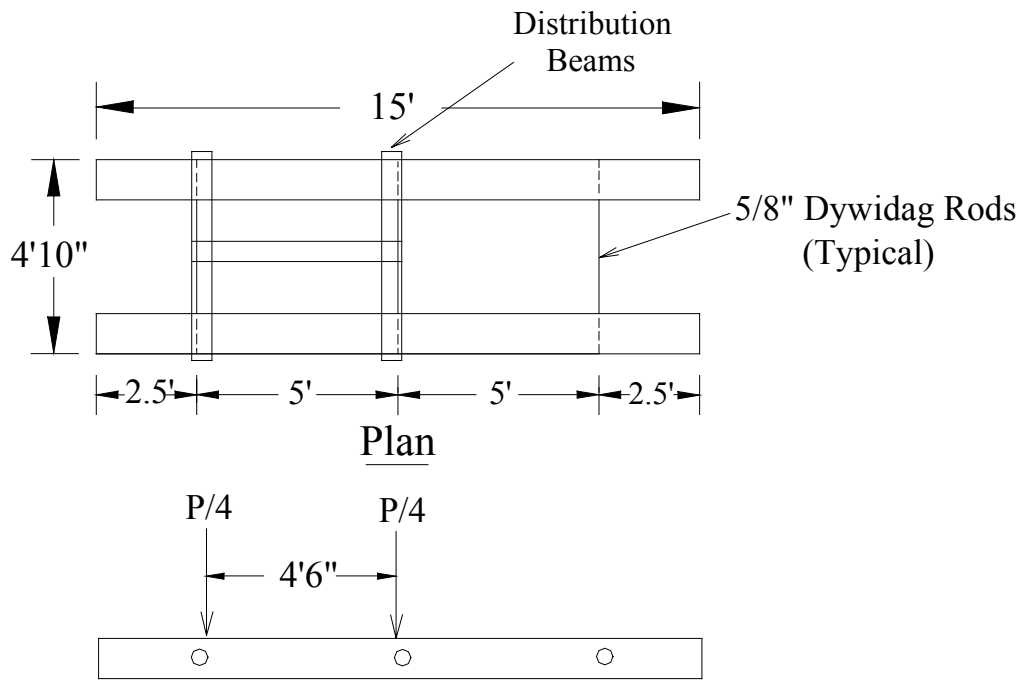

Elevation

Figure 4.6.29. Schematic of Test Setup for Two Point Loads Applied Centrally Between Left and Midspan Crossties 
Figure 4.6.30 shows the deflection results from this test. The maximum value for deflection obtained was 0.103 in. The maximum deflection obtained for the prestressed concrete panel was $0.095 \mathrm{in}$. There was an uplift on the right end of 0.003 in on the FRP beam.

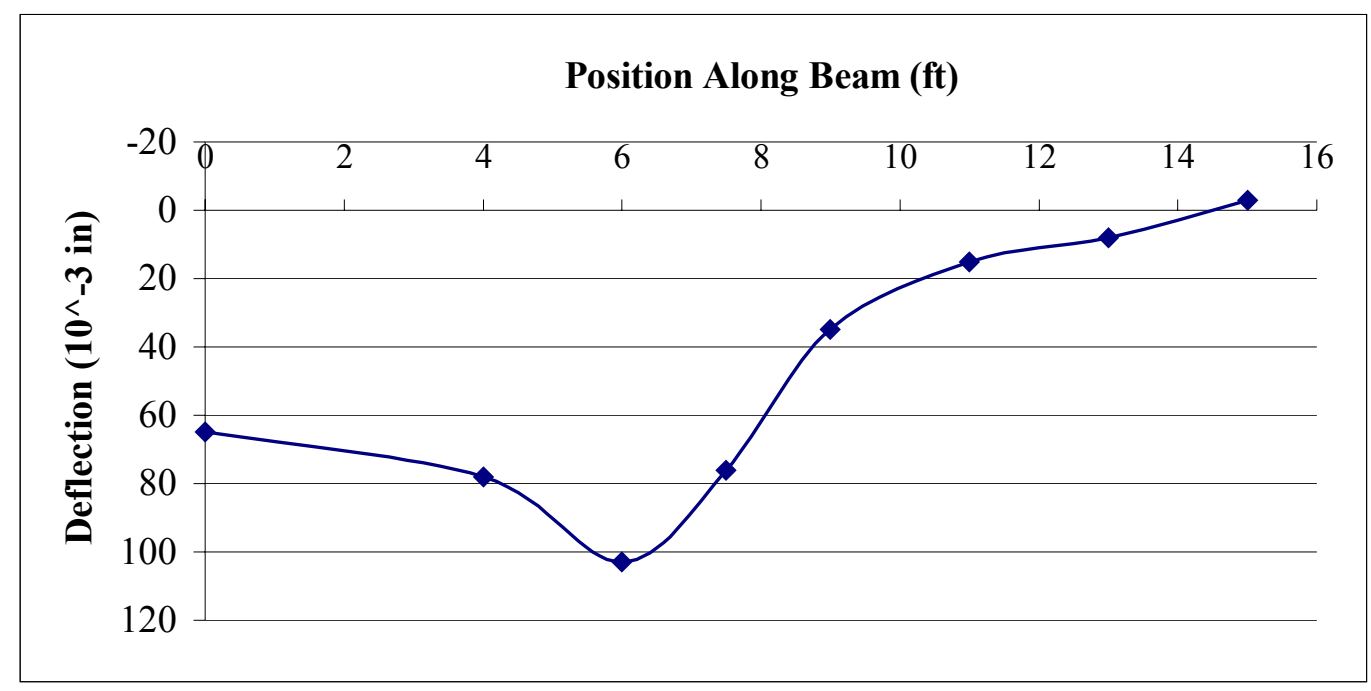

Figure 4.6.30. Deflection Values for Two Point Loads Applied Centrally Between Left And Midspan Crossties

Figure 4.6.31 shows the load distribution based on deflection. The first eight feet of the beam carries $85 \%$ of the load.

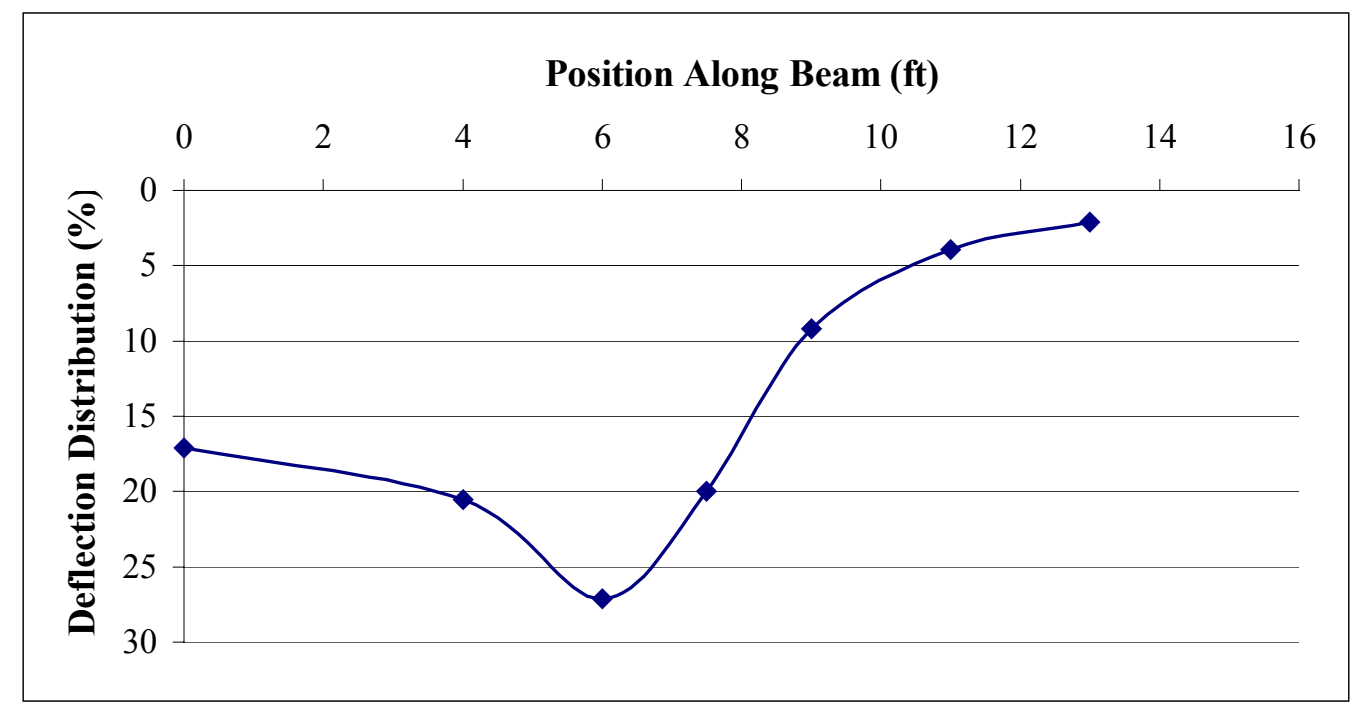

Figure 4.6.31. Load Distribution Based on Deflection for Two Point Loads Applied Centrally Between Left and Midspan Crossties 
Figure 4.6.32 shows the strain values obtained during this test. The maximum strain value obtained during this experiment was $200 \times 10^{-6} \mathrm{in} / \mathrm{in}$.

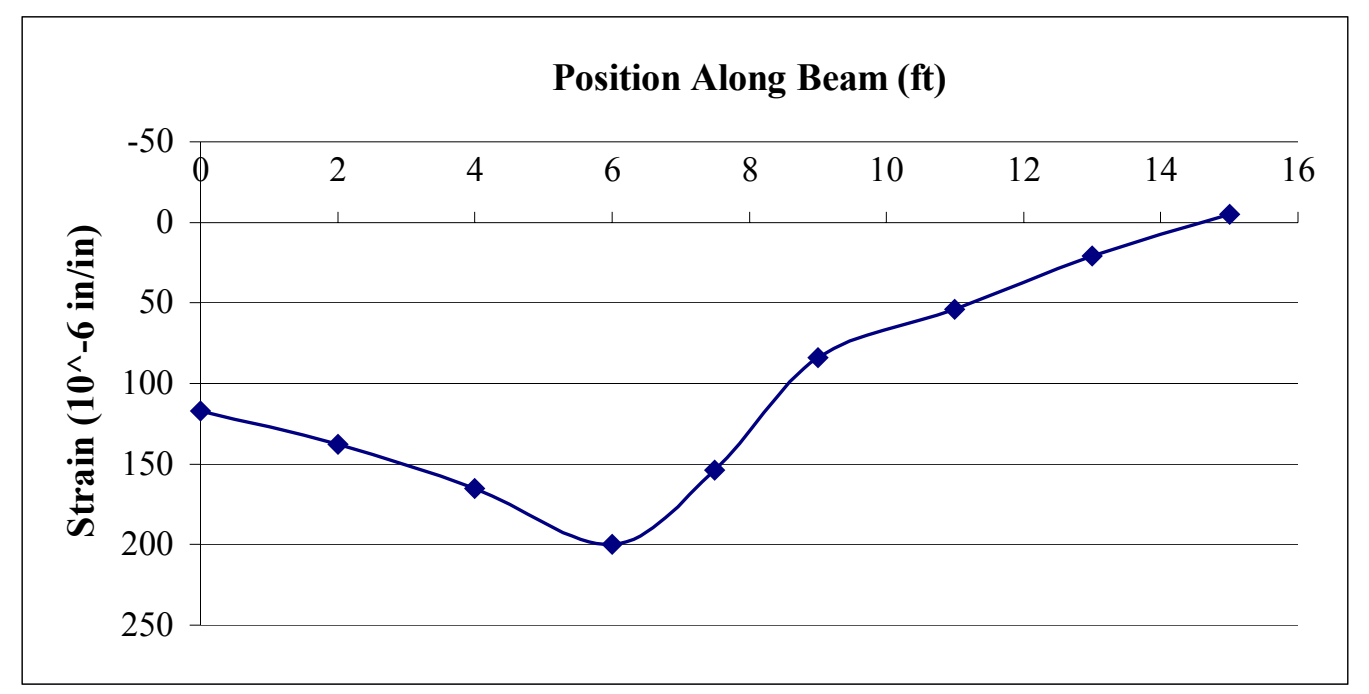

Figure 4.6.32. Strain Values for Two Point Loads Applied Centrally Between Left and Midspan Crossties

Figure 4.6.33 shows the load distribution based on strain. The first half of the beam, consisting of five locations, carries $83 \%$ of the load. If compared to the three pad locations on the prestressed concrete panel, which carry $69 \%$ of the load, the same locations on the FRP beam carry $53 \%$ of the load.

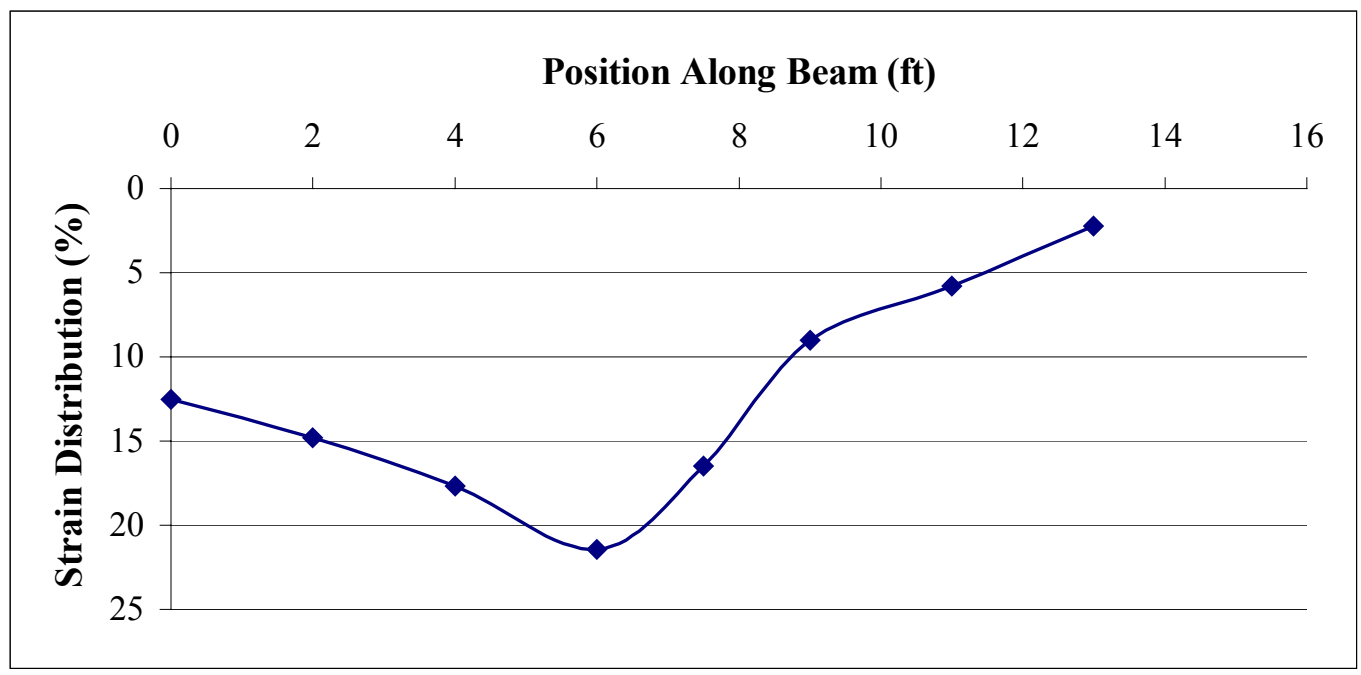

Figure 4.6.33. Load Distribution Based on Strain for Two Point Loads Applied Centrally Between Left and Midspan Crossties 
Figure 4.6.34 shows the pressure experienced by the foundation during this test. The maximum pressure was $124 \mathrm{psi}$. The maximum pressure for the prestressed concrete panel was 48 psi.

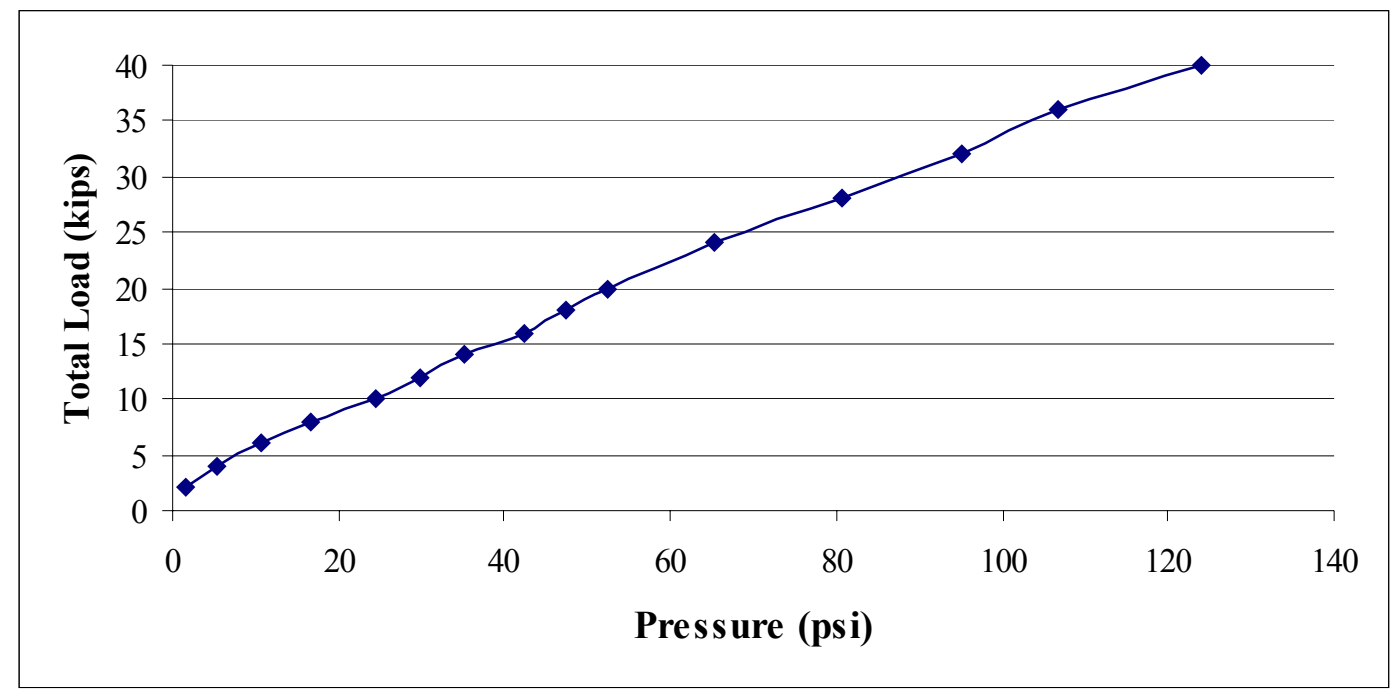

Figure 4.6.34. Pressure for Two Point Loads Applied Centrally Between Left And Midspan Crossties

\subsubsection{Two Point Loads Applied Centrally Between Right and Midspan Crossties}

Figure 4.6.35 shows the experimental set-up for this test. 


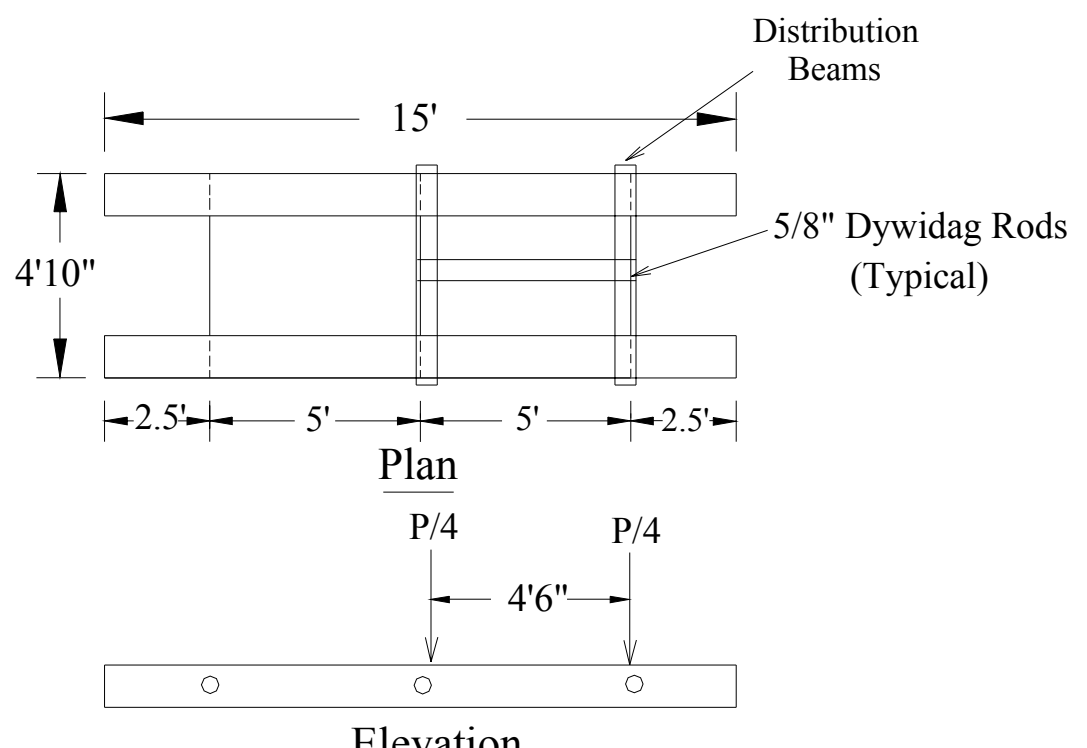

Figure 4.6.35. Schematic for Two Point Loads Applied Centrally Between Right and Midspan Crossties

Figure 4.6.36 shows the deflection results for this test. The maximum deflection obtained for this test was 0.108 in compared to 0.125 in for the prestressed concrete panel. The behavior of this beam is almost perfectly symmetric if compared to the previous test.

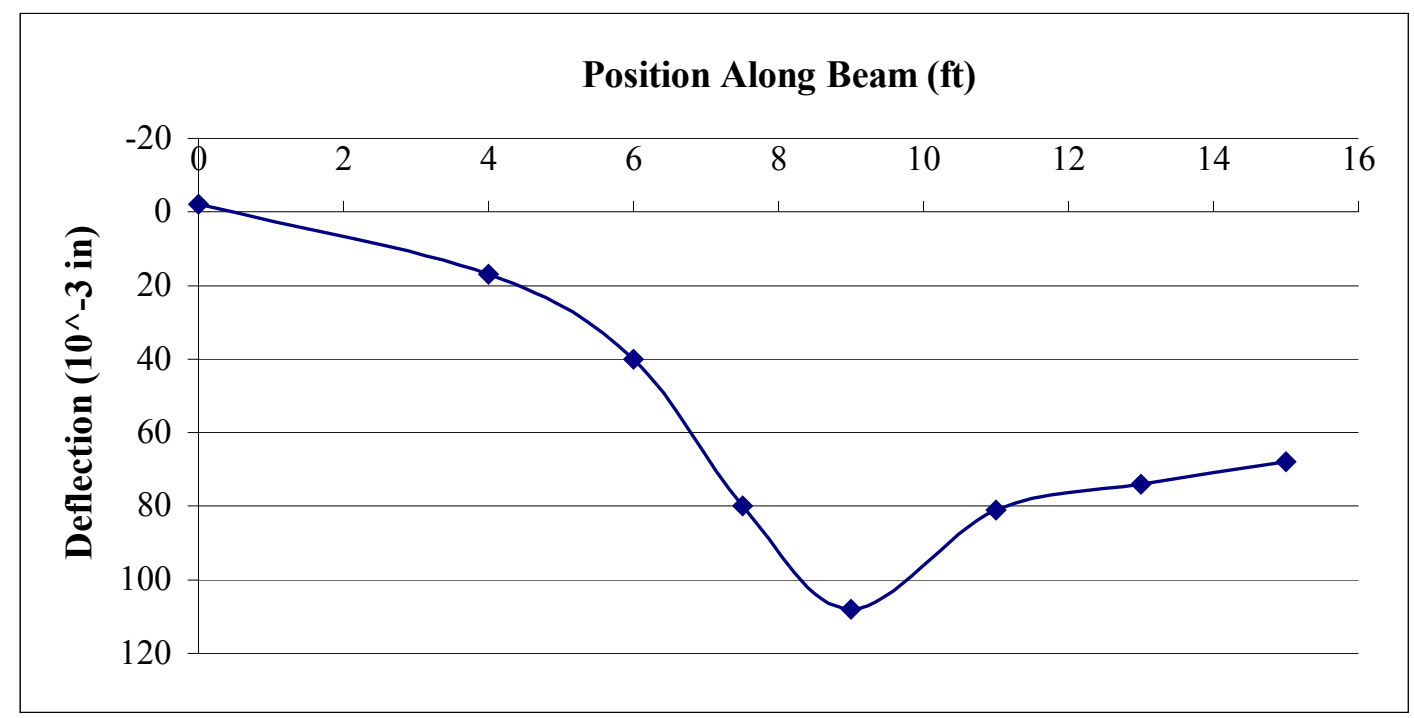

Figure 4.6.36. Deflection of Beam for Two Point Loads Applied Centrally Between Right And Midspan Crossties 
Figure 4.6.37 shows the load distribution based on deflection. The last half of the beam carries $87 \%$ of the load. If compared to the three pads on the prestressed concrete panel, which carry $65 \%$ of the load, the same locations on the FRP panel carry $55 \%$ of the load.

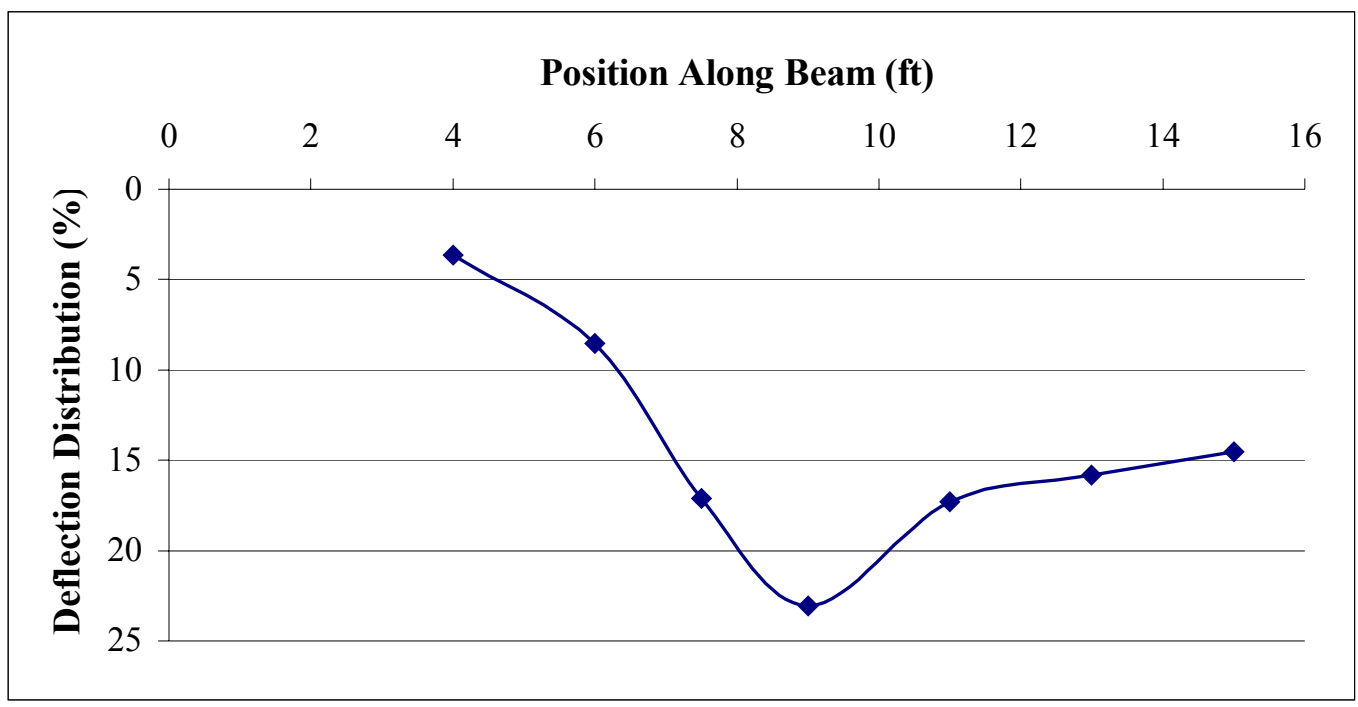

Figure 4.6.37. Load Distribution Based on Deflection for Two Point Loads Applied Centrally Between Right and Midspan Crossties

Figure 4.6.38 shows the strain values obtained during this test. The maximum value of strain obtained during this test was $211 \times 10^{-6} \mathrm{in} / \mathrm{in}$.

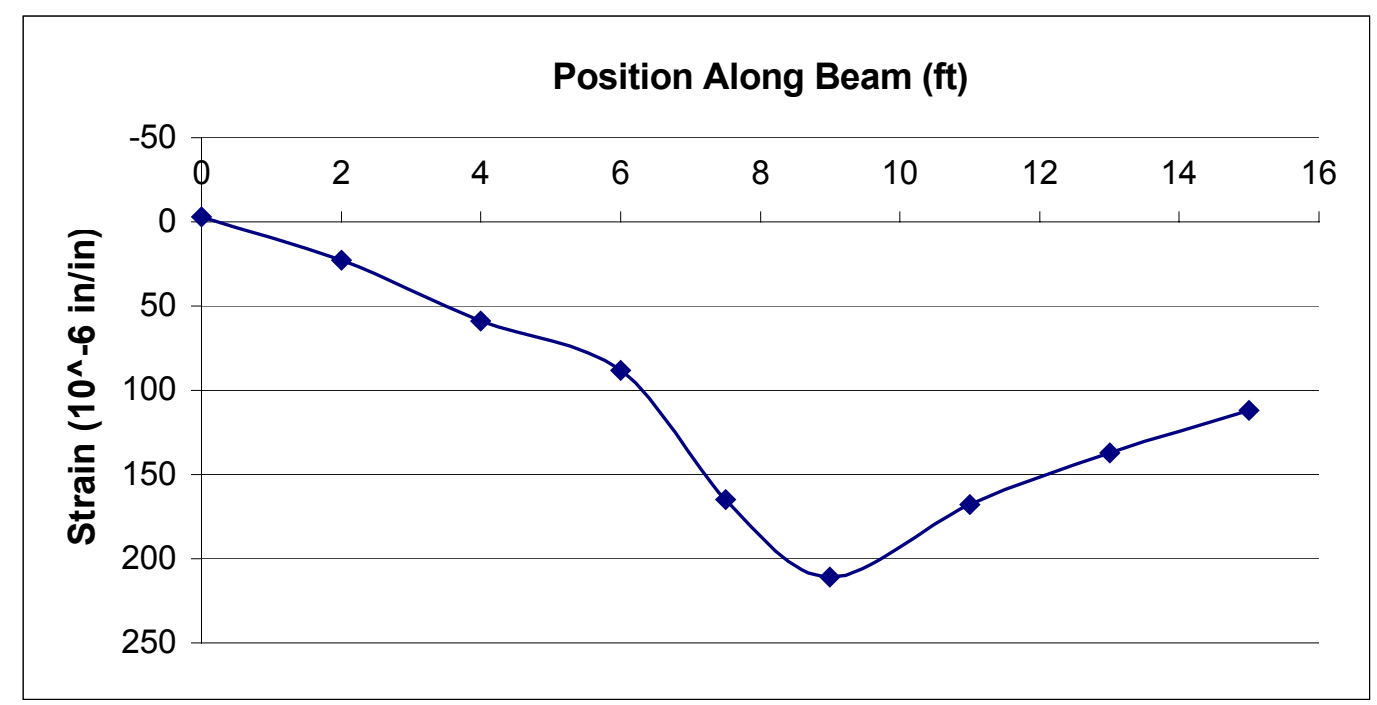

Figure 4.6.38. Strain Values for Two Point Loads Applied Centrally Between Right And Midspan Crossties 
Figure 4.6.39 shows the load distribution based on strain for this test. The distribution matches the strain distribution calculated for the previous test.

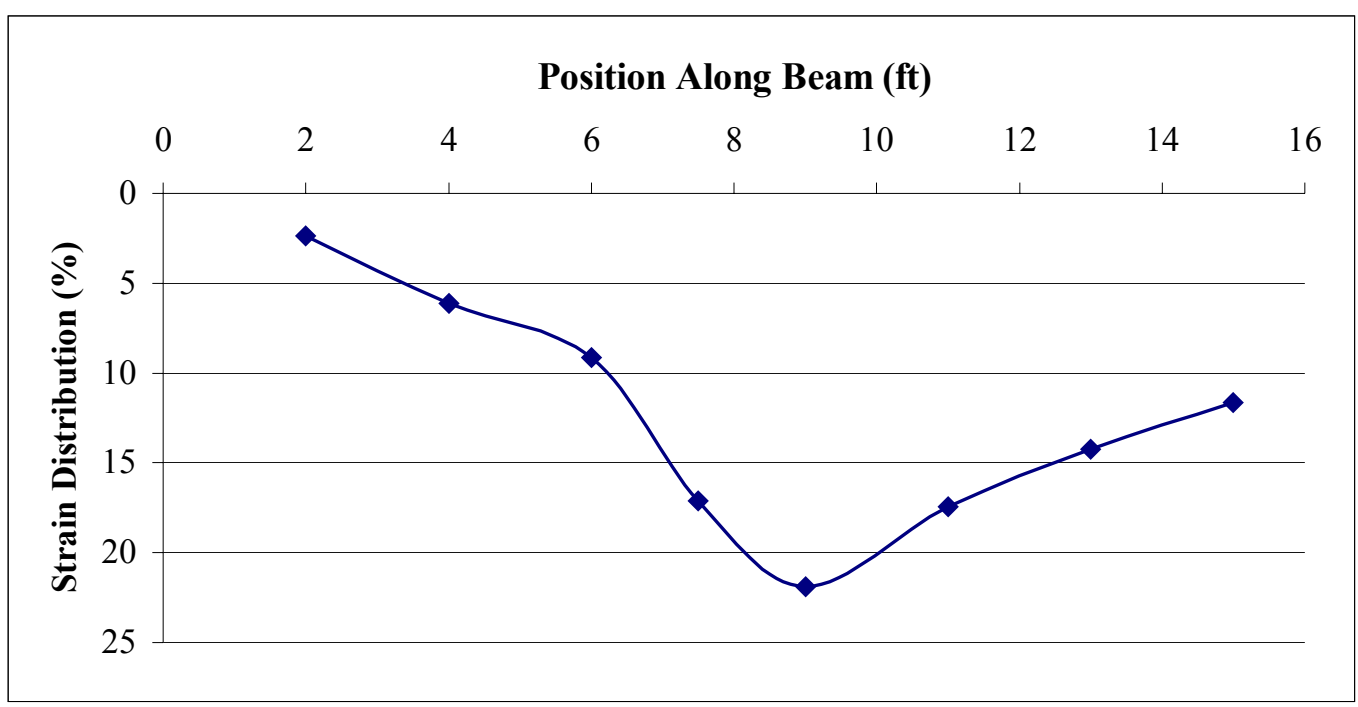

Figure 4.6.39. Load Distribution Based on Strain for Two Point Loads Applied Centrally Between Right And Midspan Crossties

Figure 4.6.40 shows the pressure experienced by the foundation. The maximum pressure was 126 psi.

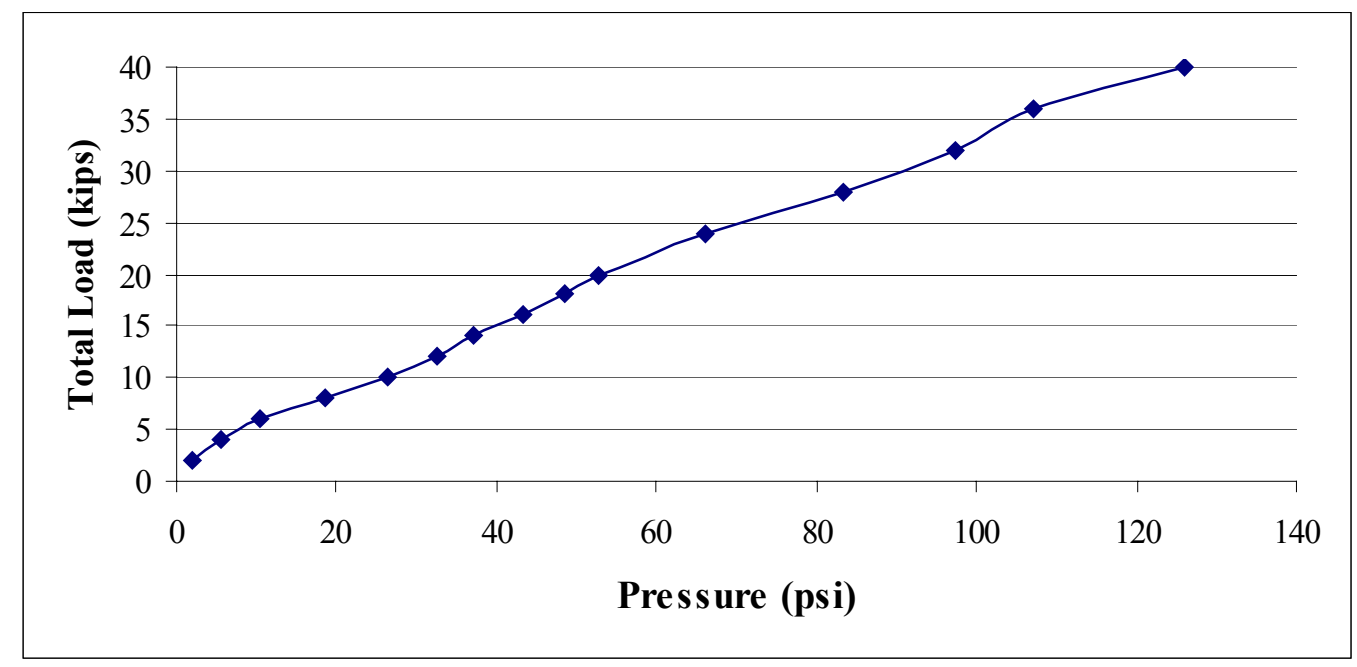

Figure 4.6.40. Pressure for Two Point Loads Applied Centrally Between Right And Midspan Crossties 


\subsubsection{Fatigue Testing}

Dynamic load testing was conducted to determine the change in stiffness of the FRP beams. Two dynamic load testing series were conducted. The first was a double point load applied centrally at the midspan with a maximum load of 40 kips and a minimum load of 5 kips. This higher load (40 kips) is designed to represent the heavier loads of locomotives. 50,000 cycles of this were applied to the specimen. Many coal mines have track lines with only one train pass per day, therefore, 50,000 cycles was a good representation of this. The second dynamic load test consisted of a single point load at midspan with a maximum load of 20 kips and a minimum load of 3 kips. Cycles of 250,000 and 500,000 were applied.

Figure 4.6.41 shows the results of the first dynamic test, in which 50,000 cycles of 40 kips at a single location were applied.

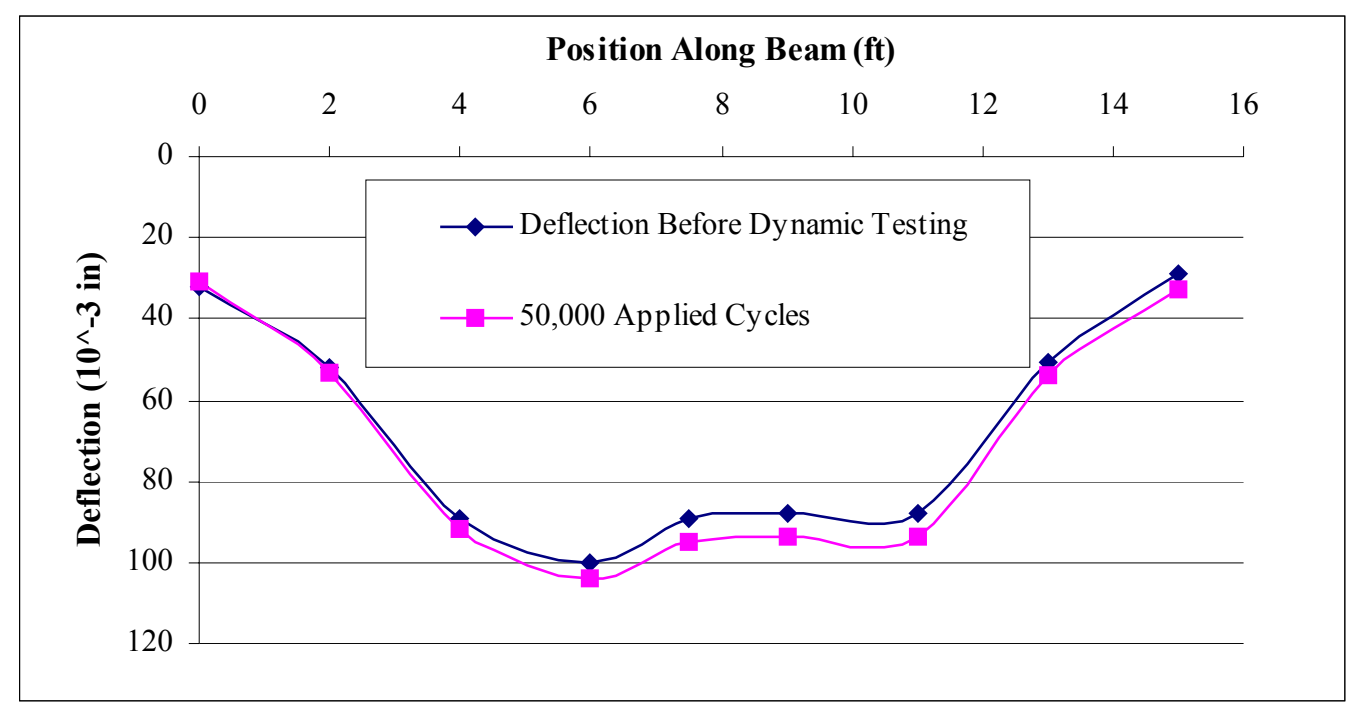

Figure 4.6.41. Deflection of FRP Beam After First Dynamic Load Testing

Figure 4.6.41 shows that the deflection of the FRP beam increased by $4 \%$ at the position of $6 \mathrm{ft}$ along the beam and 7\% at the location of $11 \mathrm{ft}$. The deflection at the location of 11 $\mathrm{ft}$ along the beam increased from 0.088 in to $0.094 \mathrm{in}$. The stiffness decreased from a value of $494 \mathrm{lbs} /$ in to $477 \mathrm{lbs} / \mathrm{in}$, a decrease of only $0.2 \%$. 
Figure 4.6.42 shows the results of the second dynamic loading test in which a single point load of 20 kips was applied at midspan.

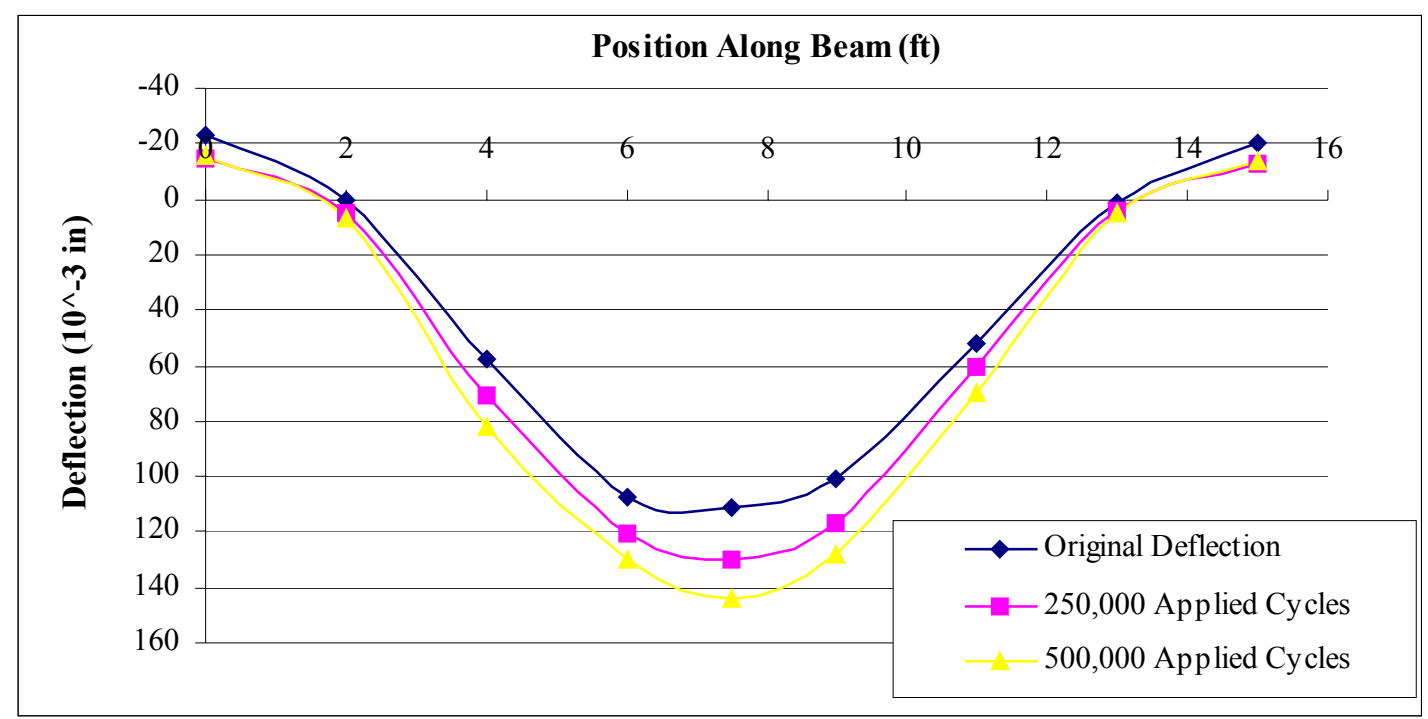

Figure 4.6.42. Deflection of FRP Beams After Second Dynamic Loading Test

Figure 4.6.42 shows that deflection at midspan increased from 0.111 in to 0.130 in after 250,000 cycles were applied, a 17\% increase. The deflection at midspan increased to 0.144 in after 500,000 cycles were applied, a 30\% increase from the deflection results before dynamic load testing began and an $11 \%$ increase from a static test conducted after 250,000 cycles of applied load. The stiffness of the beam decreased from $169 \mathrm{lbs} /$ in to a value of $147 \mathrm{lbs} /$ in after the first 250,000 cycles were applied, a decrease of $13 \%$. The stiffness calculated after 500,000 cycles of applied 20 kip loading was 134 lbs/in, a decrease of $21 \%$ decrease from the value calculated before dynamic load testing began and a $9 \%$ decrease from the value calculated from a static test conducted after 250,000 cycles of applied load.

\subsubsection{Conclusions on Full-Size FRP Panel}

The maximum deflections are in the range of 0.080 in. to 0.120 in while the maximum strain are in the range of $150 \times 10^{-6} \mathrm{in} / \mathrm{in}$. to $220 \times 10^{-6} \mathrm{in} / \mathrm{in}$. The dywidag rods sufficiently held the FRP beam in position and maintained gauge during testing. The 
FRP panel distributed load more efficiently than did the prestressed concrete panel over a longer span. The adhesive (Pliogrip) used to attach the steel rails provided sufficient ductility to distribute load. The epoxy used to attach the two separate FRP beams sufficiently held the beams together. In the future, however, the beams will be pultruded as one section. Dynamic load testing was conducted at two load levels, one was a double point load of 40 kips and the other a single point load of 20 kips, both applied centrally at midspan. After 500,000 applied cycles of the single point load, the stiffness decreased by $21 \%$. The deflection at midspan increased by $30 \%$ after 500,000 applied cycles. The foundation pressure under the FRP panel is higher than under the prestressed concrete panel because the pressure is more localized under the FRP panel and distributed better under the prestressed concrete panel. The load is transferred directly through the central web of the FRP section to the foundation, compared to the load being distributed to the entire width of the section for the prestressed concrete panel. The foundation pressure under the FRP panel will not be significantly higher than that of the prestressed concrete panel when the two-cell FRP box section is pultruded as one section instead of two separate boxes bonded together as was tested. 


\subsection{Lateral Load Testing}

\subsubsection{Introduction}

Lateral tests were also conducted on the both of the prestressed concrete panels and the FRP panel. When a "mine car" travels along a curved section of track, it exerts a radial force on the steel rail. Small lateral forces are also generated in a tangent section due to "hunting" phenomenon. These forces are approximately $30 \%$ of the axle load (Interrail). Therefore, a load of three (3) kips was applied to the steel rail to simulate a "mine car" traveling along a curved section of track. The load was applied at two locations. One location was at the location of the steel crosstie. This was done to measure the strain in the cross-tie. The other test conducted was at the location between two crossties, at the midspan location.

For both tests, the concrete beam had no deflection in the plane of loading. This was expected due to the low lateral loading and the restrain due to the steel cross-tie. For this reason, only the deflections and strains along the steel rail are reported. Figure 4.7.1 shows the cross-section and loading location for the prestressed concrete panels.

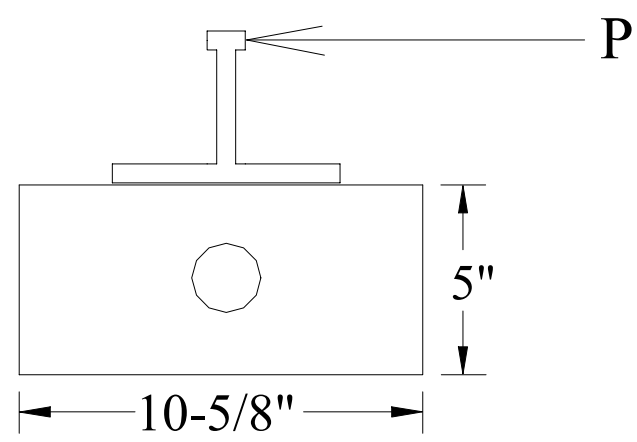

Figure 4.7.1. Prestressed Concrete Cross-Section and Loading Location for Lateral Tests 
Figure 4.7.2 provides a picture of the test set-up for the lateral load testing on the prestressed concrete panel.

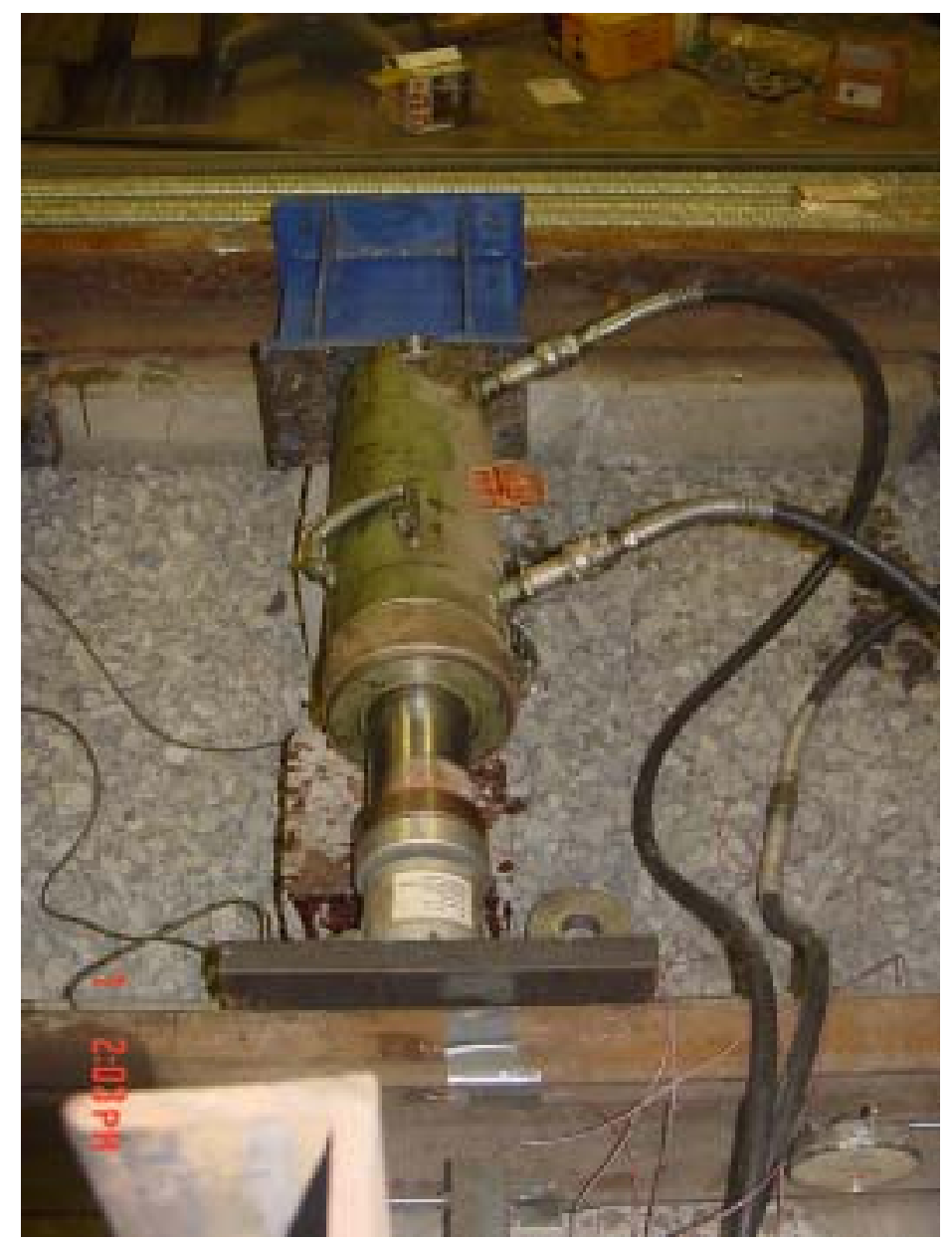

Figure 4.7.2. Lateral Testing Set-Up on Prestressed Concrete Specimen

\subsubsection{Lateral Test at Crosstie Location}

The first test conducted was the load applied at the cross-tie location. A strain gage was attached at the center of the crosstie on the top flange and one dial gage was mounted directly at the load location (gage 2 in Figure 4.7.3) to measure lateral deflection in the direction of load. Figure 4.7.3 shows the dial gage locations for this test. 

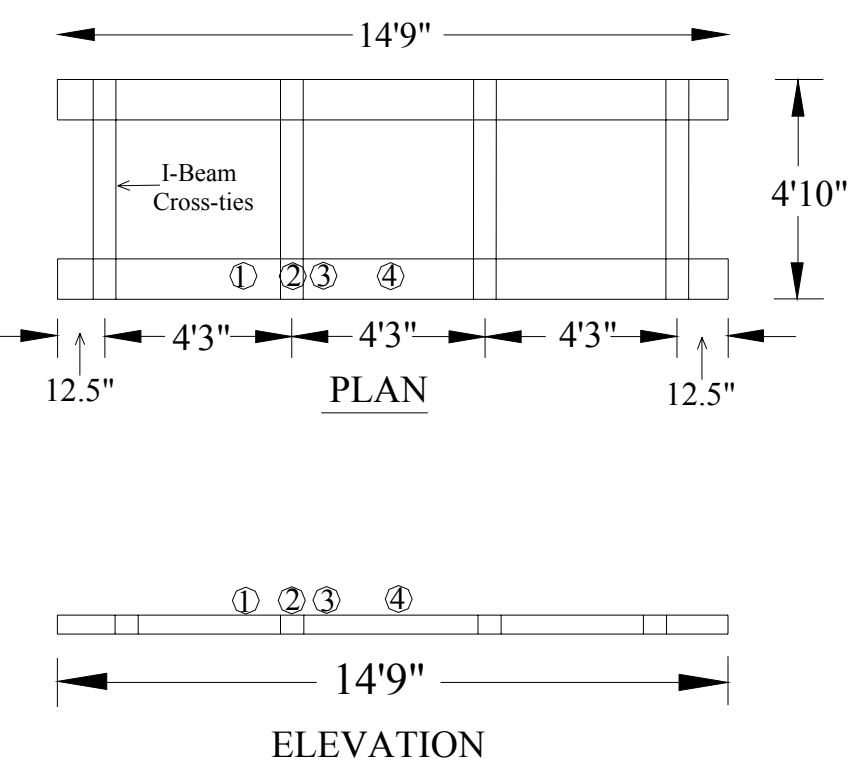

Figure 4.7.3. Dial Gage Location for Lateral Load Test at Crosstie Location

Figure 4.7.4 shows the strain values obtained for this test. Figure 4.7.4 shows a linear response for strain during this test. The maximum strain in the rail was found to be $54 \mathrm{x}$ $10^{-6} \mathrm{in} / \mathrm{in}$.

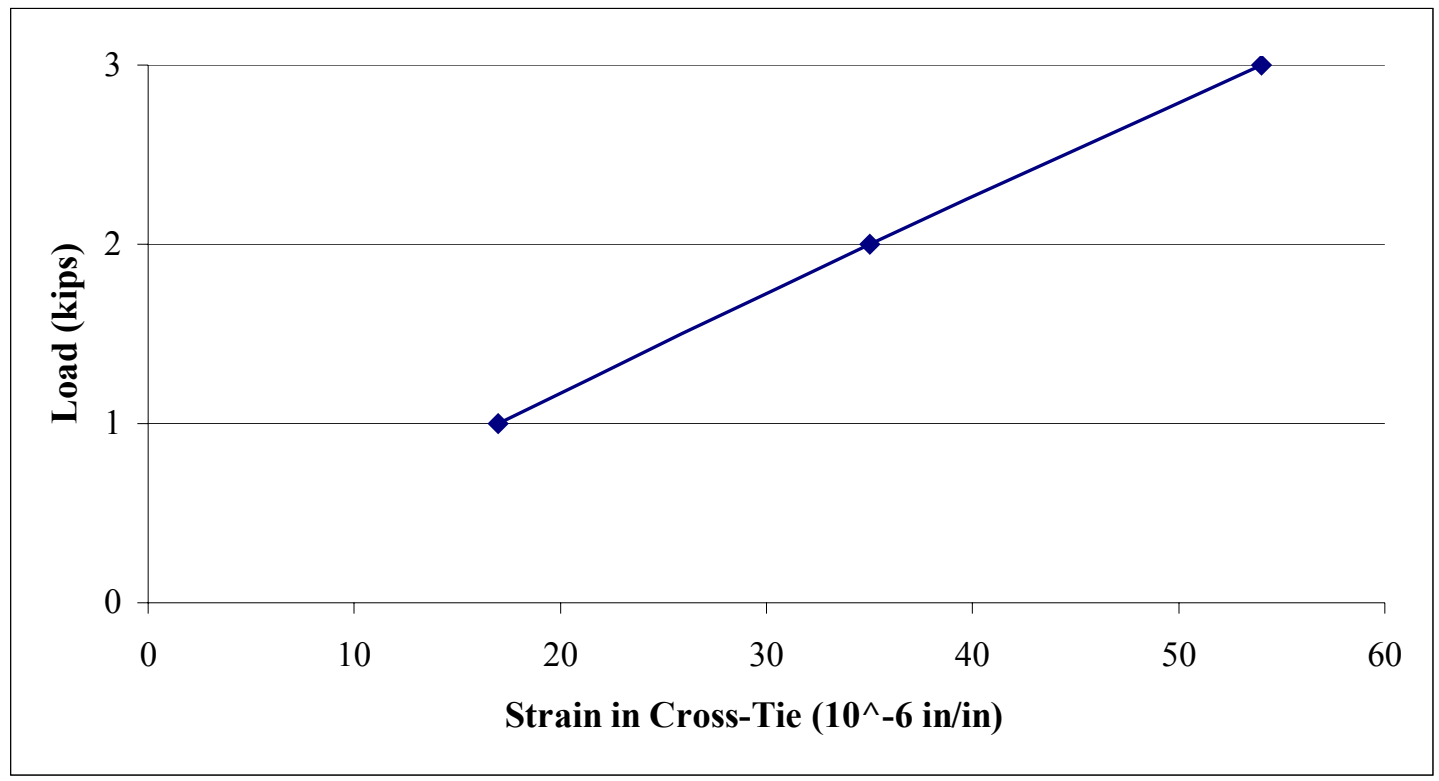

Figure 4.7.4. Strain in Crosstie for Lateral Test at Crosstie Location 
Figure 4.7.5 shows the deflection of the steel rail for this test. The maximum deflection obtained was 0.037 in. This is a very small value, which is expected because the rail clips restrain the rail from sideway movement. During the test, the rail did not deflect sideways. The steel rail rotated about its bottom edge.

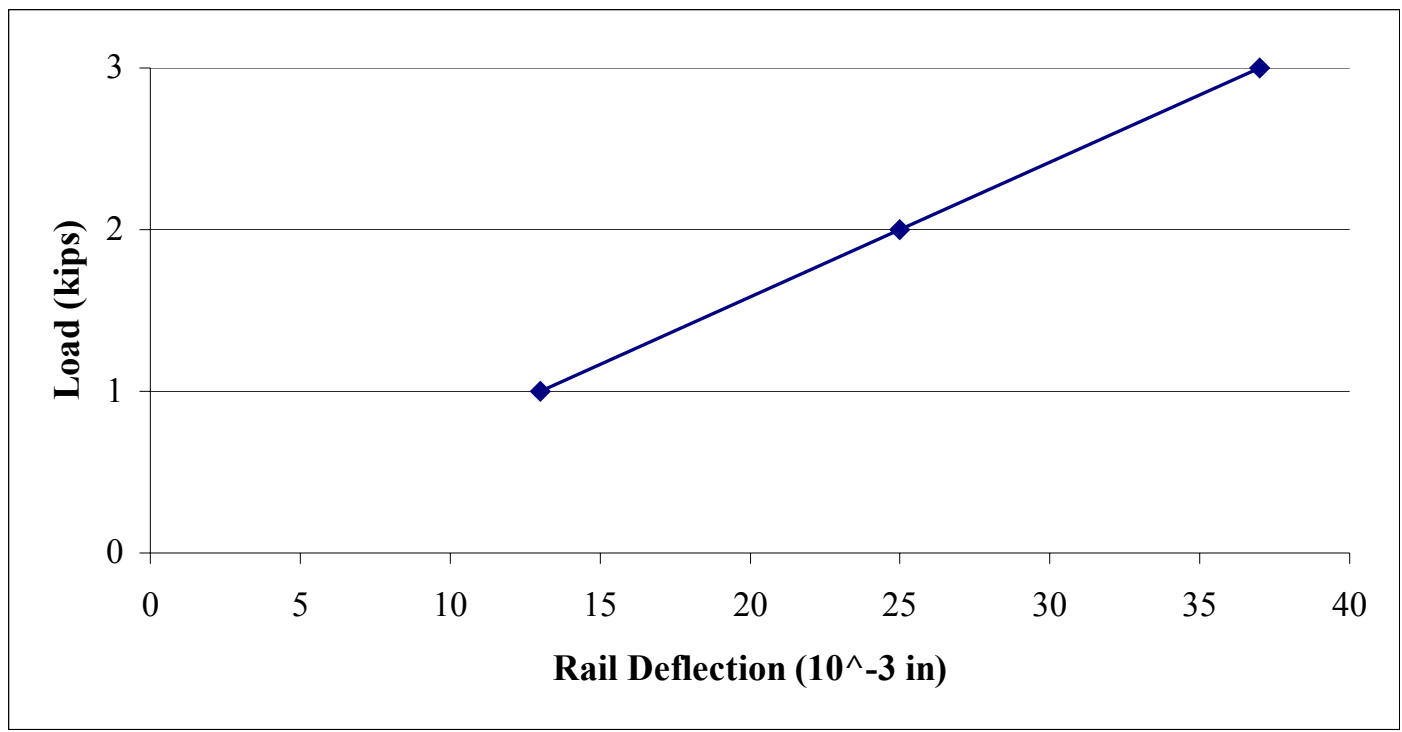

Figure 4.7.5. Deflection of Steel Rail for Lateral Test Conducted At Crosstie Location

The results in Figures 4.7.4 and 4.7.5 show small lateral deflections of the steel tee rail, indicating the Pandrol Mineclips would sufficiently hold the rail in place on a curved section of track. These small deflections should not be an issue of concern in field situations.

\subsubsection{Lateral Test At the Midspan of Two Crossties}

Figure 4.7.6 shows the dial gage locations for this test. Deflection was obtained from four (4) dial gages mounted along the steel rail. Figure 4.7.6 shows the location of these gages 

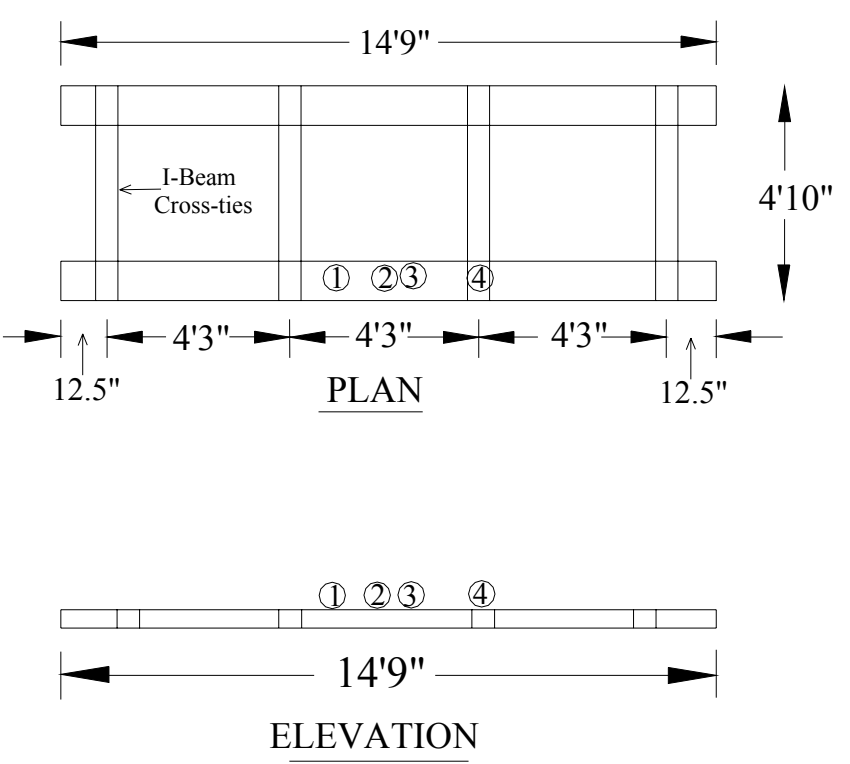

Figure 4.7.6. Dial Gage Locations for Lateral Test at Midspan of Two Crossties

In Figure 4.7.6, dail gage number 2 is at the midspan of two cross-ties. Dial gage number 1 is one foot away from dial gage number 2 and 1'1.5" from the center of the steel crosstie. Dial gage number 3 is 6 " to the right of dial gage number 2 and dial gage number 4 is at the cross-tie location. Other dial gages were used to ensure that the steel rail deflected symmetrically.

Figure 4.7.7 shows the strain values obtained during this test. A strain gage was attached along the top outside edge of the steel rail at the loading location. The maximum strain obtained was $189 \times 10^{-6} \mathrm{in} / \mathrm{in}$. The steel rail exhibited a linear behavior for strain. 


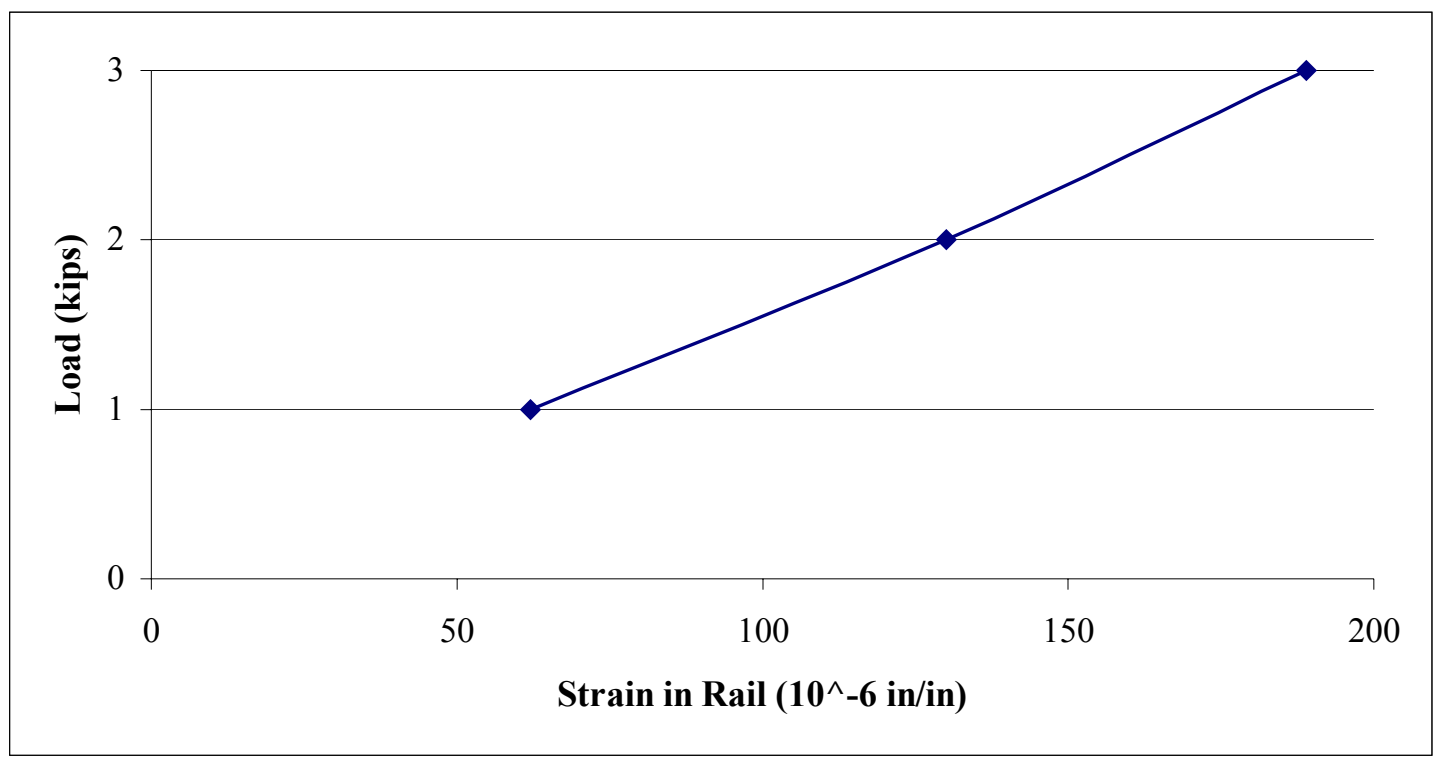

Figure 4.7.7. Strain in Steel Rail for Lateral Test Conducted at Midspan of Two Crossties on Prestressed Concrete Panel

Figure 4.7.8 shows the deflection results obtained during this test. The maximum deflection, as expected, is found at the loading location and has a value of $0.081 \mathrm{in}$. The deflection at the crosstie location was found to be $0.037 \mathrm{in}$. These small deflections should not be an issue for field applications.

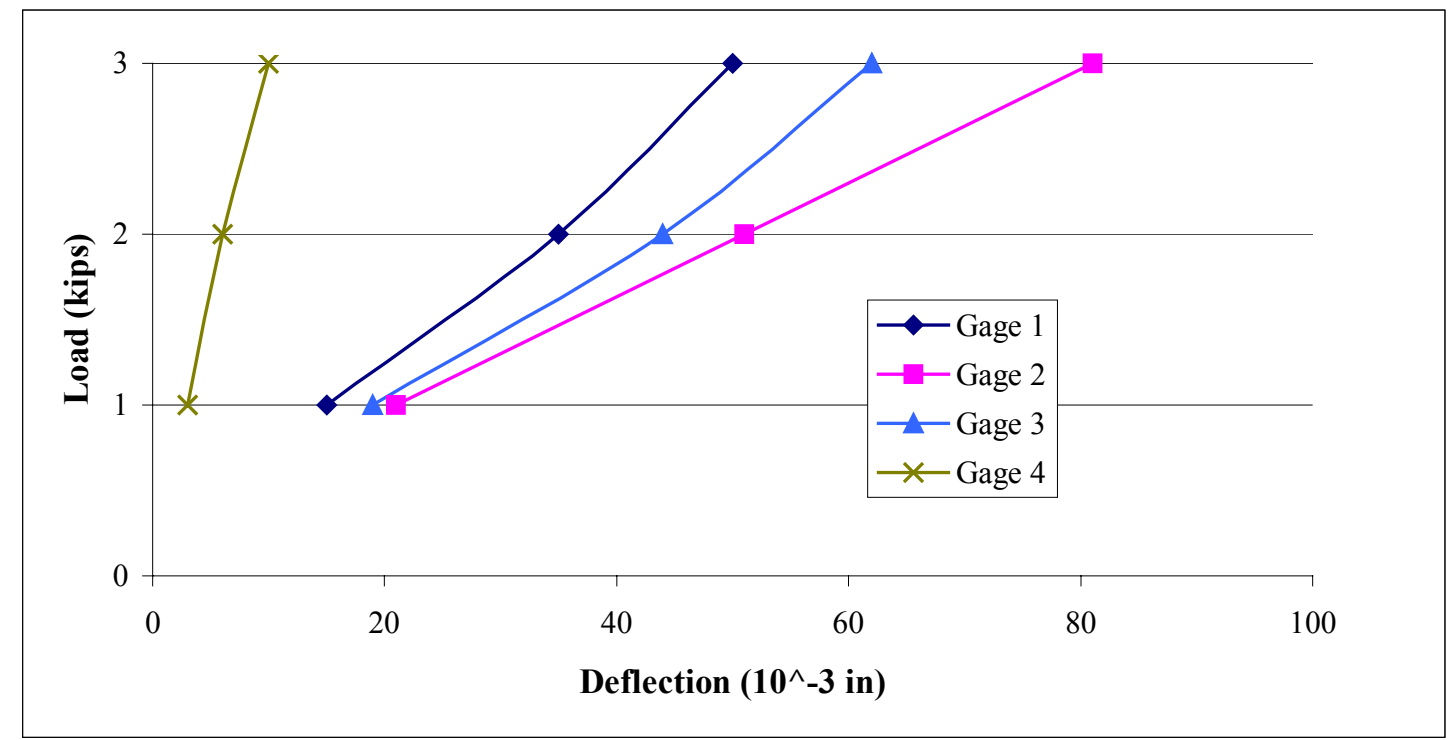

Figure 4.7.8. Deflection of Steel Rail for Lateral Load Applied at Midspan of Two Crossties on Prestressed Concrete Panel 


\subsubsection{Lateral Testing Of FRP Panel}

A lateral load of 3 kips was also applied at two locations (the location of a dywidag rod and a location at the midspan of two dywidag rods) on the FRP panel. The deflection measured was less than $10 \times 10^{-3} \mathrm{in}$. This deflection was probably due to the plates used to hold the dywidag rods tightening against the beams. Strains were also relatively insignificant with a value less than $80 \times 10^{-6} \mathrm{in} / \mathrm{in}$.

\subsubsection{Conclusions of Lateral Loading Tests}

The steel rail exhibited no lateral movement when conducting a lateral test on the prestressed concrete specimens. The "beam plus the rail" acted as a rigid body and rotated about its bottom edge. Deflection of the steel rail due to lateral loading is small. The strain in the steel cross-ties and steel rail are also small (around $40 \times 10^{-3} \mathrm{in}$ ). The rail and cross-ties exhibit a linear response to the loading for deflection and strain.

Lateral loading on the FRP panel resulted in a deflection less than $10 \times 10^{-3}$ in, compared to a maximum deflection of $81 \times 10^{-3}$ in for the prestressed concrete panel. 


\section{CHAPTER 5 - COMPARISONS OF FRP TRACK PANEL}

\subsection{Introduction}

The following figures compare load distribution based on deflections and strains obtained during the testing of the FRP panel to the ones obtained during testing of the prestressed concrete panel. The values from the second prestressed concrete panel were used for comparisons. Comparisons are made to determine which panel has better load sharing characteristics.

\subsubsection{Single Point Load Applied At Midspan}

Figure 5.1 shows that for a single point load applied at midspan, the center FRP panel carries a larger value of the load compared to the prestressed concrete panel. The central three feet of the FRP panel has nearly the same deflection. The prestressed concrete panel exhibits a more symmetric behavior, however, the load is distributed over a larger span in the FRP panel.

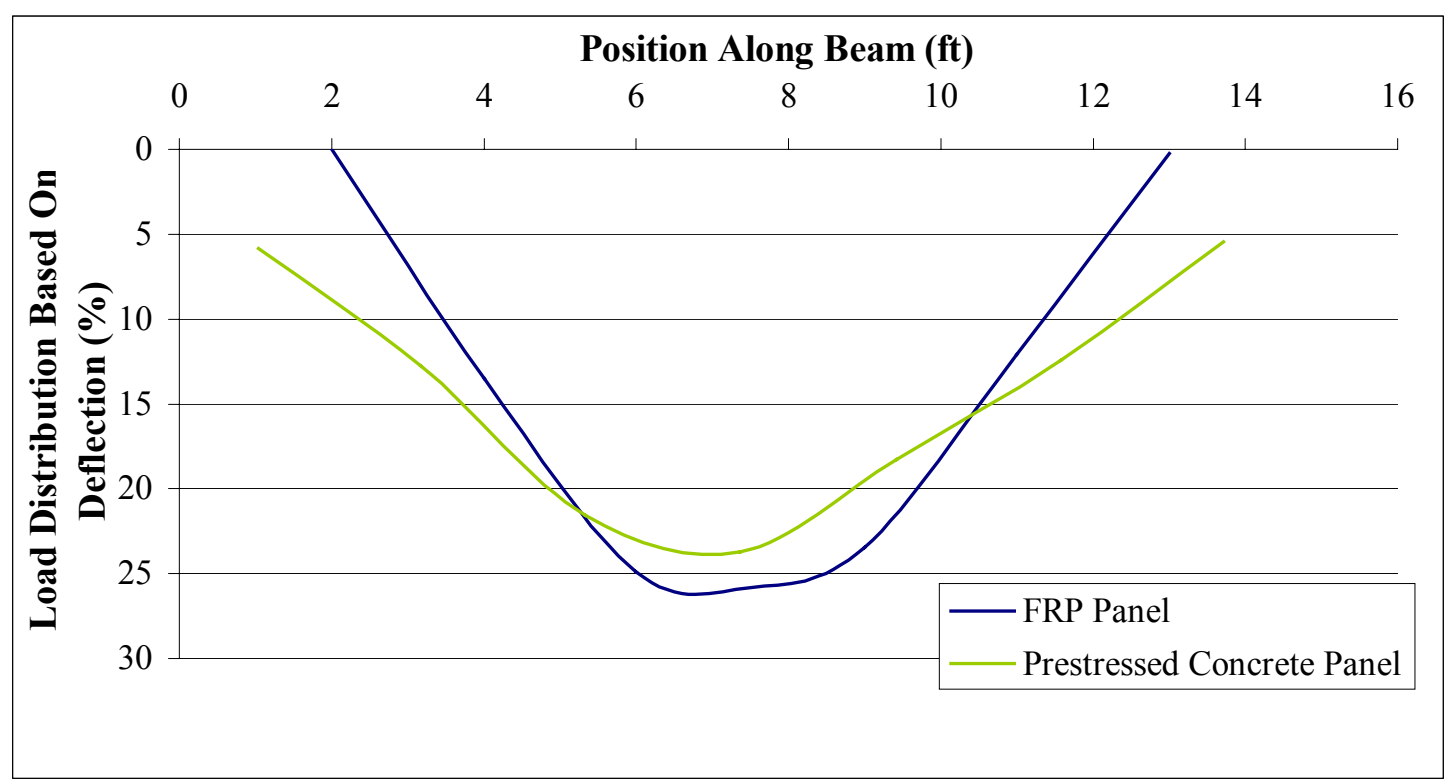

Figure 5.1. Comparison of Load Distribution Based on Deflection for Single Point Load Applied At Midspan 


\subsubsection{Double Point Loads Applied Centrally At Midspan}

Figure 5.2 shows the load distribution plots based on deflections obtained at the maximum load of 20 kips per beam. Figure 5.2 shows that the middle seven feet of the FRP beam carries nearly the entire load, while the concrete panel carries the majority of the load in the concentrated region of the central three feet. This is an indication of an improved load sharing, primarily due to the presence and ductility of the polyurethane adhesive.

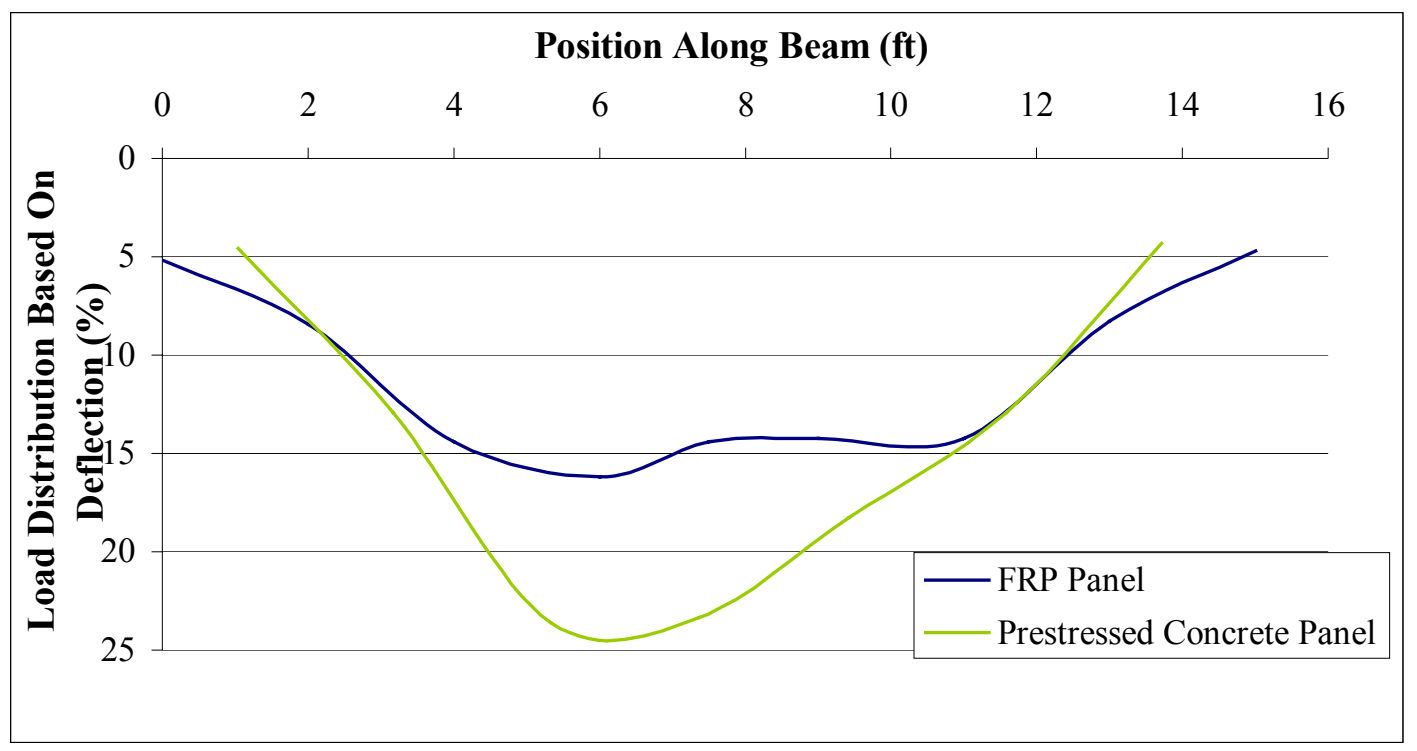

Figure 5.2. Load Distribution Based on Deflection for Double Point Loads Centrally Applied at Midspan

Figure 5.3 shows the load distribution based on strain values obtained at the maximum load. The distribution based on strain yields the same result as does the deflection. The FRP panel exhibits better load sharing distribution, and less concentration at the two load points. The FRP beam has a more even distribution of strain, which indicates the stress on the panel is more evenly distributed. 


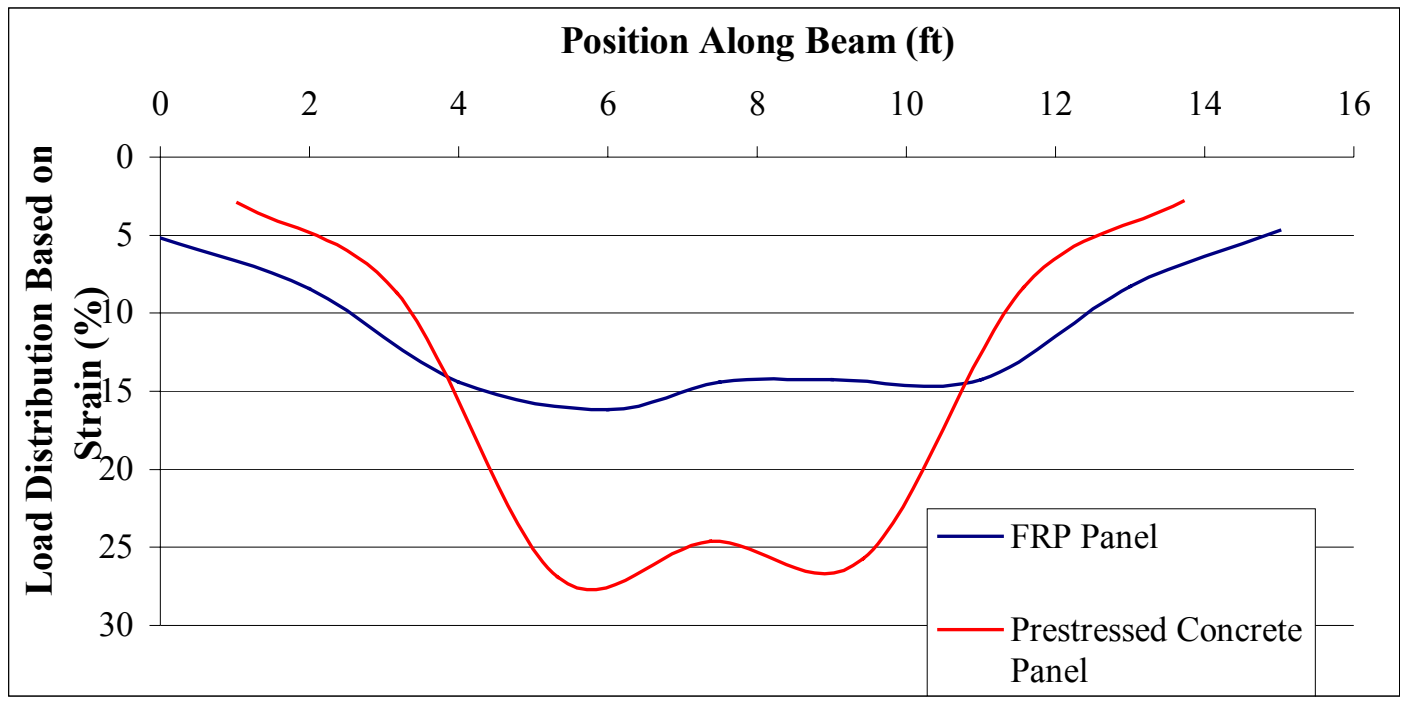

Figure 5.3. Load Distribution Based on Strain for Double Point Loads Applied Centrally At Midspan

\subsubsection{Single Point Load Applied at Midspan of Left and Midspan Crossties}

Figure 5.4 shows the load distribution based on deflection values obtained at the maximum load. As can be seen, the left end (0-6 ft) carries nearly the same load percentage.

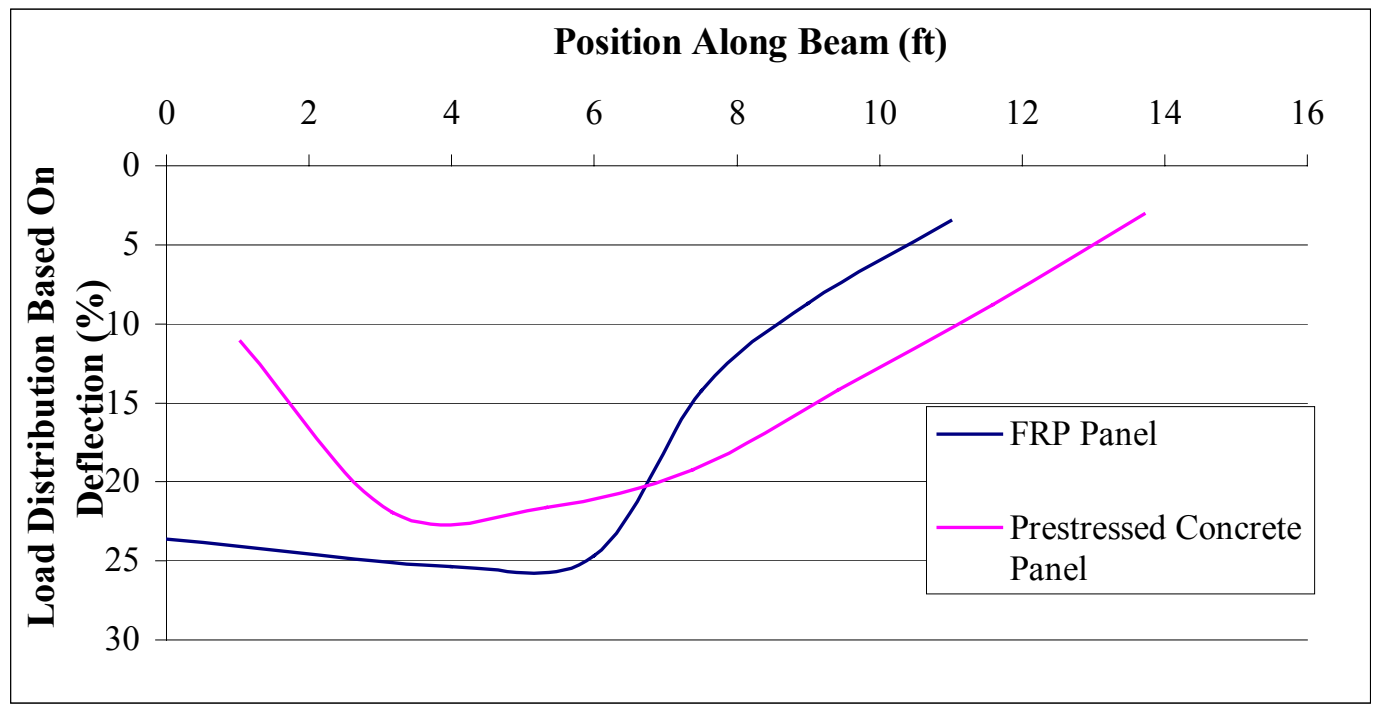

Figure 5.4. Load Distribution Based on Deflection for a Single Point Load Applied At the Midspan of the Left and Midspan Crossties 
Figure 5.5 shows the load distribution based on strain. Once again, the strain values agree with the deflection results that the FRP panel exhibits better load sharing distribution. Although, the FRP section appears to have formed a hinge around midspan, and acts like a cantilever.

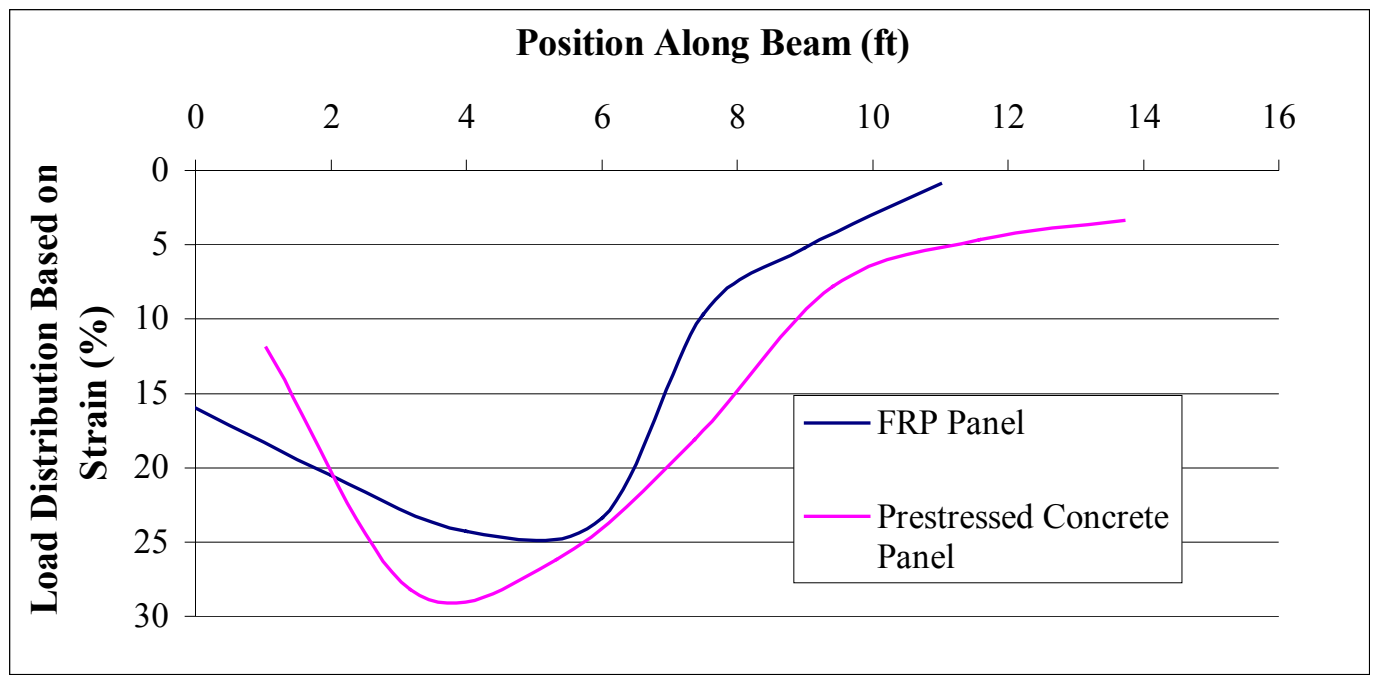

Figure 5.5. Load Distribution Based on Strain for a Single Point Load Applied At the Midspan of the Left and Midspan Crossties

\subsubsection{Double Point Loads Applied at Midspan of Left and Midspan Crossties}

Figure 5.6 shows the load distribution based on deflection values obtained.

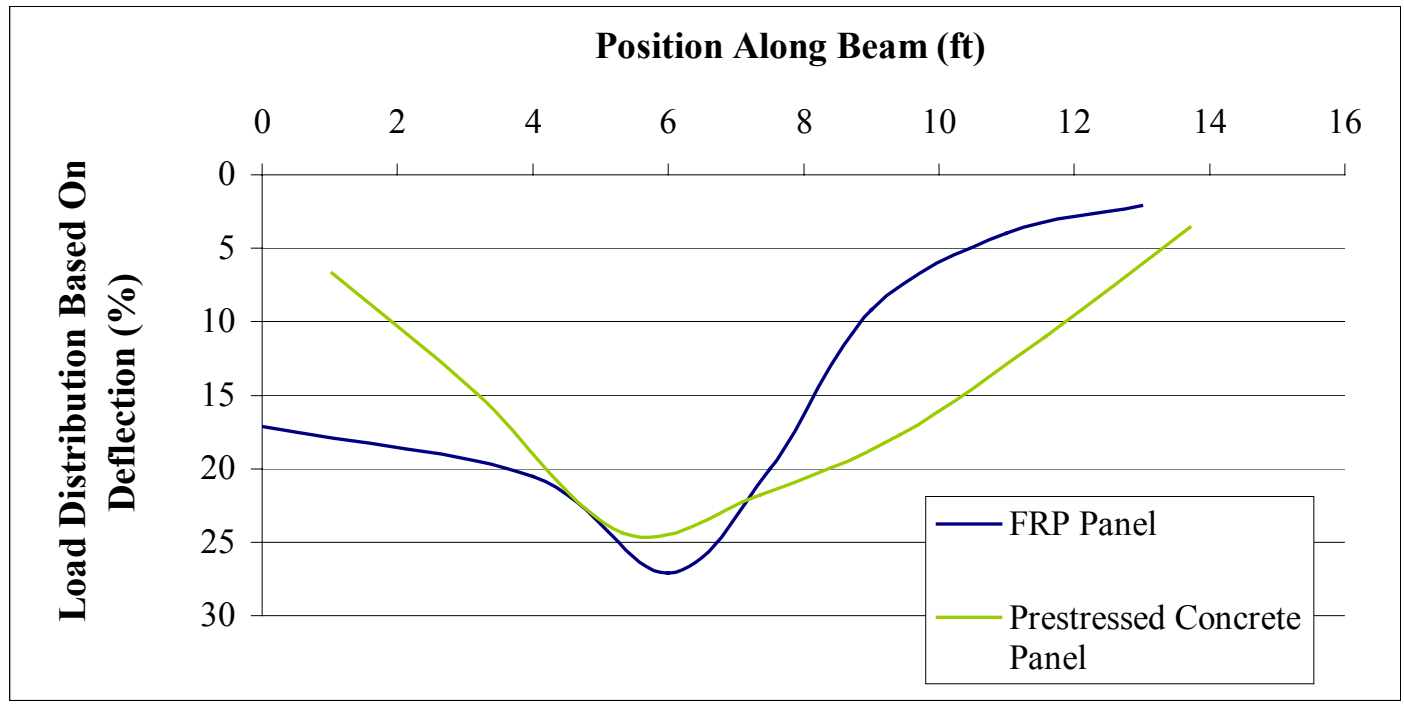

Figure 5.6. Load Distribution Based on Deflection for Double Point Loads Applied at Midspan of Left and Midspan Crossties 
Figure 5.7 shows the load distribution based on strain values obtained.

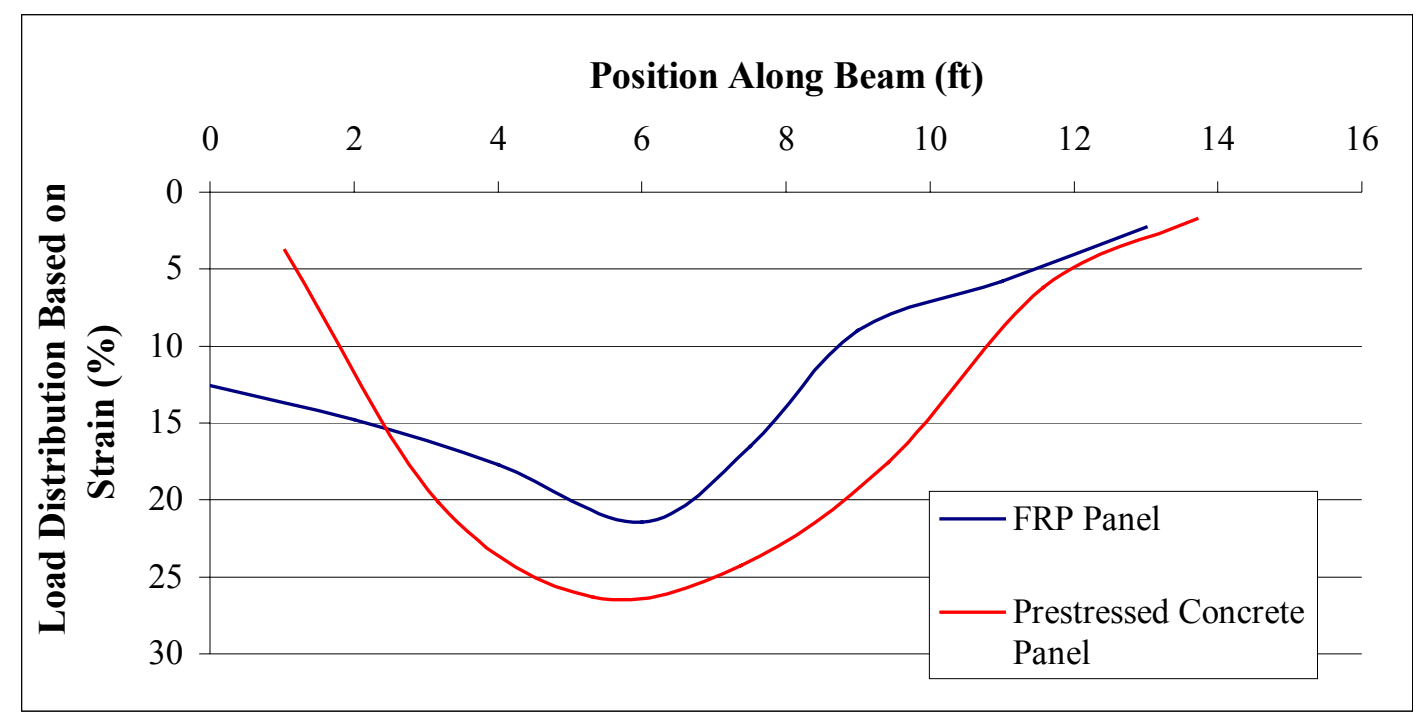

Figure 5.7. Load Distribution Based on Strain for Double Point Loads Applied at Midspan of Left and Midspan Crossties

The tests conducted on the right end of the beam are symmetric to the ones on the left and therefore, are not reported.

\subsection{Results and Discussion}

Although, the prestressed concrete panels offer a good solution to the problem of derailment in mines, there are several issues limiting their acceptance and implementation in coal mines. This issues include heavy weight (approximately $2500 \mathrm{lbs}$ ), section cracking leading to corrosion problems, and poor load distribution. The prestressed concrete panel did not exhibit good load sharing characteristics. The ballastless lightweight (250 lbs) FRP two-celled box section with dywidag rods used to maintain gauge compared favorably in terms of load distribution, durability, and strength. Although the two-celled FRP box sections were bonded together and tested for this pilot experiment, it is anticipated that a two-celled FRP box cross-section can easily be pultruded as one section with more favorably designed architecture. In addition, the use

of the FRP section with a ductile adhesive, such as pliogrip, eliminated the need for pads and fasteners. 


\subsection{Cost Comparison}

The cost of one prestressed concrete panel, one FRP composite panel, and the track structures that currently are employed in mining applications are compared in Table 5.1. The cost calculations are shown in Appendix D. Labor cost is estimated as the time it took workers in the lab to construct the specimens and also an estimate of the time it would take workers to place the specimens in field at an hourly rate of $\$ 10 / \mathrm{hr}$ (see Appendix E). The cost of the steel tee rails is omitted because they remain a constant for the three track systems.

\subsubsection{Cost of Prestressed Concrete Panel}

One prestressed concrete panel requires approximately $1 / 2$ yard of concrete, 2 dywidag rods, and 14 fasteners. The steel crossties must be manufactured by welding or and Ibeam can be used. Supplemental reinforcement is necessary for confinement and shrinkage issues. An estimate of $\$ 250$ is used for fabrication labor and installation.

\subsubsection{Cost of FRP Composite Panel}

The FRP composite used in the testing series cost approximately $\$ 10 /$ linear foot. Two (2) beams, each 15 feet long, were used for a total of 30 linear feet. One (1) dywidag rod was used for maintaining the correct beam gauge. Two (2) tubes of the adhesive (pliogrip) were used to attach the steel rails the FRP beams. Labor was estimated as $\$ 180$.

\subsubsection{Cost of Existing Track Structure}

The prestressed concrete and FRP panels are compared to an equivalent length of existing track. One panel is approximately the same length as that which seven (7) crossties currently in underground coalmines occupy. The Fairmont Supply Company in Fairmont, WV was consulted for current prices of existing track because Fairmont Supply Company provides CONSOL with its mining materials. An equivalent length (15 $\mathrm{ft}$ ) of existing track compared to the prestressed concrete and FRP panels requires seven (7) crossties, twenty-eight (28) spikes, and two (2) tons of gravel. 
Table 5.1. Cost Comparison Between Panels and Existing Track Structure

\begin{tabular}{|c|c|c|c|}
\hline & Prestressed Concrete & FRP & Existing Track \\
\hline Material & $\$ 120 / y d$ concrete & $\$ 10 /$ linear $\mathrm{ft}$ & $\$ 15 /$ crosstie \\
\hline Dywidag Rod w/nuts and plates & $\$ 60 /$ rod & $\$ 60 /$ rod & NA \\
\hline Fasteners & \$2/clip & NA & \$3/spike \\
\hline Steel Crossties w/ labor & $\$ 100$ & NA & NA \\
\hline Supplemental Steel Reinforcement & $\$ 30$ & NA & NA \\
\hline Pliogrip or Equivalent Adhesive & NA & $\$ 120$ & NA \\
\hline Gravel Base & NA & NA & $\$ 15 /$ ton \\
\hline Labor for Fabrication and Installation & $\$ 250$ & $\$ 180$ & $\$ 50$ \\
\hline $\begin{aligned} \text { TOTAL } \\
\end{aligned}$ & $\$ 616$ & $\$ 660$ & $\$ 269$ \\
\hline
\end{tabular}

The cost of the adhesive (pliogrip) used can be greatly reduced if bought in bulk (approximately \$30/tube). The cost calculations provided do not consider "down time" in a coalmine currently in use. It is estimated that approximately two derailments occur every day causing loss in time and production. (CONSOL, 2002) The calculations also do not consider the time that is required to replace damaged crossties and the periodic maintenance involved. Considering "down time" of existing track, it is estimated that the FRP track structure would pay for itself in several days. 


\section{CHAPTER 6 - CONCLUSIONS AND RECOMMENDATIONS}

\subsection{Introduction}

In this chapter, conclusions and recommendations are presented from testing full-size and half-scale prestressed concrete panels, rubber pads, and an all FRP panel.

\subsection{Full-Length Prestressed Concrete Panels}

Two full-size prestressed concrete panels were tested in bending in a simulated mine track bed foundation. The panels were prestressed with a single 5/8" Dywidag rod stressed with 10 kips. Four (4) No. 3 bars were used as supplement reinforcement. No. 3 stirrups were also provided at 4 in c-c spacing. Pandrol clips were used to fasten the steel rail to the concrete beam. Seven (7) resilient rubber pads were used on each concrete beam to distribute load. Dial gages were used to measure deflection and strain gages were attached at every pad location to measure strain. A pressure cell was also used to measure the pressure experienced by the foundation for each loading location. The panels were subjected to static tests at key locations (i.e. midspan, crosstie locations, between crossties, etc). The following conclusions are drawn from the results of testing full-size prestressed concrete panels in the major units lab.

- Maximum lab test deflections ranged in values from 0.070 in to 0.090 in simulating a single axle load along the beam and values from 0.090 in to 0.150 in for tests conducted for a double axle loading cases.

- The second full-length prestressed concrete panel tested performed better than the first. The experimental deflections obtained were compared to the deflections calculated using Enercalc and FEM analysis in Chapter 4. The experimental deflections obtained were relatively close to the ones predicted by Enercalc and FEM analysis. A major issue is the variable subgrade modulus.

- Strains varied greatly between the two full-length panels, due to the difference in concrete compressive strength. Strains were in the range of $600-800 \times 10^{-6} \mathrm{in} / \mathrm{in}$ for the first full-length prestressed concrete panel tested and $200-250 \times 10^{-6} \mathrm{in} / \mathrm{in}$ for the second full-length panel for maximum load level.

- Maximum pressures in the foundation were in the range of 40-50 psi for single axle loading cases and 120-140 psi for double axle loading cases (FRP Panel). 
- Dynamic load testing was conducted on the second full-length prestressed concrete panel tested. Deflections obtained after 250,000 and 500,000 applied cycles yielded significant changes in stiffness. However, it is more likely that the beam did not lose significant stiffness, but rather the gravel was compacted under the beam.

- The ballastless full-size track panels distributed load reasonably well. It was too heavy, however, to implement in field situations.

\subsection{Jointed Prestressed Concrete Panels}

A set of half panels was fabicated to test the open joint. The same reinforcement was used as that of the full-length prestressed concrete panels. Two tests, one single point load and one double point load, were applied centrally over the joint. The deflections and strains obtained closely resembled that of the tests at midspan conducted on the fulllength panels, revealing that the joint would not be an issue under coal mine traffic. Results of the tests are as follows:

- The maximum deflection for the test simulating a single axle load was 0.082 in and the maximum deflection simulating a double axle load was 0.107 in

- Maximum strains were in the range of $220-230 \times 10^{-6} \mathrm{in} / \mathrm{in}$

- Maximum pressures in the foundation were in the range of 50-55 psi

- Dynamic load testing was also conducted on the set of half panels. A $20 \%$ reduction in stiffness was calculated after 500,000 cycles

- There was no significant cracking or deterioration of the beam during fatigue testing

\subsection{Rubber Pads}

Two (2) rubber pads were individually fatigue tested on the Instron Loading Machine to measure the change in stiffness. The stiffness was calculated after applied loading cycles of 100,000, 250,000,500,000, and 1,000,000. A loading rate of $0.5 \mathrm{~Hz}$ was used to avoid hysteresis. The secant modulus was also calculated for each test. A toe load of 3 kips and a live load of 9 kips was used.

- Pad deflections ranged in values from 0.110 in to 0.156 in. 
- The secant moduli remained consistent for both pads and ranged in values from $106 \mathrm{kips} / \mathrm{in}$ to $112 \mathrm{kips} / \mathrm{in}$.

- No visual deterioration was seen after $1,000,000$ cycles.

- After $1,000,000$ cycles, the stiffness of Pad I decreased by only $8.4 \%$ and Pad II by only $4.6 \%$.

- The secant modulus of Pad I decreased by $3 \%$ after $1,000,000$ cycles and $5 \%$ for Pad II.

\subsection{Fiber Reinforced Polymer (FRP) Composite Panel}

The prestressed concrete panels weighed approximately 2500 pounds and it would be impractical for the miners to install them due to height restrictions within the mine. A panel made of as FRP composite was tested for bending and load sharing characteristics. The FRP panel weighed approximately 250 pounds (not including the steel rails). FRP composites are much more durable than concrete andhave the ability to provide high strength-to-weight ratios. Three (3) high-strength Dywidag rods were used as crossties. A polyurethane adhesive "Pliogrip" manufactured by the Ashland Specialty Chemical Company was used to attach the steel rail to the FRP beams. This adhesive provided the required ductility and shear strength to distribute the loads from the rail to the FRP section. Dial gages and strain gages were used to measure the response of the beam. Static load testing was conducted at several locations, discussed in Chapter 4.

- Maximum deflections were in the range of 0.080 in to 0.120 in and maximum strain in the range of $150 \times 10^{-6} \mathrm{in} /$ in to $220 \times 10^{-6} \mathrm{in} / \mathrm{in}$.

- The Dywidag rods sufficiently held the beams in place

- After analyzing the results, it was concluded that the FRP panel distributed load more efficiently than did the prestressed concrete panel

- Dynamic load testing was conducted at two load levels, one was a double point load of 40 kips and the other a single point load of 20 kips, both applied centrally at midspan

- After 500,000 applied cycles of the single point load, the stiffness decreased by $21 \%$. The deflection at midspan increased by $30 \%$ after 500,000 applied cycles 
- No visual cracking or deterioration was seen during fatigue testing indicating that the panel sufficiently sustained the loading

- Maximum pressured ranged from 120-140 psi, significantly higher than the prestressed concrete panels due to the load transferring directly through the web to the foundation

- FRP panel is well-suited for field applications. In field applications, the two-cell box will be pultruded as one cross-section

- The FRP panel eliminated the need for steel shoulders, fasteners, and railpads

- The cost to fabricate and install an FRP panel is about the same as the cost as that of a prestressed concrete panel. The track structure currently employed in coal mines using the ballasted system is approximately $\$ 400$ less, but does not offer the benefits of a modular track panel made from an FRP

Both the prestressed concrete and FRP panels, without the use of a ballast, alleviate the problem of derailment and track structural problems. Tables 6.1 and 6.2 provide values for comparison between the FRP and prestressed concrete panels.

Table 6.1. Maximum Deflections and Strains for Indicated Loading Cases

\begin{tabular}{|l|c|c|c|c|}
\hline \multicolumn{1}{|c|}{ Loading } & \multicolumn{2}{c|}{ Maximum Deflection } & \multicolumn{2}{c|}{ Maximum Strain } \\
\hline & FRP Panel & Concrete Panel & FRP Panel & Concrete Panel \\
\hline Single Pt. Load - Midspan & 0.111 in & $0.065 \mathrm{in}$ & $147 \times 10^{-6} \mathrm{in} / \mathrm{in}$ & $218 \times 10^{-6} \mathrm{in} / \mathrm{in}$ \\
\hline Single Pt. Load - Left Crosstie & $0.076 \mathrm{in}$ & $0.073 \mathrm{in}$ & $135 \times 10^{-6} \mathrm{in} / \mathrm{in}$ & $260 \times 10^{-6} \mathrm{in} / \mathrm{in}$ \\
\hline Single Pt. Load - Right Crosstie & $0.076 \mathrm{in}$ & $0.073 \mathrm{in}$ & $145 \times 10^{-6} \mathrm{in} / \mathrm{in}$ & $258 \times 10^{-6} \mathrm{in} / \mathrm{in}$ \\
\hline Double Pt. Load - Midspan & $0.100 \mathrm{in}$ & $0.093 \mathrm{in}$ & $91 \times 10^{-6} \mathrm{in} / \mathrm{in}$ & $225 \times 10^{-6} \mathrm{in} / \mathrm{in}$ \\
\hline Double Pt. Load - Left Crosstie & $0.103 \mathrm{in}$ & $0.095 \mathrm{in}$ & $200 \times 10^{-6} \mathrm{in} / \mathrm{in}$ & $248 \times 10^{-6} \mathrm{in} / \mathrm{in}$ \\
\hline Double Pt. Load - Right Crosstie & $0.108 \mathrm{in}$ & $0.125 \mathrm{in}$ & $211 \times 10^{-6} \mathrm{in} / \mathrm{in}$ & $251 \times 10^{-6} \mathrm{in} / \mathrm{in}$ \\
\hline
\end{tabular}

Table 6.2. Stiffness and Changes of Stiffness of Panels After Indicated Applied Cycles

\begin{tabular}{|c|c|c|c|c|}
\hline \multirow{2}{*}{$\begin{array}{c}\text { Applied Dynamic Cycles } \\
\text { of 10 kips/beam }\end{array}$} & \multicolumn{2}{|c|}{ Stiffness (Ib/in) } & \multicolumn{2}{c|}{ Stiffness Decrease from O Cycles (\%) } \\
\cline { 2 - 5 } & FRP Panel & Concrete Panel & FRP Panel & Concrete Panel \\
\hline 0 & 169 & 402 & 0 & 0 \\
\hline 250,000 & 147 & 301 & 13 & 25 \\
\hline 500,000 & 134 & 246 & 21 & 39 \\
\hline
\end{tabular}




\subsection{Recommendations}

The following recommendations are made:

- Pultrude a two-cell FRP box section and implement in an active mine

- If possible, implement a prestressed concrete panel with the FRP panel for comparison purposes

- Concept of using light FRP modular tracks can be extended to rail/highway crossings 


\section{References}

Boresi, Arthur P., Richard J. Schmidt, and Omar M. Sidebottom. Advanced Mechanics of Materials, $5^{\text {th }}$ Edition, John Wiley \& Sons, New York. (1993)

"Most Requested Mining Statistics - U.S. Coal Industry." National Mining Association. December 2002. http://www.nma.com

CONSOL - Personal Communication, January 2002.

Enercalc Structural Engineering Library. (Beam on Elastic Foundation Software)

Fenander, A. "Frequency Dependent Stiffness and Damping of Railpads." Division of Solid Mechanics and Chalmers Railway Mechanics, Chalmers University of Technology, Goteborg, Sweden, 1997.

Interrail, Inc. - Personal Communication, January 2002.

Markine, V.L., A.P. de Man, and C. Esveld. "A Procedure For Design and Optimization Of a Railway Track Structure.” Railway Engineering Group, Civil Engineering And Geosciences, Delft University of Technology, 1998.

"Resilient Railpads for Concrete Sleepers." Pandrol Report, 1995. Report No. 2520

“Track Design and Construction.” Railway Technical Web Pages. February 2001. http://www.trainweb.org/railwaytechnical/track.htm

Wakui, Hajime, Nobuyuki Matsumoto, and Hiromi Inoue. "Technological Innovation in Railway Structure System with Ladder Track System.” Railway Technical Institute, Structure Engineering Group, Tokyo, Japan, 2001. 


\section{Appendix A - Enercalc Output}

\section{A.1 Single Point Load At Midspan}

\begin{tabular}{|c|c|c|}
\hline SUMMARY & Value & Location \\
\hline & & $7.37 \mathrm{ft}$ \\
\hline Max Shear & $4.99 \mathrm{k}$ & $7.55 \mathrm{ft}$ \\
\hline Min Shear & $-4.89 \mathrm{k}$ & $7.37 \mathrm{ft}$ \\
\hline Max Moment & $6.11 \mathrm{k}-\mathrm{ft}$ & $3.85 \mathrm{ft}$ \\
\hline Min Moment & $-1.09 \mathrm{k}-\mathrm{ft}$ & \\
\hline & & $9.499 \mathrm{ft}$ \\
\hline Max Rotation & $0.00108 \mathrm{rad}$ & $5.45 \mathrm{ft}$ \\
\hline Min Rotation & $-0.00108 \mathrm{rad}$ & \\
\hline & & $14.75 \mathrm{ft}$ \\
\hline Max Deflection & $0.01 \mathrm{in}$ & $7.37 \mathrm{ft}$ \\
\hline Min Deflection & $-0.05 \mathrm{in}$ & \\
\hline
\end{tabular}



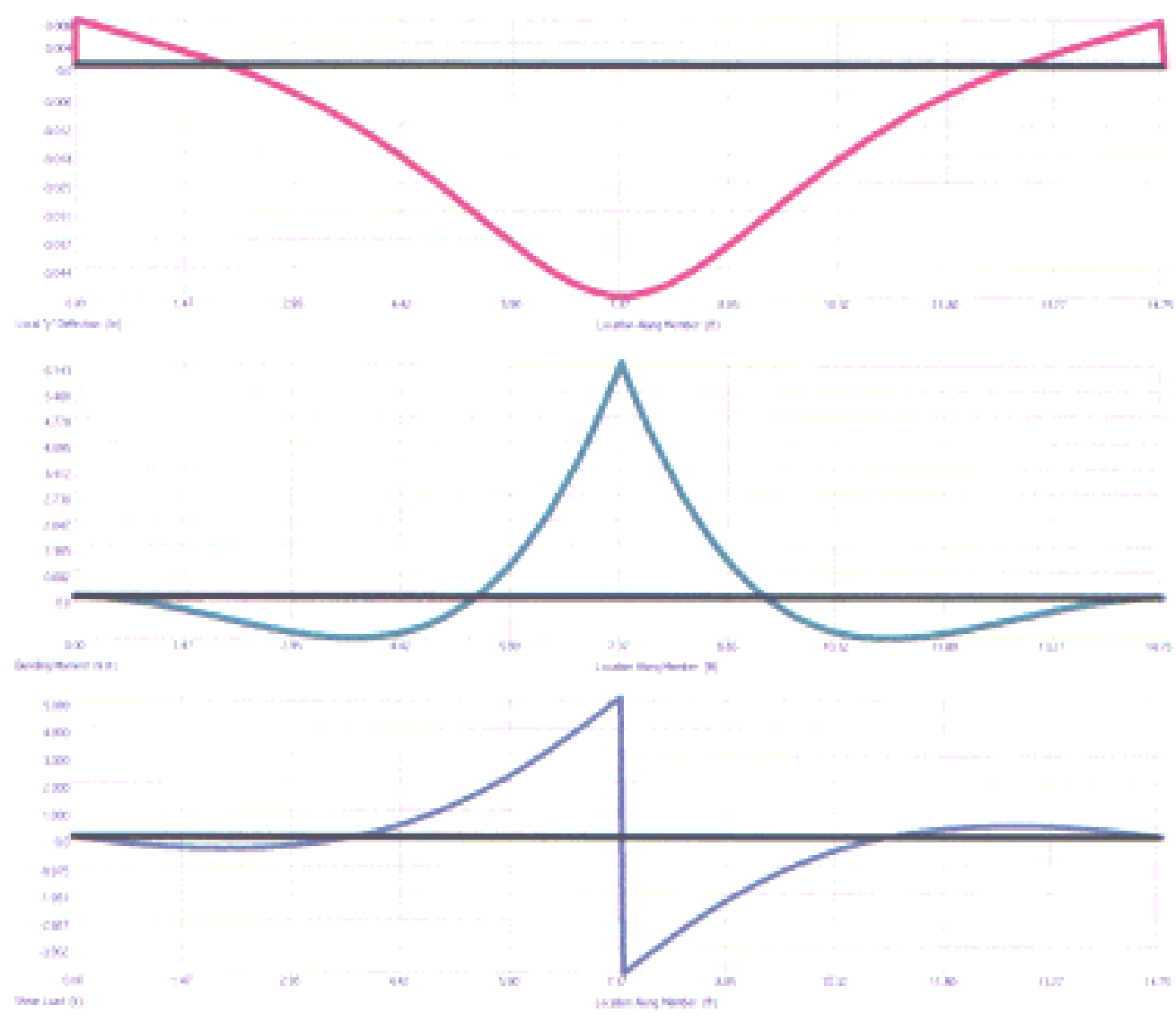


\section{A.2 Single Point Load at Left Crosstie}

\begin{tabular}{|c|c|c|}
\hline SUMMARY & Value & Location \\
\hline Max Shear & & $5.66 \mathrm{ft}$ \\
\hline Min Shear & $4.89 \mathrm{k}$ & $4.72 \mathrm{ft}$ \\
\hline Max Moment & $-4.99 \mathrm{k}$ & \\
\hline Min Moment & $6.20 \mathrm{k}-\mathrm{ft}$ & $5.66 \mathrm{ft}$ \\
\hline & $-1.29 \mathrm{k}-\mathrm{ft}$ & $9.50 \mathrm{ft}$ \\
\hline Max Rotation & $0.00111 \mathrm{rad}$ & $7.61 \mathrm{ft}$ \\
\hline Min Rotation & $-0.0015 \mathrm{rad}$ & $3.42 \mathrm{ft}$ \\
\hline & & \\
\hline Max Deflection & $0.010 \mathrm{in}$ & $0 \mathrm{ft}$ \\
\hline Min Deflection & $-0.054 \mathrm{in}$ & $5.66 \mathrm{ft}$ \\
\hline
\end{tabular}




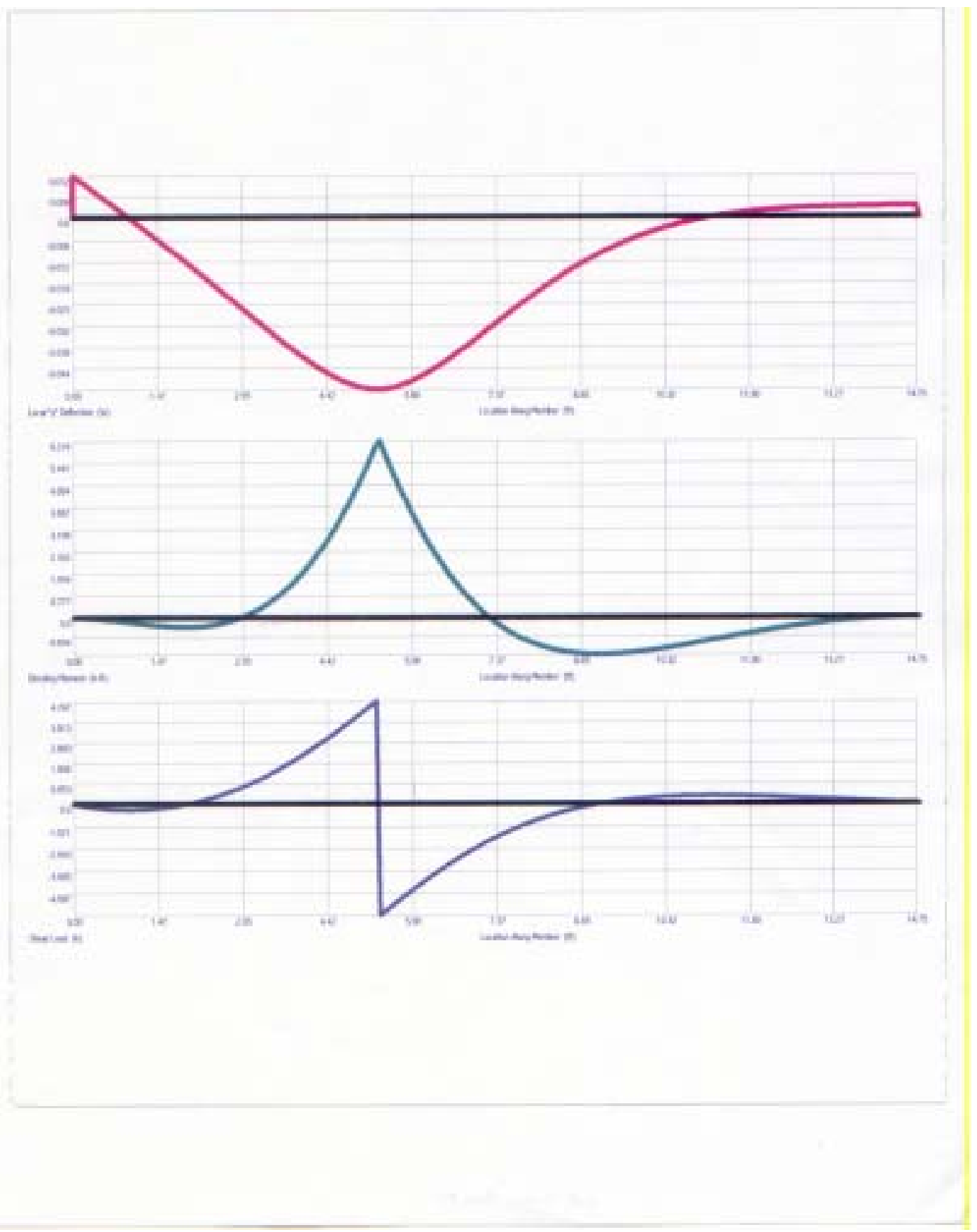




\section{A.3 Double Point Loads At Midspan}

\begin{tabular}{|c|c|c|}
\hline SUMMARY & Value & Location \\
\hline Max Shear & & $9.91 \mathrm{ft}$ \\
\hline Min Shear & $-5.13 \mathrm{k}$ & $5.72 \mathrm{ft}$ \\
\hline & & \\
\hline Max Moment & $5.04 \mathrm{k}-\mathrm{ft}$ & $9.91 \mathrm{ft}$ \\
\hline Min Moment & $-0.80 \mathrm{k}-\mathrm{ft}$ & $2.71 \mathrm{ft}$ \\
\hline & & \\
\hline Max Rotation & $0.00142 \mathrm{rad}$ & $11.92 \mathrm{ft}$ \\
\hline Min Rotation & $-0.00132 \mathrm{rad}$ & $4.01 \mathrm{ft}$ \\
\hline & & \\
\hline Max Deflection & $0.020 \mathrm{in}$ & $0 \mathrm{ft}$ \\
\hline Min Deflection & $-0.066 \mathrm{in}$ & $6 \mathrm{ft}$ \\
\hline
\end{tabular}




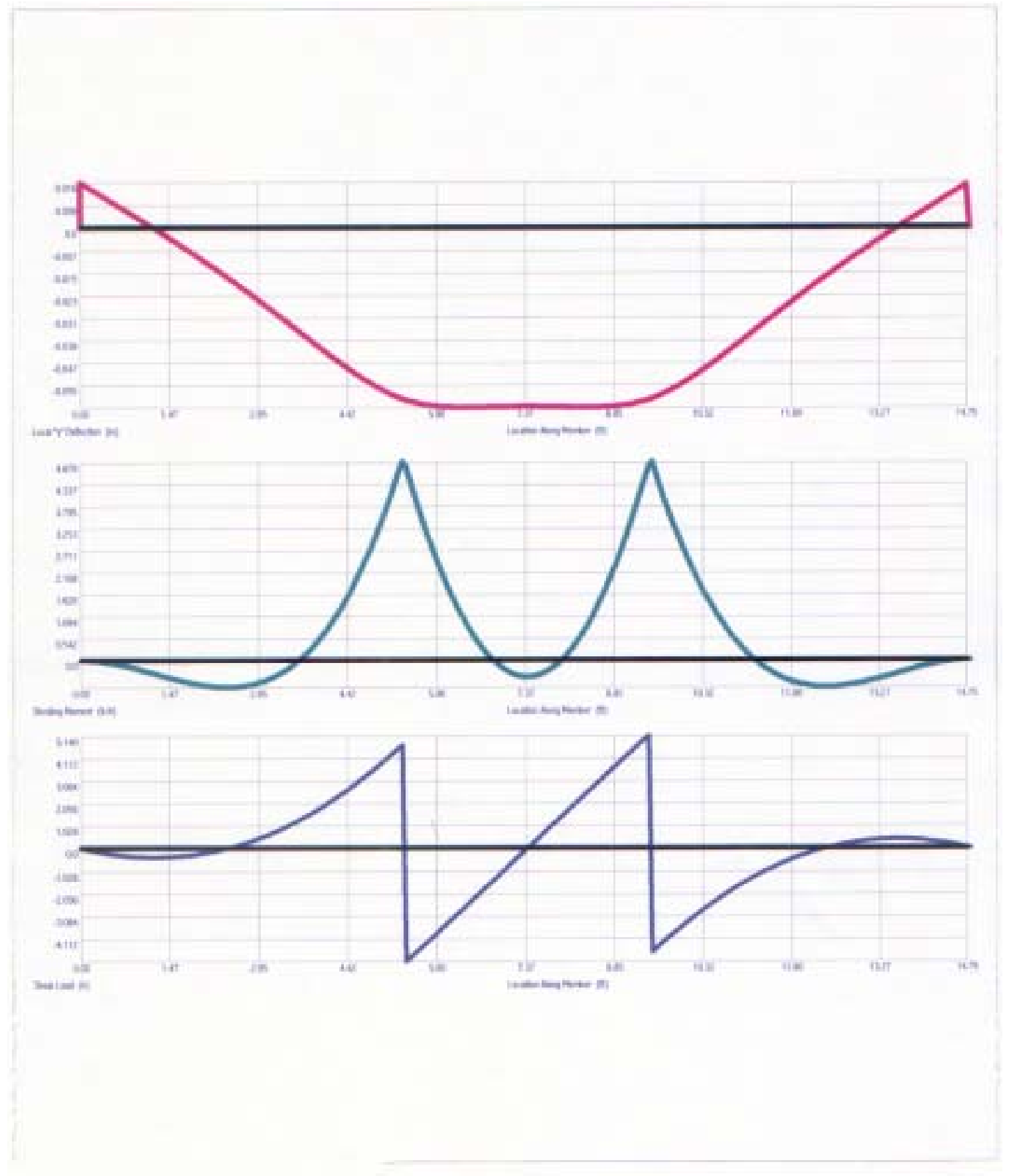




\section{A.4 Double Point Loads at Left Crosstie}

\begin{tabular}{|c|c|c|}
\hline SUMMARY & Value & Location \\
\hline Max Shear & & $7.37 \mathrm{ft}$ \\
\hline Min Shear & $4.95 \mathrm{k}$ & $3.67 \mathrm{ft}$ \\
\hline Max Moment & $-5.16 \mathrm{k}$ & \\
\hline Min Moment & $5.31 \mathrm{k}-\mathrm{ft}$ & $3.60 \mathrm{ft}$ \\
\hline & $-1.50 \mathrm{k}-\mathrm{ft}$ & $10.50 \mathrm{ft}$ \\
\hline Max Rotation & $0.00139 \mathrm{rad}$ & $8.79 \mathrm{ft}$ \\
\hline Min Rotation & $-0.00176 \mathrm{rad}$ & $0.708 \mathrm{ft}$ \\
\hline & & \\
\hline Max Deflection & $0.010 \mathrm{in}$ & $14.75 \mathrm{ft}$ \\
\hline Min Deflection & $-0.062 \mathrm{in}$ & $5.31 \mathrm{ft}$ \\
\hline
\end{tabular}



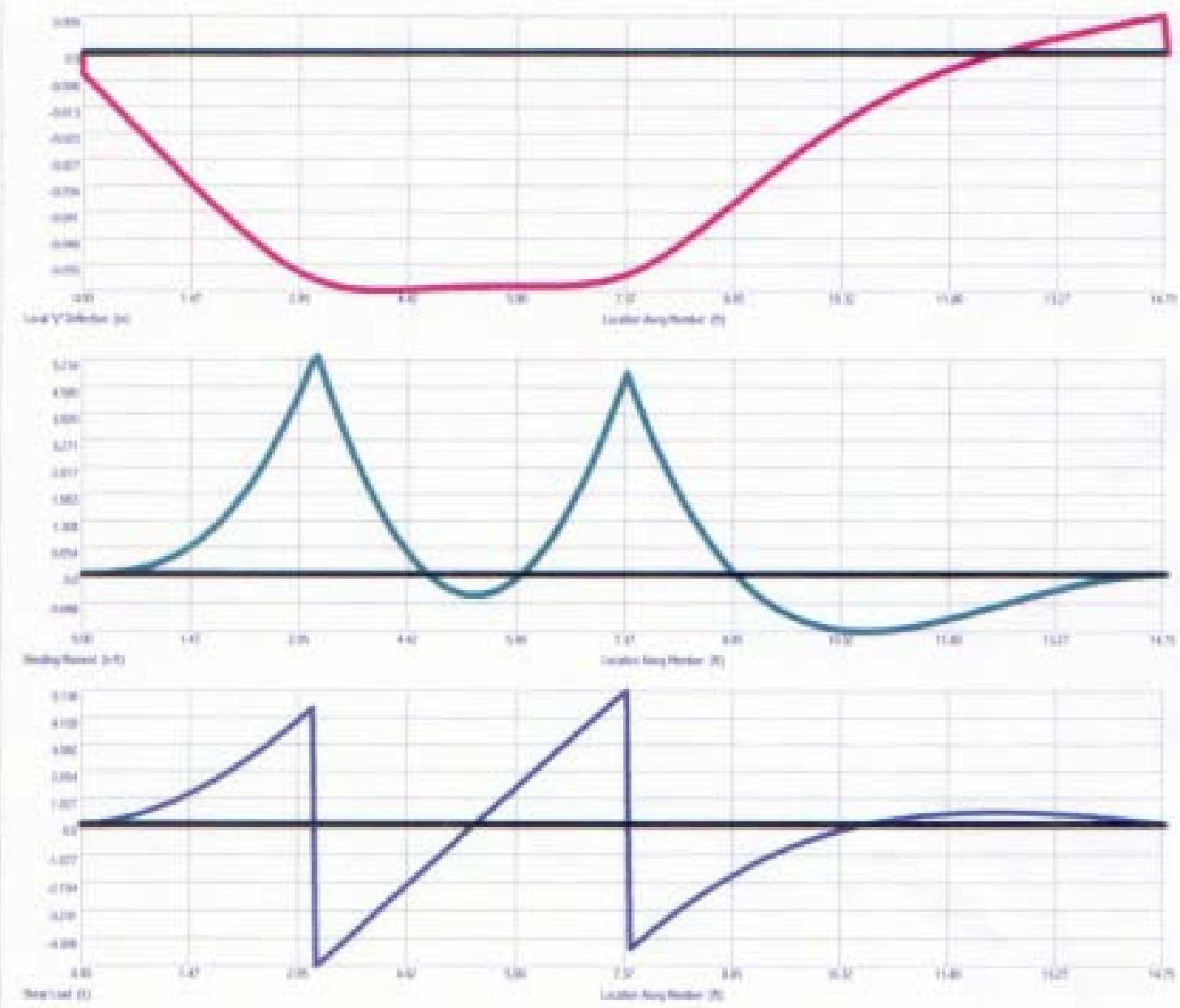


\section{Appendix B - FEM Input In FEMAP}

B.1 Properties for FEMAP

Page 1 of 1

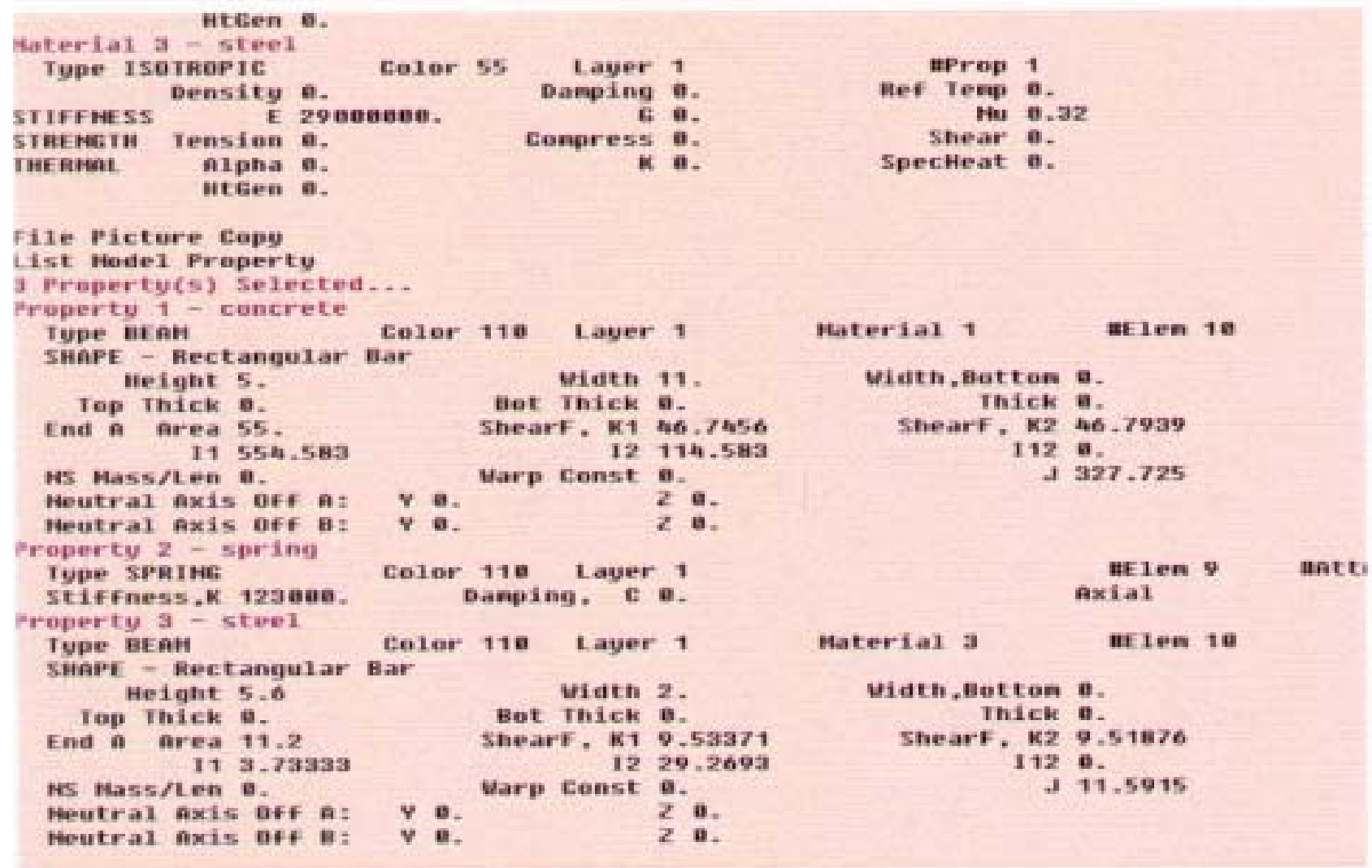




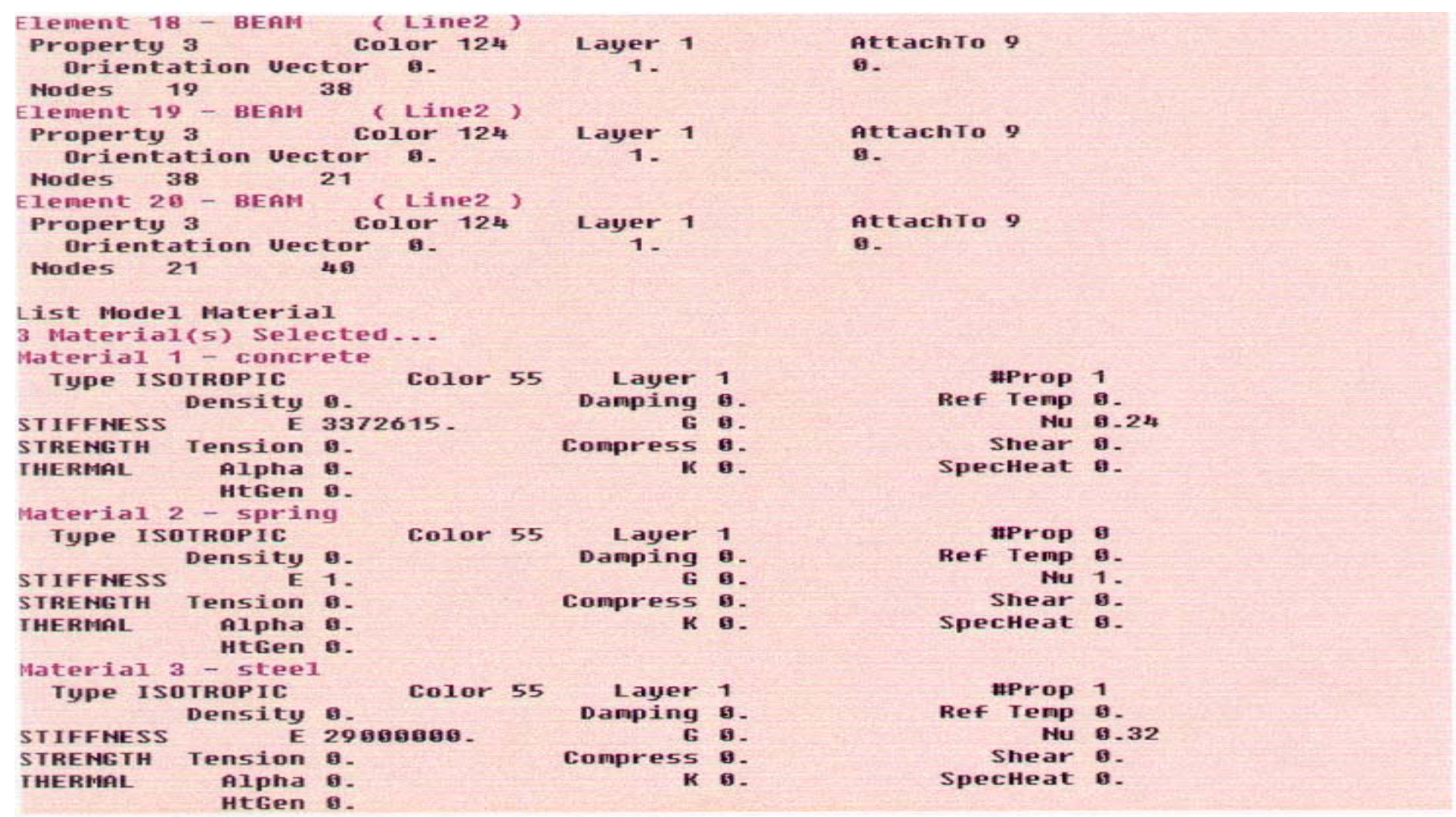




\section{Appendix C - FEM Results Provided by Interrail, Inc.}

\begin{tabular}{|c|c|c|c|c|}
\hline \multicolumn{5}{|c|}{ 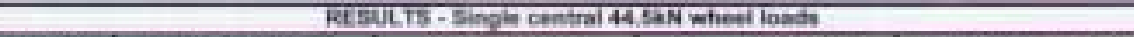 } \\
\hline Pad No & $\begin{array}{c}\text { Pasharait Loed } \\
\text { IN }\end{array}$ & $\begin{array}{l}\text { Pad Defiectien } \\
\text { min }\end{array}$ & $\begin{array}{l}\text { Geam Deflection } \\
\text { mm }\end{array}$ & $\begin{array}{l}\text { Beam Stress (Top) } \\
\text { Noy mn }\end{array}$ \\
\hline t & 128 & 0.01254 & 0.07611 & 205 \\
\hline 2 & 315 & -0.02126 & -0.22423 & 0.33 \\
\hline 3 & -963 & -009552 & $-0.7 A B 2$ & -107 \\
\hline 4 & 21.316 & -0.21543 & 4.03902 & 3.86 \\
\hline 5 & -963 & -0.09553 & -0.74918 & -708 \\
\hline f & $3: 15$ & -0.03127 & -0.29422 & 0.33 \\
\hline 7 & 1.264 & 001254 & 0.0761 & 0.56 \\
\hline
\end{tabular}

\begin{tabular}{|c|c|c|c|c|}
\hline \multicolumn{5}{|c|}{ 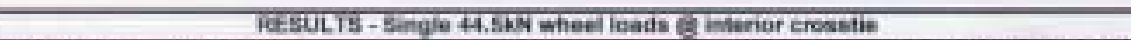 } \\
\hline Pad & $\begin{array}{l}\text { Aniartoat } \\
\text { kN }\end{array}$ & $\begin{array}{l}\text { Defiectian } \\
\text { min }\end{array}$ & $\begin{array}{l}\text { Geam danection } \\
\mathrm{mm}\end{array}$ & 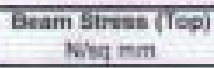 \\
\hline t & 1.364 & D.0525a & 0.10212 & 041 \\
\hline 2 & 0.693 & -0.00537 & 0.03452 & 0.45 \\
\hline 3 & -3033 & -0.00004 & $-03+265$ & 062 \\
\hline 4 & 9585 & -0.09507 & -0.74952 & -0.87 \\
\hline 5 & $21 \$ 7$ & $-02160 \mathrm{e}$ & -109713 & -404 \\
\hline fi & 9.028 & -0.0975 & -073110 & 435 \\
\hline 7 & -1.107 & $-0,01189$ & 0.2000 & .0 .38 \\
\hline
\end{tabular}




\begin{tabular}{|c|c|c|c|c|}
\hline \multicolumn{5}{|c|}{ 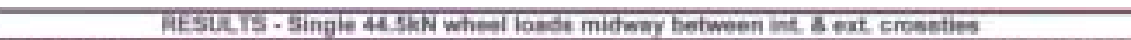 } \\
\hline T或 NE. & $\begin{array}{c}\text { Ansiltand } \\
\text { vid }\end{array}$ & $\begin{array}{l}\text { Definctinn } \\
\mathrm{mm}\end{array}$ & $\begin{array}{c}\text { Heam definction } \\
\text { mm }\end{array}$ & 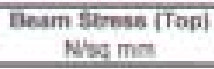 \\
\hline 1 & Q.756 & ocotsi & 0.0649 & 0.13 \\
\hline 2 & Q 405 & 0,00402 & 004887 & 022 \\
\hline 3 & 0.960 & -0 cosest & -000779 & 0.65 \\
\hline 4 & 2.763 & -0.02736 & 4.28800 & 0.75 \\
\hline 5 & -9.46 & -000412 & -0.73446 & -0.75 \\
\hline 6 & .22 .60 & .0 .22490 & 1.09 & -1.62 \\
\hline 7 & -10.665 & -0.10542 & -0.95173 & - 0 BS \\
\hline
\end{tabular}

\begin{tabular}{|c|c|c|c|c|}
\hline \multicolumn{5}{|c|}{ RESULIS - Doubio 44:SkN central barta } \\
\hline Pad No. & $\begin{array}{l}\text { Acrial Load } \\
\text { KN }\end{array}$ & $\begin{array}{c}\text { Lerfection } \\
\mathrm{mm}\end{array}$ & $\begin{array}{c}\text { Beam defiection } \\
\mathrm{mm}\end{array}$ & $\begin{array}{l}\text { Deten Strese (Tap) } \\
\text { Nisumm }\end{array}$ \\
\hline 1 & -000 & -0.00000 & -12512 & 074 \\
\hline 2 & 41124 & -0.11031 & -078221 & -106 \\
\hline 3 & -24.561 & -0.24359 & $-1.329 \% 5$ & -3.35 \\
\hline 4 & .18 .003 & 0.17914 & -1.45436 & -165 \\
\hline 5 & -24552 & -0.2435 & -132977 & 335 \\
\hline 6 & $+11+1+5$ & -0.11032 & -0.78221 & -100 \\
\hline 7 & 0.00 & $-0,00068$ & -0.12812 & 0.74 \\
\hline
\end{tabular}




\begin{tabular}{|c|c|c|c|c|}
\hline \multicolumn{5}{|c|}{ 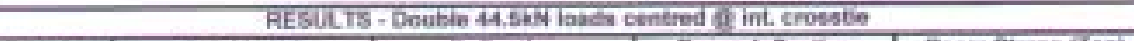 } \\
\hline Pad $\mathrm{ko}$. & $\begin{array}{l}\text { Anal Los } \\
\text { IN }\end{array}$ & $\begin{array}{l}\text { Defaction } \\
\text { mm }\end{array}$ & $\begin{array}{l}\text { Boam deflecsion } \\
\text { min }\end{array}$ & $\begin{array}{c}\text { Deaim Streses (fop) } \\
\text { Nhy memt }\end{array}$ \\
\hline 1 & 1.095 & 0.0182 & 0.13315 & 0.67 \\
\hline 2 & -2000 & -0 c2865 & -0.25253 & 0.49 \\
\hline 3 & -10.568 & -0.16478 & 0.79948 & -063 \\
\hline 4 & -24201 & .0 .24009 & -1 35451 & 307 \\
\hline 5 & +17902 & -0.17841 & -143717 & -15 \\
\hline 5 & -25542 & .025337 & +136092 & 3.16 \\
\hline 7 & 70314 & -0.10233 & 0.9225 & -94 \\
\hline
\end{tabular}




\section{Appendix D - Prestress Calculations}

\section{Calculations for Post-Tensioning Concrete}

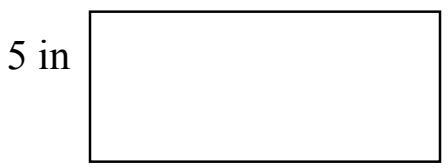

10.625 in

Area $=(5$ in $)(10.625$ in $)=53.125$ in $^{2}$

$$
\begin{aligned}
& \sigma_{D L}=\frac{M c}{I} \text { where } M=\frac{\omega l^{2}}{8} \\
& \omega=\frac{(10.625 \mathrm{in})(5 \mathrm{in})}{144 \mathrm{in}^{2} / \mathrm{ft}} \times 150 \mathrm{lb} / \mathrm{ft}^{3}=55.34 \mathrm{lb} / \mathrm{ft} \\
& M=\frac{(55.34 \mathrm{lb} / \mathrm{ft})\left(14.75 \mathrm{ft}^{2}\right)}{8}=1505 \mathrm{ft} \cdot \mathrm{lb}=18,059 \mathrm{in} \cdot \mathrm{lb} \\
& I=\frac{b h^{3}}{12}=\frac{(10.625 \mathrm{in})(5 \mathrm{in})^{3}}{12}=111 \mathrm{in}^{4} \\
& \sigma_{D L}=\frac{\left(18,059 \mathrm{in}^{3} \mathrm{lb}\right)(2.5 \mathrm{in})}{11 \mathrm{in}^{4}}=407 \mathrm{psi}
\end{aligned}
$$

Setting $\frac{M c}{I}=\frac{P}{A}, \mathrm{P}$ can be found as $21.6 \mathrm{kips}$

From the Manufacture's Information, $F_{p u}=150 \mathrm{ksi}$

$0.5 \mathrm{~F}_{\mathrm{pu}}=75 \mathrm{ksi}$

Area $5 / 8$ " Rebar $=0.31 \mathrm{in}^{2}$

$\mathrm{P}_{\mathrm{ALL}}=(75 \mathrm{ksi})\left(0.31 \mathrm{in}^{2}\right)=23.25 \mathrm{kips}$ 
Modulus of Rupture:

$$
\begin{aligned}
& f r^{\prime}=7.5 \sqrt{f c^{\prime}}=7.5 \sqrt{3600}=450 p s i \\
& \therefore|450-407|=43 p s i \\
& (43 p s i)\left(53.125 \mathrm{in}^{2}\right)=2284 \mathrm{lb}=2.28 \mathrm{kips}
\end{aligned}
$$

Apply P of 5, 7, or 10 kips

$\Rightarrow$ Check Against Compression Limit

AASHTO $^{*}-0.4 \mathrm{fc}^{\prime}=1440 \mathrm{psi}$

$\mathrm{ACI} * * \quad-0.6 \mathrm{fc}^{\prime}=2160 \mathrm{psi}$

Using AASHTO since it's controlling value

For P of 5 kips: $\sigma=\frac{P}{A}=\frac{5000 l b}{53.125 i^{2}}=94 p s i<1440 p s i$

For P of 7 kips: $\sigma=\frac{P}{A}=\frac{7000 l b}{53.125 \mathrm{in}^{2}}=132 \mathrm{psi}<1440 \mathrm{psi}$

For P of 10 kips: $\sigma=\frac{P}{A}=\frac{10,000 l b}{53.125 \text { in }^{2}}=188 p s i<1440 p s i$

Check:

$$
\begin{aligned}
& f_{\text {bot }}=-\frac{P}{A}+\frac{M c}{I} \text { which should be }<\text { than } \mathrm{fr}^{\prime}=450 \mathrm{ksi} \\
& =-188 \mathrm{psi}+407 \mathrm{psi} \\
& =219 \mathrm{psi}<450 \mathrm{psi} \\
& 219 \mathrm{psi}<(0.5)(450 \mathrm{psi})=225 \mathrm{psi}
\end{aligned}
$$

*AASHTO (1985) Section 2.9.2

**ACI Building Code 318-99 18.4.1 


\section{Appendix E - Cost Calculations}

\section{Prestressed Concrete Panel}

$1 / 2$ yard of concrete at $\$ 120 /$ yard

$\begin{array}{ll}= & \$ 60 \\ = & \$ 120 \\ = & \$ 56 \\ = & \$ 100 \\ = & \$ 30 \\ = & \$ 250 \\ = & \$ 616\end{array}$

2 dywidag rods at $\$ 60 / \mathrm{rod}$

28 fasteners at $\$ 2 /$ clip

Steel crossties with labor

Supplemental reinforcement

$=\$ 616$

\section{FRP Composite Panel}

30 linear feet material at $\$ 10 /$ linear foot

1 dywidag rod at $\$ 60 /$ rod

$\begin{array}{ll}= & \$ 300 \\ = & \$ 60 \\ = & \$ 120 \\ = & \$ 180 \\ = & \mathbf{\$ 6 6 0}\end{array}$

Adhesive

\section{Existing Track Currently Employed}

7 crossties at $\$ 15 /$ crosstie

28 spikes at $\$ 3 /$ fastener

$$
\begin{array}{ll}
= & \$ 105 \\
= & \$ 84 \\
= & \$ 30 \\
= & \$ 50 \\
= & \$ \mathbf{2 6 9}
\end{array}
$$$$
\text { Fabrication Labor and Installation }
$$

TOTAL

Note: Fabrication Labor and Installation cost is estimated as the time it took in the lab to construct and position the panels. This includes time for making stirrups, pouring concrete, hammering the Pandrol Mineclips in place, sanding the FRP panel for the steel rail and strain gages, attaching the FRP beams to one anther with expoxy, etc. 


\section{Appendix F - Coal Mining Facts}

\begin{tabular}{|c|c|c|c|c|c|c|c|}
\hline & ans & t9: & tert & 1394 & 1Wentick & 2000 ifne & anse \\
\hline 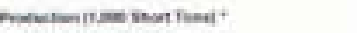 & tasente & $\cos =$ & vones & titersat & t.tiente & tenste & stessus \\
\hline 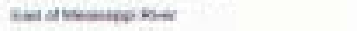 & seaven & $-\infty=0$ & 0000 & mon & saillet & sutsin & seiver \\
\hline nestaxhasisp & 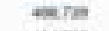 & $\operatorname{sen}=0$ & sume & $=-$ & nower & ensen & theser \\
\hline trate & $43=1$ & etion & trim & $\tan x$ & inm & encis & $a t,=$ \\
\hline hisen & nesent & $\operatorname{tinsin}$ & $\begin{array}{l}\text { toumen } \\
\text { ettint }\end{array}$ & ain ree & nases & $\operatorname{sen} 0$ & stare \\
\hline 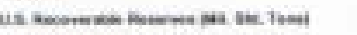 & men & काart & maven & msa & $\operatorname{sman}$ & enkin & atsese \\
\hline \multicolumn{8}{|l|}{ 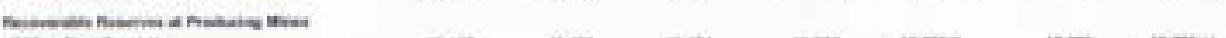 } \\
\hline 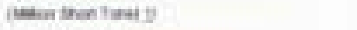 & asiet & wete & 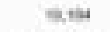 & axil & tevos & $10 \mathrm{~m}$ & $\operatorname{tinse}=0$ \\
\hline teenes atsin & rases $=0$ & sasutian & aruatsan & eneramen & ateanes & anconsian & Iuswirse \\
\hline 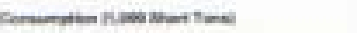 & messin & mistin & coerses & $\operatorname{lecsin}$ & neases & $1=n$ & taman \\
\hline Desominas & $\operatorname{sen}$ & wein & $n=1$ & nam & ex: & masn & 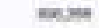 \\
\hline 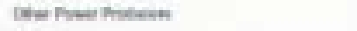 & $20=4$ & man & stm & inger & wasi & anam & werr \\
\hline $\cos 5$ & tan & $t t=0$ & min & in: & $=n$ & men & wan \\
\hline itemans & num & $n=$ & naw & enta & $n=$ & $m=$ & 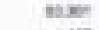 \\
\hline neteviares & $\sin$ : & $\operatorname{sen}$ & teet & $A=$ & un & $s w$ & cut \\
\hline \multicolumn{8}{|l|}{ 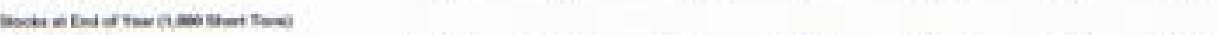 } \\
\hline Denemes 7 & man & wasn & naser & tastz & tatias & $=1 \mathrm{tat}$ & soum \\
\hline Fucouetsabsan & $3=24$ & aneit & anm & man & m,ns & 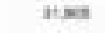 & tam \\
\hline Cupos numbers 1 mai & mul & wath & ase & newe & man & sin & $a n=$ \\
\hline 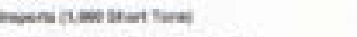 & $\sin$ & ans & than & stan & ans & tate & nawe \\
\hline \multicolumn{8}{|l|}{ 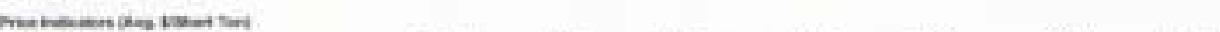 } \\
\hline Wherokitus $y$ & nasi & ate & ane & wife? & ists & towe & anda \\
\hline 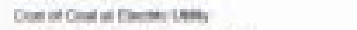 & suret & tas & ax: & soset & $\operatorname{sen} 2$ & Dein & exe \\
\hline 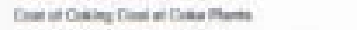 & uran & and & anten & mis & Sesss & $\sin$ & $\min$ \\
\hline 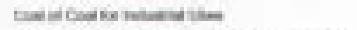 & se.ti & ve $x$ & In+4 & sexin & tatse & ats & $\tan$ \\
\hline 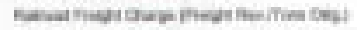 & smon & $\operatorname{ten}$ & vea & naer & troat & tean & knas \\
\hline \multicolumn{8}{|l|}{ tentangs } \\
\hline \multicolumn{8}{|l|}{ 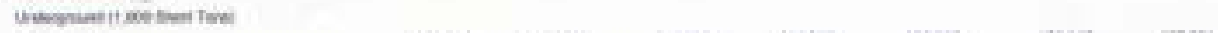 } \\
\hline turevest & pinat & $\cos 3$ & sous 0 & inis & ands & thes & arsai \\
\hline Canembine & wats & xen & aner & mas & we & $2,2 \mathrm{a}$ & $2=0$ \\
\hline$t=0$ & mater & $-\infty=4$ & surs & imsen & iesen & laswor & netive \\
\hline ats & $m$ & $m$ & $\lim$ & 2514 & 48 & $3 \pi$ & un \\
\hline Pas ineromed hatuter & mas & enses & eniany & nipar & wive & nsem & moser \\
\hline 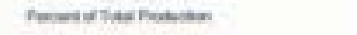 & $m$ & $3 \times$ & $\operatorname{sen}$ & $31 \mathrm{n}$ & $\mathrm{nm}$ & sest & nes \\
\hline Sumentios sention & entas & nows & maze & asest & $\operatorname{rosen}$ & moss & menes 10 \\
\hline 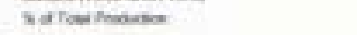 & ets & $\sin$ & nan & es & $\operatorname{sen}$ & an & exis \\
\hline netsmar. & int & int & tast & trat & 160 & 1.0 & 26 \\
\hline Indegenention & $m$ & $=$ & 34 & $\theta$ & mis & N & $\omega$ \\
\hline Sotessutes & tits & ves & $m$ & $=$ & sei & as & ru \\
\hline 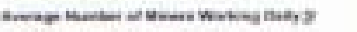 & mate & ase: & nave & mate & sates & $\operatorname{ten} x$ & $\operatorname{nsw}$ \\
\hline 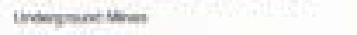 & vente & antor & Quar & tix & essi & cease & 4.2.200 \\
\hline Bortenities & $\operatorname{sen}$ & aven & anes & anat & ate & antive & move \\
\hline theser or bus benes & tart & $H=$ & sine & $s=$ & 450 & ers & swir \\
\hline$t=1 \quad x+2$ & 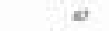 & $=$ & $\mathbf{x}$ & $=$ & $a$ & a & at \\
\hline nentady & $r a x$ & $t r=$ & 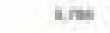 & sata & atai & wast & 40 \\
\hline 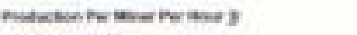 & sin & 26 & ane & $* \pi$ & $\operatorname{sen}$ & 7 iv & tis \\
\hline Untovmmines: & $x=$ & ast & ses & 10 & 200 & all & $4:$ \\
\hline Sutesune & $=$ & ais & $=26$ & 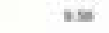 & nas & tose & $n=$ \\
\hline \multicolumn{8}{|l|}{$=$} \\
\hline \multicolumn{8}{|c|}{ 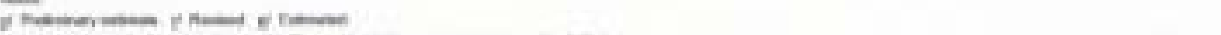 } \\
\hline \multicolumn{8}{|c|}{ 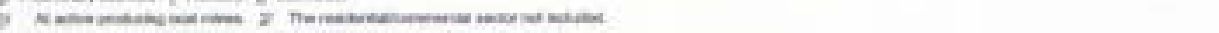 } \\
\hline \multicolumn{8}{|c|}{ 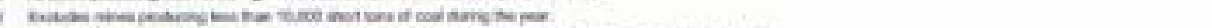 } \\
\hline
\end{tabular}

